\title{
DESIGN AND OPERATION OF A WIRELINE RETRIEVABLE MOTOR DRIVEN CORE BARREL
}

\author{
OCEAN DRILLING PROGRAM \\ TEXAS A\&M UNIVERSITY
}

\author{
Technical Note 23 \\ Michael A. Storms, David Huey, and William C. Rhinehart \\ Ocean Drilling Program \\ Texas A\&M University Research Park \\ 1000 Discovery Drive \\ College Station, Texas 77845-9547 \\ U.S.A.
}

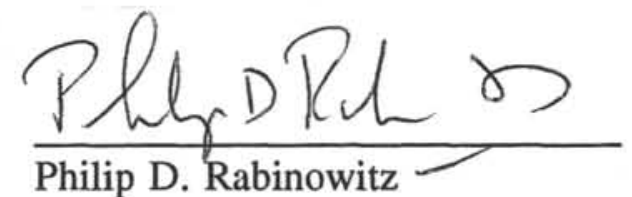

Director

ODP/TAMU

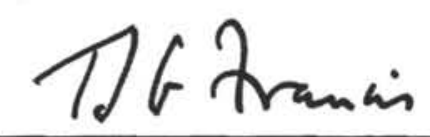

Timothy J.G. Francis

Deputy Director

ODP/TAMU 
Material in this publication may be copied without restraint for library, abstract service, educational, or personal research purposes; however, republication of any portion requires the written consent of the Director, Ocean Drilling Program, Texas A\&M University Research Park, 1000 Discovery Drive, College Station, Texas 77845-9547, U.S.A., as well as appropriate acknowledgment of this source.

Technical Note No. 23

First Printing 1994

\section{Distribution}

Copies of this publication may be obtained from the Director, Ocean Drilling Program, Texas A\&M University Research Park, 1000 Discovery Drive, College Station, Texas 77845-9547, U.S.A. Orders for copies may require payment for postage and handling.

\section{IS CLA IMER}

This publication was prepared by the Ocean Drilling Program, Texas A\&M University, as an account of work performed under the international Ocean Drilling Program, which is managed by Joint Oceanographic Institutions, Inc., under contract with the National Science Foundation. Funding for the program is provided by the following agencies:

Canada/Australia Consortium for the Ocean Drilling Program Deutsche Forschungsgemeinschaft (Federal Republic of Germany) Institut Français de Recherche pour l'Exploitation de la Mer (France) Ocean Research Institute of the University of Tokyo (Japan)

National Science Foundation (United States)

Natural Environment Research Council (United Kingdom)

European Science Foundation Consortium for the Ocean Drilling Program:

Belgium, Denmark, Finland, Iceland, Italy, Greece, The Netherlands, Norway, Spain, Sweden, Switzerland, and Turkey)

Any opinions, findings, and conclusions or recommendaions expressed in this publication are those of the author(s) and do not necessarily reflect the views of the National Science Foundation, the participating agencies, Joint Oceanographic Institutions, Inc., Texas A\&M University, or Texas A\&M Research Foundation. 


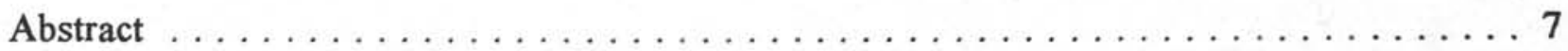

Chapter 1: Conceptualization of a Motor-Driven Core Barrel $\ldots \ldots \ldots \ldots \ldots$

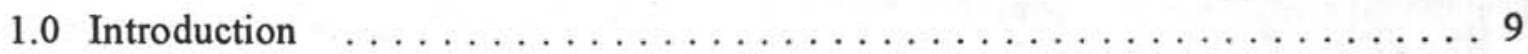

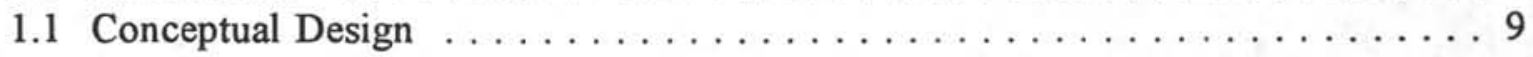

Chapter 2: NCB1: Development, Land Testing, and Sea Trials $\ldots \ldots \ldots \ldots \ldots \ldots 11$

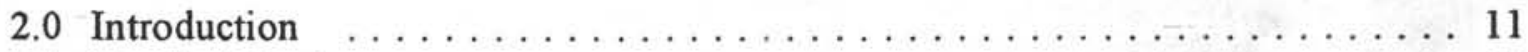

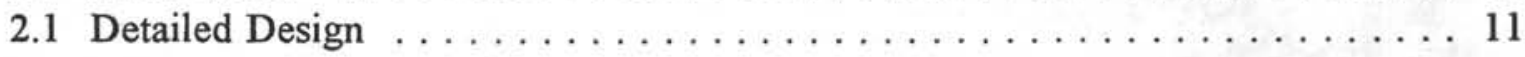

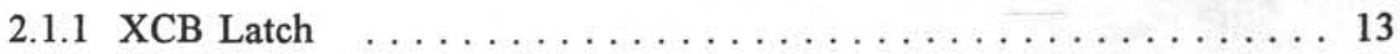

2.1.2 Fluid Spring/Thruster Unit/Flow Restrictor $\ldots \ldots \ldots \ldots \ldots \ldots 13$

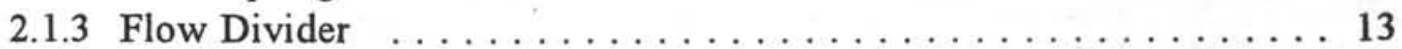

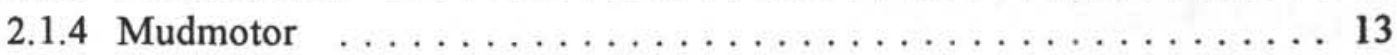

2.1.5 Diamond Bit and Core Barrel $\ldots \ldots \ldots \ldots \ldots \ldots \ldots \ldots \ldots \ldots \ldots \ldots \ldots \ldots$

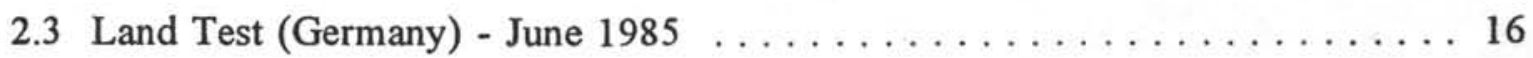

2.4 NCB1 Sea Trials: Leg 104 - July $1985 \ldots \ldots \ldots \ldots \ldots \ldots \ldots \ldots$

Chapter 3: NCB2: Development, Land Testing and Sea Trials $\ldots \ldots \ldots \ldots \ldots \ldots$

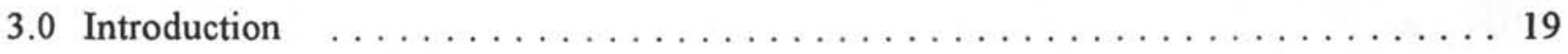

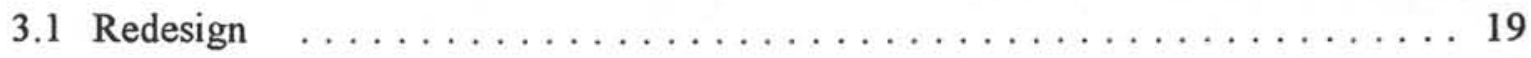

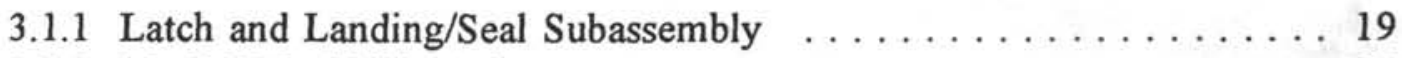

3.1 .2 Mach I Navidrill Mudmotor ................... 20

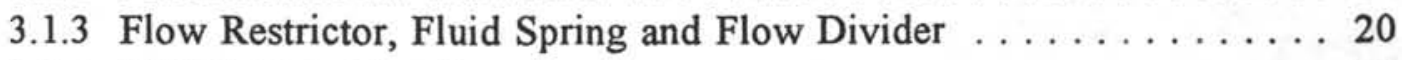

3.1.4 HWD4 Core Barrel ..................... 21

3.2 Land Test (Germany) - January $1987 \ldots \ldots \ldots \ldots \ldots \ldots \ldots \ldots \ldots \ldots \ldots$

3.3 NCB2 First Sea Trials: Leg 114 - February $1987 \ldots \ldots \ldots \ldots \ldots \ldots \ldots 24$

3.4 NCB2 Second Sea Trials: Leg 118 - September $1987 \ldots \ldots \ldots \ldots \ldots \ldots 24$ 
Chapter 4: NCB-121: Development, Lab Testing and Sea Trials . . . . . . . 25

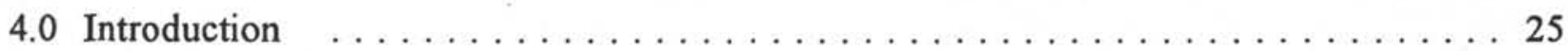

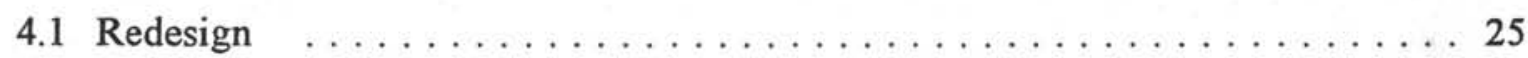

4.2 NCB-121 Land Test (Germany) - March $1988 \ldots \ldots \ldots \ldots \ldots \ldots$

4.3 NCB-121 Sea Trials: Leg 121 - May - June $1988 \ldots \ldots \ldots$

4.4 NCB Sea Trials: Leg 124E - January/February $1989 \ldots \ldots \ldots \ldots \ldots$

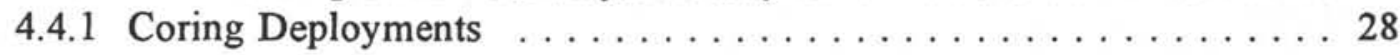

4.4 .2 NCB Deck Tests ........................... 29

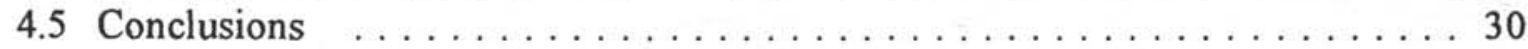

Chapter 5: MDCB: Development, Testing and Sea Trials (December 1990

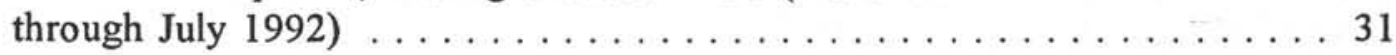

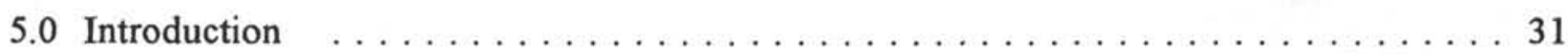

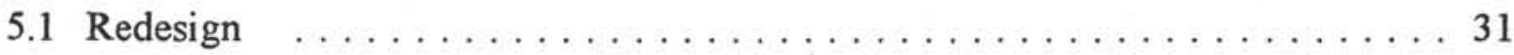

5.1 .1 Key Features of the New MDCB $\ldots \ldots \ldots \ldots \ldots \ldots \ldots \ldots \ldots$

5.1 .2 MDCB Performance Analyses $\ldots \ldots \ldots \ldots \ldots \ldots$

5.2 MDCB Sea Trials: Leg 134 - October $1990 \ldots \ldots \ldots \ldots \ldots$

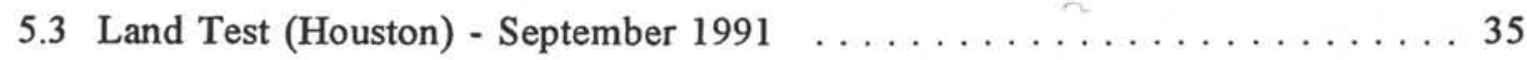

5.4 MDCB Sea Trials: Leg 141 - November $1991 \ldots \ldots \ldots \ldots$

5.5 MDCB Deployment Summaries: Leg 144 - June - July $1992 \ldots \ldots$. . . . . . 38

Chapter 6: Status of Motor Driven Core Barrel Development $\ldots \ldots \ldots \ldots \ldots$. . . . 41

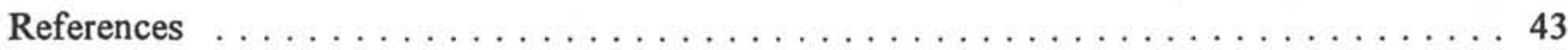


II:

Figure 2.1

Figure 2.2

Figure 2.3

Figure 2.4

Figure 3.1

Figure 5.1

Figure 5.2

\section{LIST OF FIGURES}

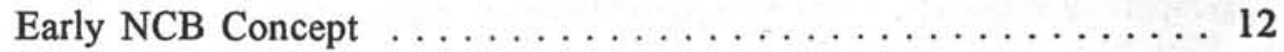

Norton Christensen MACH 1 "Navi-Drill" Mudmotor . . . . . . . 14

HWD4 Mining Core Barrel $\ldots \ldots \ldots \ldots \ldots$

Diamond Core Bit $\ldots \ldots \ldots \ldots \ldots \ldots \ldots \ldots$

Graywacke recovered - Clausthal, Germany, Jan. $1987 \ldots 23$

MDCB (Motor Driven Core Barrel) . . . . . . . . . . . 33

Example of MDCB Operating Parameters . . . . . . . . . . 39 
III:

Appendix A:

Appendix B:

Appendix C:

Appendix D:

Appendix E:

Appendix F:

Appendix G:

Appendix H:

Appendix I:

Appendix J:

Appendix K:

Appendix L:
APPENDICES

NCB1: Leg 104 Run Data ... . . . . . . . . . . 45

NCB2: Leg 114 Run Data .................... . . 49

NCB2: Leg 118 NCB Report . . . . . . . . . . . . . 59

NCB-121: Leg 121 Run Data . . . . . . . . . . 67

NCB-121: Leg 124E Run Data . . . . . . . . . . . 107

MDCB: Summary Report - September 1990 . . . . . . . . . . . 119

MDCB: MDB-134 Final Report . . . . . . . . . . . . . . . . . 149

MDCB: Summary Report - February $1992 \ldots \ldots \ldots \ldots 17$

MDCB: Source Code for "MDCBTIME" . . . . . . . . . . . . 185

MDCB: Leg 141 Report . . . . . . . . . . . . . . . 199

MDCB: Leg 144 Report ... . . . . . . . . . . . 211

MDCB: Operator's Manual . . . . . . . . . . . 217 


\title{
DESIGN AND OPERATION OF A WIRELINE RETRIEVABLE MOTOR DRIVEN CORE BARREL
}

\begin{abstract}
The Ocean Drilling Program (ODP) Technical Note No. 23 discusses the design and operation of a wireline retrievable Motor Driven Core Barrel (MDCB).

The MDCB is a prototype coring system developed by ODP. The MDCB was designed for complete compatibility with the Bottom Hole Assembly (BHA) used by the Advanced Piston Corer (APC), Extended Core Barrel (XCB), and Pressure Core Sampler (PCS) coring systems.

The purpose of the MDCB is three-fold:

- To allow single bit APC/XCB holes to be extended to greater depths and into more indurated formations, particularly fractured crystalline basement rocks.

- To improve recovery in hard/soft interbedded formations such as soft chalks laced with chert stringers.

- To use modern mining technology to core hard fractured crystalline rock, shallow water reef complexes, and other difficult-to-core formations using high speed, thin kerf diamond bits.
\end{abstract}

This Technical Note covers the development of the MDCB from its beginnings as the Navidrill Core Barrel (NCB) in 1984 to its reaching operational status in 1992. The chart on the following page summarizes the development history of the MDCB. 


\begin{tabular}{|c|c|c|}
\hline 1984 & $\begin{array}{l}\text { Initiation of } \\
\text { NCB } \\
\text { Development }\end{array}$ & \\
\hline 1985 & $\prod_{\text {NCB2 }}^{\text {NCB1 }}$ & $\begin{array}{l}\text { Jun - Land Tests, EC, Celle, Germany } \\
\text { Jun/Jul - Leg } 104\end{array}$ \\
\hline 1986 & & \\
\hline 1987 & $\sum_{\text {NCB }-121}$ & $\begin{array}{l}\text { Jan - Land Tests, ITE, Clausthal, Germany } \\
\text { Feb - Leg } 114 \\
\text { Sep - Leg } 118\end{array}$ \\
\hline 1988 & & $\begin{array}{l}\text { Mar - Land Tests, ITE, Clausthal, Germany } \\
\text { May/Jun - Leg } 121\end{array}$ \\
\hline 1989 & MDCB & Jan/Feb - Leg 124E \\
\hline 1990 & & Oct - Leg 134 \\
\hline 1991 & & $\begin{array}{l}\text { Sep - Land Tests, SES, Houston, Texas } \\
\text { Nov/Dec - Leg } 141\end{array}$ \\
\hline 1992 & 5 & Jun/Jul - Leg 144 \\
\hline
\end{tabular}




\section{Conceptualization of a Motor-Driven Core Barrel}

\subsection{Introduction}

In late 1984 the Engineering and Drilling Operations group at the Ocean Drilling Program began investigating ideas to extend $\mathrm{APC} / \mathrm{XCB}$ holes into more indurated formations. At the time, when such a formation was reached the only option was to trip the pipe back to the surface, switch to the RCB Bottom Hole Assembly (BHA), run the pipe down, reenter the hole, and continue drilling. This is a very time consuming process, and often the RCB was needed only to drill a few cores into basement to verify it had been reached.

In addition to extending the APC/XCB, a means was sought to improve core recovery in difficult to core formations. These formations included hard, fractured crystalline rock, interbedded formations, such as soft chalks laced with chert stringers, and shallow water reef complexes.

\subsection{Conceptual Design}

After considering several ideas ODP decided to adapt modern mining technology for offshore use. This technology entailed drilling/coring relatively small diameter holes with high RPM and light bit weights using narrow kerf diamond core bits. The mining industry uses this technique to successfully core deeply into all types of formations with virtually 100 percent recovery. To apply this new approach to ODP's scientific coring operations three major requirements had to be met: 1) a prime mover was required which would drive the core barrel at high rpm (2001000) without having to rotate the drillstring or BHA, 2) accurate weight-on-bit control for the diamond bit had to be achieved in a remotely operated mechanism, and 3) the entire coring tool had to be packaged for wireline coring through 5 -inch drill pipe.

Originally dubbed the Navidrill Core Barrel (NCB), the NCB/MDCB development effort was ODP's first attempt to apply mining concepts to offshore, oil field type coring operations. The new coring tool was to be free-fall deployed and wireline retrieved so that it could be used at any point in the coring operation. It was to be fully interchangeable with the APC and XCB, thus allowing the choice of the coring system to be optimized from the mudline down to and into indurated formations and/or basement rock. The MDCB diamond core bit was to be advanced into the formation ahead of the stationary roller cone bit and recover a nominal $57-\mathrm{mm}$ (2.25-in.) diameter by 4.0 meter (13.25 ft.) long core in a clear plastic liner.

The initial concepts for the NCB were the result of meetings held with engineers from the Norton Christensen company (later Eastman Christensen). The Christensen specialists pointed out that most of the elements already existed to make a motor-driven core barrel system compatible with the ODP drillstring. Positive-displacement mudmotors (PDM's) were available in off the shelf sizes and would produce the necessary rotational speeds and drilling torque. Standard mining core barrels, diamond bits, and reamer shells could be used. Therefore, the efforts for developing 
the new NCB tool for ODP could focus on the remaining design requirements:

- a hydraulic thruster system using flow to or from the mudmotor to create accurate drilling weight on the diamond bit.

- a thruster telescoping system to allow the diamond core barrel to advance ahead while transmitting torque to the bit.

- a means to react drilling torque to the BHA.

- an adjustable flow divider system to split pumped seawater between the diamond bit and the main roller cone bit.

- a shock absorber system to eliminate damage to motor bearings when the freefall core barrel landed in the BHA.

- an unlatching mechanism that would hold the thrusting/telescoping section of the tool in its collapsed state during the trip to the bit through the impact of landing in the BHA. This mechanism would release/unlatch the telescoping mechanism when the diamond bit had reached sufficient rotational speed to begin rock coring.

During the conceptual design phase numerous configurations for the tool were considered, briefly analyzed, and finally either accepted or rejected until the first prototype design concept evolved. Early ideas included several schemes to allow coring ahead of the roller cone bit without requiring a splined thruster mechanism, adding drill rods to lengthen the core barrel for greater penetration ahead of a non-functional roller cone bit, and a fluid spring concept to act as both drilling shock sub and core jam indicator. 


\title{
NCB1: Development, Land Testing, and Sea Trials
}

\author{
1984 to July 1985
}

\subsection{Introduction}

Following the conceptualization and feasibility analysis stages the ODP Development Engineering group chose to pursue development of a prototype tool, nicknamed NCB1. Detailed design of the NCB1 was assigned to Eastman Christensen in Celle, Germany under consultation with ODP. The new tool was to be made ready for land testing in Germany in June 1985 and sea trials during Leg 104.

\subsection{Detailed Design}

Design analysis, detailed design and fabrication of most of the custom parts were undertaken by engineers at Norton Christensen. Outer barrel (BHA) components and various other associated parts were developed and/or provided by ODP. The first prototype tool comprised the following main components or subassemblies:

-XCB latch

-Fluid spring / thruster unit / flow restrictor assembly

-A flow divider

-A 95-mm (3.75-in.) outside diameter positive displacement mud motor for generating downhole rotation and torque

-A 95-mm (3.75-in.) outside diameter narrow kerf diamond core bit, reamer shell, and 3.62-in diameter HWD4 mining core barrel to cut the core

Figure 2.1 shows the early NCB concept. Descriptions of the subassemblies follow: 


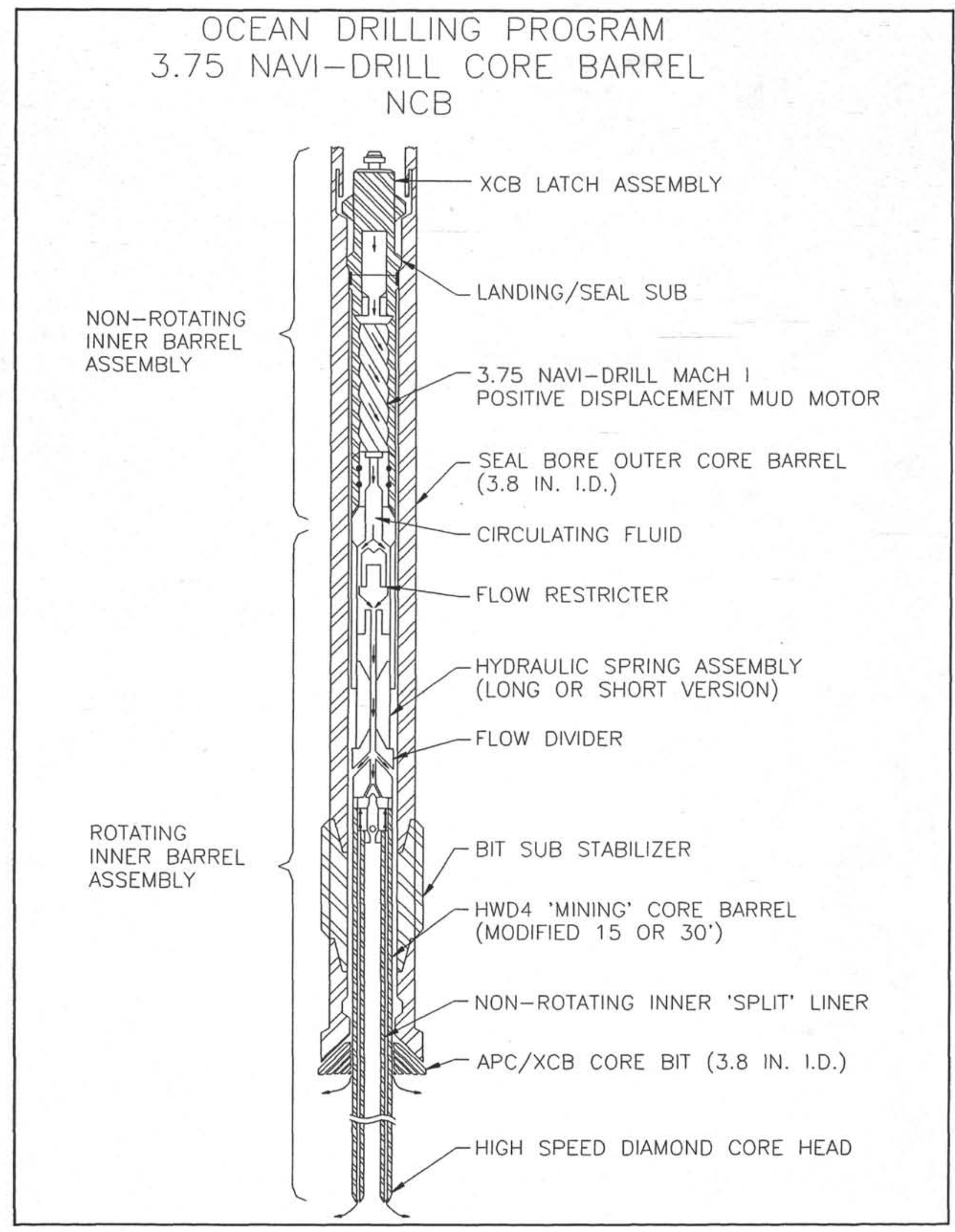

Figure 2.1 Early NCB Concept 


\subsubsection{XCB Latch}

The latch was borrowed from the XCB coring system to provide for latch-down and torque reaction in the $\mathrm{BHA}$. It used positive, lock-out dogs to engage the slots in a latch window in the BHA.

\subsubsection{Fluid Spring / Thruster Unit / Flow Restrictor}

The fluid spring had sets of nozzles used to provide variable pressure drop which was converted to hydraulic thrust for selected weight on bit. The spring mechanism allowed for 36 inches of stroke to provide cushioning and/or shock absorption during drilling. Alternatively, the stroke could be increased to allow the diamond bit to drill ahead without the necessity of reaming the hole simultaneously. The flow restrictor device closed off one nozzle flow path in the flow divider to throttle flow and increase system back pressure as a signalling device to the driller when reaming down over the extended barrel or when core blockage occurred.

\subsubsection{Flow Divider}

The flow divider provided for passive flow division of the circulating fluid between roller cone bit and diamond bit.

\subsubsection{Mudmotor}

A 3-3/4 inch Christensen "MACH 1" model, Navidrill brand positive displacement mudmotor was chosen for the prototype NCB tool. A simple schematic of the mudmotor is shown in Figure 2.2. Its performance characteristics are as follows:

$\begin{array}{ll}\text { Tool Size (in, O.D.) } & 3-3 / 4 \\ \text { Lobes } & 5 / 6 \\ \text { Pump Rate (gpm) } & 145 \\ \text { Bit Speed (rpm) } & 250 \\ \text { Maximum Torque (ft-lbf) } & 740 \\ \text { Efficiency } & >90 \% \\ \text { Motor Pressure (psi) } & 640 \\ \text { Power (hp) } & 35\end{array}$




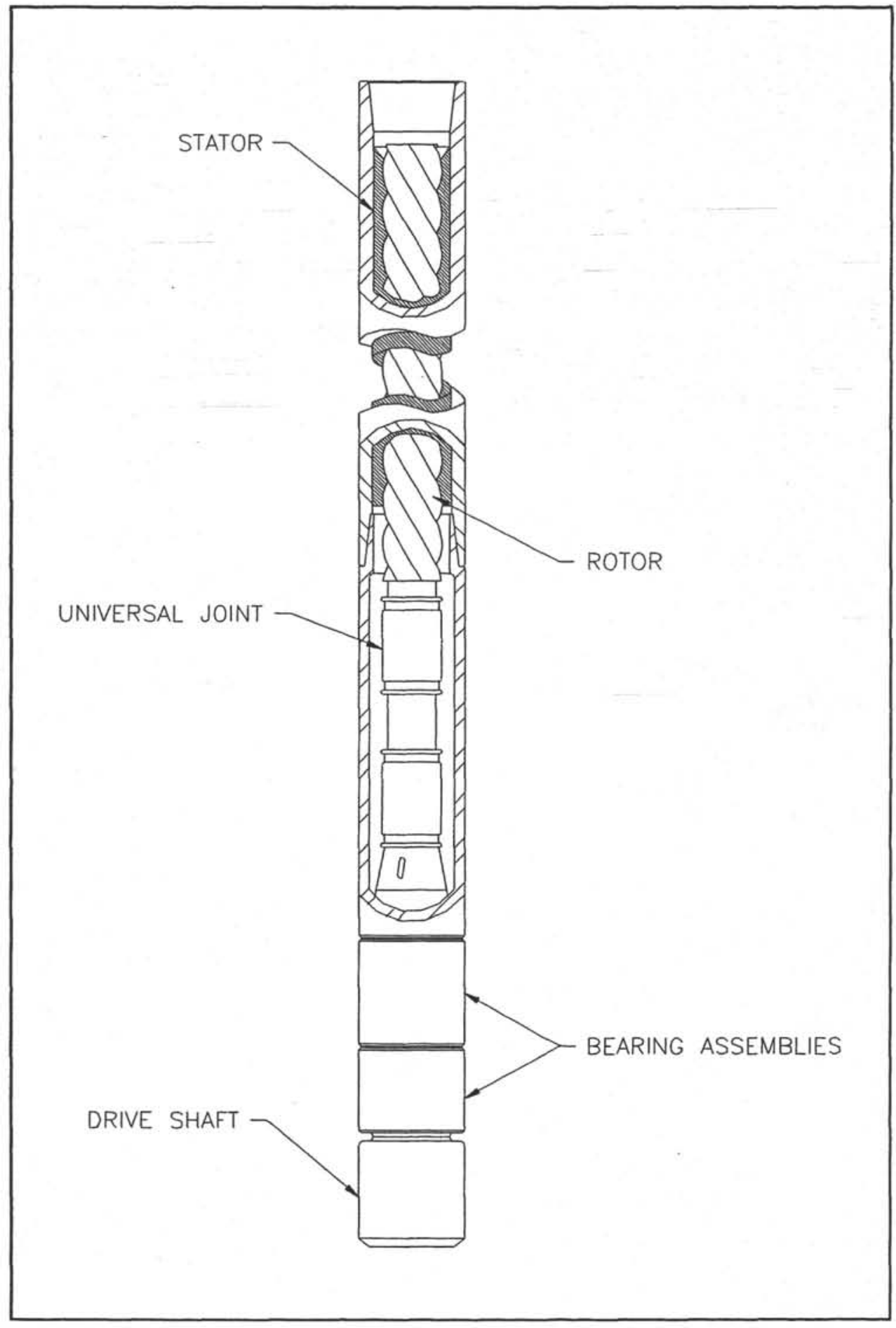

Figure 2.2 Norton Christensen $\mathrm{MACH} 1$

"Navi-Drill" Mudmotor 


\subsubsection{Diamond Bit and Core Barrel}

A 3-3/4 inch $(95 \mathrm{~mm})$ diamond bit producing a nominal 2-1/4 inch $(57 \mathrm{~mm})$ core was chosen for the NCB system. A modified HWD4 mining core barrel was selected which included a nonrotating inner barrel with an optional clear plastic (polycarbonate) liner. See Figure 2.3. This core barrel was considered to be the most rugged available in the mining $\mathrm{H}$-series. By using a standard core barrel size, a wide variety of commercially proven parts would be readily available for the evolving NCB system, including many types of diamond bits (Figure 2.4), reamer shells, core catchers, anti-jam devices, inner bearings, and crossover subs.

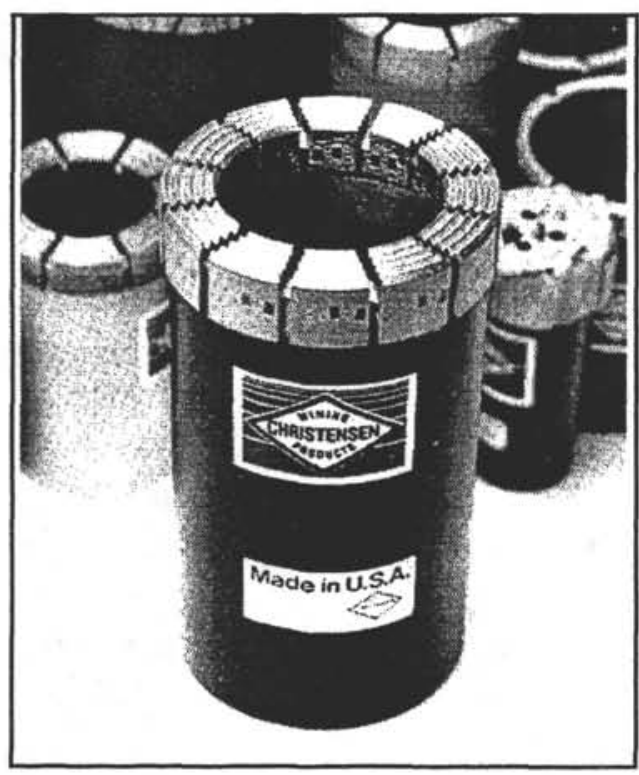

Figure 2.4 Diamond Core Bit

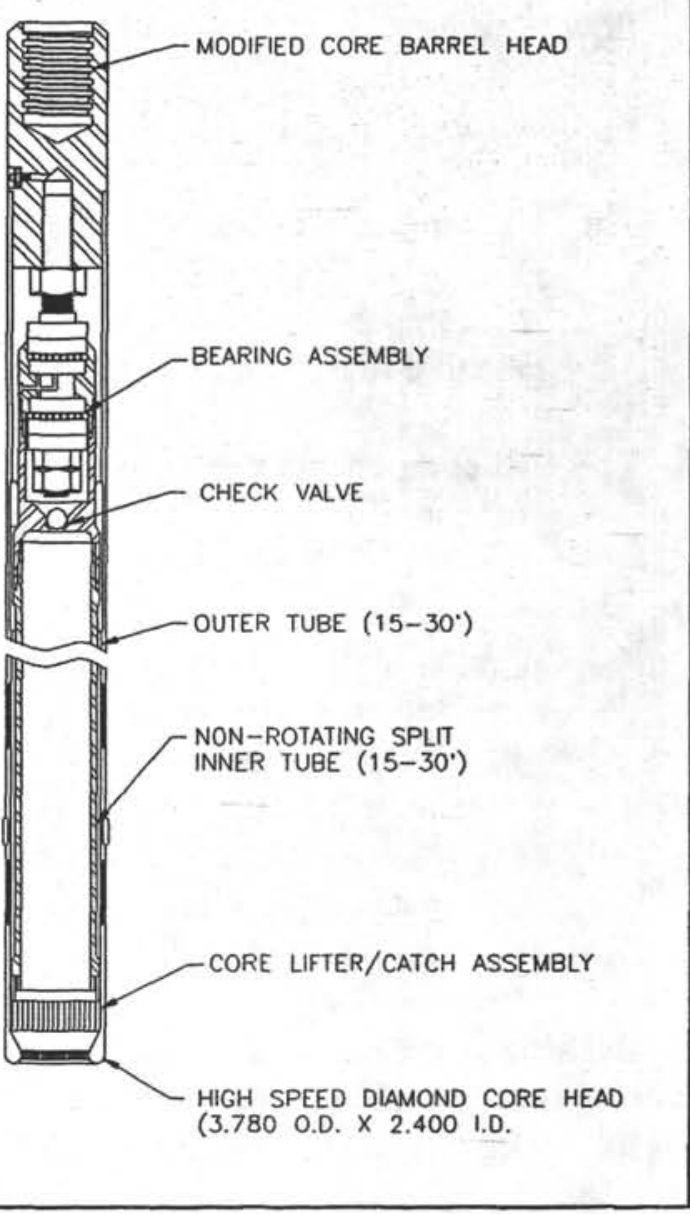

Figure 2.3 HWD4 Mining Core Barrel 


\subsection{Land Test (Germany) - June 1985}

Shore based testing of the Navidrill Core Barrel (NCB) system was conducted at Norton Christensen's test facility in Celle, Germany during June of 1985. This facility is designed for flow testing prototype mud motors and proved to be an excellent place to test the hydraulics of the NCB1. The Leg 104 port call was also in Germany, which eliminated a trans-Atlantic shipment to return the tool.

The following areas were addressed during the shore-based testing program:

- All components were inspected to be sure that the parts were made correctly as per the machine drawings.

- All components were assembled into subassemblies and major assemblies to ensure proper compatibility.

- Proper spacing and latch down of the wireline components within the BHA was verified. A potentially disastrous interference between the NCB bearing assembly and the inner diameter of the BHA was identified and corrected.

- Valuable information on the performance of the prototype Mach 1 Mudmotor was obtained.

- Flow tests on the Fluid Spring, Flow Restrictor, and Flow Divider systems were conducted and their operation verified.

Because of delays caused by a mix up in shipments and assembly of the test equipment, the test program was abbreviated and obtained less data than desired. However, from this testing the following major recommendations were made:

1) The NCB coring system was viable enough to be deployed on sea trials, although it did have some shortcomings that should be corrected with future models.

2) The outer diameter of the HWD4 core barrel had to be reduced from 3.75 inches to 3.50 inches. The pressure drop along the annulus between it and the seal bore drill collar of the BHA was too high and had to be reduced.

Based on the results of the test program, the decision had to be made whether to rent or purchase the Navidrills for the upcoming sea trials. Two factors were taken into consideration;

1) The Mach I Navidrill had previously not been made in the 3.75 -in. size. Therefore, they were also prototypes.

2) The Christensen engineers had reservations about the ability of the Mach $I$ in this size to handle the high potential torque generation at maximum flow rates $(740 \mathrm{ft}$.-lbs. at 145 GPM). The concern was over the strength of the flame-cut u-joints. Although an alternate 
flex joint design was available, it would have changed the spacing of the system too drastically and could not have been incorporated into the design in time for the scheduled sea trials.

The decision was made to rent the Navidrills for the sea trial period.

\subsection{NCB1 Sea Trials: Leg 104 - July 1985}

Following lab testing of the NCB1 tool in Celle, the necessary hardware for sea trials was shipped to the JOIDES Resolution in port in Bremerhaven, Germany. NCB testing was not a primary objective of the leg, but adequate downhole opportunities for initial testing were expected to occur. Full integration of the lab version of the NCB1 into the shipboard environment was done in preparation for sea trials.

The NCB was deployed twice on Site 642. The decision to run the NCB was made when the $\mathrm{XCB}$ penetration rate and recovery percentage began to deteriorate. The NCB1 cored 3.5 meters of basalt and recovered 2.0 meters (57\% recovery). Coring was done with both the APC/XCB bit and the NCB1 bit rotating simultaneously, with the face of the NCB1 bit extending $30 \mathrm{~cm}$ in front. The Leg 104 run data appear in Appendix A.

This sea trial was very limited so it was difficult to make any definitive statements concerning the future of the NCB1. However, valuable insight into this new application of technology was obtained. Without doubt, the single most significant accomplishment of the Leg 104 NCB sea trials concerns the application of Positive Displacement Mudmotors (PDM's) to wireline coring operations. The ability to deploy a small PDM through the ODP drill string and power a coring system independently of the top drive system had been proven. The use of state-of-the-art PDM technology was the key to the success of the NCB coring system.

At this point, it appeared that the NCB was a viable coring system, but it would require a significant design and test effort before it achieved operational readiness. 


\title{
NCB2: Development, Land Testing and Sea Trials
}

\author{
August 1985 - September 1987
}

\subsection{Introduction}

Following the brief lab tests and sea trials, the prototype NCB1 was judged to merit further developmental work. New plans for a second generation "NCB2" were laid out, including redesign, additional fabrication, more land (lab) testing and sea trials.

During the NCB1 phase of the development the following were discovered as problem areas applying to both the operational deployment philosophy for the tool and certain mechanical and hydraulic performance parameters:

- The excessively high pressure drop with the NCB in place in the seal bore drill collar in the BHA.

- The inability to circulate at flow rates above 125 GPM, well below what was required for a truly "operational" hard rock coring system.

- Problems and inconsistencies in the test frame load cell system related to the electrical wiring and the water tight integrity of the connections.

- The relatively low (145 GPM) maximum flow rating for the Mach I mudmotor.

\subsection{Redesign}

The most important difference between the NCB2 and its predecessor (NCB1) was that coring would now take place while the main APC/XCB bit was kept motionless on bottom. Enough weight would be maintained on the $\mathrm{APC} / \mathrm{XCB}$ bit so that the drilling heave compensator is operational. Design evaluations for each NCB2 subassembly are provided below.

\subsubsection{Latch and Landing/Seal Subassembly}

The XCB latch had performed flawlessly and appeared to be fully operational. The Landing/Seal Sub also worked well, but the following design changes were made:

- The 3.75-in. diameter above the landing shoulder was also being used below the landing shoulder. 
- The reduced bore at the bottom end of the sub was initiated just above the landing shoulder. This enabled a "short" 3.5-in. OD section directly below the landing shoulder to be incorporated for use with standard core barrel handling clamps.

- The threaded connection at the bottom of the Landing Sub and at the top of the Top Connector Spacer Tube was provided with a positive locking system.

\subsubsection{Mach I Navidrill Mudmotor}

In spite of the fact that the 3.75 inch Mach I Navidrill mud motor was used only a minimum number of rotating hours, several observations were made. The motor demonstrated that it could be pumped down the drill string, absorb the landing impact, and still function properly. It appeared that a PDM could be used simultaneously with a top drive pipe rotating system with no adverse effects to either system. It was also advisable to incorporate a newer, stronger flex-joint assembly into the tool for future operations. This required simply adjusting the spacing of the NCB. However, the relatively low (145 GPM) maximum flow rating for the Mach I was a definite drawback.

\subsubsection{Flow Restrictor, Fluid Spring and Flow Divider}

The most significant modifications and concept changes to the NCB were concentrated in this area.

- The inner diameter of the bore through the Female Spline had to be made smaller or the minimum diameter of the threads larger so that the T-seal and back-up rings did not hang up in the threads during installation.

- The seal bore of the Female Spline was Xylan coated.

- The stroke length of the fluid spring was made longer and the flow restrictor components were designed so that the driller could set down weight until a predetermined pressure was reached for a given flow rate. The driller knew at this point what the position of the core head was relative to the main bit face. As the core head was allowed to drill off, the driller knew at what pressure the core head reached full extension so that more BHA weight could be applied.

- The outside diameter of the Plunger was reduced. At the flow rates typically used during hard rock coring, the tolerances did not have to be so tight to get an effective rig floor signal. Xylan coating of the Plunger and Flow Restrictor was also done.

- The counterbore for the nozzles in the Flow Divider was made slightly larger. These holes tended to get burred from the chain tongs, making it difficult to install and remove the nozzles. 
- The long nozzles were abandoned and only short nozzles used in both internal and external applications.

- An assembly tool was provided that aided in piloting the Male Spline through the Female Spline during assembly. This was also useful during disassembly if force was required.

\subsubsection{HWD4 Core Barrel}

The Core Barrel Head and Bearing assembly of the HWD4 core barrel had worked well with no significant problems. However, the following modifications were made:

- The Outer Core Tubes were reduced to 3.5-in. maximum outside diameter.

- The stabilization of the Inner Tube Shoe inside the throat of the Core Head was improved. A shoe with flutes for centering was provided to prevent the core receptacle from becoming off center and jamming in hard rock.

- A provision for utilizing the standard ODP plastic liner was incorporated.

\subsection{Land Test (Germany) - January 1987}

The land test facility chosen for the drilling testing of the NCB2 was the ITE labs in Clausthal, Germany. ITE and Eastman Christensen in nearby Celle, Germany maintain a close and cooperative relationship which greatly enhanced the utility of the ITE labs for the testing work.

The following tasks were outlined for the drilling tests in the early planning stage:

- Implementation of drilling tests that had the following characteristics:

- Vertical test arrangement.

- $\quad$ Uncurtailed deployment of all the NCB2 parts and all BHA parts.

- The same method of operation for handling the wireline retrievable NCB2 parts as on board the Resolution.

- Core drilling and core recovery in hard fractured rock.

- Practical proof of the hydraulic parameters as defined in the previous tests in Celle and how they related to the operation of the tool during real drilling.

- Estimation of rate of penetration (ROP), weight on bit (WOB), and rotations per minute (RPM) as a function of flow rate and nozzle size in the Thruster Nozzle Sub. 
- Weak point analyses of all components during drilling prior to sea trials by choosing test conditions which were as close to the shipboard deployment mode as possible.

A total of six core runs (9.3 meters total) were made in graywacke with recovery of almost $100 \%$. A photograph of a small section of recovered core is reproduced in Figure 3.1. A significant testing accomplishment was the development of a chart for operating the NCB2 on the ship. Also from this round of testing the following conclusions were arrived at:

- While the NCB2 was definitely viable onshore, it remained to be seen if adequate WOB control could be maintained from the floating JOIDES Resolution.

- The improvements to the tool were sufficient to warrant further sea trials.

- Future design efforts might include a rate of penetration (ROP) indicator, anti-jam features, and core blockage indicators. 


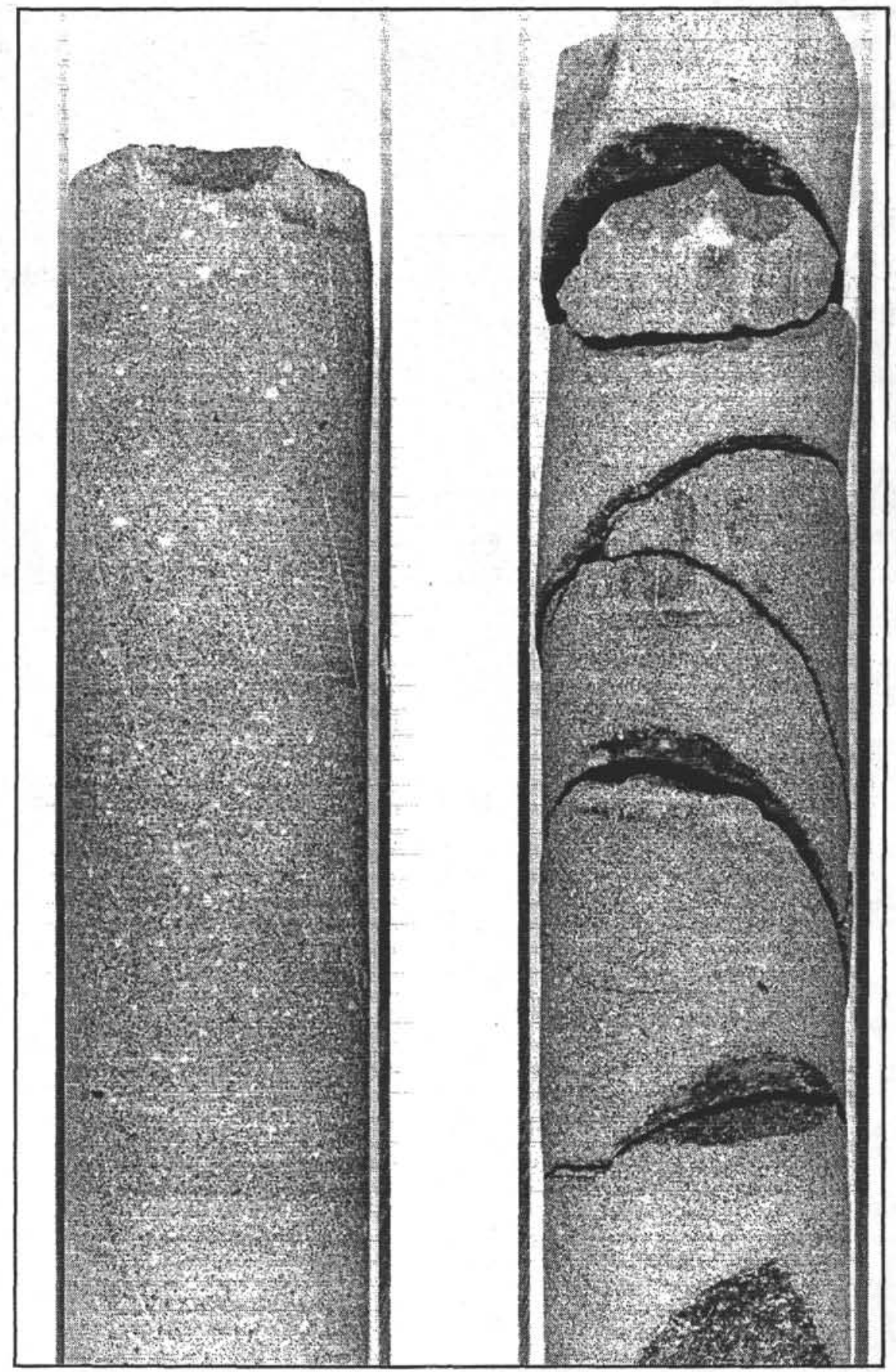

Figure 3.1 Graywacke recovered - Clausthal, Germany, Jan. 1987 


\subsection{NCB2 First Sea Trials: Leg 114 - February 1987}

Testing on Leg 114 included five actual drilling tests at Sites 702B, 703A and 704B. The testing consisted of two flow tests after the pipe cleared the mudline at Site 704B, three fit and flow tests on deck, and two fit tests in the tool repair shop between runs. Overall rig time spent for testing totaled 37.5 hours. The results of all testing were inconclusive. The only cores cut were two steel cores out of the hole cover plate on the rotary table during the third deck test prior to running in Hole 704A.

In spite of the lack of ability to cut a formation core with the NCB2 on this leg, it was proven that a secondary coring system could be deployed through the APC/XCB bit and operated without the influence of heave. The details from the core runs for Leg $114 \mathrm{can}$ be found in Appendix B.

\subsection{NCB2 Second Sea Trials: Leg 118 - September 1987}

The NCB2 was deployed twice on Leg 118. The first deployment was in Hole 735B. The tool recovered 0.7 meters of unbroken, excellent quality gabbro core, the longest continuous length of unbroken core for the leg. An unsupported spud-in was also attempted, but was unsuccessful. Further details on the Leg 118 sea trials appear as Appendix C. 


\title{
NCB-121: Development, Lab Testing and Sea Trials
}

\author{
March 1988 through February 1989
}

\subsection{Introduction}

The development of the NCB system had matured through the Leg 118 sea trials phase with enough significant results to enable further development aimed at perfecting the technology and making the tool a standard part of ODP's operational downhole arsenal. Lab and sea trial testing revealed numerous problem areas and presented new viewpoints for improving the overall design of the NCB.

\subsection{Redesign}

The main emphasis of the redesign effort was to address two problems:

- The tendency for the latch/release mechanism balls to gall on the hex shaft and the thruster adapter.

- Design a full separation between the functions of shock absorbing on landing when freefalling the tool and releasing the tool with pressure to start the coring sequence downhole.

The following list summarizes the changes made immediately after Leg 118.

- The combo system, which previously combined the functions of shock absorbing upon landing and releasing when pressuring up to start coring, was separated into two independent mechanisms.

- The six 9/16-in. steel ball latching elements had a tendency to gouge into the thruster adaptor and hex shaft. They were replaced with twelve 5/8-in. tungsten carbide balls along with an extra set of grooves in which to operate.

- A large, solid teflon (or teflon/bronze) hex seal replaced the multi-element rubber seal package on the upper end of the male spline shaft.

- A new layout of the tool was made in which the stroke for shock absorption and release was increased from 2 to 10 inches. Along with this, a Latch Sub was . added to the BHA above the Top Sub (in place of the normal Head Sub) which had vertical grooves to engage the torque segments of the NCB rather than have 
them engage in the Double Window Latch Sleeve used for the XCB.

- A general clean-up of the design as first produced by EC was done. This included increasing clearances on several sliding parts, reducing spring pre-load for the release mechanism, adding numerous chamfers and knurls to make the tool more user friendly, and increasing the cross-section of the thruster choke sub to survive retrieval through the drill pipe.

\subsection{NCB-121 Land Test (Germany) - March 1988}

The new releasing mechanism arrangement was tested at ITE where drilling tests were conducted along with hydraulic mapping calibrations. The drilling tests included coring in specially prepared models of gabbro, basalt, basalt/clay interbeds, and granite/chalk interbeds. This extensive test program highlighted a few other mechanical design changes desirable prior to more sea trial usage. Eastman-Christensen inspected and overhauled the Mach 1 mudmotor and found that the U-joint in the motor used during the two runs on Leg 118 was cracked. It was replaced and a flex shaft with housing was also sent along for possible use on Leg 121 if more problems were experienced.

\subsection{NCB-121 Sea Trials: Leg 121 - May - June 1988}

The NCB enjoyed a high priority status with the co-chiefs on Leg 121 and got its share of test time. The system was deployed at three sites and recovered ten cores in twelve runs. Both the Mach 1 and Mach 3 mud motors were used successfully. Specific details of each of the core runs appear in Appendix D. With each core run description and data sheet are the strip chart recordings from flow meter and pressure transducers specially installed for monitoring the NCB trials on Leg 121.

The major successes were several runs in which the tool performed exactly as it was originally envisioned. Two outstanding cores were cut in material too resistant for effective XCB coring (one in limestone/chert, one in basalt). A third run was spoiled by an apparent core catcher failure when most of a 4 meter basalt core appeared to get away. There were also very poor runs where the reason for the failure of the tool was not always clear. The results as predicted by the ITE model tests could not be repeated, even in formations which appeared to be similar to that tested. Large variations from the ITE-derived parameters of flow rate, flow division, and weight on bit were tried during the Leg in an attempt to achieve successful coring results. In fact, the most successful cores during Leg 121 were taken using operating parameters significantly different than those identified as optimum during the land tests. Because of this, the ITE test data proved to be of limited value.

The most significant malfunction of the leg was a devastating failure of the U-joint on the Mach I motor. After eight core runs, it was inspected and found to be demolished. The combined evidence of the cracked U-joint found after two runs on Leg 118 and this failure on 
Leg 121 led to the conclusion that the knuckle-type U-joint was not capable of being used for the NCB downhole coring conditions with the Mach I mud motor. Eastman Christensen often used a flex shaft in place of the U-joint for this size mud motor. This option was available for NCB usage, but required that space be made for the flex shaft, which would add to the overall space out length for the tool in the BHA.

The two best core runs achieved penetration rates of $9 \mathrm{~m} / \mathrm{hr}(4.5 \mathrm{~m}$ penetration) in softish limestone and chert, and $3.7 \mathrm{~m} / \mathrm{hr}(4.2 \mathrm{~m}$ penetration) in vesicular basalt. The times required to drill off the "rathole" in preparation for the next core were 35 minutes and 78 minutes, respectively. This equated to net hole deepening rates of $4.1 \mathrm{~m} / \mathrm{hr}$ in limestone/chert and $1.7 \mathrm{~m} / \mathrm{hr}$ in basalt. These figures and the general low success rate of NCB deployments so far did not extend the capabilities of the XCB unless round tripping for the RCB system was out of the question due to time constraints.

The other results and conclusions about the NCB from the Leg 121 sea trial experiences can be summarized as:

- Under the right conditions of formation and operating parameters the NCB produced cores comparable to conventional diamond coring equipment at the bottom of an ODP hole cored to XCB refusal.

- Surface set, impregnated, and geoset bits were used successfully.

- Both the Mach 1 and Mach 3 mudmotors were used successfully.

- The NCB assembly was freefalled to the bit without damage to the mechanism or mud motor. It reached the bit in about the same elapsed time as a regular XCB barrel. This method of deployment was significantly better than delivery by sandline because it was faster and helped control problems with fill accumulation in the hole.

- The mechanical problems which plagued the sea trial deployments of the NCB during Legs 114 and 118 were solved. A number of mechanical improvements were still called for, but none were as critical as the problems of the recent past.

- A pilot hole 3-3/4-in. $(95 \mathrm{~mm})$ diameter was made at least $4.5 \mathrm{~m}$ ahead of the roller cone bit for deploying the Geoprops probe or wireline packer, although it was likely that keeping it free from fill and debris was a problem. Drilling off the shoulder of the pilot hole to get to new formation was done using the APC/XCB roller cone bit in limestone/chert and in basalt.

- The knuckle-type U-joint supplied with the Mach 1 motor was not adequate for NCB operations. The alternative flex shaft was not tested on Leg 121. The same type of U-joint used on the Mach 3 motor did not suffer any damage in four deployments. 
- A strip chart recorder for pressure responses during NCB runs was extremely useful for proper operation of the tool.

- Overhaul and maintenance of the mud motors at sea would be a problem unless maintenance information and appropriate spare parts were made available.

- During Leg 121, the NCB was still not very reliable. Stall outs, core jams, and other forms of failure were more common than successful runs. Only one run of twelve achieved the full $4.5 \mathrm{~m}$ stroke. Even though painting the core barrel before each core run helped, it was not always possible to determine how much penetration ahead of the roller cone bit was achieved on a given core run. Thus, the amount of rathole to drill off was often a mystery.

\subsection{NCB Sea Trials: Leg 124E - January/February 1989}

The data summary sheets for Leg 124E Navidrill core runs are included in Appendix E.

\subsubsection{Coring Deployments}

After establishing the depth of the hard strata $(38.0 \mathrm{~m}$ bsf in Holes 777A-D and $41.5 \mathrm{~m}$ BSF in Holes $777 \mathrm{E \& F}$ ), the NCB was deployed and attempts to core were made nine times. Of these deployments, two should be disregarded as legitimate coring attempts because of mechanical failures unrelated to lithology. One tool failed to unlatch and begin coring when a previously unused thruster unit was assembled to the motor and core barrel sections. The landing sleeve on the thruster unit had been inadvertently jammed during initial assembly in Manila and would not move, thus preventing the tool from initiating the coring sequence. One other deployment was thwarted by a malfunctioning motor. Although it was not discovered until later, the motor was apparently bad as delivered from the factory (specifically ordered for this leg) and would not rotate under any flow or pressure conditions and thus never cut any core.

The first two NCB deployments suffered catastrophic failures of the 3-3/4-in. diamond core bits. In both cases, the bits fractured about 1-1/2-inches from the crown in what appeared to be low cycle fatigue of the metal bodies. Such a failure mode was unexpected and difficult to explain since the bits are standard products of the mining industry and routinely subjected to generally equivalent conditions in normal operations. Back to back failures of this sort at Site 777 suggested that the specific conditions imposed on the bits in Holes B and C were extreme. The most likely cause was excessive bending at the bit face from a lack of horizontal stabilization of the BHA in the extremely soft sediment.

To combat the stabilization problem, the remaining NCB attempts in Holes 777D and 777E were conducted only after using the XCB to make $10 \mathrm{~m}$ or more of hole into the chert/porcellanite layer below the sediment overlayer in order to have a firm supporting 
medium for the lowermost drill collar. This approach met with success as no further NCB bit fatigue failure indications were observed. Another artifact of the early NCB deployments were belled box connections on the NCB bits, the lower core barrel, or both. The indications were common evidence of overtorque, although the amount of torque required to cause such damage would be several times the maximum stall torque possible from the mud motors. The cause of this troublesome phenomenon was not determined. It had no direct effect on the results of the coring attempts.

Three valid coring deployments were made in Hole 777D. In each case, the NCB appeared to function properly in all mechanical aspects but only minimal amounts of core were recovered. Indicated penetrations and core recoveries for the three runs were as follows:

\begin{tabular}{ccc} 
Core & Penetration & Recovery \\
\hline $2 \mathrm{~N}$ & $1.1 \mathrm{~m}$ & $0.27 \mathrm{~m}$ \\
$3 \mathrm{~N}$ & $4.1 \mathrm{~m}$ & $0.37 \mathrm{~m}$ \\
$4 \mathrm{~N}$ & $4.0 \mathrm{~m}$ & $0.50 \mathrm{~m}$
\end{tabular}

The indicated penetration was derived by measuring the amount of paint removed on the core barrel that had extended beyond the bit face. There was considerable doubt as to the legitimacy of this measurement since the core recovery was slight by comparison and the core catchers were jammed tight in all three cases. In order for the amount of penetration indicated in cores $3 \mathrm{~N}$ and $4 \mathrm{~N}$ to have occurred without a corresponding recovery of core, the core barrel would have had to advance into the sediment with the core firmly blocked (supposedly impossible with a mining type diamond coring system in hard formation) or the core block had to have coincidentally occurred in both cases at the very end of the cored interval where missing core represented soft material that had been washed away. Neither explanation was particularly satisfying. Hole 777D was terminated when an external spring on the NCB thruster unit shattered (assumed to have been caused by stress corrosion) and caused the NCB to become irretrievably jammed in the BHA, forcing a full pipe round trip to dislodge it.

Following two aborted deployments in Hole 777E in which the faulty Mach $1 \mathrm{C}$ mud motor was used, two additional NCB core runs were conducted. In both cases, penetration of the coring assembly into the formation was virtually nil and the total recovery was only a few chunks of fractured chert. All indications were that in both cases the mud motor stalled due to excessive torque demands at the bit-chert interface. It was concluded that the jamming was an inevitable result of attempting to start the NCB in a hole with fractured chert rubble present at the bottom. Further NCB deployments were not considered worthwhile since there was no way to thoroughly clean the bottom of the hole between runs.

\subsubsection{NCB Deck Tests}

Rather than run the tool downhole, time was set aside for deck testing to clarify two important points: 
- The two mudmotors were functioning normally.

- The thruster unit was unlatching and allowing the NCB to core ahead as designed.

Both mud motors were set up on a makeshift test stand on the rig floor and drill water was pumped into them. The Mach IP motor used on seven of the nine NCB runs functioned normally with rotation initiating at about $100 \mathrm{psi}$. The Mach $1 \mathrm{C}$ motor failed to rotate under any combination of flow and pressure up to 300 GPM and 1500 psi, far exceeding the maximum required parameters for the motor as quoted by the manufacturer. Mysteriously, the rotor was not frozen and rotated within the stator with moderate torque applied externally with pipe wrenches. The motor was packed for immediate return to the manufacturer for failure analysis.

To demonstrate that the thruster unit was operating correctly, the NCB with Mach 3 mud motor (low torque, high speed) was set on top of a barrel of cement on the rig floor and a drill test was conducted. The thruster unit allowed the NCB core barrel to unlatch and initiate the coring sequence properly. However, the motor was unable to penetrate into the cement. The NCB stalled in the semi-cured cement and actually began to transmit left-hand stall torque to the suspended BHA causing it to rotate backwards despite up to 20,000 lbs. of weight on the XCB core bit against the cement. This result was unexpected, but served to demonstrate how easily the NCB stalled at initial contact with a soft formation, especially using the lower torque motor.

\subsection{Conclusions}

Despite typical prototype-system problems with jammed sleeves, a faulty mud motor, and a shattered thruster spring the NCB-121 performed reasonably well. Two problems dominated the use of the NCB and accounted for the poor overall core recovery. The inability to stabilize the BHA in the shallow holes led to fatigue failures of two diamond core bits and contributed to the mysterious over-torqued connections. When the bit bodies fatigued and separated during a core run, the advance of the NCB in the formation was terminated and it was not known whether a good core could have been achieved. Core blocking in the core catchers and motor stalling, either or both of which dominated most of the "promising" NCB core runs, were both results of the interbedded chert conditions in the hole. Although attempts were made to condition the holes between NCB core runs, the bottom of the hole still contained unremoved chips from the previous cored or drilled-down interval. This rubble surface was the first thing encountered by the NCB core bit when it unlatched and began the coring sequence. In typical mining diamond coring operations, the driller started such a core run with very light weight on bit and controlled RPM until the bit was seated smoothly in fresh rock. The NCB was not capable of such delicacy and often plunged ahead into a core jam or stall condition. 


\title{
MDCB: Development, Testing and Sea Trials
}

\author{
December 1990 through July 1992
}

\subsection{Introduction}

After Leg 124E, the fundamental concept of the hydraulic thrust system inherent to the NCB1/NCB2 tool design was subject to question and further analysis. There was considerable intuitive information and test data to suggest that the tool suffered from a built-in tendency toward producing its own stall conditions under most operating scenarios.

To test this theory, a hydraulic analysis of the current NCB configuration was required by way of a computer model. Eastman Christensen did not feel qualified to perform this work for ODP so a consulting firm was sought to handle the job. Stress Engineering Services of Houston, Texas was chosen and went to work on modeling both the existing NCB and several new concepts for a significantly improved version of the tool. The resulting changes to the design were great enough to merit a new name for the device, and "Motor-Driven Core Barrel (MDCB)" was selected.

Besides analyzing and optimizing the hydraulic performance characteristics of the MDCB, other improvement goals were identified, including:

- $\quad$ a reliable Mach 1 torque coupling system (U-joint or flex shaft),

- more rugged torque segments with positive engagement,

- improvements to the anti-jam system,

- quick release for the joint between the thruster adaptor and the mudmotor,

- simplification of threads in the assembly,

- better choices of materials for several components subject to corrosion,

- positive stop for resetting the thruster to the latched position,

- fool-proof penetration indication that could be read when the tool was back on deck.

\subsection{Redesign}

The design of the new MDCB was derived by an extensive computer model analysis. The biggest change in design was the repositioning of the motor and thruster sections. The motor in the NCB2 was immediately above the core barrel section and was allowed to move down as the core barrel advanced. This system made motor pressure drop, which was variable, a part of the thrust pressure which created weight on bit. The resulting undesirable positive feedback almost always caused the motor to stall when tough coring conditions were encountered. 
The MDCB had the thruster section moved between the motor and the core barrel. See Figure 5.1 below. The motor was on top and sat firmly on the landing shoulder in the seal bore saver sub; Its variable pressure drop was not felt as part of the WOB thrust. The flow down the pipe was allowed to flow both through the motor (about $85 \%$ of the total) and around the motor (about $15 \%$ ). The portion passing through the motor created both torque and WOB. The portion of the flow allowed to pass around the motor went exclusively to the diamond bit at the end of the core barrel. This arrangement led to negative pressure feedback which kept the system from stalling when coring conditions became difficult.

The motor used was a 3-3/4 in. Eastman-Christensen Mach 1P "drainhole technology" positive displacement mud motor. The Mach 1P motor produced a better combination of torque and RPM than any motor previously available in this size range. Because it had much more torque potential than the motors used with $\mathrm{NCB} 2$ it produced a more stable output with minimum RPM variation, even when the formation changed suddenly. It was left in its normally oversize OD (up to about $3.82 \mathrm{in}$.) because it did not enter the restricted, $3.800 \mathrm{ID}$ of the seal bore drill collar.

\subsubsection{Key Features of the New MDCB}

The heart of the new MDCB was the drill motor. The Christensen Mach 1-P, 7/8 lobe, drainhole motor had been specified due to the outstanding torque and speed capabilities as represented by Christensen. One set of specifications for this motor gave a torque of 1,250 ft.-lbs. at 410 RPM, yielding 96 Horsepower. This performance was specified at a $1,160 \mathrm{psi}$ differential pressure at 170 GPM. These numbers indicated a $83 \%$ efficiency. It was envisioned that the high torque and speed capabilities of this motor would greatly enhance the coring performance of the new $\mathrm{MDCB}$, resulting in high penetration rates and unlikely motor stalling.

The new layout of the tool was as follows. Again see Figure 5.1. A latch mechanism was located on top of the motor to counteract motor torque at the latch sub in the BHA. The lower end of the motor was connected to the fluid swivel housing which was, in turn, supported on the landing shoulder in the BHA. The motor bearing housing and drive sub were modified for this purpose. All flow exhausting the motor passed through a fluid swivel shaft and was forced to exit through a nozzle sub with restrictive orifices. This produced a high pressure on the top side of a hydraulic piston. This piston was connected to the core barrel via a hex-shaped shaft (kelly). In this way, downward thrust for coring was produced. Motor torque and rotation were transmitted through the fluid swivel shaft 


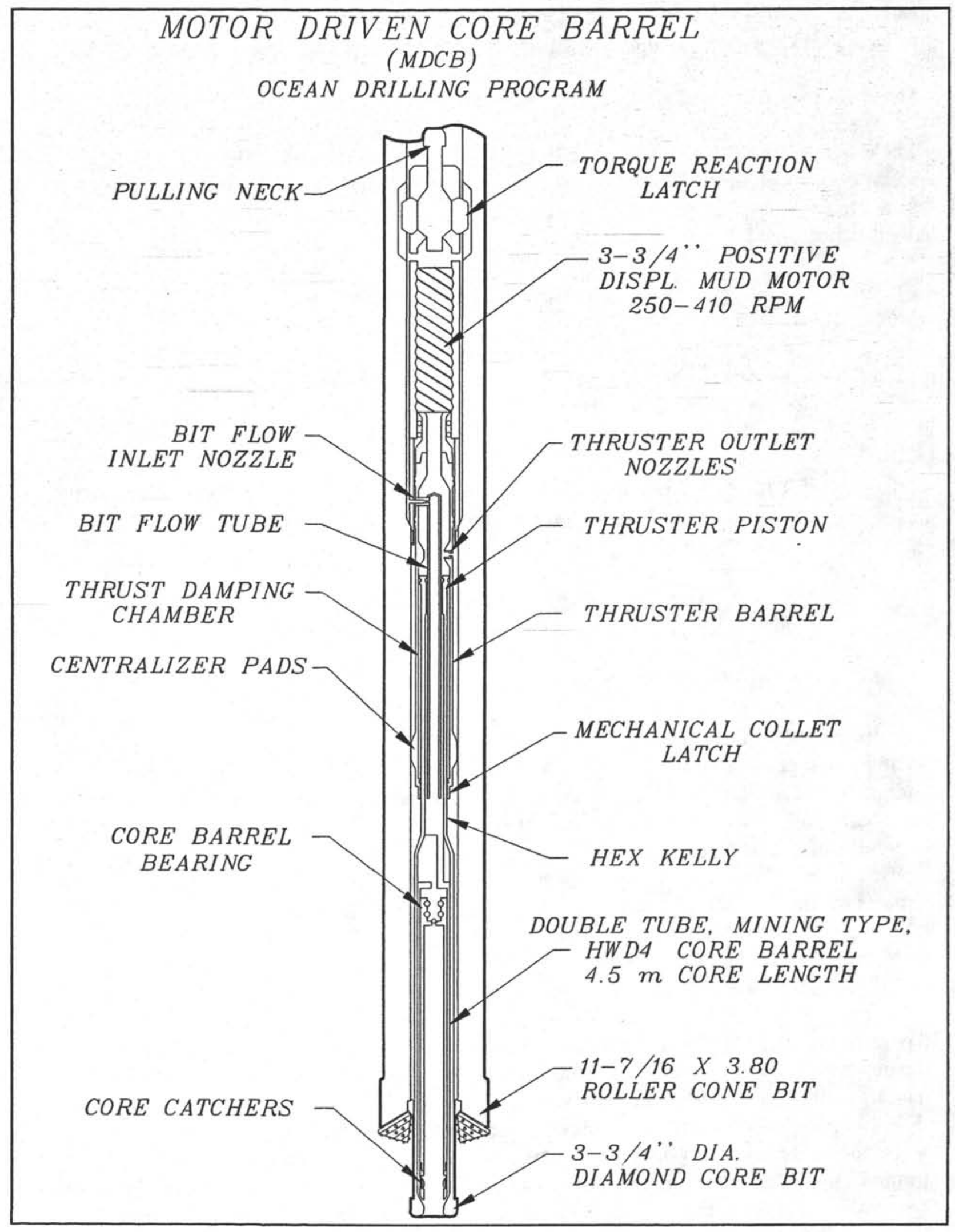

Figure 5.1 MDCB 
and nozzle sub to the thruster cylinder. A female drive hex was located in a sub which was threaded into the lower end of the thruster cylinder to conduct torque to the kelly.

The fluid swivel divided bit flow from motor flow at motor entry while accommodating relative rotation of the bit and the motor housing. As opposed to the earlier NCB2, bit flow was arranged in parallel with the drill motor. This was made possible by the fluid swivel section which included flow restriction nozzles in the rotating fluid swivel shaft and a central flow tube which conducted fluid directly to the core barrel. Two totally separate flow paths for the motor and the bit were produced. Several benefits accrued from this new layout:

- Overall system flow rate was increased.

- Flow to the bit was regulated by nozzles due to the higher available pressure above the motor. The restriction of these nozzles was much higher than the restriction of the bit itself. Therefore, any attempt to clog the bit was met with a rapid increase in bit face feed pressure.

- For the same reason as above, pump-off force, resulting from high bit feed pressure, would become rapidly available to reduce WOB during clogging conditions.

- During high torque demand some motor flow would be diverted to the bit, reducing WOB and increasing the motor stall threshold.

In addition to the above, other design changes were incorporated into the new MDCB. A control orifice was included in the hydraulic piston to throttle the flow out of the thruster area, preventing the core barrel assembly from "lunging". The new piston assembly also included a means to lock the thruster to determine penetration. A hydraulic end-of-stroke indicator was added. To ease adjustment and maintenance, both bit flow and thruster nozzles were externally accessible without disassembly of the tool. Also, a sealed quick release sub, a pre-existing ODP design, was located between the core barrel and the latch sub to allow quick change of the core barrel between coring runs. The summary report covering the major aspects of the new MDCB design can be found in Appendix F.

\subsubsection{MDCB Performance Analyses}

To verify the new design a performance analysis was done on computer. A program was written so that variables could be changed and the new results seen in a short amount of time. The time domain analysis approach was chosen since frequency and phase responses and dynamic interactions were automatically manifested in the results. Transient peak events that were not easily predicted became apparent and non-obvious phenomena were noted. This program provided the predicted MDCB performance that would be used as the guide during sea trials. This program was later modified; The new source code appears as Appendix I. 


\subsection{MDCB Sea Trials: Leg 134 - October 1990}

The Leg 134 MDCB Engineering Report can be found in Appendix G. The results from that leg are summarized here for convenience.

Only three downhole deployments with the MDCB were attempted during Leg 134, primarily due to the fact that XCB coring was terminated long before depths were reached where lithified sediments suitable for diamond coring were encountered. At Hole 828A, the MDCB experimentation was stopped after two cores when marginal recovery and slow penetration rate led to the decision to make an immediate change to the RCB coring mode.

At Hole $831 \mathrm{~A}$, a classic, coral limestone sequence offered a rare opportunity to attempt diamond coring in a formation which was generally unrecoverable by conventional coring techniques. Only one MDCB core was attempted, however, after it was discovered that the formation would not allow the placement of adequate WOB to produce BHA reaction weight. Two XCB cores were attempted after the single MDCB deployment, but each netted zero recovery. XCB coring was terminated long before the hole was deepened to a point where MDCB coring could have been more productive.

\subsection{Land Test (Houston) - September 1991}

The following is a list of deficiencies with the MDCB as noted during Leg 134.

- $\quad$ Slow Penetration Rate

High penetration rates were thought to be the cumulative result of many coring parameters being correct, including proper bit selection for the formation, rotational speeds, bit flow rate, and weight on bit. At least one of these key parameters (WOB) was significantly higher than intended. There could also have been mechanical interference impeding core barrel stroke.

- $\quad$ Higher than Predicted Pump Pressures (by about 500 psi)

Two significant sources of higher than predicted pump pressures were found that explain the field observations. The first was due to the use of a pre-existing quick release sub component in combination with the MDCB. In the MDCB, the majority of the pump flow traveled in the annulus between the inside diameter of the seal bore drill collar and the outside diameter of the $Q / R$ sub. The large 3.75 inch outside diameter of the $Q / R$ sub restricted flow leaving the thruster unit, thereby causing increased thruster pressures and increased WOB. This $Q / R$ sub contributed approximately $300 \mathrm{psi}$ to the pressure overage. The other source of increased pressures was found during testing where it was noted that the "no-load" motor pressure was about 50 psi greater than predicted, and the full load pressure 
loss was about 350 psi higher than previously thought. Remedial action was taken to correct these two problems. A new 3.5 in. outside diameter Q/R sub was designed and procured. And the recommended baseline flow rate was reduced from 215 GPM to 190 GPM to allow adequate operating "headroom" for the tool.

- Premature Deployment of the Core Barrel

On Leg 134, one MDCB run gave very strong evidence that the core barrel had arrived downhole in the full stroke condition. In addition, analyses indicated that shock accelerations at the MDCB core barrel were on the order of $50 \mathrm{G}$ 's during landing in the BHA, which results in rapid core barrel advance prior to achievement of steady, high motor flow. In order to combat deployment and landing problems, a locking device was designed that required a pressure differential to unlock the core barrel latch. This pressure differential was thought to exist only when the core barrel was within the seal bore drill collar and steady flow was in progress.

- $\quad$ No End-of-Stroke Indication

After Leg 134, a mechanical interference was discovered that prevented the Endof-Stroke Valve to properly trigger. Additional modeling showed that the valve design was theoretically flawed in that, once opened, the leakage flow created by the valve opening would experience the vast majority of the pressure loss prior to reaching the location of the valve spool, resulting in insufficient opening pressure. The analysis results showed that the full open position of the valve spool was not an equilibrium position and thus the spool would repetitively re-seat or achieve an oscillatory state. The solution was to restrict the outlet of the valve to shift the majority of the pressure drop to downstream of the valve. While this slightly decreased the effectiveness of the valve, pump pressures on the order of 1,000 psi were anticipated. By comparison, the lowest conceivable core block pressures, as indicated by the zero torque pressure, would be between 1,250 and 2,100 psi, depending on the nozzle combination used.

- $\quad$ Piston Brake (penetration indication) Inoperable

The locking piston assembly was unable to provide adequate friction to lock the core barrel in place. Another proposal was made that relied on a hydraulic lock to hold the core barrel in final position. It was still unclear as to the proper solution to this design problem. The core marking function remained inoperable for Legs 141 and 144.

The above design deficiences were corrected and the MDCB was flow-tested at Stress Engineering's facility in Houston, Texas. The data from this testing redefined the operating parameters of the new tool. An example of the new operating parameter charts is shown in Figure 5.2. A more detailed account of this phase of the MDCB development can be seen in 
the February 1992 Summary Report included as Appendix H.

\subsection{MDCB Sea Trials: Leg 141 - November 1991}

The MDCB was deck tested successfully on November 21, 1991 during the Leg 141 transit from Panama to Valparaiso. Two fifty-five gallon drums filled with cement, unconsolidated sand, gravel, and rocks were used as the formation. Seven tests were conducted, three of which were completely successful. Improper bit selection hindered three runs, while a core jam stopped the remaining test. Standpipe pressures were within 10-15 percent of those predicted from the testing done at Stress Engineering. The new positive latch system and the 3.50 inch quick release sub was used successfully.

At Hole 863B, the MDCB was deployed for Cores $7 \mathrm{~N}$ and $8 \mathrm{~N}$ shortly before the $\mathrm{XCB} / \mathrm{MDCB} \mathrm{BHA}$ was to be pulled to change to the RCB drilling mode. The formation was very firm siltstone with some cemented sandstones. Non-cemented, loose constituents could have been present. The formation was either quite fractured or very fracturable. It was too tough for several TC-insert, hard formation XCB cutting shoes. The core runs are summarized as follows;

Core 7N: Recovered $2.51 \mathrm{~m}$, about half highly fractured and half well preserved and trimmed. Recovery appeared to be 100 percent. (Lack of penetration indicator made this only an estimate at best, based on the amount of paint worn off of the outer core barrel.) A surface set piloted diamond bit was used with about 5,000 lb. WOB.

Coring time was 32.5 minutes and ended when the pressure suddenly climbed 1,400 psi (to 3,000 psi) and held there. The bit was undamaged and unclogged. No core was blocked in the bit or core catchers.

Core $8 \mathrm{~N}$ : Recovered $1.37 \mathrm{~m}$ similar to core $8 \mathrm{~N}$. On this run, penetration was about $4 \mathrm{~m}$ so some core must have been washed away. An ODP designed sawtooth impregnated bit was used with approximately 5,000 lb. WOB. The bit had about 10 percent wear. Coring time was 51 minutes. The run was terminated arbitrarily due to the length of time downhole. End-of-stroke indication was induced during pullout while the motor was still running.

Both runs: Pressures at constant flow rate were about 350 psi lower than the cement barrel deck tests when using the same bit and also lower than predicted ranges. RPM was 360-400 (according to charts). In both runs, the tool apparently stroked out during pump down and seemed to stroke back together at the bottom for 3-4 minutes before actually beginning to core. This was indicated by a low starting pressure that gradually built up to operational pressure as the seals engaged the seal bore drill collar. However, there were no apparent adverse effects from this.

XCB Cores $5 \mathrm{X}$ and $6 \mathrm{X}$, just before the MDCB run, recovered only jammed cutting shoe samples $(0.27 \mathrm{~m}$ and $0.46 \mathrm{~m})$. Core $9 \mathrm{X}$, after MDCB runs, recovered a similar 
small amount $(0.52 \mathrm{~m})$. Recovery rate and quality of preservation in the MDCB cores were superior to the XCB cores immediately before and after.

The Leg 141 Engineering Report section covering the MDCB testing appears as Appendix J.

\subsection{MDCB Deployment Summaries: Leg 144 - June - July 1992}

The MDCB was deployed in Hole 873B in an attempt to capture the interface material between the pelagic cap and manganese-crusted limestone that had not been recoverable with either the XCB or RCB on previous holes. The MDCB was run three times, beginning at $1,403 \mathrm{~m}$ and ending at $1,414 \mathrm{~m}$. Cores were consecutively numbered $8 \mathrm{~N}, 9 \mathrm{~N}$, and $10 \mathrm{~N}$. All the core runs were performed with the same geoset diamond bit and flow settings. The recovery rate for the three holes averaged 39 percent, compared to an RCB recovery of less than 2 percent in the same interval in nearby Hole 873B. An excerpt from the Leg 144 Engineering Report can be seen in Appendix K. 


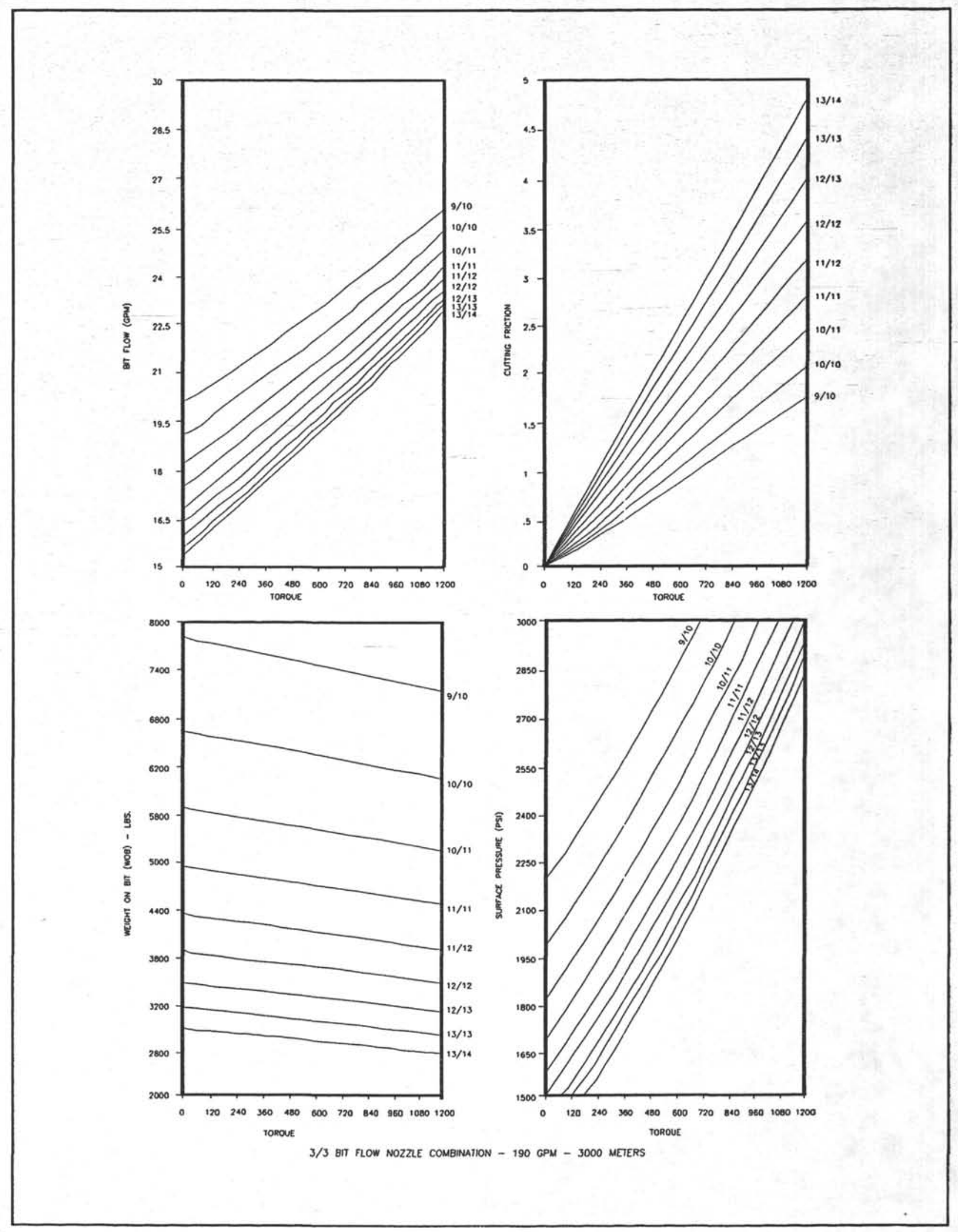

Figure 5.2 Example of MDCB Operating Parameters 


\section{Status of Motor Driven Core Barrel Development}

Following the successful runs on Leg 144, the MDCB system was declared operational. To ODP this means that the no further major development work will be undertaken on a tool until further runs are obtained. The MDCB is presently on board the JOIDES Resolution and is ready for deployment.

Despite the MDCB's operational status, there are several improvements already identified for future versions of the tool. These include:

. A reliable penetration indicator for the MDCB.

. An anti-jam system, possibly one adapted from the mining industry.

- An additional quick release above the kelly to decrease rig floor handling time.

- Further study into the intermittent apparent pre-release during deployment.

. Further study into the optimum seal configuration for the hex kelly. 


\section{References}

The following references were used to create this history of the development of the Motor Driven Core Barrel:

Storms, Michael A., Navi-Drill Core Barrel - Celle, Germany Test Report, Ocean Drilling Program, June 1985.

Storms, Michael A., Navi-Drill Core Barrel Sea Trials Report - Leg 104, Ocean Drilling Program, July 1985 .

Storms, Michael A., A Report on the Ocean Drilling Program's Shore Test of the NCB2 Coring System at Clausthal, West Germany, Ocean Drilling Program, January 1987.

Storms, Michael A., and Young, Thomas F., Navi-Drill Core Barrel (NCB2) Preliminary Sea Trials $\underline{\text { Report }}=\underline{\text { Leg } \_114}$, Ocean Drilling Program, May 1987.

Howard, Steven P., NCB-118 Leg Results and ITE Test Data, Ocean Drilling Program, September 1987.

Huey, David P., Sea Trials Engineering Report - Navidrill Core Barrel NCB2-121 - Leg 121, Ocean Drilling Program, May/June 1988.

Leg 124E Engineering Report - Navidrill Core Barrel (NCB-124E), Ocean Drilling Program, Jan/Feb 1989.

Miller, Jack E., Summary_Report: Motor Driven Core Barrel Engineering_Development, Stress Engineering Services, September 1990.

Huey, David P., MDCB-134 Final Report - Motor Driven Core Barrel, Ocean Drilling Program, December 1990.

Leg_141 Special_Tools Report, Ocean Drilling Program, January 1992.

Miller, Jack E.,_Summary Report:_Motor Driven Core Barrel_Engineering_Update Through Leg 141, Stress Engineering Services, February 1992.

Pettigrew, Thomas L., Leg 146 Engineering Report (Appendix II to Leg 146 Operations Report), Ocean Drilling Program, September 1992. 
Due to space and budget constraints much of the detail information had to be omitted. If you need to obtain one or more of these references or the detailed drawings for the MDCB please contact:

\author{
Engineering and Operations Department \\ Ocean Drilling Program \\ Texas A\&M University \\ 1000 Discovery Drive \\ College Station, TX 77845-9547 USA \\ Tel $409-845-8481$ \\ Fax 409-845-2308
}




\section{Appendix A}

NCB1: Leg 104 Run Data 
NAVIDRILL CORING DATA FORM

$3.75 \mathrm{MACH}$ I NAVIDRILL

OPTION I

LEG NO. 104

TOTAC DEPTH (MIETERS)

HOLE NO. 642D

CORE NO. $19 \mathrm{~N}$

DATE JULY 2, 1985

TOP 1618.5

NCB RUN N0.1

TIME ON DECK 1905 HRS

BOTTOM 1621.0

PENET (BSF) 328.9

NBC EOUIPMENT DATA

NOZZLE NUMBER/SIZE

MAVIDRILL PLUGGED

FLUID SPRING 107/16"

FLOW DIVERTER 4 OPEN

CORE RARREL

1 OPEN

DIAMOND CORE HEAD

TYPE BLACK \#2 DIA. IMPREG.

SIZE 3.780 OD 82.4 ID

SERIAL NO. 5S-2135

IINIXR TYPE SPLIT

CORE CATCHER TYPE

SKIRIIDO SKIRTLESS 8

HO. OF DRILL ROD USED 0

\section{CORE DATA}

MIFIERS CORED/REC 2.5/1.5 PERCENT RECOVERY ROP (M/HR) 1.7 608
OPERATIONAL DATA

RIG FLOOR

STROKES 35 IINER SIZE 6" TOTAL FLOK RATE (GPM) 147 STANDPIPE PRESSURE (PSI) 2100 TOP DRIVE RPM $70 / 85$

MAIN BHA CORE BIT

TYPE/SIZE XCB 11.37 OD X 3.8 ID

BIT KEIGHT (LBS) $10,000-20,000$

EST. FLOW RATE (GPM) $\div 80$

DIAMOND CORE HIXAD

BIT KIEIGH (LBS) $3,000-4,000$

EST. FLON RATE (GPM) 67

TOTAL EFFECTIVE RPM $320 / 335$

ROTATING HOURS

CUMULATIVE ROTATING FRS 1.5

MAVIDRILI

FLOW THROUGH STATOR (GPM) $\frac{147}{0}$
FLOW THROUGH ROTOR (GPM)

MUDMOTOR RPM 250

ROCK TYPE WEATHERED BASALT, ASH AND INTERBEDDED CLAY

RTYARKS

ACB DROPPED \& 1635. PUMPED DOWN Q 35 SPM. ON BOTTOM Q 1645.

FLOW RATES ASSUME PUMPS Q 96\% BFFICIENCY. SPM 84.2 GPS = GPM

PRESSURE WITH NCB UNSEATED KRS APPROX. 100-150 PSI

PRESSURE WITH NCB SEATED WAS 2100 PSI

TYPICAL DRILLING PRESSURES RANGED FROM 2200 TO 2500 PSI

ON RECOVERY CORE HEAD DRY/JAMMED, FACE WORN INTO CONICAL SHAPE

SPLIT LINER JAMMED IN BARRET, TAPE STRETCHED, LINER HALVES SEPERATED

SKIRTLESS CORE LIFTER WAS FOUND O THE TOP OF THE CORE

CORE DRY/PACKED IN LINER. HAD TO BE DUG OUT WITH SPOON.

TOTAL HOURS ON NAVIDRILL INCLUDING KL TIME $=2.5$ 


\section{NAVIDRILL CORING DATA FORM \\ $3.75 \mathrm{MACH}$ I NAVIDRILL \\ OPTION I}

L.EG NO. 104

HOLE NO. $642 D$

CORE NO. $20 \mathrm{~N}$

NCB RUN No. 2
DATE JULY 2, 1985 TIME ON DECK 2208 HRS
TOTAL DEPTH (METERS)

TOP BOTTOM $\frac{1621.0}{1622.0}$

PENET (BSF) 329.9
NBC EOUIPMENT DATA

NOZZLE NUMBER/SIZE

NAVIDRILL PLUGGED

FLUID SPRING $\frac{103 / 8^{\prime \prime}}{407 / 16^{\prime \prime}}$

CORE BARREL 1 OPEN

DIAMOND CORE HEAD

TYPE SURFACE SET DIAMOND SIZE 3.780 OD $\times 2.4$ ID

SERIAL NO. 5S-2134

IINER TYPE SPLIT

CORE CATCHIBR TYPE

SKIRTED \& X SKIRTLESS

MO. OF DRILL ROD USED 0

CORE DATA

METERS CORED/REC $1.0 / 0.5$ PERCENT RECOVERY $\frac{1.010 .5}{50 \%}$ ROP (M/HR) 2.0

ROCK TYPE MASSIVE BASALT, MELTED DOWN CORE BIT, BAKED CUITINGS

\section{ROMARKS}

NCB DROPPED O 2018. PUMPED DOWN \& 35 SPM. ON BOTTOM \& 2028. PRESSURE WITH NCB SEATED WAS AS 3,000 PSI

DRILLING PRESSURES RANGED FROM 3100 TO 3500 PSI

THREAD FAILED AT HWD4 CORE BARREL AFTER 40,000 LB OVERPULL CIRCULATION AND ROTATION WAS HALTED PRIOR TO PULLOUT ATTEDYPT CORE HEAD SPACE OUT WAS 48" AHEAD OF MAIN BIT FACE

LEFT REAMING SHELL AND DIAMOND CORE HEAD IN HOLE

EVIDENCE OF HIGH HEAT SHOWN IN DISCOLORATION OF FAILED METAC LINER STRIATIONS ON SIDE OF MASSIVE BASALT FROM CORE LIFTER

TOTAL HOURS ON NAVIDRILL INCLUDING WL TIME $=1.8 \mathrm{HRS}$ 
Appendix B

NCB2: Leg 114 Run Data 


\section{NAVIDRILL CORE BARREL - NCB 2 \\ L E G 1114 \\ DATA SUMMARY SHEET \\ GENERAL DATA}

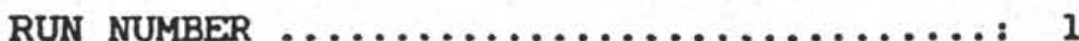

HOLE NUMBER ...................

DATE AND TIME OF DEPLOYMENT $\ldots \ldots \ldots \ldots \ldots$ : WATCH

WATER DEPTH BELOW DUAL ELEVATOR STOOL ....: HOLE DEPTH BSF AT TIME OF DEPLOYMENT ...... DRILLSTRING LENGTH AT TIME OF DEPLOYMENT .:

XCB/APC BIT TYPE AND SIZE ............ NUMBER AND SIZE OF NOZZLES IN BIT .......

BOTTOM HOLE ASSEMBLY CONFIGURATION ....... BOTTOM HOLE ASSEMLY SPECIALS

............

TOOL DATA
702 B

4-15-1987, 02:00-06:00 H MAS, TFY

$3094.2 M$ $294.3 \mathrm{M}$ $3388.5 \mathrm{M}$

RBI C-37, 5 CONE, 10-1/2" $\times 3.8 "$ 5, $10 / 32 "$

SEE ATTACHED LIST

NOTHING
TYPE OF THRUSTER RELEASE SPRING WIDTH OF GAP CHOKE SUB/FEMALE SPLINE ...... LENGHT OF CHOKING MANDRET ON CHOKE SUB ...: TYPE OF TORQUE SEGMENT ............... NAVIDRILL MUD MOTOR TYPE .............. TYPE OF INNER CORE BARREL ........... TYPE OF CORE LIFTER $\ldots \ldots \ldots \ldots \ldots \ldots \ldots \ldots$ : TYPE OF DIAMOND BIT ................ SIZE AND NUMBER OF DIAMOND BIT .......... OD AND NUMIERR OF REAMING SHELL ......... NUMBER AND SIZE OF NOZZLES IN THRUSTER SUB: NUMBER AND SIZE OF NOZZLES IN FLOW DIVIDER:
0-RING, 9 O-RINGS + 11 SPACERS $6 \mathrm{MM}$

$176 \mathrm{MM}$

BRASS, ORIGINAL EC-DESIGN

MACH III

POLYCARBONATE INNIR TUBE SRIRILESS

IMPRECHATYD, COLOUR-CODE TAN

$3.750^{\circ} \times 2.400 \%$. 7-\$-262-T

$3.750^{\circ}, 7-\mathrm{C}-263$

3. $9 / 32^{\prime \prime}-10 / 32^{\prime \prime}-0$

3. $8 / 32 "-9 / 32 "-0$

OPERATING DATA

SEA STATE, HEAVE ..................

SEA STATE, ROLL

SEA STATE, PITCH $\ldots \ldots \ldots$

WIND SPEED

TYPE OF ROCK EXPECTED

TYPE OF SPACE OUT CKECK

DEPLOYMENT MODE

WEIGHT ON XCB/APC BIT DURING CORING

DESIGN FLON RATES AND PRESSURES TEST FLON RATES AND PRESSURES

STATUS OF TOOL AFTER RETRIEVAL
$1 \mathrm{M}$

2.2 DEGREE

1.8 DEGRED

2.8 KNOTS

SIIICIFIED LIMIESTONE, CHERT LAYERS DECKIFST 3-20-87, SHOPTEST 4-3-87 NIRM.INE 20,000 LBF

SES ATIACHED WORKING SHIEET SEE OPERATING NOTES

S以马 FINAL OPHRATIN NOTHS 


\section{NAVIDRILL CORE BARREL - NCB 2 \\ L E G 1 I 4 \\ DATA SUMMARY SHEET}

GENERAL DATA

RUN NUMBER $\ldots \ldots \ldots \ldots \ldots \ldots \ldots \ldots \ldots \ldots \ldots \ldots$. 2

HOLE NUMBER $\ldots \ldots \ldots \ldots \ldots \ldots \ldots \ldots$ :

DATE AND TIME OF DEPLOYMENT $\ldots \ldots \ldots \ldots \ldots$ :

WATCH

WATER DEPTH BELOW DUAL ELEVATOR STOOL ....: HOLE DEPTH BSF AT TIME OF DEPLOYMENT ...... DRILLSTRING LENGTH AT TIME OF DEPLOYMENT .:

XCB/APC BIT TYPE AND SIZE ............. NUMBER AND SIZE OF NOZZLES IN BIT .......

BOTTOM HOLE ASSEMBLY CONFIGURATION ....... : BOTTOM HOLE ASSEMBLY SPECIALS ..........

\section{2}

$702 \mathrm{~B}$

4-15-87, 06:00-13:31 H

MAS, TFY

$3094.2 \mathrm{M}$

$294.3 M$

$3388.5 \mathrm{M}$

RBI C-37, 5 CONE, 10-1/2" X 3.8" $5,10 / 32 "$

SEE ATIACHDO LIST

NOTHIMG

TOOL DATA

TYPE OF THRUSTER RETEASE SPRING ........ WIDIH OF GAP CHOKE SUB/FEMALE SPLINE ..... : LENGHT OF CHOKING MANDRET ON CHOKE SUB ...: TYPE OF TOROUE SEETIDNT ............... MAVIDRILL MUD MOTOR TYPE ............. TYPE OF IMMER CORE BARREL $\ldots \ldots \ldots \ldots \ldots \ldots$; TYPE OF CORE LIFTER ................ TYPE OF DIAMOND BIT ................. SIZE AND NOMBER OF DIAMOND BIT .........: OD AND NUMBER OF REAMING SHETL ......... NUMBER AND SIZE OF NOZZLES IN THRUSTER SUB: NUMBER AND SIZE OF NOZZLES IN FLOW DIVIDER:
STFEי (OP5945), EC P/N 900001113

6 May

$176 \mathrm{~m}$

BRASS, ORIGIMAC DC-DESIEN

MACH III

POLYCARBOMATE IMIER TUBE

SkIramess

IFRRDETIND, COLOUR-CODE TAN

$3.750 \% \times 2.400 \%, 7-3-262-T$

$3.750^{\circ}, 7-\mathrm{C}-263$

3. $9 / 32^{\prime \prime}-10 / 32^{\prime \prime}-0$

3, $8 / 32^{\prime \prime}-9 / 32^{\prime \prime}-0$

\section{OPERATING DATA}

SEA STATE, HEAVE ..................

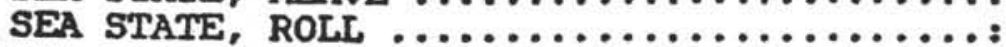

SEA STATE, PITCH $\ldots \ldots \ldots \ldots \ldots \ldots \ldots \ldots$

NIND SPEED $\ldots \ldots \ldots \ldots \ldots \ldots \ldots \ldots \ldots \ldots$

TYPE OF ROCK EXPECTED $\ldots \ldots \ldots \ldots \ldots \ldots . . . . .$.

TYPE OF SPACE OUT CKECK ............... DEPLOVMENT MODE .................... WEIGHT ON XCB/APC BIT DURING CORING $\ldots \ldots \ldots$

DESIGN FLOW RATES AND PRESSURES ......... TEST FLOW RATES AND PRESSURES ...........

STATUS OF TOOL AFTER RETRIEVAL
$1 \mathrm{M}$

2. 2 DDERTS

2.1 DPERTS

13.2 KeroTs

SILICIFIED LIMESTONE, CHERT LAYERS

DECKMEST 3-20-87, SHOPT2ST 4-3-87 WIRETINE, ONINIENITIONAL FREKFALI 20,000 IBF

SEE ATHACHID MORKING SHEXT SEE OPERATING NOTES

SEE FINAL OPERATING NOTES 


\section{NAVIDRILL CORE BARREL - NCB 2 \\ L E G 114 \\ DATA SUMMARY SHEET}

GENERAL DATA

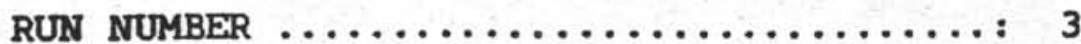

HOLE NUMBER ........................ 703 A

DATE AND TIME OF DEPLOYMENT $\ldots \ldots \ldots \ldots \ldots \ldots \ldots \ldots$ 4.24-87, 09:45-13:30 H
KATCH $\ldots \ldots \ldots \ldots \ldots \ldots \ldots \ldots \ldots \ldots \ldots \ldots \ldots \ldots \ldots$
MAS, IFY

WATER DEPTH BELOW DUAL ELEVATOR STOOL ...: $1806.6 \mathrm{M}$ HOLE DEPTH BSF AT TIME OF DEPLOYMENT ..... : $377.4 \mathrm{M}$ DRILLSTRING LENGTH AT TIME OF DEPLOYMENT - :

XCB/APC BIT TYPE AND SIZE ............. NUMBER AND SIZE OF NOZZLES IN BIT .......

BOIHOM HOLE ASSEMBLY CONFIGURATION ....... BOTIOM HOLE ASSEMBLY SPECIALS ...........

TOOL DATA

TYPE OF THRUSTER RETEASE SPRING ......... WIDIH OF GAP CHOKE SUB/FEMALE SPLINE ..... IFNGTI OF CHOKING MANDREL ON CHOKE SUB ...: TYPE OF TOROUE SEGMIFI ............... MAVIDRILT MUD MOTOR TYPE .............. TYPE OF INNIR CORE BARREL ............. TYPE OF CORE LIFTHA $\ldots \ldots \ldots \ldots \ldots \ldots \ldots \ldots \ldots$

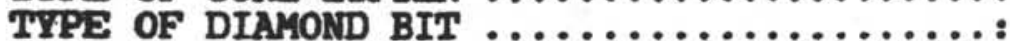
SIZE AND NUMBER OF DIAMOND BIT .......... OD AND NUMBER OF REAMING SHELL .......... NUMBER AND SIZE OF NOZZLES IN THRUSTER SUB: NUMBER AND SIZE OF NOZZLES IN FLOW DIVIDER:
NO SPRING, SOLID LANDING SHOULDER 4.5 MM

$176 \mathrm{MA}$

STसМा, GFS-114 DESIGA

MACH III

STEXI P/B WITH 114 P/P ADAPIER

SKIRALO

IMPRTEARTEN, COLOURCODE TAN

3.750 " X 2.400", 7-8-257-T

$3.570^{\circ}, 7-\mathrm{C}-265$

3. $9 / 32^{\prime \prime}-10 / 32 "-0$

$3,8 / 32^{\prime \prime}-9 / 32^{\prime \prime}-0$

OPERATING DATA

SEA STATE, HEAVE

SEA STATE, ROLL SEA STATE, PITCH

WIND SPEEED

TYPE OF ROCK EXPECTED

TYPE OF SPACE OUT CKECK

DEPLOYMFNT MODE

WEIGHY ON XCB/APC BIT DURING CORING

DESIGN FLON RATES AND PRESSURES TEST FLOW RATES AND PRESSURES

STATUS OF TOOL AFTER RETRIEVAL
$3.4 M$

2.8 DEGRES, MAXIMUM 8 DEGRW 2.6 DFGRJE, MAXIMUM 4 DEGRF5 42 KNOTS, GUSTS 52 KNOTS

KEATHIXRXD AMYGDALOIDAI BASALT

SHOPTIST 4-18-87, DECKCIDT 4-21-87 FRFFFAT. 20,000 LAF

SES ATIPACIND HORKING SHEF SEE OPERATING NOTES

SEE FINAL OPERATING NOTES 


$$
\begin{gathered}
\text { NAVIDRILL CORE BARREL - NCB } 2 \\
\text { L E G } 114
\end{gathered}
$$

DATA SUMMARY SHEET

GENERAL DATA

RUN NUMBER

HOLE NUMBER $\ldots \ldots \ldots \ldots \ldots \ldots \ldots$

DATE AND TIME OF DEPLOYMENT $\ldots \ldots \ldots \ldots \ldots$ :

WATCH

WATER DEPTH BELOW DUAL ETEVATOR STOOL

HOLE DEPTH BSF AT TIME OF DEPLOYMENT ......

DRILLSTRING LENGTH AT TIME OF DEPLOYMENT .:

XCB/APC BIT TYPE AND SIZE

NUMBER AND SIZE OF NOZZLES IN BIT .......

BOTTOM HOLE ASSEMBLY CONFIGURATION ........

BOTTOM HOLE ASSPMRLY SPECIALS ............

TOOL DATA
TYPE OF THROSTYR REIEASE SPRING ....

LENGH OF CHOKTHG MANDRTS ON CHOKE SUB

TYPE OF TOROUE SECMTET

MAVIDRILL MUD MOTOR TYPE $\ldots \ldots \ldots \ldots \ldots \ldots \ldots$ :

TYPE OF IMLITR CORE BARRET ............

TYPE OF CORE LIFIYR $\ldots \ldots \ldots \ldots \ldots \ldots \ldots \ldots \ldots$ :

TYPE OF DIAYOLD BIT $\ldots \ldots \ldots \ldots \ldots \ldots \ldots \ldots$

SIZE AND NUMBER OF DIAMOID BIT .........

OD AND NUMRER OF REAMIIMG SHETLL ..........

NUMBER AND SIZE OF NOZZLES IN THRUSTER SUB:

NUMBER AND SIZE OF NOZZLES IN FLOW DIVIDER:
4

704 B

$4-30-87,09: 58-11: 45 \mathrm{H}$

MAS, TFY

$2530.8 \mathrm{M}$

$633.7 \mathrm{M}$

$3164.5 \mathrm{M}$

RBI C-3, 4 CONE, 11-7/16" X 3.8" 4. $16 / 32^{\prime \prime}$

SER ATMACHED LIST

MECHAUICAT BIT RETEASE

\section{OPERATING DATA}

SEA STATE, HEAVE .................

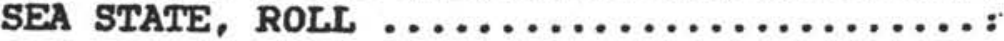

SEA STATE, PITCH . .................

WIND SPEED $\ldots \ldots \ldots \ldots \ldots \ldots \ldots \ldots \ldots \ldots \ldots$ :

TYPE OF ROCK EXPECTED $\ldots \ldots \ldots \ldots \ldots \ldots \ldots$ :

TYPE OF SPACE OUT CKECK .............

DEPLOYMENT MODE ...................

WEIGHT ON XCB/APC BIT DURING CORING ......

DESIGN FLOW RATES AND PRESSURES ......... TEST FLOW RATES AND PRESSURES .........

STATUS OF TOOL AFTER RETRIEVAL .........
$2.1 \mathrm{M}$

1.8 DEGREE

3.5 DEGRER

26 KNOTS, GUSTS 32 KNOTS

IMDURATED CHALK

DECKDEST ON APRIL 25,87

FREMFAIT

$20,000 \mathrm{LBF}$

SEE ATTACHED WORKING SHEXT

SEE OPERATING NOTES

SEE FINAL OPERATING NOTES 


\section{NAVIDRILL CORE BARREL - NCB 2 \\ L E G 114 \\ DATA SUMMARY SHEET \\ GENERAL DATA}

RUN NUMBER $\ldots \ldots \ldots \ldots \ldots \ldots \ldots \ldots \ldots \ldots \ldots$. 5

HOLE NUMBER .....................

DATE AND TIME OF DEPLOYMENT $\ldots \ldots \ldots \ldots \ldots$ :

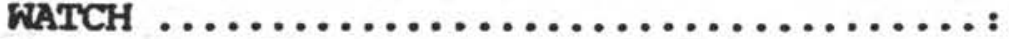

WATER DEPTH BELOW DUAL ELEVATOR STOOL ....: HOLE DEPTH BSF AT TIME OF DEPLOYMENT ...... DRILLSTRING LENGTH AT TIME OF DEPLOYMENT .:

XCB/APC BIT TYPE AND SIZE ............. . NUMBER AND SIZE OF NOZZLES IN BIT .......

BOTTOM HOLE ASSEMRLY CONFIGURATION ....... BOTIOM HOLE ASSEMBLY SPECIALS ..........

\section{5}

704 B

$4-30-87,11: 46-16: 04 \mathrm{H}$

MAS, TFY

$2530.8 \mathrm{M}$

$633.7 \mathrm{M}$

$3164.5 \mathrm{M}$

RBI C-3, 4 CONE, 11-7/16" X 3.8" $4,16 / 32^{n}$

SEX ATIACFIXD LIST

MECHANICAL BIT RFTEAASE

TOOL DATA

TYPE OF THRUSTER RETEASE SPRING ........ WIDTH OF GAP CHOKE SUB/FEMALE SPLINE ..... : LENGFI OF CHOKING MANDRET ON CHOKE SUB .... TYPE OF TOROUE SEEMENT .............. MAVIDRILI MUD MOTOR TYPE ............. TYPE OF INRER CORE BARREL ............ TYPE OF CORE LIFTER ............... TYPE OF DIAMOND BIT $\ldots \ldots \ldots \ldots \ldots \ldots \ldots \ldots$ : SIZE AND NUMBER OF DIAMOND BIT ......... OD AND NUMBER OF REAMIMG SHIELL ......... NUMBER AND SIZE OF NOZZLES IN THRUSTER SUB: NUMBER AND SIZE OF NOZZLES IN FLOW DIVIDER:
NO SPRING, SOLID LANDING SHOULDER $4.5 \mathrm{MM}$

176 MA

STrW, GFS-114 DESIGN

MACH III

SIYXOI WITH POLYCARBONATE IINER

8 FIHGER COMB. CATCHIXR, 114 DESIG SURFACE SET, 12-15 ST/CT

$3.750^{\circ} \times 2.400^{\circ}, * 47521$

$3.750 \mathrm{~m}, 7-\mathrm{C}-264$

3. $11 / 32^{\prime \prime}-11 / 32^{\prime \prime}-0$

$3,8 / 32^{\prime \prime}-9 / 32^{\prime \prime}-0$

\section{OPERATING DATA}

SEA STATE, HEAVE ..................

SEA STATE, ROLL .................

SEA STATE, PITCH $\ldots \ldots \ldots \ldots \ldots \ldots \ldots \ldots$ :

WIND SPEDD .....................

TYPE OF ROCK EXPECTED $\ldots \ldots \ldots \ldots \ldots \ldots \ldots$.

TYPE OF SPACE OUT CKECK ..............

DEPLOTMENT MODE .....................

VIEIGHT ON XCB/APC BIT DURING CORING ......:

DESIGN FLOW RATES AND PRESSURES ......... TEST FLOW RATES AND PRESSURES

STATUS OF TOOL AFTER RETRIEVAL
$2.5 \mathrm{M}$

1.7 DEGREE

2.7 DEGREE

29 KNOTS, GUSTS TO 35 KNOTS

INDURATED CHALK

DECKTEST ON APRIL 25, 87

FREXXFALI TWO TIMES

20,000 LBF

SEE ATTACHID WORKING SHEET SEE OPERATING NOTES

SEE FINAL OPERATING NOTES 


\section{NAVIDRILL CORE BARREI - NCB 2 \\ L E G 1114 \\ DATA SUMMARY SHEET}

GENERAL DATA

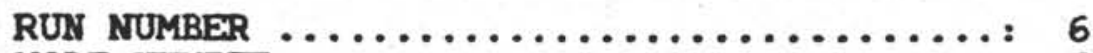

HOLE NUMBER ...................... 704 B

DATE AND TIME OF- DEPLOYMENT $\ldots \ldots \ldots \ldots \ldots \ldots$ : 5-3-87, 02:15-03:41 H

WATCH $\ldots \ldots \ldots \ldots \ldots \ldots \ldots \ldots \ldots \ldots \ldots \ldots \ldots \ldots$ MAS, TFY

WATER DEPTH BELOW DUAL ELEVATOR STOOL ....: $2530,8 \mathrm{M}$

HOLE DEPTH BSF AT TIME OF DEPLOYMENT ..... : DRILL STRING HAD CLEARED MUDLINE

DRILLSTRING LENGIH AT TIME OF DEPLOYMENT .: $2500.0 \mathrm{M}$

XCB/APC BIT TYPE AND SIZE $\ldots \ldots \ldots \ldots \ldots \ldots$.

NUMBER AND SIZE OF NOZZLES IN BIT $\ldots \ldots \ldots$ :

BOTTOM HOLE ASSEABLY CONFIGURATION $\ldots \ldots \ldots$ :

BOTTOM HOLE ASSEMBLY SPECIALS $\ldots \ldots \ldots \ldots \ldots$ :

BIT INAS ALREADY RETEASED

SEE ATTACHID LIST

MBR TOP COANECTOR

TOOL DATA

TYPE OF THRUSTER RETEASE SPRING $\ldots \ldots \ldots \ldots$ : WIDTH OF GAP CHOKE SUB/FEMALE SPLINE ...... LENGT OF CHOKING MANDRET ON CHOKE SUB ...: TYPE OF TORQUE SEGMENT ............. NAVIDRILC MUD MOTOR TYPE ............. TYPE OF IMIER CORE BARREL ............ TYPE OF CORE IIFTER $\ldots \ldots \ldots \ldots \ldots \ldots \ldots \ldots \ldots$ : TYPE OF DIAMOLD BIT AND NUMBER ........ REMMING SHIXI NUMBER ................ NUMRER AND SIZE OF NOZZLES IN THRUSTER SUB: NUMBER AND SIZE OF NOZZLES IN FLON DIVIDER:
NO SPRING, SOLID LANDING SHOULDER 4.5 MM $176 \mathrm{Fy}$

STEMT. GFS-114 DESIGN

MACH III

RON WITHOUT CORE BARRET AND $Q / R$

---

$--$

3, 11/32" - 11/32" - 0

$3,8 / 32^{\prime \prime}-9 / 32^{\prime \prime}-0$

OPERATING DATA

SEA STATE, HEAVE ................. -

SEA STATE, ROLL ................... --

SEA STATE, PITCH $\ldots \ldots \ldots \ldots \ldots \ldots \ldots \ldots \ldots \ldots \ldots$ : --

TYPE OF ROCK EXPECTED .............. -

TYPE OF SPACE OUT CKECK $\ldots \ldots \ldots \ldots \ldots \ldots \ldots$ :

DEPLOYMEAT MODE ....................

WEIGHT ON XCB/APC BIT DURING CORING ......

DESIGN FLOW RATES AND PRESSURES .........

TEST FLOW RATES AND PRESSURES ..........

STATUS OF TOOL AFTER RETRIEVAL ........
DECKIEST ON APRIL 25, 87 WIREXINE

SEE ATTACHIXD WORKING SHEET SEE OPERATING NOTES

SEE FINAL OPERATING NOTES 


\section{NAVIDRILL CORE BARREL - NCB 2 \\ L E G 1114 \\ DATA SUMMARY SHEET}

GENERAL DATA

RUN NUMBER ......................... 7

HOLE NUMBER ........................... 704 B

DATE AND TIME OF DEPLOYMENT $\ldots \ldots \ldots \ldots \ldots \ldots$ : 5-3-87, 03:45-04:50 H

$\ldots \ldots \ldots \ldots \ldots$ Mas, TFY

WATER DEPTH BELOW DUAL ELEVATOR STOOL ...: $2530.8 \mathrm{M}$

HOLE DEPTH BSF AT TIME OF DEPLOYMENT .....: DRILL STRING HAD CLEARED MUDLINE DRILLSTRING LENGTH AT TIME OF DEPLOYMENT .: $2500.0 \mathrm{M}$

XCB/APC BIT TYPE AND $8 I Z E \ldots \ldots \ldots \ldots \ldots$ : NUMBER AND SIZE OF NOZZLES IN BIT .......

BOTTOM HOLE ASSEMBLY CONFIGURATION ....... BOTTOM HOLE ASSEMELY BPECIALS

\section{TOOL DATA}

TYPE OF THRUSTER RELEASE SPRING $\ldots \ldots \ldots \ldots$ : WIDTH OF GAP CHOKE SUB/FEMALE SPLINE ..... LENGHT OF CHOKING MNDDRES ON CHOKE SUB ...: TYPE OF TOROUE SEGMITI $\ldots \ldots \ldots \ldots \ldots \ldots$. NAVIDRILL MUD MOTOR TYPE $\ldots \ldots \ldots \ldots \ldots \ldots$ : TYPE OF INNER CORE BARREM ........... TYPE OF CORE LIFIER $\ldots \ldots \ldots \ldots \ldots \ldots$ TYPE OF DIAMOND BIT AND NUMBER .........

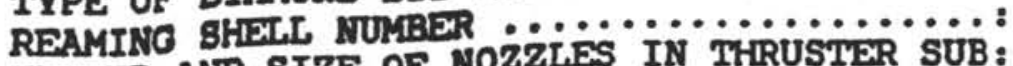
NUMBER AND SIZE OF NOZZLES IN FLOW DIVIDER: NUMBER AND SIZE OF NOZZLES IN

\section{BIT WAS ALREADY RETEASED}

SEE ATTACHED IIST

MBR TOP CONNECTOR

\section{OPERATING DATA}

SEA STATE, HEAVE $\ldots \ldots \ldots \ldots \ldots \ldots \ldots \ldots \ldots \ldots \ldots \ldots$
SEA STATE, ROLL $\ldots \ldots \ldots \ldots \ldots \ldots \ldots \ldots \ldots \ldots$

TYPE OF ROCK EXPECTEDD

TYPE OF SPACE OUT CKECK .............

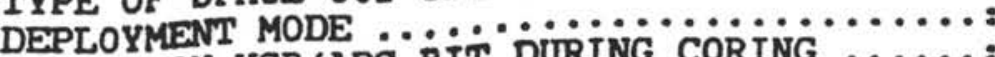
WEIGHT ON XCB/APC BIT DURING CORING ...... DESIGN FLOW RATES AND PRESSURES $\ldots \ldots \ldots \ldots$ : TEST FLOW RATES AND PRESSURES $\ldots \ldots \ldots \ldots \ldots$. STATUS OF TOOL AFTER RETRIEVAL .........
NO SPRING, SOLID LANDING SHOULDER 4.5 MM

$176 \mathrm{MM}$

STसभ, GFS-114 DESIGN

RUN WITHOUT MUD MOTOR

RUN WITHOUT CORE BARREI AND $Q / R$

- -

3, 11/32" - 11/32" - 0

3 , $8 / 32 "$ - $9 / 32 "$ - 0 
Appendix C

NCB2: Leg 118 NCB Report 


\section{Excerpt from Leg 118 Engineering Report..}

\section{NAVIDRILL DEPLOYMENT (NCB-118)}

\section{ASSEMBLY}

Assembly of the Navidrill upper, middle, and lower sections was done carefully to ensure that the required components were put together in the correct configuration. The upper section was assembled with one of the new steel splines. Removal of the teflon coating after the test at I.T.E. alleviated the clearance problem that prevented installation of the female spline onto the male spline in Germany. The female spline slid freely over the entire length of the spline prior to installing the thruster adapter. The new quick release assembly compatible with the Leg 118 flow divider was used. The lower core barrel section was assembled with the anti-jam system, a short break off sub, and a slip type catcher. The flow divider was jetted with two each 11/32 and one 20/32 nozzles. The thruster nozzle was jetted with one 11/32 and one 10/31 nozzle. This nozzle configuration was selected to provide adequate thrust for drilling the dense/hard gabbro formation to be encountered in hole $735 \mathrm{~B}$.

A hard formation impregnated bit was selected for the coring run in Hole 735B. The bit was manufactured by Christensen Mining Company. The bit had a square crown and was classified as a soft matrix bit. The soft matrix allowed the diamonds as they dulled to be worn-abraded away at a moderate rate exposing new sharp diamonds to continue aggressively cutting of the hard abrasive gabbro formation. Due to the excellent core recovery that was realized using the conventional rotary core barrel system and lack of core jamming, a core liner was not run.

\section{NCB DECK TEST}

A standard APC/XCB outer core barrel assembly with one $81 / 4^{\prime \prime}$ drill collar was made up and hung off at the rig floor. A standard long top sub (OL1022) was run in place of the special top subs made in Germany with the reduced bore. This was done because of the possibility of being required to recover a sample with the advanced piston corer. [If adequate sediment cover was encountered in subsequent NCB coring operations outside of hole 735B.]

Prior to conducting the deck drilling test a space out test was conducted. The NCB assembly was run into the outer core barrel assembly and landed in place with the new Christensen delivery system. The space out measurement for the NCB core bit was 2.406" instead of the required 3.031". The space out error of $.625^{\prime \prime}$ was attributed to tolerance problems with the length of the outer core barrel assembly. A natural diamond bit was used for the deck drilling test. The natural diamond bit was selected because the cement test block was not fully cured (hardened).

The cement test block was positioned under a dummy test bit and approximately six thousand pounds of weight were applied to the test bit. A flow rate of 30 GPM was established, with no pressure indication on the rig floor gage. The flow rate was increased to $40 \mathrm{GPM}$. The core bit was observed to start to rotate and scope out. At 45 GPM a pressure of 350 psi was noted. The flow rate was increased to $50 \mathrm{GPM}$ and the NCB was visually confirmed to have unlatched and 
was coring the cement test block. The pressure increased at a moderate rate during the time period that it took to cut through the cement. The NCB cut completely through the block of cement and the bucket the cement was contained, in three minutes. The indicated surface pressure at this point was 2500 psi and still increasing when the bit broke through the bottom of the cement test block. It was necessary to stop rotation before the pressure had time to stabilize due to the short period of time it took to cut through the test block.

The NCB was pulled from the OCB and laid out. Difficulty was encountered rescoping and relatching the thruster adapter-ball latch system. Though there was some evidence of galling on the male spline the damage was considered minimal at this point. When the tool re-latching and the compression in the springs on the female spline suddenly released rapidly, it sounded like a shot gun discharging. The springs appeared to have been compressed to near their solid height. The dampening cylinder 0 -ring was checked and found to be in good condition. The lower core barrel section was redressed with the hard formation impregnated bit.

A space check with the new impregnated bit was done prior to running the NCB in the hole. The NCB bit rather than passing through the end of the bit was found to be resting on top of the XCB float valve spacer ring (OL1031). The spacer ring has a 3.800" diameter bore and the NCB bit outside diameter is $3.750 "$. The square crown on the Impregnated bit has a maximum of a $1 / 16^{\prime \prime} \times 45$ degree chamfer on the edge of the crown. The $.050 "$ minimal clearance int he spacer ring coupled with the square crown profile caused the NCB bit to hang up in the bit sub.

The bit dummy and the spacer ring were removed. The spacer ring bore was machined to $4.050 "$ and a 30 degree chamfer was machined out to $4.300^{\prime \prime}$. The space out was re-checked with the modified spacer ring. The space out measured exactly $3-1 / 32 "$ as specified. The NCB was removed from the outer core barrel and re-landed. The space out was re-checked and again measured 3-1/32". No problems were encountered with the NCB bit hanging up in the bit throat after the spacer ring was modified. The natural diamond bit used for the cement drilling test had a more rounded crown which tended to pilot itself into the spacer ring more than the square crown NCB bit designs. The $5 / 8$ " space out discrepancy noted with the natural diamond bit during the initial space out test was attributed to the tight clearance in the spacer ring rather than a dimensional problem with the APC/XCB outer core barrel assembly as originally thought. The difficulties encountered, not being able to establish rotation with the Navi-drill downhole, may have been associated with the spacer ring clearance problem.

\section{NCB DEPLOYMENT 735B}

Upon completing the space out test, the NCB outer core barrel system was tripped into the hole. Prior to re-entering the guide base the Eastman Christensen delivery tool was tested with the dummy bit positioned 30 meters off the seafloor. The purpose of the test was to ascertain if there was any problems with the E.C. delivery tool prematurely releasing the NCB causing the tool to free-fall down the drill pipe. There was a high degree of confidence that the NCB dampening system would properly decelerate the tool when landed. However, due to the significant scientific value of Hole $735 \mathrm{~B}$, it was necessary to take precautionary measures to preserve the integrity of the hole. The NCB was run in the hole and released with no problems. Upon retrieving the NCB assembly with a standard RS type overshot, Hole 735B was reentered and 
the dummy bit was run to the bottom of the hole.

It was necessary to build a special APC/XCB dummy bit that was compatible with the 9-7/8" hole size. Both the 11-7/16" and the 10.5" APC/XCB bits on the ship were not compatible with the 9-7/8 hole size. It was planned to cut a maximum of 15 feet of core with the NCB in the bottom of hole. Since it was not necessary to advance the large bit and the hole was extremely clean, a dummy bit that would maintain the proper spacing off the bottom of the hole could be used. The cones and legs of a used 10-1/2 APC/XCB bit were removed. In place of the cones, five landing feet were welded in place. The exact overall height and space out relationships of a APC/XCB bit were maintained. It was planned to run 25 thousand pounds weight on the bit. After completing the construction on the bit dummy it was decided that only 15 thousand pounds should be run on the dummy bit to ensure that the welded feet did not come off and possibly junk the hole. The finished bit dummy diameter was nine inches outside diameter.

The bit dummy was positioned in the bottom of the hole with 15 thousand pounds of weight and the hole was conditioned. Two 25 barrel high viscosity mud sweeps were pumped spaced out with 100 barrels of salt water in between. This was followed by 5 times the hole volume of salt water pumped at $1000 \mathrm{gpm}$. Upon completing conditioning the hole, the NCB coring assembly was run in on the wireline with the E.C. delivery tool. Below is an account of the NCB coring run made in Hole 735B.

1835 HRS. - BREAK CIRCULATION, 50 GPM, NO INDICATED PRESSURE AT THE SURFACE.

1835 HRS. - INCREASE FLOW RATE TO 100 GPM, 700 PSI INDICATED SURFACE PRESSURE, WITH THE PRESSURE GRADUALLY INCREASING.

1840 HRS. - INCREASE FLOW RATE TO 150 GPM, INDICATED SURFACE PRESSURE 2500 PSI, 15 THOUSAND POUNDS WEIGHT ON BIT. SURFACE PRESSURE STABILIZING. APPEARS NCB CORING.

1842 HRS - MAINTAINING 150 GPM, 2300 PSI SURFACE PRESSURE, 15 THOUSAND POUNDS WEIGHT ON BIT.

1845 HRS. - INCREASED WEIGHT ON BIT TO 20 THOUSAND POUNDS. CONCERNED THAT BIT POSSIBLY HEAVING OFF BOTTOM OF THE HOLE DUE TO THE PRESSURE FLUCTUATION. SURFACE PRESSURE INCREASED TO 2900 PSI, SUSPECT MOTOR STALLED.

1850 HRS. - ADJUSTED WEIGHT ON BIT WITH HEAVE COMPENSATOR BACK TO 10-15 THOUSAND POUNDS WEIGHT ON BIT.

1855 HRS. - SUDDEN INCREASE IN PRESSURE TO 2800 PSI.

1900 HRS. - SUSPECT MOTOR STALLED OR POSSIBLY CUT FULL LENGTH 
CORE AND PRESSURE INCREASE CAUSED BY THRUSTER NOZZLE ENTERING CHOKE SUB. ADJUST WEIGHT ON BIT TO 8 TO 10 THOUSAND POUNDS. PRESSURE DROPPED TO 2500 PSI.

\section{HRS. - MAINTAINING 150 GPM, SURFACE PRESSURE 2450 PSI, AND 12 THOUSAND POUNDS WEIGHT ON BIT. STOP ROTATION AND PICK BIT UP OFF BOTTOM. HAD 20 THOUSAND POUNDS OVERPULL - POSSIBLE INDICATION OF A CORE BREAK. ACTUAL CORING TIME 1840 HRS. TO 1905 HRS. 25 MINUTES ROTATING TIME.}

The dummy bit was picked up off bottom and the NCB coring assembly was retrieved. The upper and middle sections of the NCB were kept together and hung off in the handling shuck. The lower core barrel section laid out and the NCB bit was removed. The core barrel contained .7 meters of excellent quality gabbro core. It should be noted that this NCB cored section was the longest length of continuous unbroken core recovered out of hole 735B. The bit crown was severely damaged by a possible core stub left in the hole from the previous rotary core bit run, one or two small pieces of broken core left in the hole, and several carbide buttons lost off the rotary core bits. The inside of the bit crown appeared to have been worn (beveled somewhat) heavily towards the center of the bit possibly by the core stub. The water courses were also worn away and plugged. The diamonds in the bit face were not polished. Had the bit been run much longer damage due to excessive friction and heat build up would have most certainly occurred.

It was decided to suspend coring operations in hole 735B in effort to preserve the integrity of the hole. There was warranted concerns that a core barrel or bit crown could possibly be left in the hole caused by not being able to run an adequate amount of weight on the dummy bit to keep the bottom hole assembly motionless in the bottom of the hole. If it had been possible to cut a second core in hole $735 \mathrm{~B}$, considerably better results would have been expected. The improved geometry in the bottom of the hole (absence of RCB core stub) and grinding up of core fragments on the first NCB coring run provided considerably better conditions for continued coring operations.

\section{UNSUPPORTED SPUD-IN CORING ATTEMPT WITH THE NCB IN HOLE 735B}

After tripping the pipe out of Hole 735B it was planned to run the NCB back in the drill pipe on wireline using the E.C. delivery tool and attempt to cut a core with a unsupported bottom hole assembly. It was recognized that testing the NCB with an unsupported bottom hole assembly was not an ideal situation. However, the information that could be gained from the test would be of great benefit in accessing the capabilities of doing shallow exploratory coring operations in a similar manner as done with the positive displacement coring motors. Also factored into the decision, there was not sufficient time to relocate the ship to an area where sediment cover was present. If the first coring attempt was successful a second coring run would be made with the unsupported bottom hole assembly after free-falling the NCB system to the seafloor. While running the NCB in on wireline there was evidence on the wireline weight indicator that the tool was floating somewhat. This was an indication that the check ball installed on top of the motor was forcing the fluid inside the drill pipe to flow around the NCB assembly and was producing 
a significant breaking-dampening effect on the system. This evidence coupled with the results of the testing in Germany justified conducting a free-fall test in open water.

Prior to running the NCB in on the wireline significantly more difficulty was encountered relatching the thruster adapter-ball latch assembly. It was necessary to repeatedly drop the upper and middle sections of the tool together in the handling shuck on a tugger line to get the tool to re-latch. More damage was noted on the spine corners where the balls ride. Again when the tool finally did re-latch as the springs expanded it sounded like a shot gun blast.

The tool was run in on wireline and delivered again without any difficulties with the E.C. delivery tool. The area in the vicinity of the beacon was covered with a thin layer of coarse alsand/sediment. The bit was lowered to the bottom and 15 thousand pounds of weight was put o the bit. The sediment cover appeared to be no more than two inches thick. The rock below the thin sediment cover was presumed to be gabbro. Below is an account of the unsupported NCB coring run.

2315 HRS. - TAG THE SEAFLOOR AND APPLY 15 THOUSAND POUNDS OF WEIGHT TO THE BIT.

2318 HRS. - BRING FLOW RATE UP SLOWLY TO 150 GPM, INDICATED SURFACE PRESSURE OF 2700 PSI. READJUST PUMP TO 140 GPM, SURFACE PRESSURE 2400 PSI. OBSERVE BIT DUMMY ROTATING ON THE BOTTOM AND REACTIVE TORQUE IN THE DRILL PIPE BACK TO THE SURFACE. LOCK TOP DRIVE BREAK TO COUNTER REACTIVE TORQUE.

2325 HRS. - DROP FLOW RATE TO 135 GPM, SURFACE PRESSURE 2400 PSI WITH OCCASIONAL SPIKE TO 3000 PSI. SUSPECT MOTOR STALL ASSOCIATED WITH BHA MOTION.

2328 HRS. - OBSERVED BIT PUMPED OFF BOTTOM AND NCB CORE BARREL BENDING. CEASE NCB CORING OPERATIONS IMMEDIATELY AND TRIP PIPE OUT OF THE HOLE WITH THE NCB IN OUTER CORE BARREL ASSEMBLY.

It was necessary to torch the core barrel in three places to free up the NCB coring assembly. The core barrel was bent three feet from the NCB bit and slightly bent for $2 / 3$ of the entire barrel length. Had extreme difficulty scoping the spline out to remove the core barrel. It appears that when the core barrel scoped out on the sea floor significant galling occurred. After removing the lower and upper sections from the outer core barrel an attempt was made to re-latch the thruster adapter-ball latch assembly. After working the female spline onto the thruster adapter the assembly jammed. The ball ports in the female spline were $1 / 2$ of an inch from the ball groove in the thruster adapter when the latch jammed. It was necessary to grind/cut the landing dampening sleeve off the female spline to release the compression on the balls and thruster adapter shaft. No grit or sand was found inside the system. The springs remained loaded until the dampening-landing sleeve was cut into. Inspection of the male spline revealed significant 
galling along the corners of the spline where the balls make contact. The female spline would no longer slide along the male spline with out applying excessive force with tuggers. 


\section{Appendix D}

NCB 121: Leg 121 Run Data 
MAUIDRILL CORE BARREL

NCB2-121

DAIA SUKMARY SHEET.

GENERAL

CORE NO. ..................... : $19 N$

HOLE ........................ : 754A

DATE ....................... 5-14-88

WATER DEPTH ................. 1076.4 .

DEPTH BSE .................. $159.8 \mathrm{~m}$

APC/XCR BII....................: 11-7/16' Security, $4 \times 16$ jets

BHA NOTES ...................... : LEV, Non-wag Latch Sub

\section{NCB_DETAILS}

MOTOR .............................. BII TYPE $\ldots \ldots \ldots \ldots \ldots \ldots \ldots \ldots \ldots \ldots \ldots$ CORE CATCHER TYPE...$\ldots \ldots \ldots \ldots \ldots \ldots$ THRUSTER NOZZLES ............... FLOW DIVIDER NOZZLES $\ldots \ldots \ldots \ldots \ldots \ldots$ INNER TUBE / LINER .............. ANTI-JAM / HWD4 STD. BEARING ....... DEPLOYKENT MODE .................: Sandline w/ releasing overshot UNLATCH MECH. RESET WHEN RECOUERED? : YeS

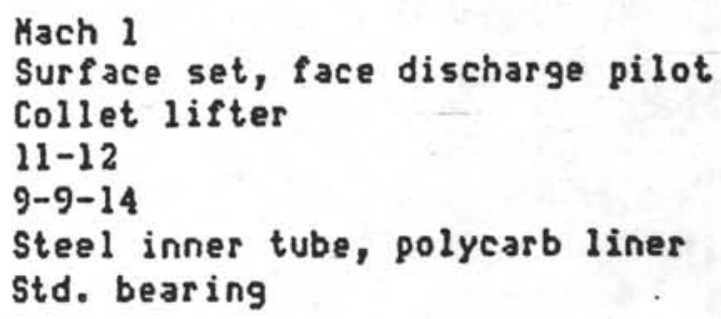

\section{OPERAIING DAIA}

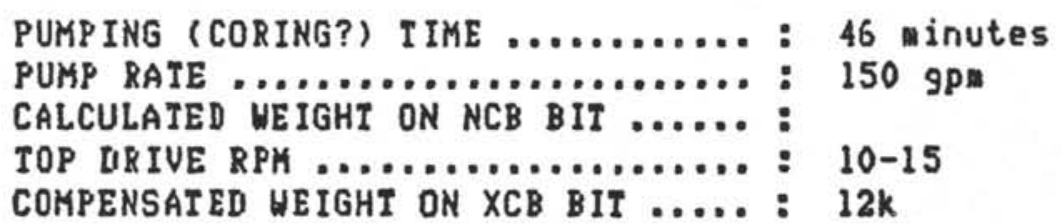

HOLE CONDITIONS ................. : Poor, fill between all connections ASSUMED EORHATION ............... : Chert, chalk/clay

\section{RESULIS}

INDICATED PENETRATION $\ldots \ldots \ldots \ldots \ldots$ : 1 . AMOUNT OE CORE ................. : 0.7 . CORE DESCRIPIION ................: Jamued clay, baked, welted liner BIT CONDIIION ..................... : Dastroyed matrix, overheated 
NOIES $=754 A-19 N$

The hole exhibited a constant tendency to fill whenever the puaps were stopped despite ud sweeps after XCB refusal and before NCB deployment. This -ade sandline delivery of the NCB very awkward as the bit kept tagging bottom while inserting and removing the sinker bars and running the NCB to the bottol.

The tool was stuck in the BHA when first retrieval was attempted probably due to the distortion of the bit matrix material. One segment of the bit was nissing when recovered, probably broken off while jarring on the stuck barrel. The releasing over shot was used first for retrieval but the dogs distorted outwards while jarring and released. The tool was recovered using an otis RS overshot.

The destruction of the diamond bit and the partially melted condition of the core liner at the botton indicated that too wch heat had been generated and that flow to the core barrel was insufficient. Penetration was probably stopped after 8-9 ainutes when the clay packed off in the liner.

2.1 meter of 1 imestone was drilled of 1 in 20 minutes in preparation for core $20 \mathrm{~N}$. 


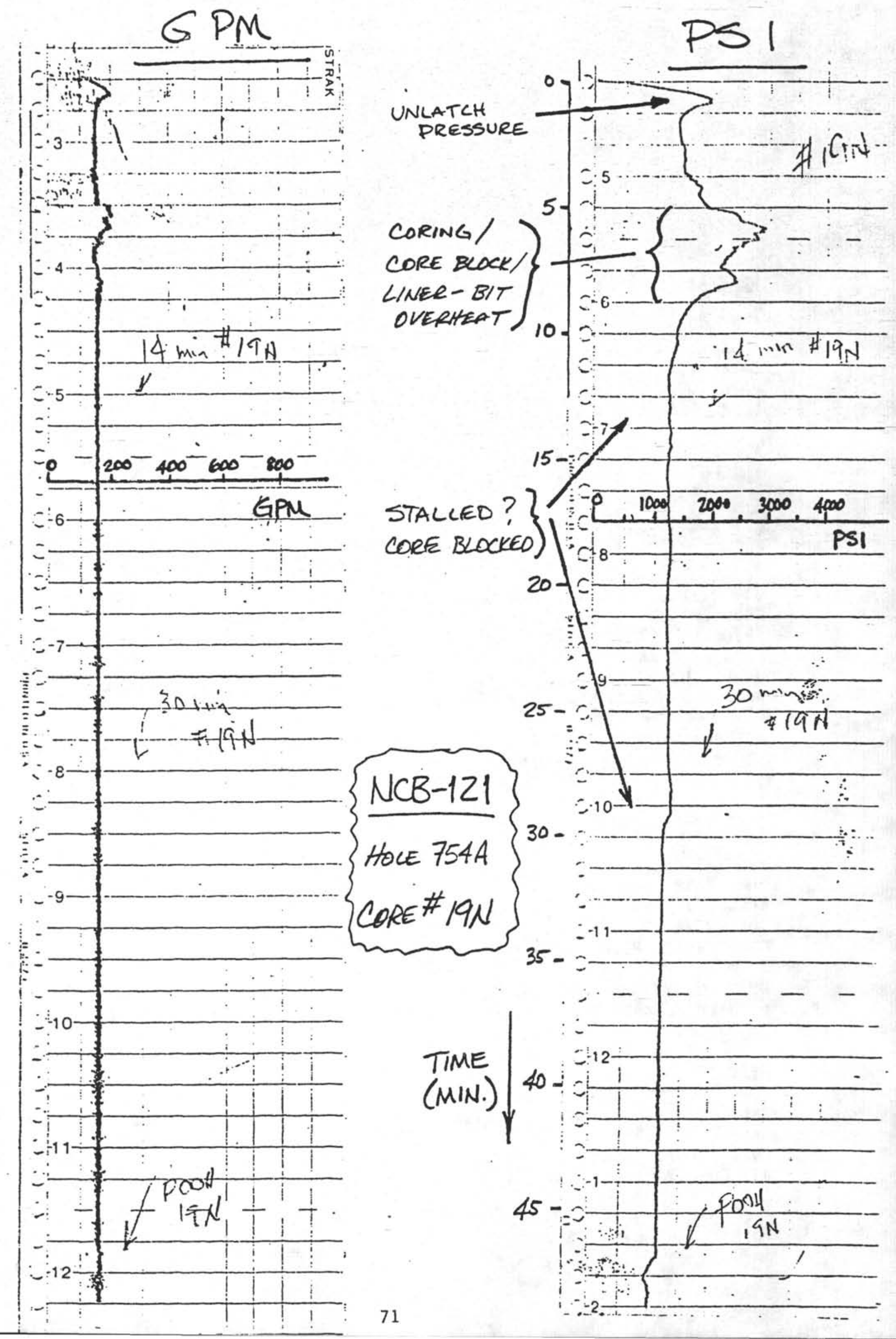




\section{NAVIDRILL CORE BARREL \\ NCB2-121}

DATA SUMYARY SHEEI.

\section{GENERAL}

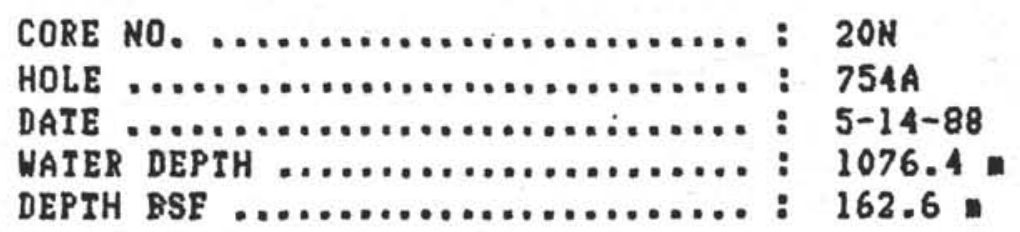

APC/XCB BIT .................. $11-7 / 16$ Security, $4 \times 16$ jets BHA NOTES .................... : LEV, Non-mag Latch Sub

\section{NCB DETAILS}

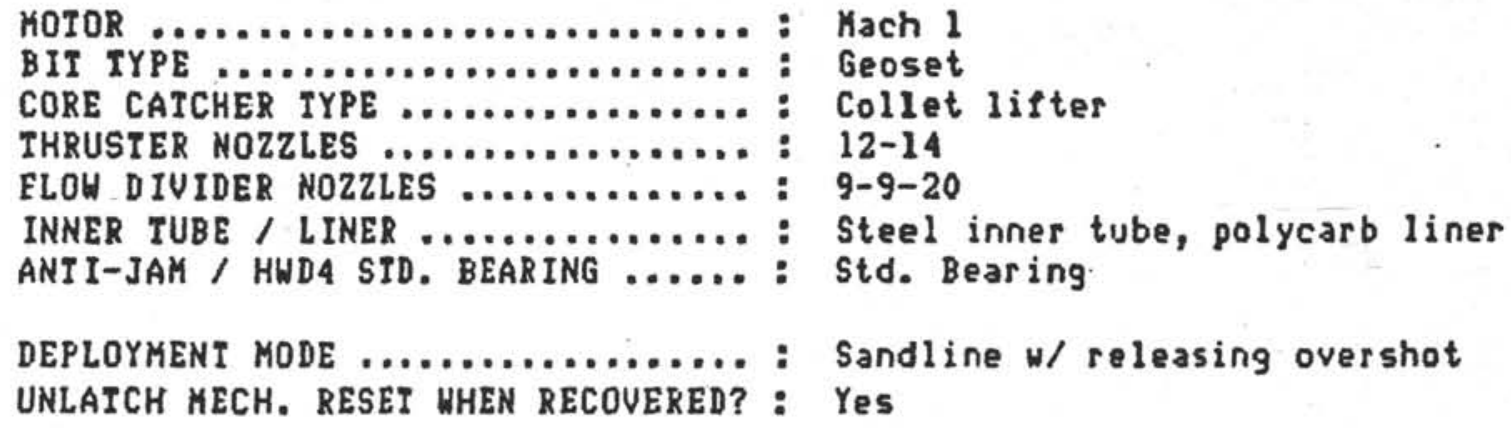

\section{OPERAIING DATA}

PUMPING (CORING?) TINE .......... PUMP RATE .................. CALCULATED WEIGHT ON NCB BIT .....: TOP DRIVE RPK ................ COMPENSATED WEIGHI ON XCB BIT .....

HOLE CONDITIONS ASSUMED FORKAIION

RESULTS

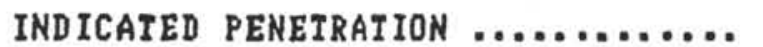
AHOUNT OE CORE ................ CORE DESCRIPIION $\ldots \ldots \ldots \ldots \ldots \ldots \ldots$ BIT CONDITION
30 in 40 sec (End-of-stroke spike) $1539 p=$

$10-25 \mathrm{rpm}$

$12 k$

Poor, lill between connections Chalk, clay, possible chert 


\section{NOTES $=754 \mathrm{~A}-20 \mathrm{~N}$}

This was an ideal run with lots of indication of coring from pressure responses. Full stroke pressure spike was unmistakable. External warks on core barrel also confiraed full stroke. Lack of full core inside barrel was probably due to collet core catcher failure in "solt" rock. The torque segments showed significant wear and distortion but were rerunable. Drilled off 4.5 . pilot hole in 35 minutes with difficulty. 


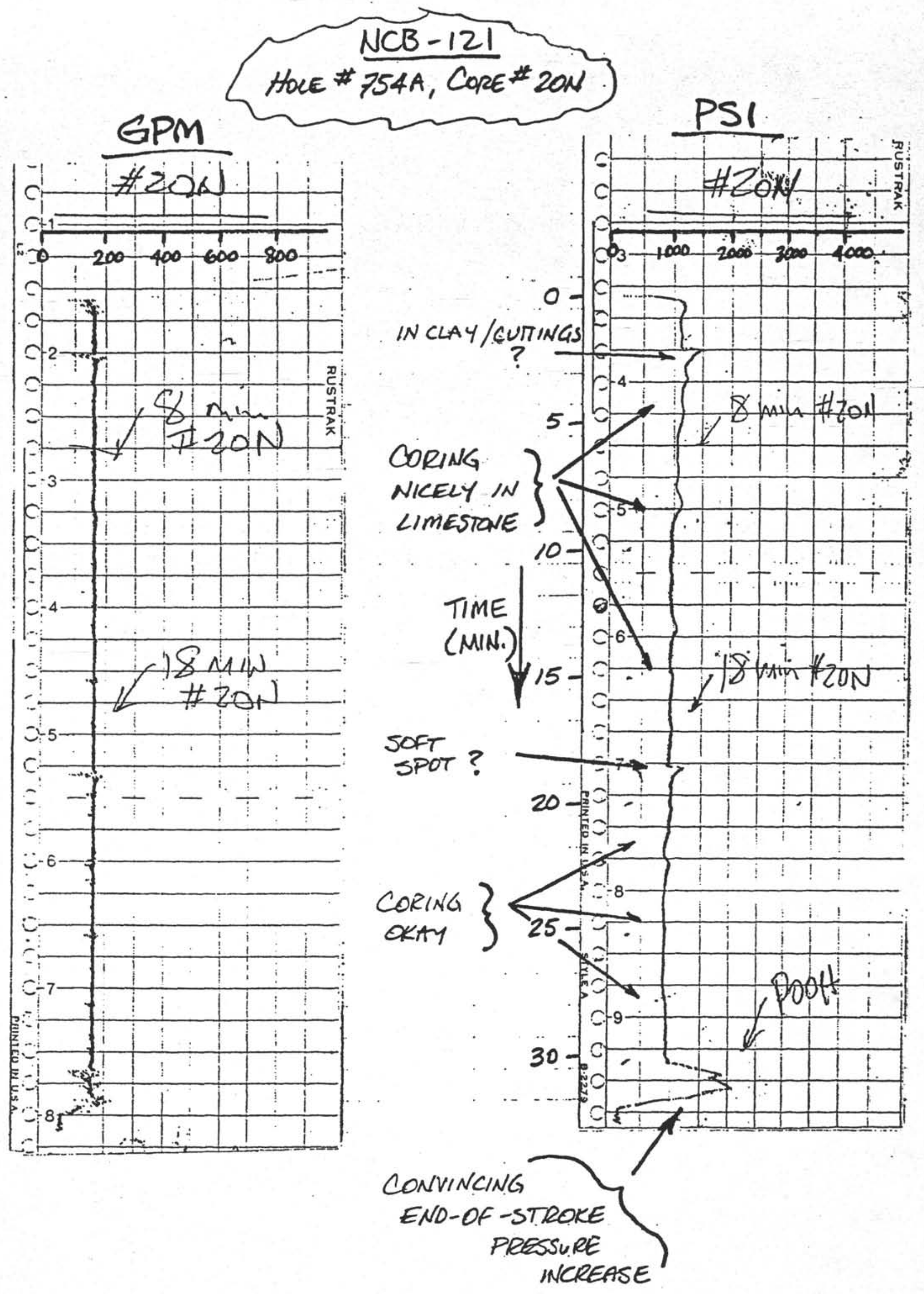

74 
NAUIDRILL CORE BARREL

NCB2-121

\section{DATA SUKHARY SHEET}

\section{GENERAL}

CORE NO.

$21 \mathrm{~N}$

HOLE $\ldots \ldots \ldots \ldots \ldots \ldots \ldots \ldots \ldots \ldots \ldots \ldots \ldots$. $754 A$

DATE $\ldots \ldots \ldots \ldots \ldots \ldots \ldots \ldots \ldots \ldots \ldots \ldots$ : $5-14-88$

WATER DEPTH .................. 1076.4 .

DEPIH BSE .................... : 167.1

APC $/ X C B$ BIT .................... $11-7 / 16$ Security, $4 \times 16$ jets

BHA NOTES

LFV, Non-wag Latch Sub

\section{NCB DETAILS}

MOTOR $\ldots \ldots \ldots \ldots \ldots \ldots \ldots \ldots \ldots \ldots \ldots \ldots$

BIT IYPE .......................

CORE CATCHER IYPE ..............

THRUSTER NOZZLES ................

FLOW DIUIDER NOZZLES ............

INNER TUBE / LINER ..............

ANTI-JAK / HWD 4 STD. BEARING ...... :

DEPLOYKENT KODE ................. UNLATCH HECH. RESET WHEN RECOUERED? :
Hach 1

Geoset, rerun fron previous core Collet lifter

$12-14$

9-9-20

Steel inner tube, polycarb liner Std. Bearing

Ereefall, punped down in 10 in. Yes

\section{OPERAIING DAIA}

PUMP ING (CORING?) TIKE ..........

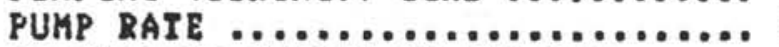
CALCULATED UEIGHT ON NCB BIT ...... TOP DRIVE RPK ................. COMPENSATED WEIGHI ON XCB BIT .....

HOLE CONDITIONS ................ ASSUMED FORKATION
16.5 minutes 152-165 gpm

$10-15$ rpm

$12 k$

Eair, winimal fill

Chalk, limestone, possible chert

\section{RESULTS}

INDICATED PENETRATION Uncertain

AMOUNT OE CORE 1.79 .

CORE DESCRIPTION BIT CONDITION

Chalk, soft limestone, 4 cm chert Good but all ISD's worn 50\% 


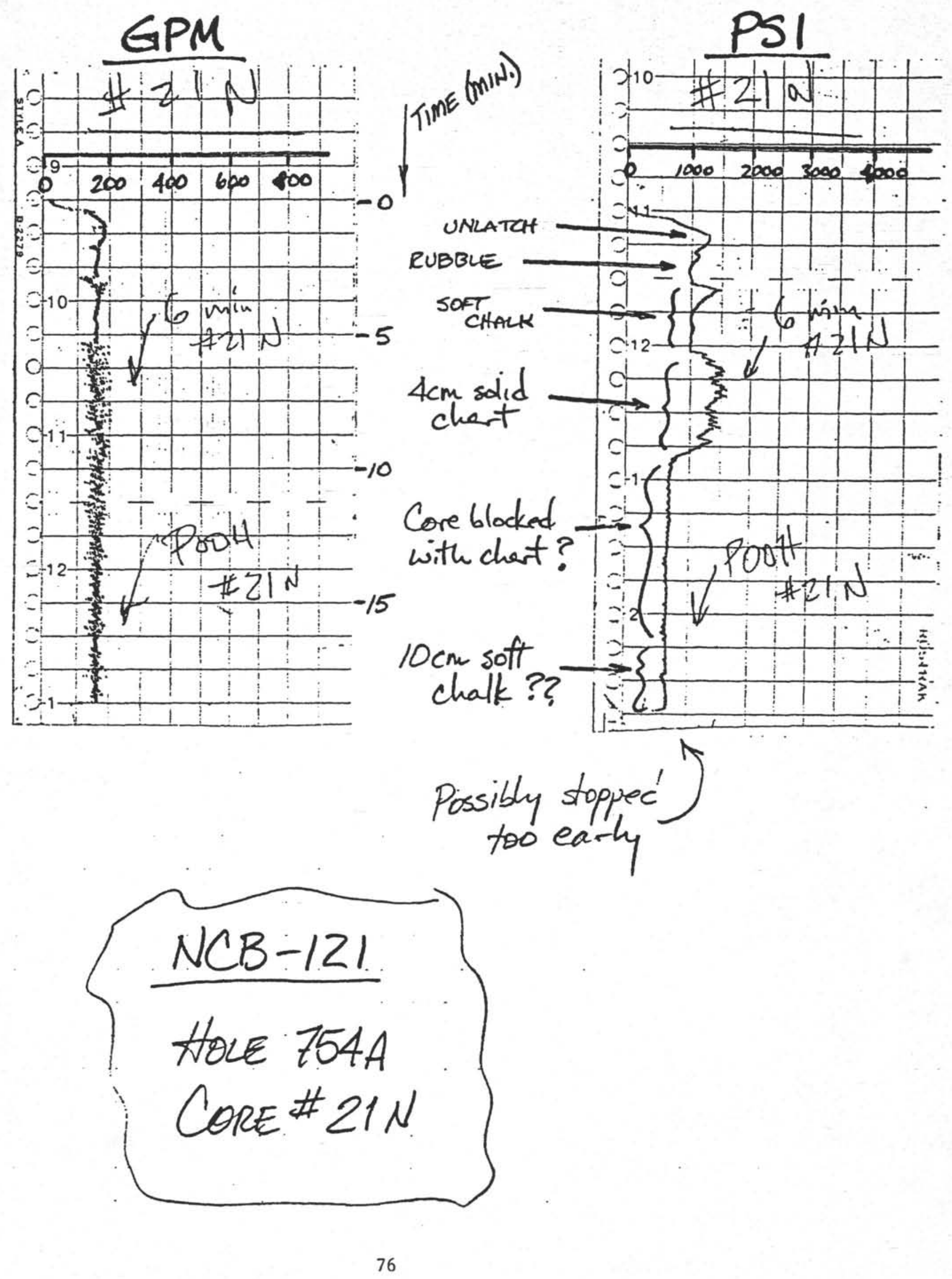




\section{NAVIDRILL CORE BARREL \\ NCE2-121}

DATA SUMHARY SHEEI

\section{GENERAL}

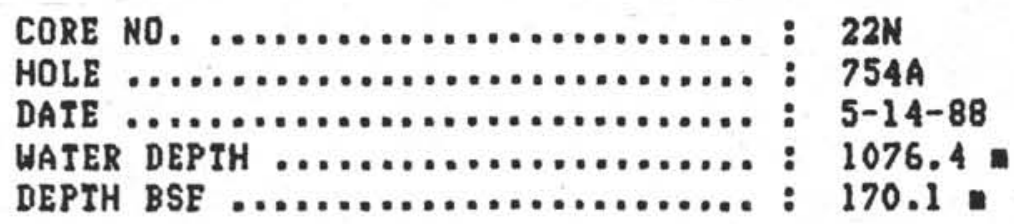

APC/XCB BIT ................... 11-7/16 Security, $4 \times 16$ jets BHA NOTES .................... : LEV, Non-mag Latch Sub

\section{NCB DETAILS}

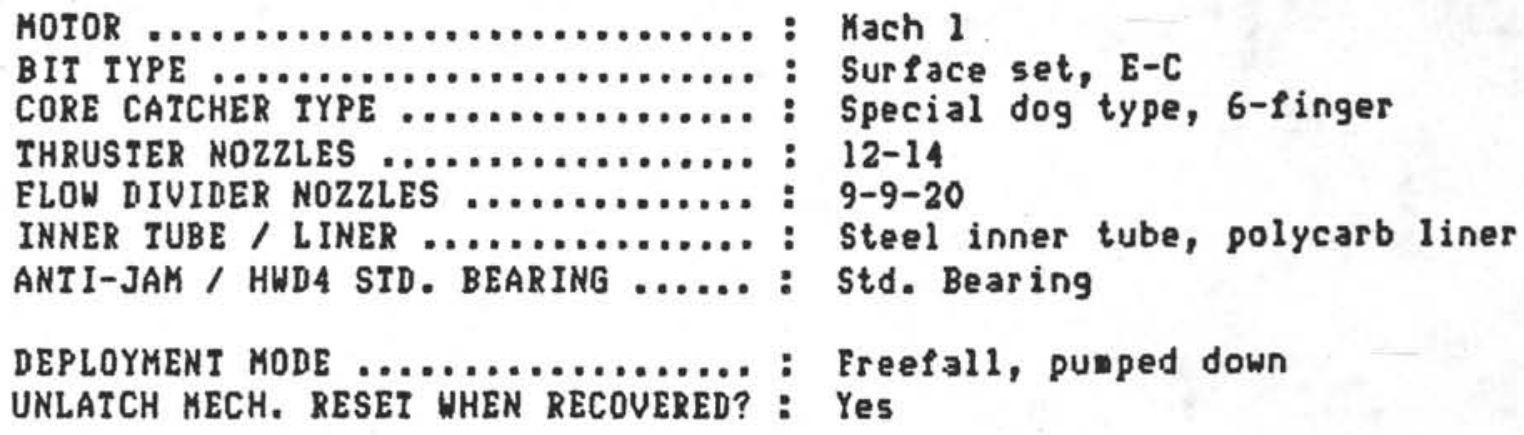

\section{OPERATING DAIA}

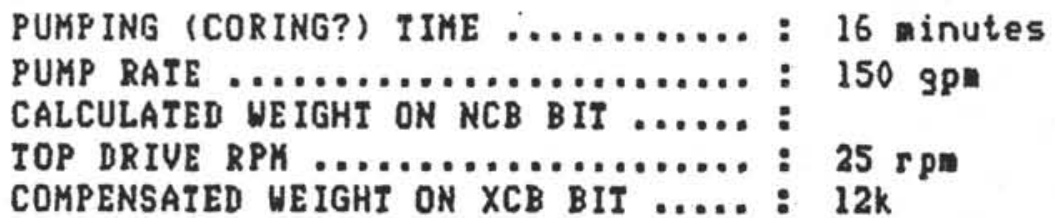

HOLE CONDITIONS $\ldots \ldots \ldots \ldots \ldots \ldots \ldots$ : Eair

ASSUMED FORMATION ............... Chert, chalk

\section{RESULIS}

INDICATED PENETRATION ............: Uncertain AMOUNT OE CORE ................. : $0.59 \mathrm{n}$ CORE DESCRIPIION ............... $7 \mathrm{~cm}$ black chert, solt white chalk BIT CONDITION .................. : Worn in rings entire face, .0.50.' deep 
NOTES $=754 \mathrm{~A}-22 \mathrm{~N}$

Possibly terminated too soon. Pressure dropped fron 1300 psi to 750 after nine winutes and did not increase.

Drilled off one weter in 6 inutes. 

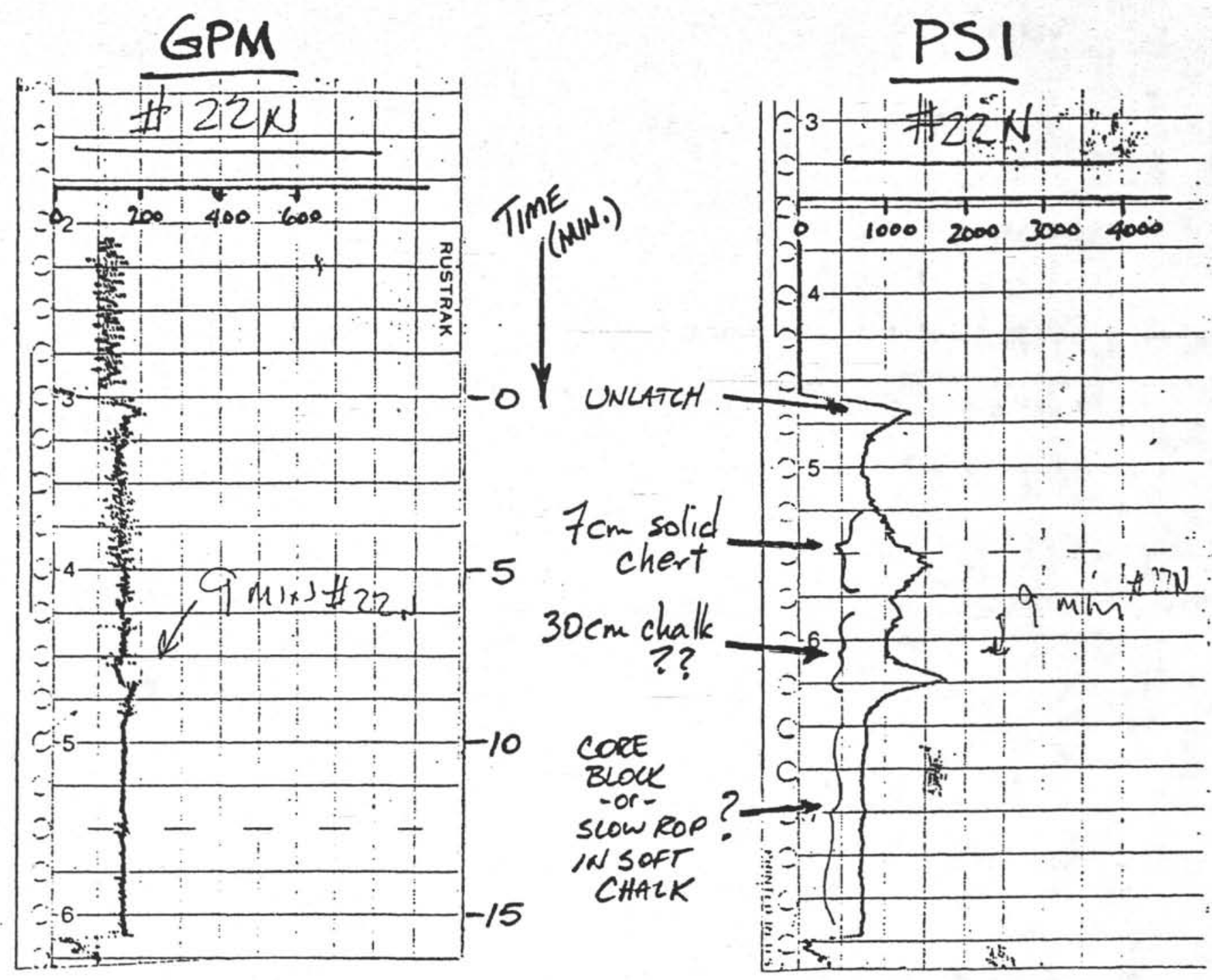

$$
\begin{aligned}
& \text { NCB-121 } \\
& \text { HOLE } 754 A \\
& \text { CORE \#22N }
\end{aligned}
$$


NAVIDRILL CORE BARREL

NCB2-121

\section{DATA SUMMARY SHEET}

\section{GENERAL}

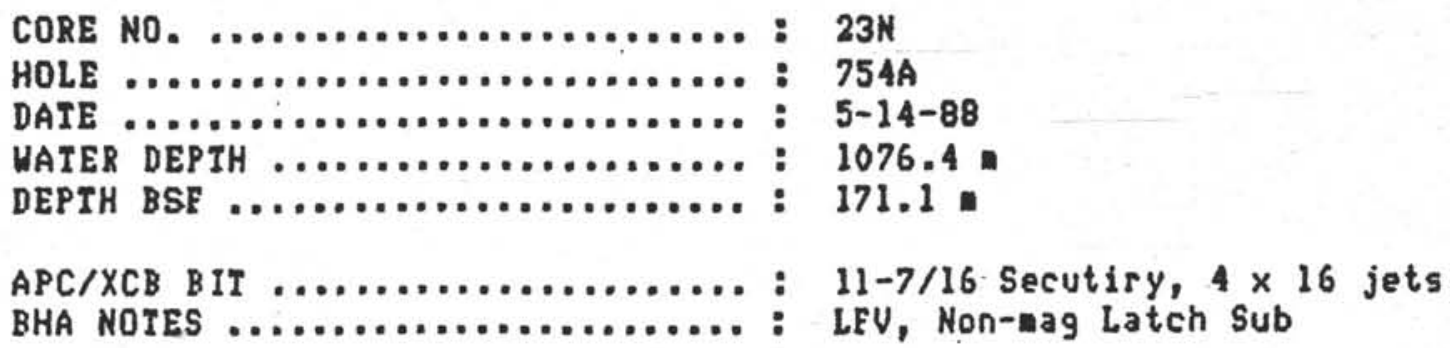

NCB DEIAILS

MOTOR ........................ : Mach 1

BIT IYPE ...................... I Inpregnated, 'Ian' matrix

CORE CATCHER IYPE ................ : 6 - finger dog type

IHRUSTER NOZZLES .............. : 12-14

FLOW DIUIDER NOZZLES ............ 9 : $9-20$

INNER IUBE / LINER .............. : Steel inner tube, polycarb liner

ANII-JAM / HWD4 STD. BEARING ......: Std. Bearing

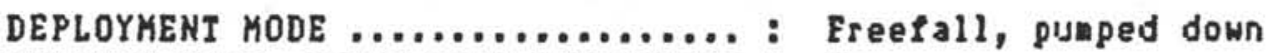

UNLATCH HECH, RESET MHEN RECOUERED? : YeS

\section{OPERATING DATA}

PUKP ING (CORING?) TIKE .......... : 23 winutes

PUKP RATE ..................... : 150-158 9P

CALCULATED WEIGHT ON NCB BIT ......:

IOP DRIVE RPH ................ $25 \mathrm{rpw}$

COKPENSATED WEIGHT ON XCB BII ....: : $12 \mathrm{k}$

HOLE CONDITIONS ................. : Okay

ASSUMED EORKATION .............. : Chert, chalk

\section{RESULIS}

INDICATED PENETRATION ...........: Uncertain

AKOUNT OE CORE ..................: 0.96 .

CORE DESCRIPIION ................: Karbled chalk/linestone w/ash layers

BIT CONDITION

Sove wear 


\begin{abstract}
NOIES $=754 A-23 N$
Unimpressive run with unclear pressure responses observed on deck. Poor recovery ma have been due to mild core block and/or inefficiency of impregnated bit in solt chalky material.

Dininishing returns and other scientific objectives spelled end of NCB experiment for this hole.
\end{abstract}




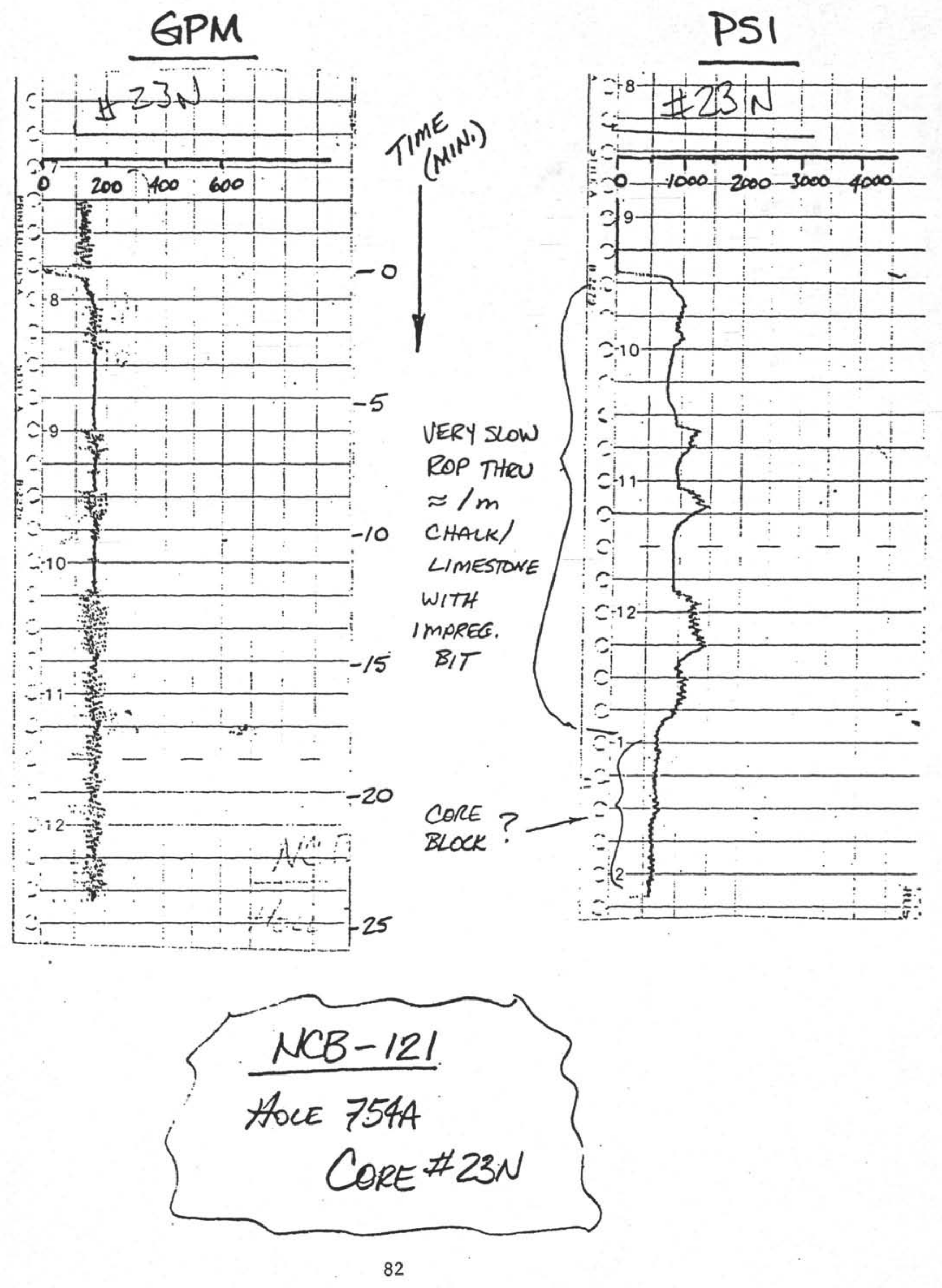




\section{NAVIDRILL CORE BARREL \\ NCB2-121}

\section{DATA SUMKARY SHEEI}

\section{GENERAL}

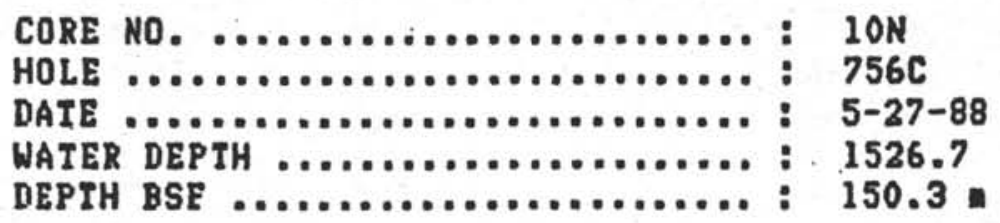

APC/XCB BII ....................; $11-7 / 16$ Security, $4 \times 16$ jets

BHA NOTES ...................... : Non-mag Latch Sub, Baker Eloat Valve

NCB DETAILS

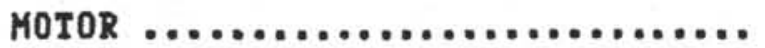

BIT IYPE $\ldots \ldots \ldots \ldots \ldots \ldots \ldots \ldots \ldots \ldots \ldots \ldots$

CORE CATCHER IYPE $\ldots \ldots \ldots \ldots \ldots \ldots \ldots \ldots$

THRUSTER NOZZLES $\ldots \ldots \ldots \ldots \ldots \ldots \ldots \ldots \ldots$

ELOW DIVIDER NOZZLES $\ldots \ldots \ldots \ldots \ldots \ldots$

INNER TUBE / LINER .............

ANTI-JAH / HHD4 STD. BEARING ......

Nach 1

Surpace set (used)

Collet lifter spring

$10-10$

9-9-20

DEPLOYMENT KODE ................: Ereefall, pUIPed down

UNLATCH MECH. RESET WHEN RECOUERED? : Yes

\section{QPERATING DATA}

PUMPING (CORING?) TIKE ............

PUMP RATE ........................

CALCULATED WEIGHT ON NCB BIT .....:

TOP DRIVE RPM ................ : 10-15 rpm

COMPENSATED WEIGHI ON XCB BIT ....: $12 k$

67 inutes

150 gpn

HOLE CONDITIONS $\ldots \ldots \ldots \ldots \ldots \ldots \ldots \ldots$.......... No problens

ASSUKED FORMATION ................ Hard limestone or altered basalt

\section{RESULTS}

INDICATED PENETRATION ........... 4.2 :

AMOUNT OF CORE .................. 4.21 .

CORE DESCRIPTION ................. Solid vesicular basalt, well trimmed

BII CONDIIION .................. No detectable wear 


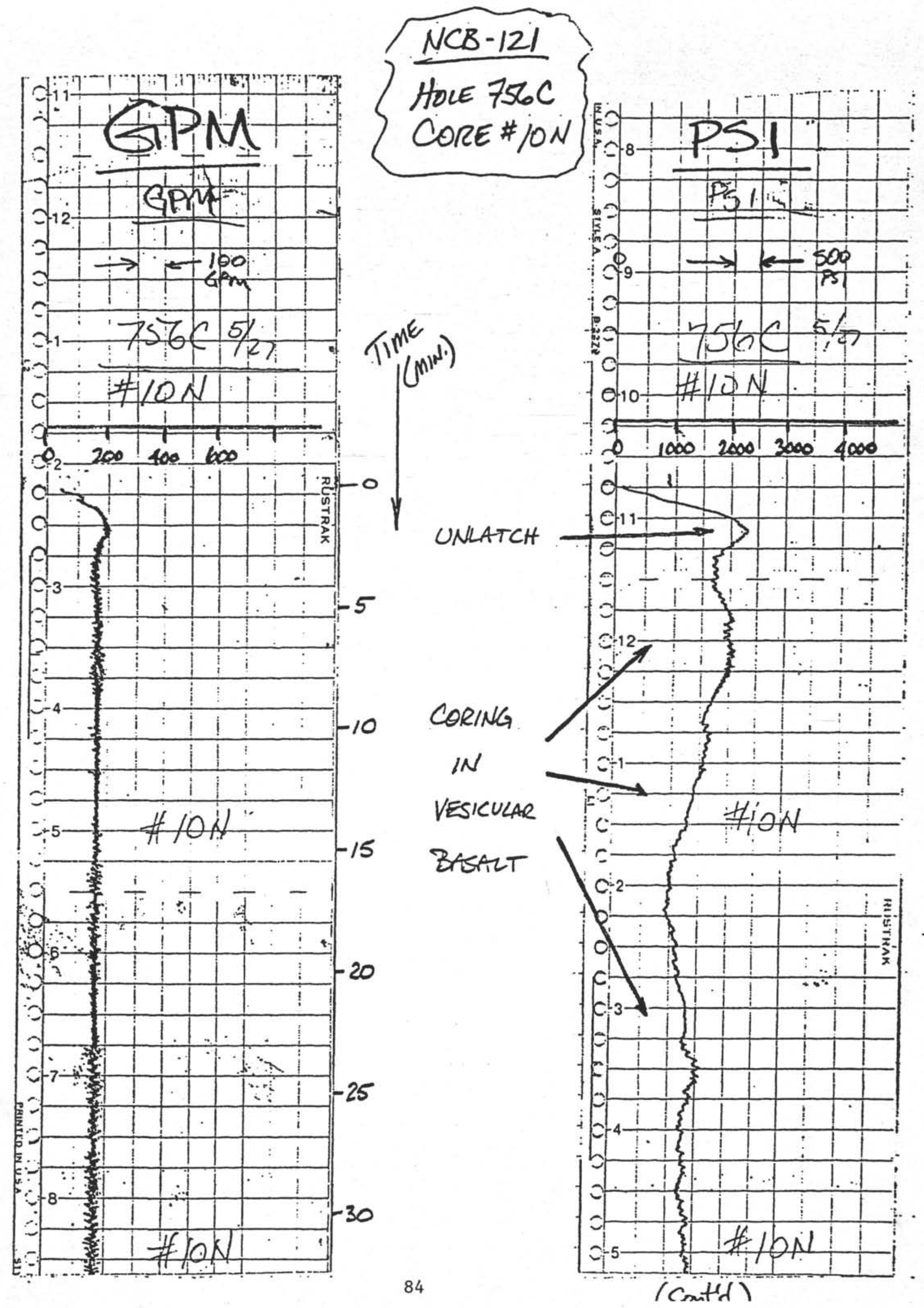




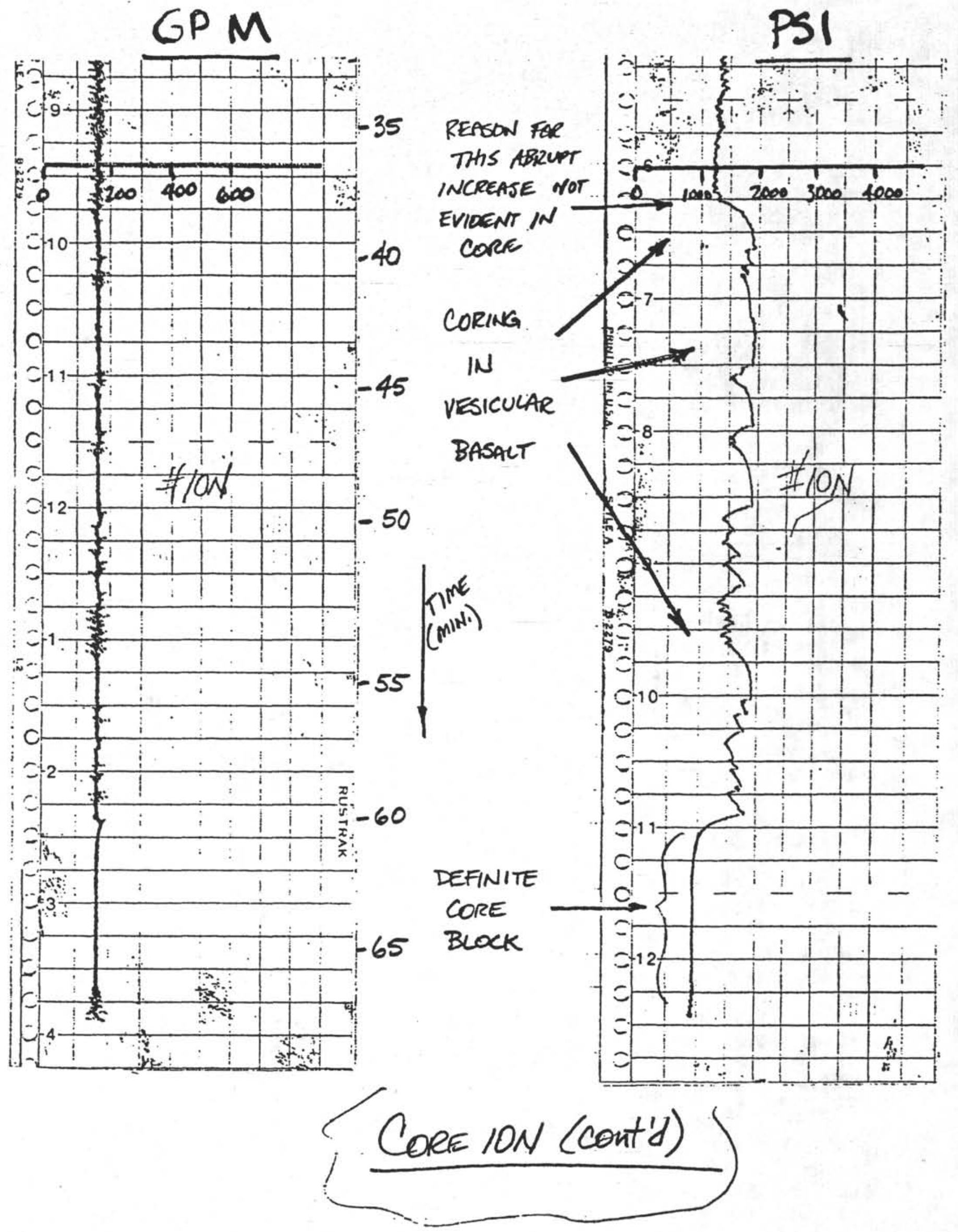

85 


\section{NAUIDRILL CORE BARREL \\ NCB2-121}

DATA SUKMARY SHEEI

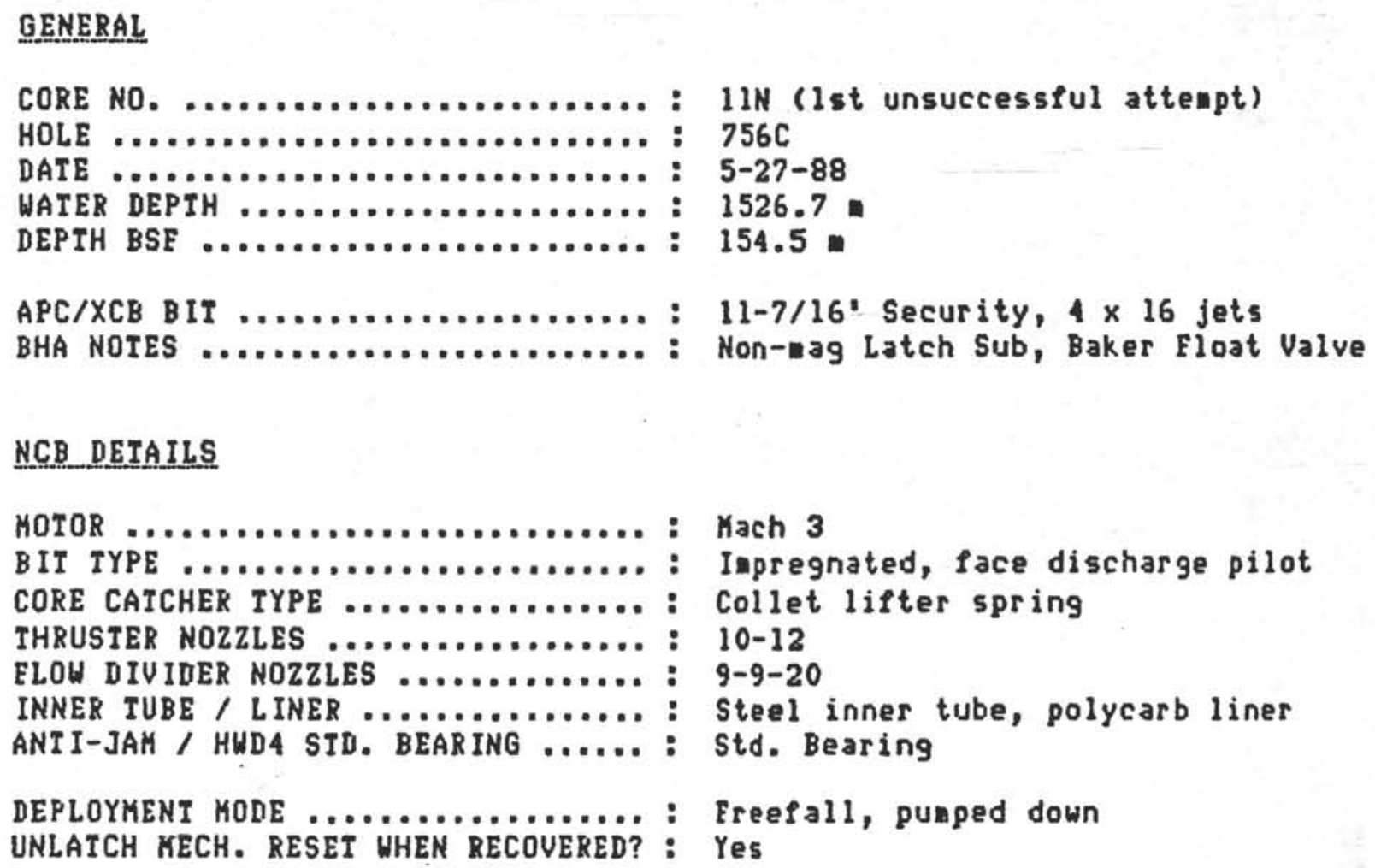

\section{RESULIS}

INDICATED PENETRATION ............: None AKOUNT OE CORE ................: None CORE DESCRIPTION ............... : -

BIT CONDITION ................ : No wear, but bit did contact formation 
NOTES $=756 C-11 \mathrm{~N}$ (15t attempt)

A bad run but not clear what went wrong. High pressure at first $(1800$ psi) dropped to 1380 then around 800 after 9 minutes. No real-indication of unlatch, coring or core block. Lack of any penetration or core suggests stall out inmediately but why -such low pressure indications after a few winutes?? The hole caved at roughly the sane time as the pressure loss and the pipe had to be picked up $1.5-2$. to keep from getting stuck. High (50) RPK momentarily during this episode to keep pipe free.

The torque segments were badly distorted (laterally) and worn on the driving edges. They were stuck in the collapsed condition when the tool was retrieved and had to be redressed with a file to function freely in their slots. 


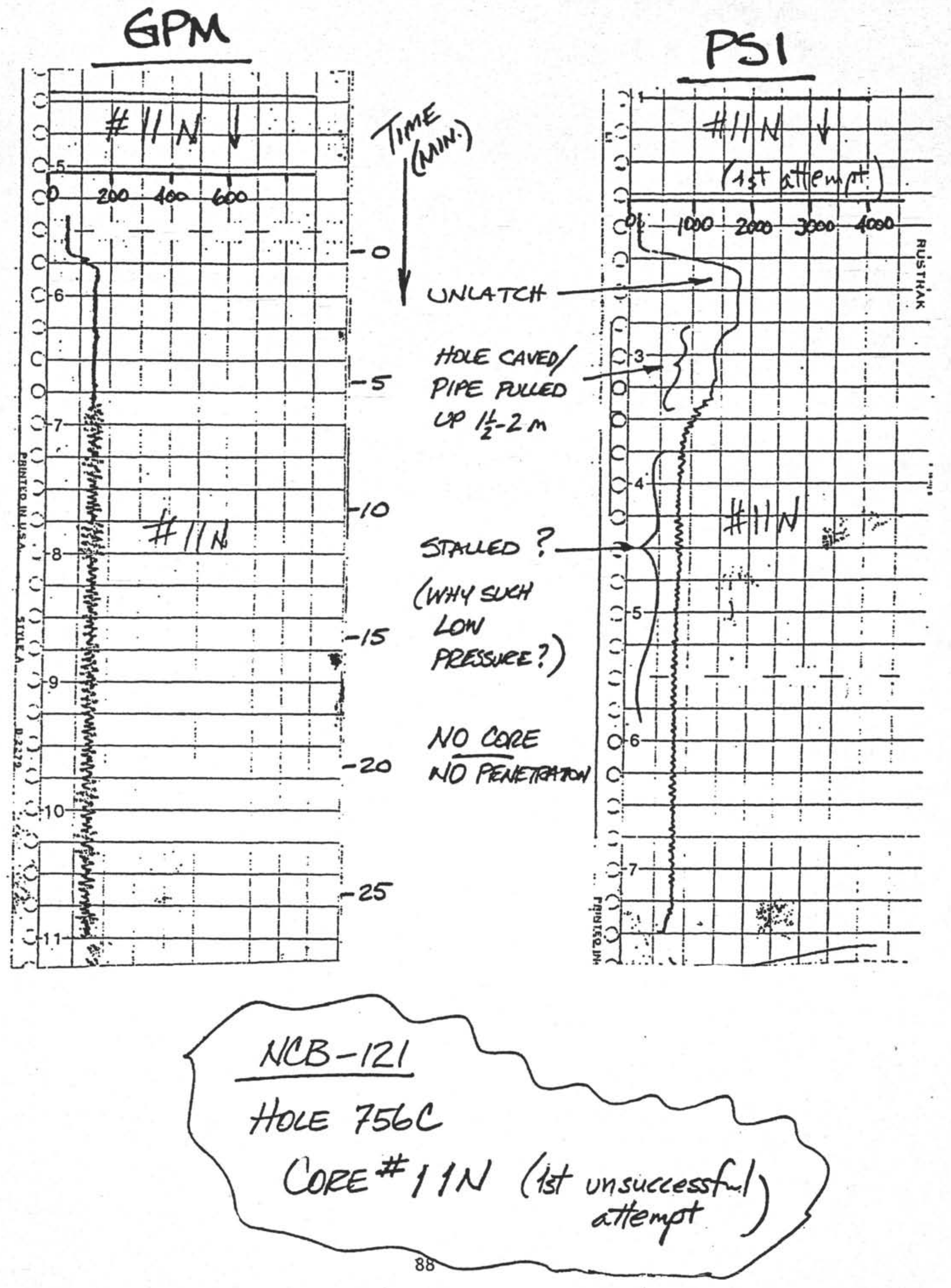




\section{NAVIDRILL CORE BARREL \\ NCB2-121}

\section{DATA SUKMARY SHEET}

\section{GENERAL}

CORE NO. ..................... $11 N$ (2nd unsuccessful attenpt)

HOLE ........................ $756 C$

DATE ........................ 5-27-88

WATER DEPIH ................. : 1526.7 .

DEPTH BSE .................. : 154.5 .

APC/XCB BIT ....................: 11-7/16' Security, $4 \times 16$ jets

BHA NOTES ................... : Non-mag Latch Sub, Baker Eloat Valve

\section{NCB DETAILS}

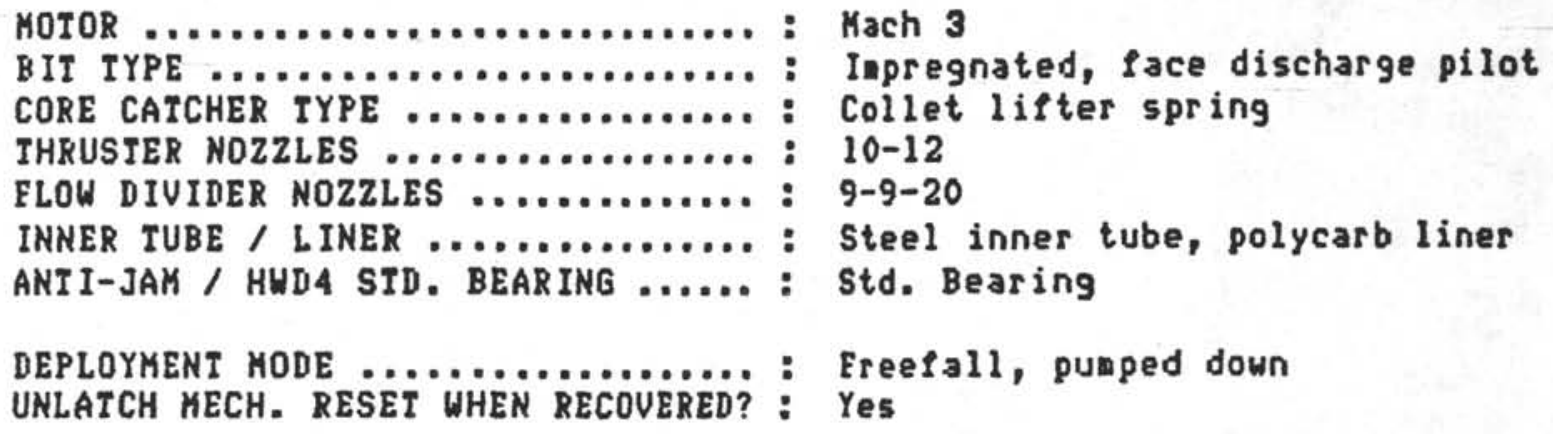

\section{RESULIS}

INDICATED PENETRATION ...........: None

AMOUNT OE CORE ................... N None

CORE DESCRIPTION ................ : -

BIT CONDIIION .................. No wear, but bit did contact formation 
NOTES 756C - 11N (2nd atteapt)

The pressure was too high (1500-1600 psi) for the entire time and very steady after 4 inutes indicating stallout eron the start. The torque segments were again badly distorted and stuck in the collapsed postion when recovered. New torque segnents were installed. 


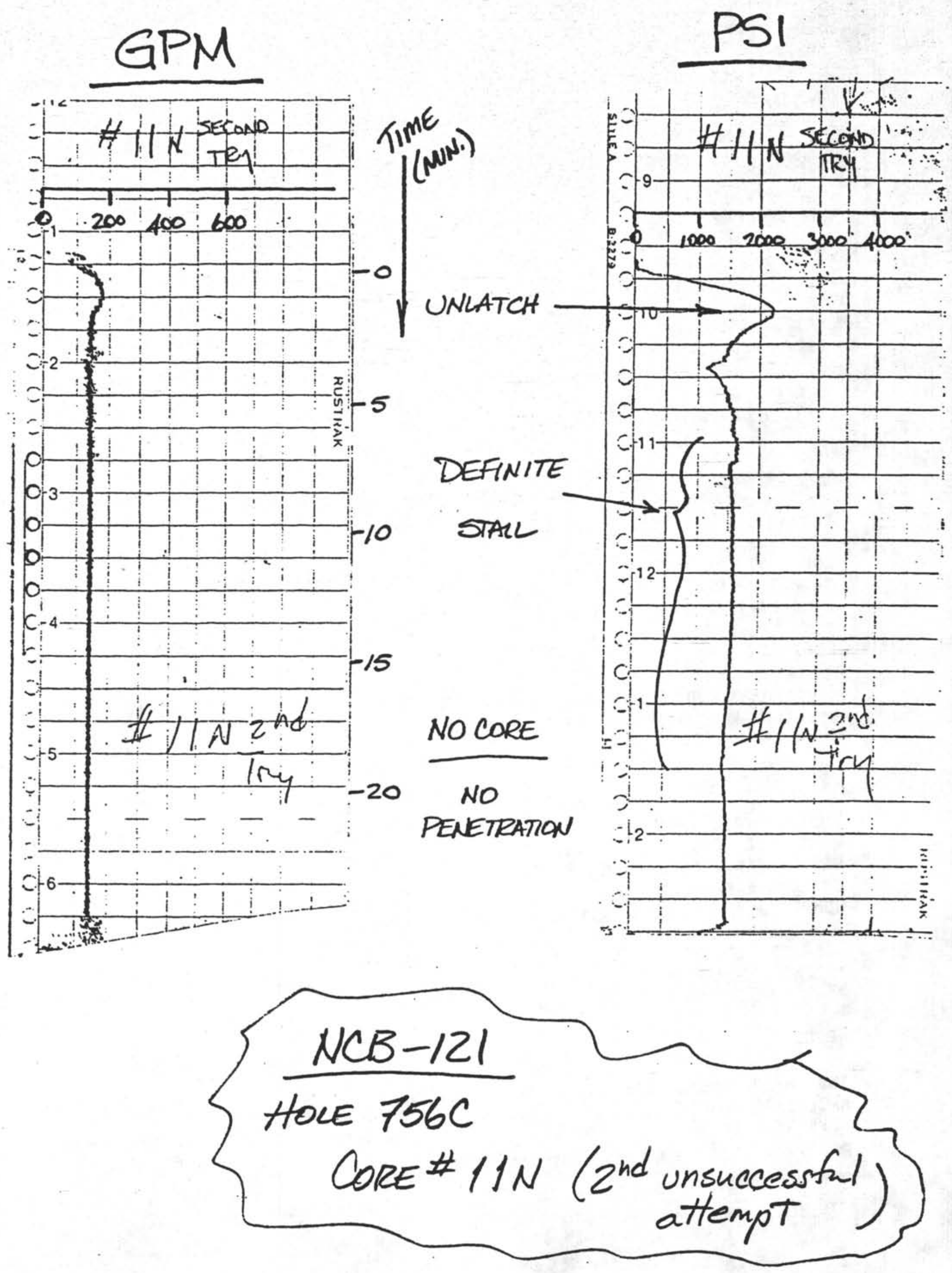

91 


\section{NAVIDRILL CORE BARREL \\ NCB2-121}

\section{DATA SUMMARY SHEET.}

\section{GENERAL}

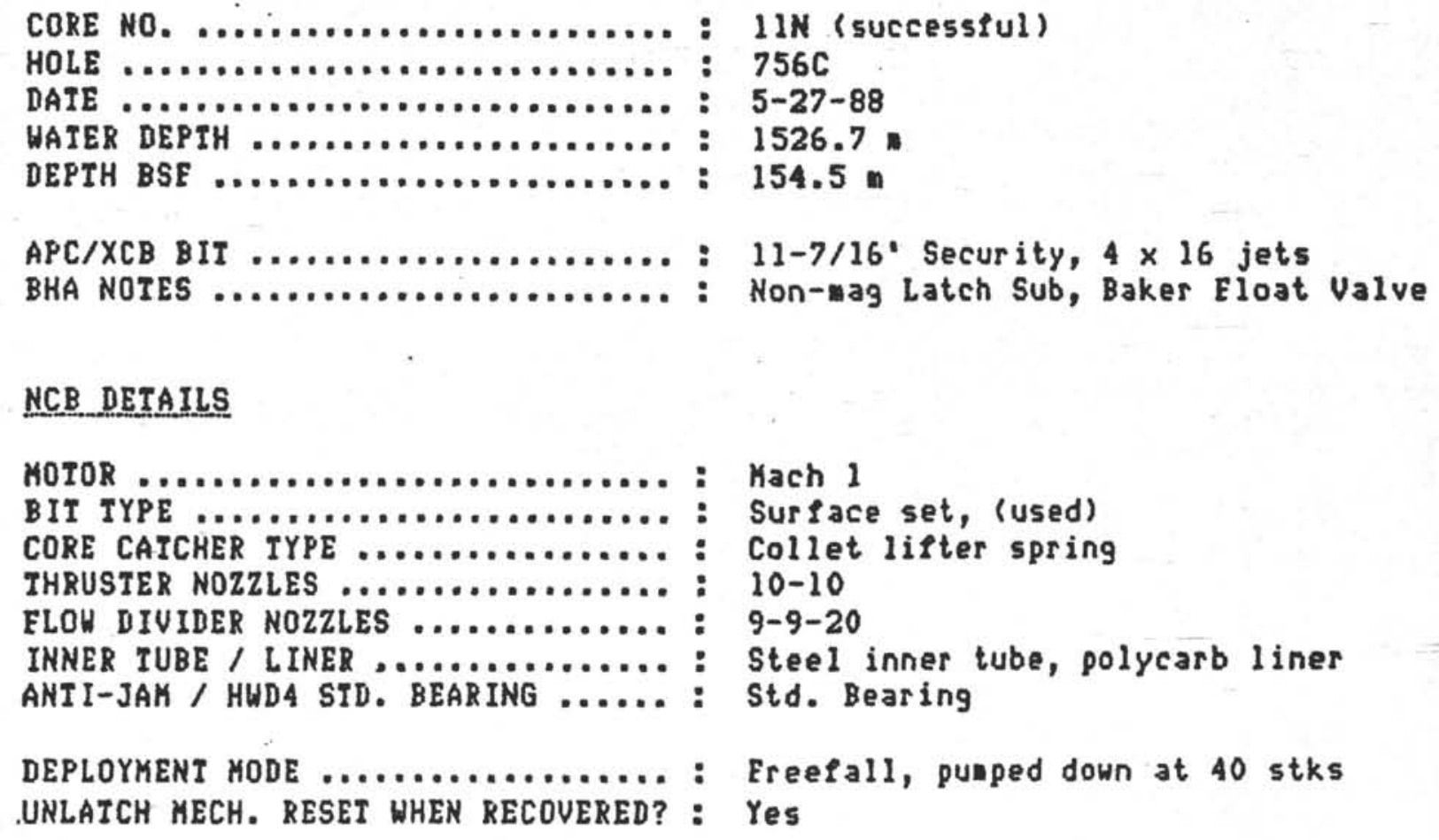

\section{RESULTS}

INDICATED PENETRATION $\ldots \ldots \ldots \ldots \ldots: 2.0$

AMOUNI OE CORE $\ldots \ldots \ldots \ldots \ldots \ldots \ldots \ldots$ : 1.13.

CORE DESCRIPTION ................: : Basalt chunks, baked soil, red clay

BIT CONDITION .................. : Gummęd up a little but no wear 


\section{NOTES $=756 C-11 N$ (successful)}

Change back to Mach 1 with higher torque apparently worked. According to pressure responses the core was cut in the first 8 to 14 winutes and then stall pressure was noted which persisted until the run was ended. Encountering bakad soil and then soft red clay was enough to stall the Hach 1. The core barrel was 1 anded harder than intended (at 40 strokes rather than 15 ) but suffered no apparent danage. After the diagnosis of stall the pipe was raised and lowered several times to see if the motor could be restarted but to no avail.

Torque segments were again distorted and stuck in their slots. They were ground plat on the sides and reinstalled.

Drilled off 2 meters between cores in five ainutes. 


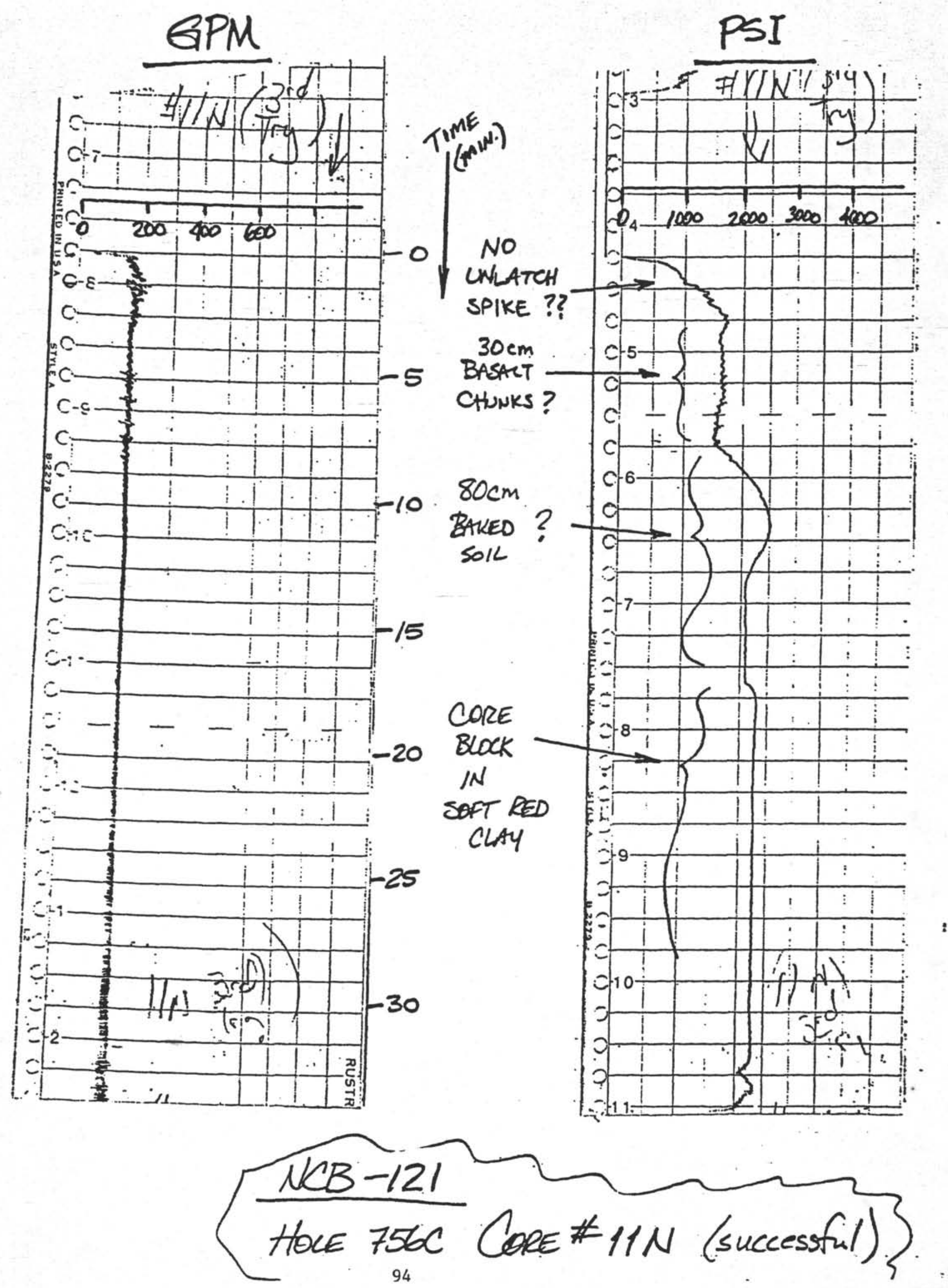




\section{NAVIDRILL CORE BARREL NCB2-121 \\ DATA SUMKARY SHEET}

\section{GENERAL}

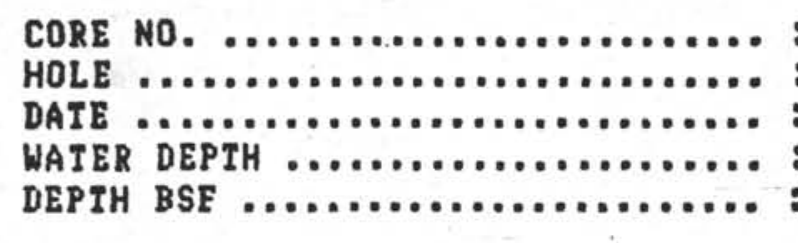

APC/XCB BIT ...................: 11-7/16' Security, $4 \times 16$ jets BHA NOTES ..................... : Non-mag Latch Sub, Baker Eloat Valve

\section{NCB DEIAILS}

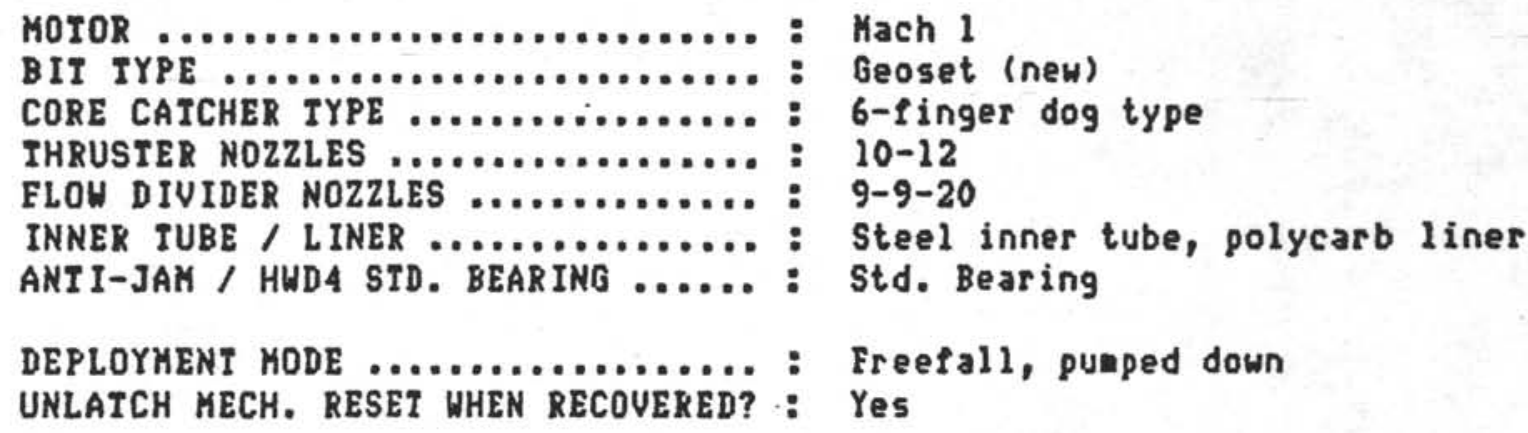

\section{RESULTS}

INDICATED PENETRATION ............: Unclear

AMOUNT OE CORE .................. : 0.40 .

CORE DESCRIPIION ................ : Basalt pea gravel and chunks

BIT CONDITION ISD's worn 50\%, box conn. bulged $1 / 8^{\circ}$ 
NOTES $=756 C-12 \mathrm{~N}$

Mysterious pressure responses led to long wait before terminating run. Just enough pressure changes to suggest the tool was coring. Later examination revealed that the knuckle-type universal joint in the Mach 1 wotor had self destructed, probably on this run. Both knuckle assemblies had been turned into shrapnel.

The torque segments were badly distorted, cracked and stuck in their slots again. 


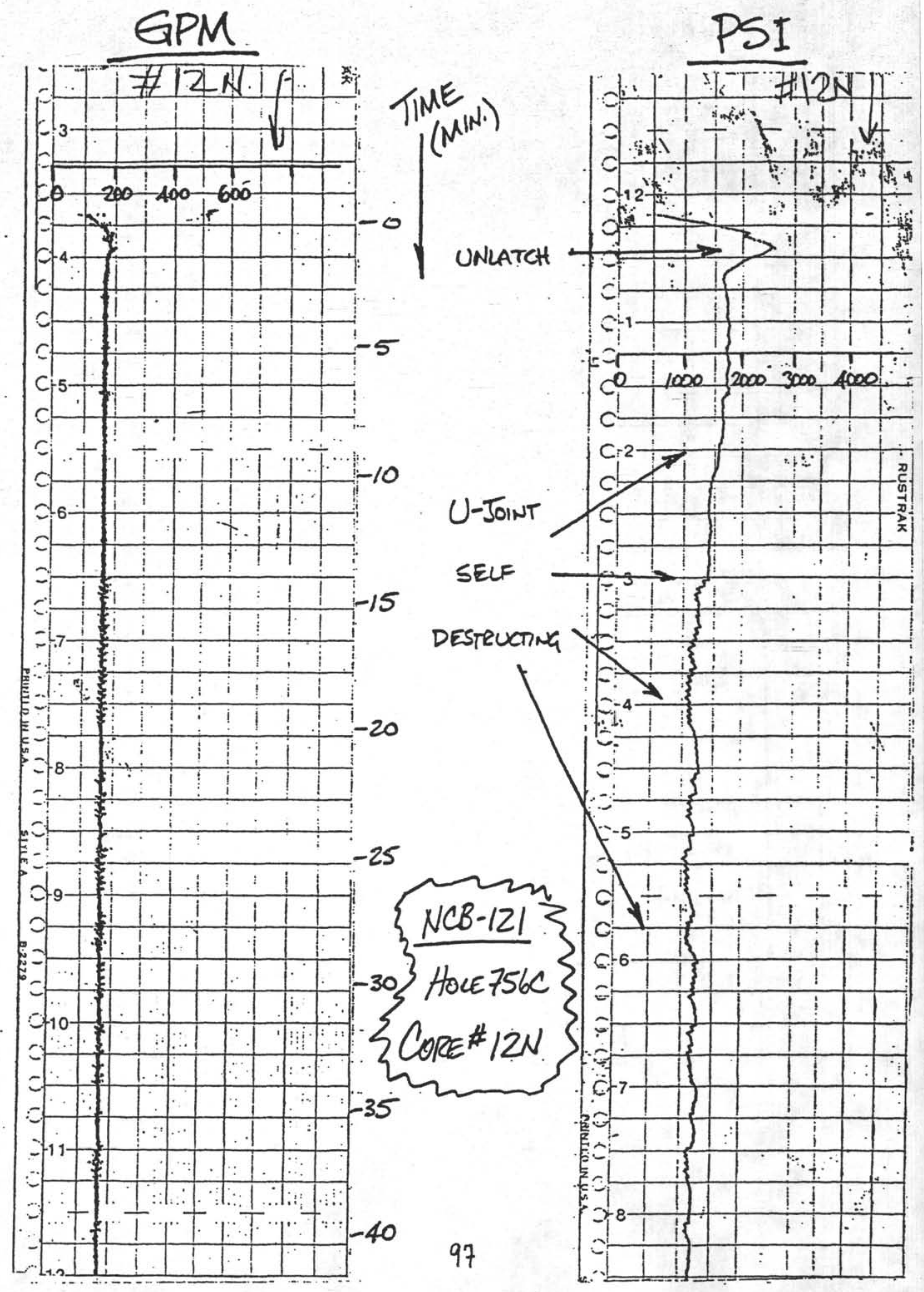




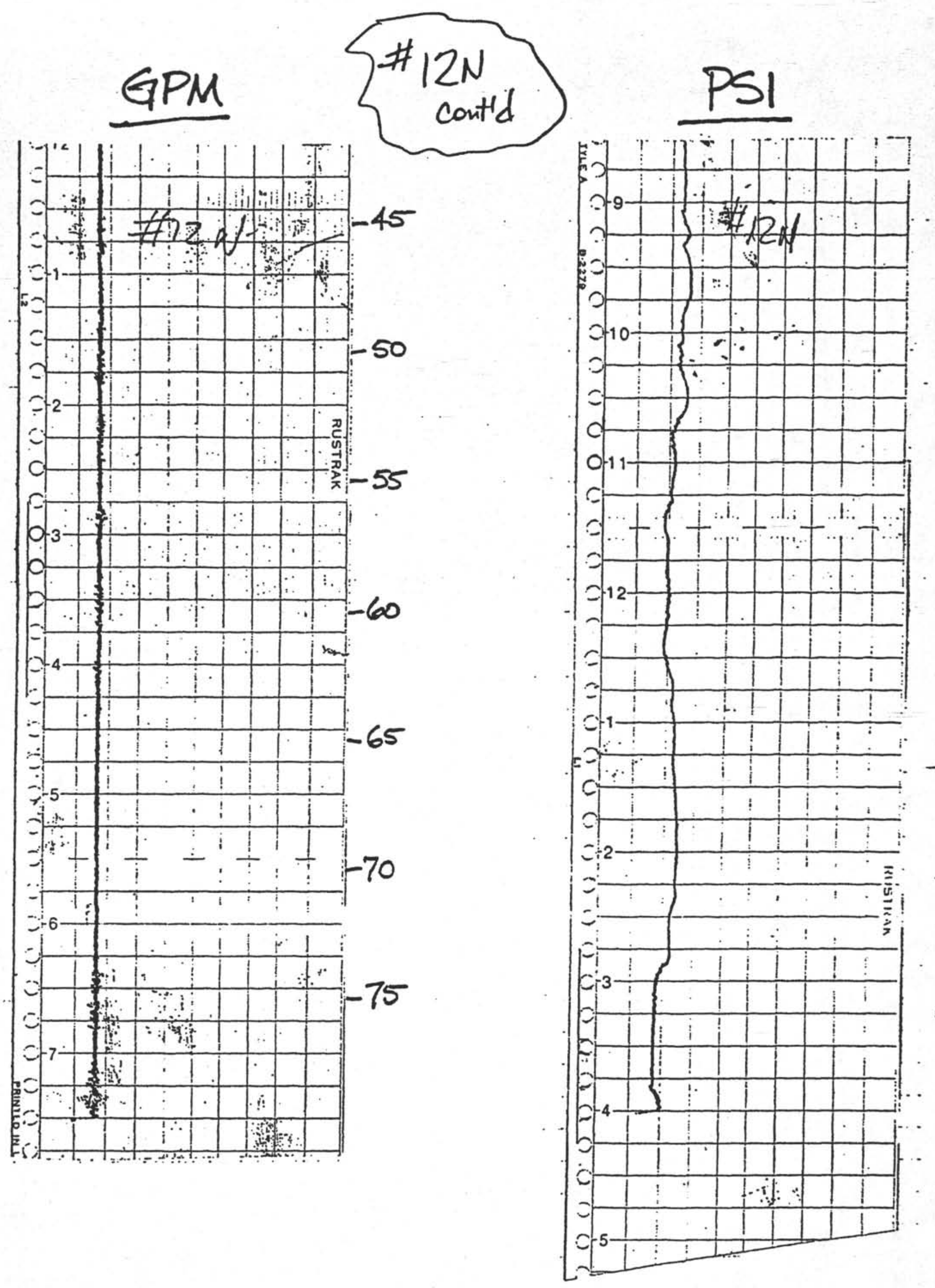

9.8 


\section{NAVIDRILL CORE BARREL \\ MCB2-121}

\section{DATA SUMMARY SHEEI}

\section{GENERAL}

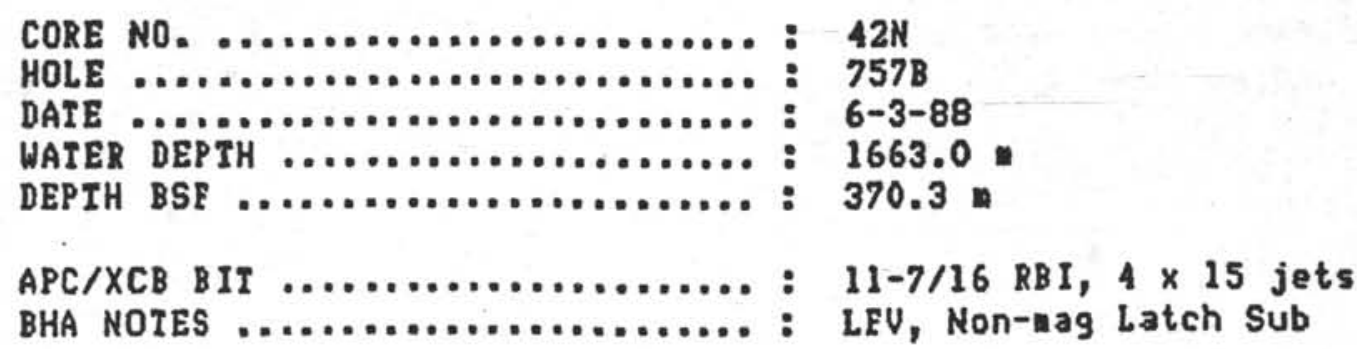

\section{NCB DETAILS}

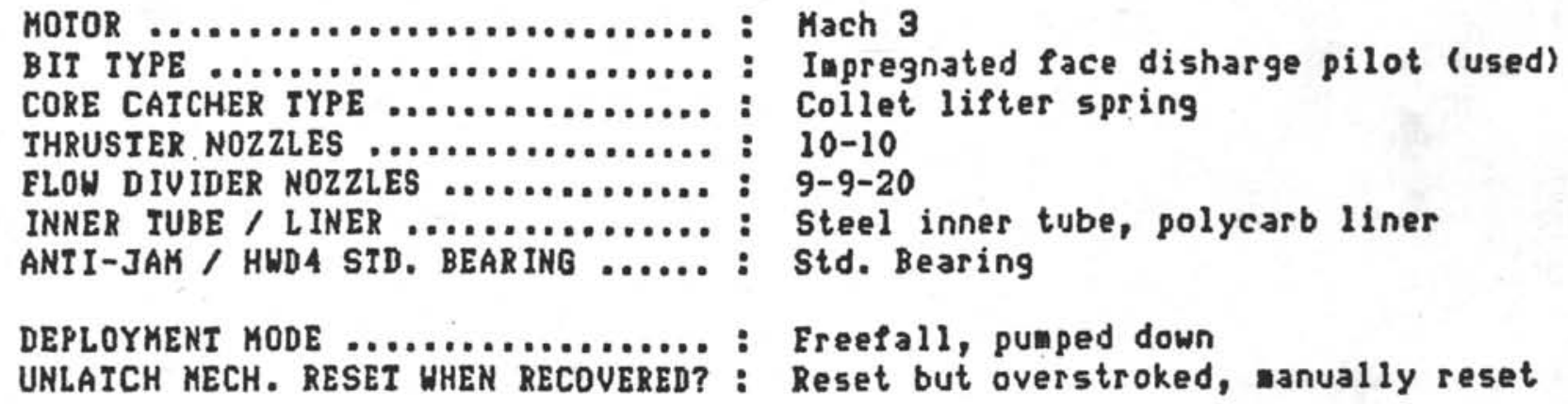

\section{OPERATING DAIA}

PUKPING (CORING?) TIME ........... 55 minutes

PUKP RATE ...................... : 135 g.pm

CALCULATED WEIGHT ON NCB BIT $\ldots \ldots$ :

TOP DRIVE RPH ................ : 10-15 rpm

COMPENSAIED WEIGHT ON XCB BIT ....: $12 \mathrm{k}$

HOLE CONDITIONS $\ldots \ldots \ldots \ldots \ldots \ldots \ldots \ldots$ : Good

ASSUMED EORKATION ............... : Solid basalt

\section{RESULISS}

INDICATED PENETRAIION ............: $4.0 \mathrm{~m}$ (very clear)

AMOUNT OE CORE .................. : 0.65 .

CORE DESCRIPTION ................. : Hell trimmed basalt, 4 pieces

BIT CONDITION ................... : No wear, ports all clogged with chips 
NOTES $=757 \mathrm{~B}-42 \mathrm{~N}$

A good run with pressure indications suggesting coring for the first 35 minutes and then too steady for 20 minutes but not clearly stalled or core blocked. Very clear indications of 4 penetration on core barrel paint job but nost of the core was apparently lost when the tool was pulled. Drilling off the pilot hole was hard and rough suggesting broken pieces of lost core were in the hole. Drilling of 1 took 86 minutes with 20-25k WOB.

The release mechanisa overstroked while the tool was being recovered and had to be nudged back to its latch position. The hex shaft slid smoothly and relatch was accomplished by tapping with a hammer to get the balls to jump into the latched position.

The torque segwents were again distorted requiring grinding to make the operate in their slots. 


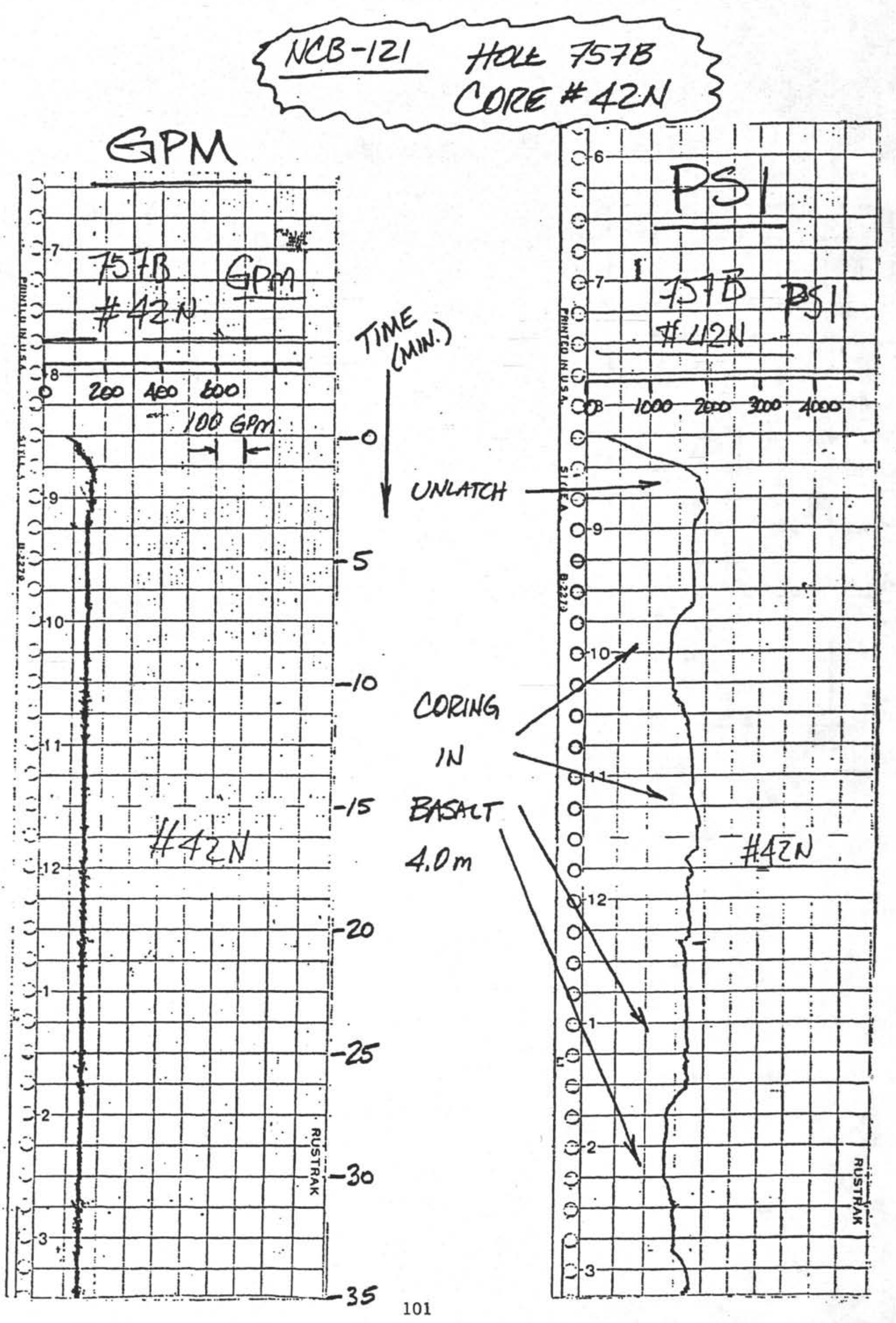




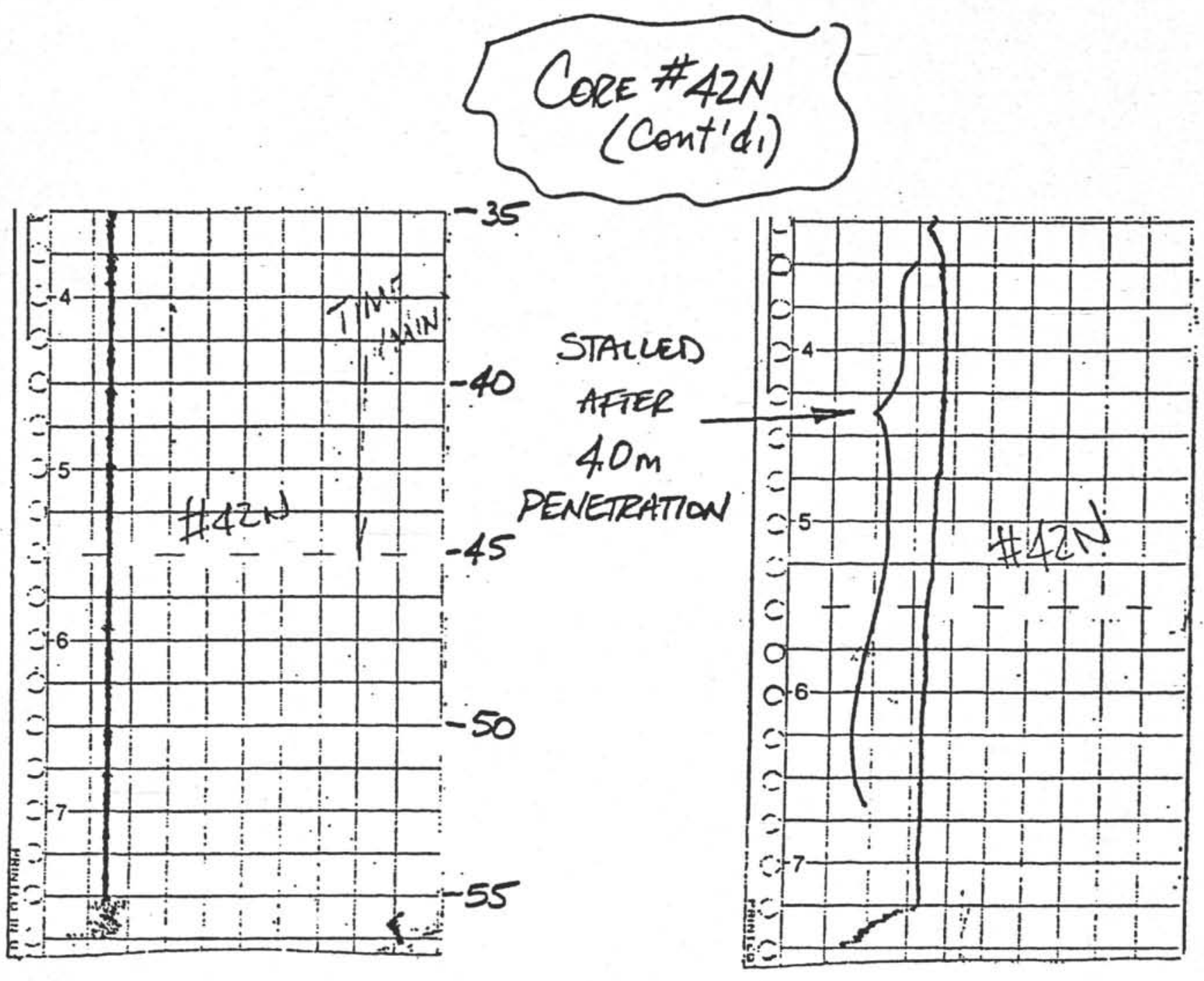


NAVIDR ILL CORE BARREL

NCB2-121

DAIA SUHKARY SHEEI

\section{GENERAL}

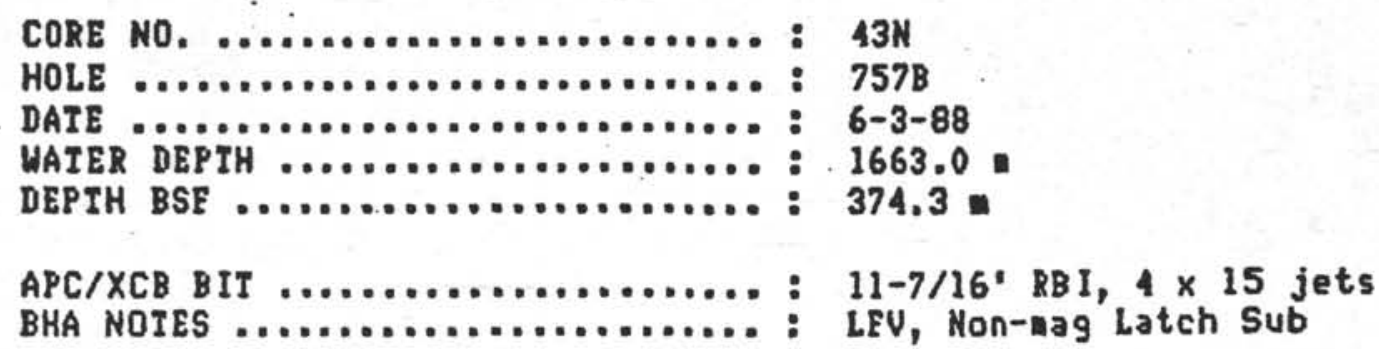

\section{NCB DEIAILS}

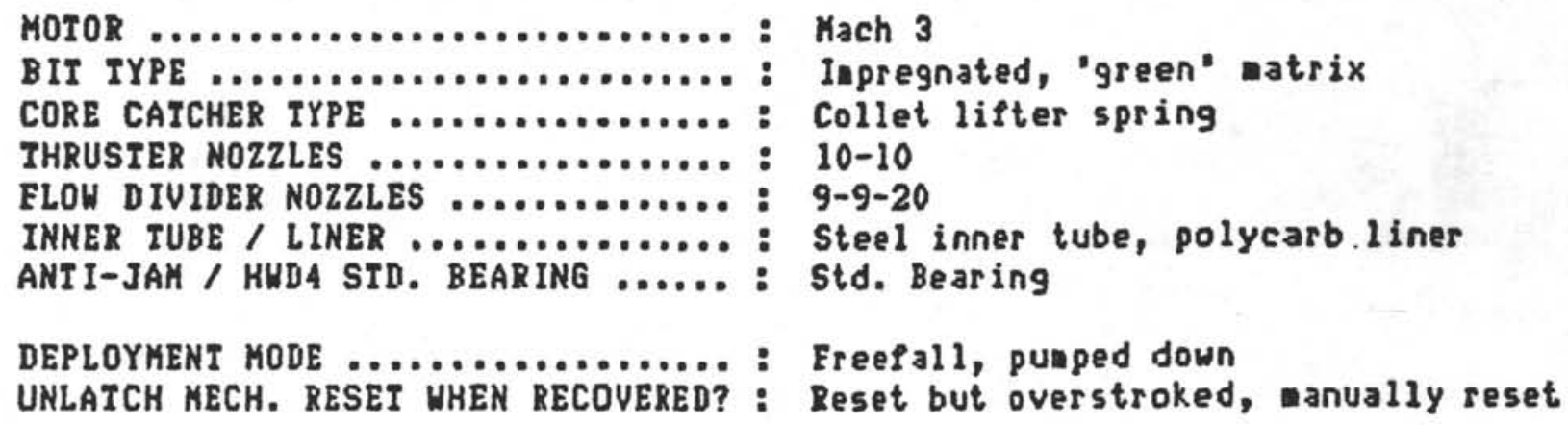

\section{OPERATING DATA}

PUMPING (CORING?) TIME ..........: 67 minutes

PUMP RATE ....................... : $135 \mathrm{gPm}$, several changes to restart

CALCULATED WEIGHT ON NCB BIT ......

TOP DRIVE RPM ................. $10-15 \mathrm{spm}$

COMPENSATED HEIGHT ON XCB BIT ....: $12 \mathrm{~K}$

HOLE CONDITIONS ................ : Good

ASSUMED FORMATION ............... B : Basalt

\section{RESULTS}

INDICATED PENETRATION ........... : 0.5 .

AMOUNT OE CORE .................. 3 egg-sized chunks of basalt

CORE DESCRIPIION ................. : gray basalt pieces (1ron prev. core?)

BIT CONDITION .................. : Sone wear but re-runable 
NOTES $=757 B-43 N$

The pressure was very low at first $(900 \mathrm{psi})$. Possible that unlatch did not occur or tool had not seatied properly in BHA. Increased pump rate to 165 9pw for 2 minutes twice and got indications of drilling at increased pressure ( $1900 \mathrm{psi}$ ) after bringing $110 \mathrm{w}$ back to $135 \mathrm{gpm}$. Continued llow rate manipulations and got some suggestions that it was working. Finally gave up aftr 67 inutes.

The reset mechanis again overstroked and had to be reset by hand and hamer tap. When the tool was disasseabled later the thruster adaptor, balls, and landing sleeve all looked okay but had quite a bit of rust llake accumulation which ay have caused balls to hang up and allow overstroke.

It was probable that his run was spoiled either by basalt chunks ir on the previous core in the hole or by pieces of basalt in the BHA which interfered with the NCB. The rach 3 notor was probably stalled for most of the 67 inutes. 


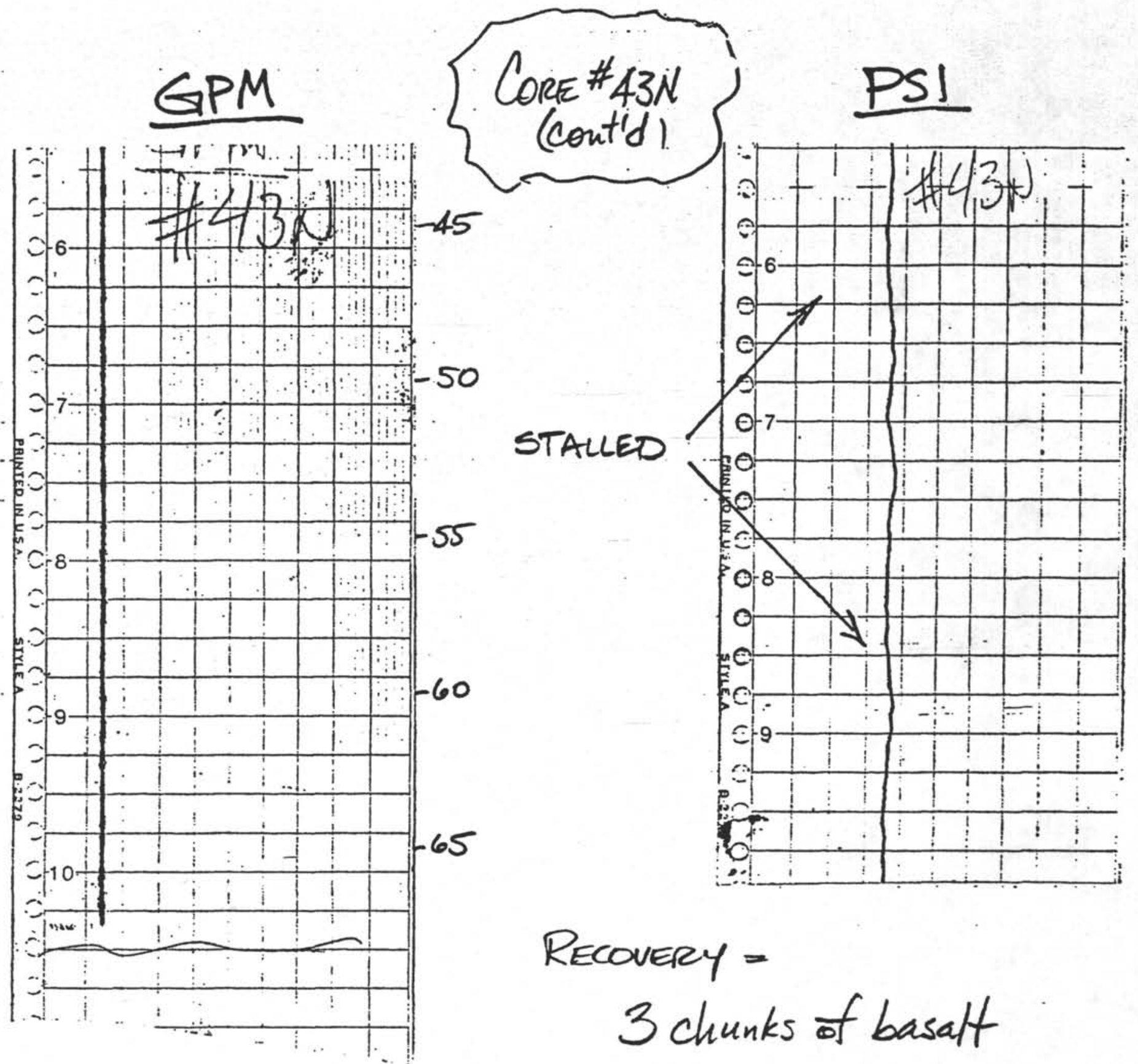




\section{Appendix E}

NCB 121: Leg 124E Run Data 
NAVIDRILL CORE BARREL

NCB-124E

DATA SUMMARY SHEET

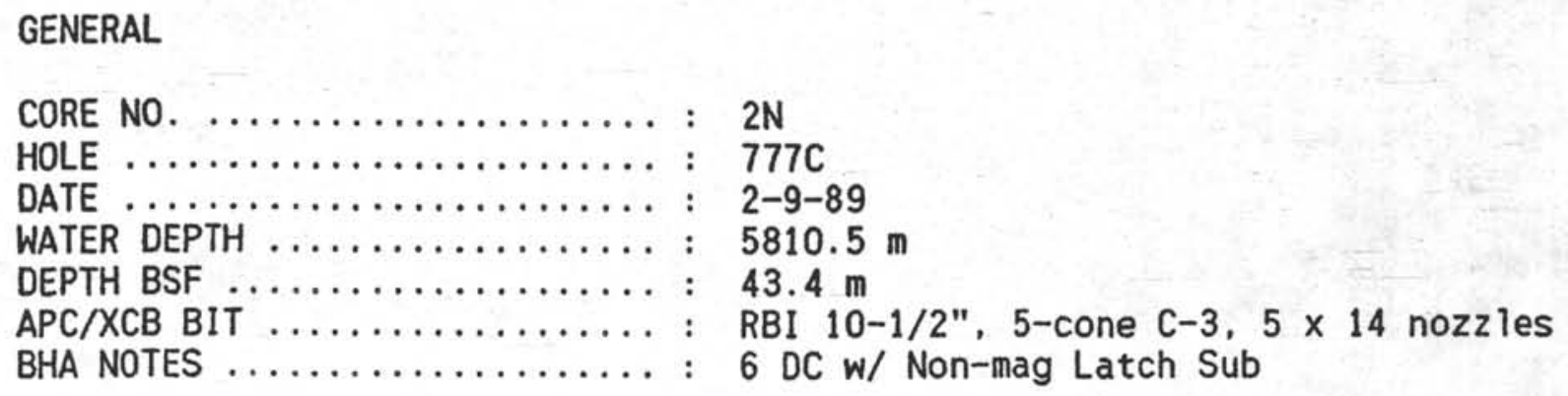

NCB DETAILS

MOTOR $\ldots \ldots \ldots \ldots \ldots \ldots \ldots \ldots \ldots \ldots$ :

BIT TYPE $\ldots \ldots \ldots \ldots \ldots \ldots \ldots \ldots \ldots \ldots$

CORE CATCHER TYPE $\ldots \ldots \ldots \ldots \ldots$ :

THRUSTER NOZZLES $\ldots \ldots \ldots \ldots \ldots$ :

FLOW DIVIDER NOZZLES $\ldots \ldots \ldots \ldots$ : $11-11-18$

INNER TUBE / LINER ........... : Plastic liner

ANTI-JAM /HWD4 STD.BEARING ....: : Std. bearing

DEPLOYMENT MODE ............ : Freefa11, 43 minutes to bottom

UNLATCH MECH. RESET WHEN RCVD? . : Yes

OPERATING DATA

PUMPING (CORING?) TIME .......: 70 minutes

PUMP RATE $\ldots \ldots \ldots \ldots \ldots \ldots \ldots$ : $140-185 \mathrm{gpm}, 5$ " pump 1 iners

CALCULATED WEIGHT ON NCB BIT ... :

TOP DRIVE RPM $\ldots \ldots \ldots \ldots \ldots \ldots: 15 \mathrm{rpm}$

COMPENSATED WT. ON XCB BIT ...: 10 : $12 \mathrm{~K}$

HOLE CONDITIONS ............ : $4.6 \mathrm{~m}$ rathole into hard streak under soft

ASSUMED FORMATION ........... : Chert/porcellanite interbedded with ??

RESULTS

INDICATED PENETRATION ......... : AMOUNT OF CORE $\ldots \ldots \ldots \ldots \ldots \ldots$ :

CORE DESCRIPTION $\ldots \ldots \ldots \ldots \ldots$ :

BIT CONDITION ................

OTHER MECHANICAL PROBLEMS .....: : Bit box belled noticeably, liner partially $3.96 \mathrm{~m}$ (false indication ?)

$0.71 \mathrm{~m}$

Jammed and baked, chert chunks and clay Broken, 1-1/2" of crown lost, same as core $5 \mathrm{~N} / \mathrm{Hole} 777 \mathrm{~B}$ melted, torque segments okay 
NAVIDRILL CORE BARREL

NCB-124E

DATA SUMMARY SHEET

\section{GENERAL}

CORE NO.

HOLE

DATE $\ldots \ldots \ldots \ldots \ldots \ldots \ldots \ldots$ :

WATER DEPTH $\ldots \ldots \ldots \ldots \ldots \ldots$ :

DEPTH BSF ............

APC/XCB BIT $\ldots \ldots \ldots \ldots \ldots \ldots$ :

BHA NOTES
$5 \mathrm{~N}$

$777 \mathrm{~B}$

2-9-89

$5810.5 \mathrm{~m}$

$38.4 \mathrm{~m}$

RBI 10-1/2", 5-cone C-3, $5 \times 14$ nozzles

6 DC, w/ Non-mag Latch Sub

NCB DETAILS

MOTOR

BIT TYPE

CORE CATCHER TYPE

THRUSTER NOZZLES $\ldots \ldots \ldots \ldots \ldots \ldots$

FLOW DIVIDER NOZZLES $\ldots \ldots \ldots \ldots$ :

INNER TUBE / LINER ...........

ANTI-JAM /HWD4 STD.BEARING .... :

DEPLOYMENT MODE ...........

UNLATCH MECH. RESET WHEN RCVD? . :
Mach 1P - Drain Hole type

Used surface set

Collet

14-14

$11-11-18$

Plastic liner

Std. bearing

Freefall, pumped $w / 40$ stks, $42 \mathrm{~min}$.

Yes

OPERATING DATA

PUMPING (CORING?) TIME ......: 30 minutes

PUMP RATE $\ldots \ldots \ldots \ldots \ldots \ldots \ldots$ :

CALCULATED WEIGHT ON NCB BIT .. :

TOP DRIVE RPM ............

COMPENSATED WT. ON XCB BIT .... :

HOLE CONDITIONS ............

160-190 gpm, 5" pump liners

ASSUMED FORMATION

$15 \mathrm{rpm}$

$10-12 k$

BHA poorly buried in very soft sediment

Chert/porcellanite interbedded with ??

RESULTS

INDICATED PENETRATION ........ : AMOUNT OF CORE ............

$1.47 \mathrm{~m}$

$0.72 \mathrm{~m}$

Banded porcellanite, dark brown, very hard, mostly broken but some 3" pieces well trimmed, apparent hole drift of 20-30 degrees.

BIT CONDITION Body completely separated 1-1/2" from crown Torque segments okay 


\author{
NAVIDRILL CORE BARREL \\ NCB-124E \\ DATA SUMMARY SHEET
}

\title{
GENERAL
}

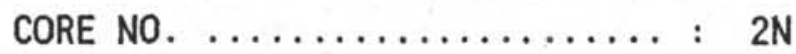

HOLE $\ldots \ldots \ldots \ldots \ldots \ldots \ldots \ldots, 7770$

DATE ................... $2-10-89$

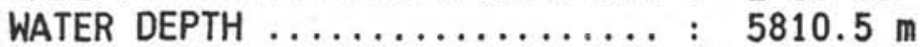

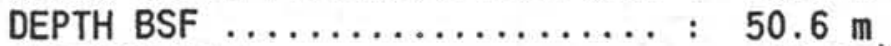

APC/XCB BIT $\ldots \ldots \ldots \ldots \ldots \ldots \ldots$ : RBI 10-1/2", 5-cone C-3, 5 x 14 nozzles

BHA NOTES $\ldots \ldots \ldots \ldots \ldots \ldots \ldots$ : $6 \mathrm{DC}$ w/ Non-mag Latch Sub

NCB DETAILS

MOTOR $\ldots \ldots \ldots \ldots \ldots \ldots \ldots \ldots$ : Mach 1P, Drain Hole type

BIT TYPE $\ldots \ldots \ldots \ldots \ldots \ldots \ldots$ : New surface set, Eastman-Christensen

CORE CATCHER TYPE $\ldots \ldots \ldots \ldots \ldots$ : Collet

THRUSTER NOZZLES $\ldots \ldots \ldots \ldots \ldots: 16-16$

FLOW DIVIDER NOZZLES $\ldots \ldots \ldots \ldots$ : $11-11-8$

INNER TUBE / LINER ........... : Plastic liner

ANTI-JAM /HWD4 STD.BEARING ....: : Std. bearing

DEPLOYMENT MODE ............ : Freefall, $60 \mathrm{spm}, 30 \mathrm{~min}$. to bottom

INLATCH MECH.RESET WHEN RCVD? - : YeS

OPERATING DATA

PUMPING (CORING?) TIME ...... : 76 minutes

PUMP RATE ................ :

CALCULATED WEIGHT ON NCB BIT ... :

TOP DRIVE RPM ............ No rotation of drillpipe

COMPENSATED WT. ON XCB BIT .... : 10-12k

HOLE CONDITIONS $\ldots \ldots \ldots \ldots \ldots, 2-3 \mathrm{~m}$ fill getting back to bottom

ASSUMED FORMATION ........... : Chert/porcellanite interbedded w/ ??

RESULTS

INDICATED PENETRATION ....... : $4.1 \mathrm{~m}$ (false indication ?)

AMOUNT OF CORE ........... $0.27 \mathrm{~m}$

CORE DESCRIPTION ............ : Jammed in CC, chunks

BIT CONDITION .............. Ringed out, some lost diamonds, box

OTHER MECHANICAL PROBLEMS .....: Torque segments okay 


\section{NAVIDRILL CORE BARREL \\ NCB-124E}

DATA SUMMARY SHEET

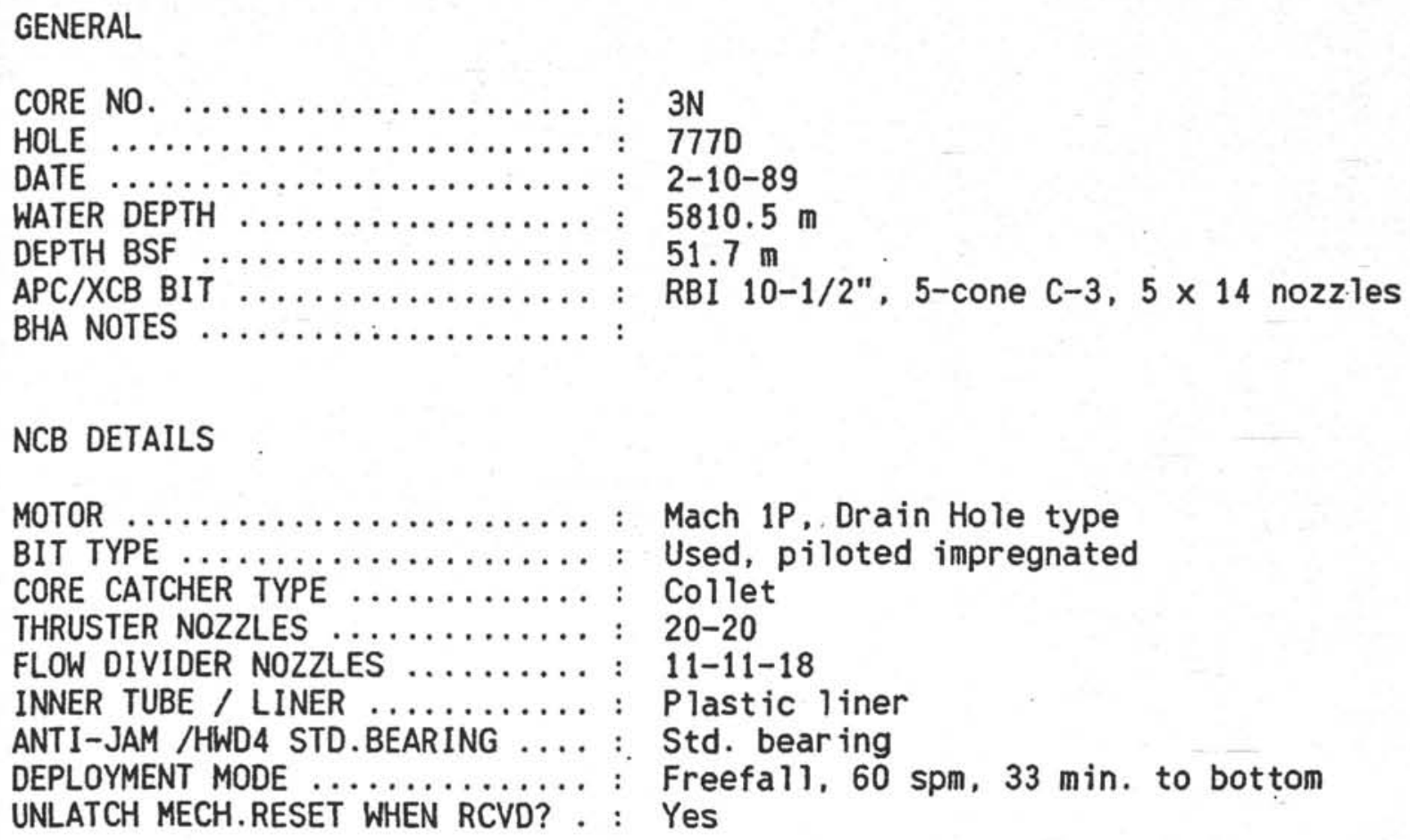

RESULTS

INDICATED PENETRATION .......: $4.1 \mathrm{~m}$ (probable false indication)

AMOUNT OF CORE ........... $0.37 \mathrm{~m}$

CORE DESCRIPTION ........... Jammed in CC but some well-trimmed pieces

BIT CONDITION .............. : Worn, but properly

OTHER MECHANICAL PROBLEMS .....: Slight wear on drive flanks of tor que segments 


\section{NAVIDRILL CORE BARREL \\ NCB-124E}

DATA SUMMARY SHEET

\section{GENERAL}

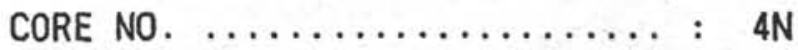

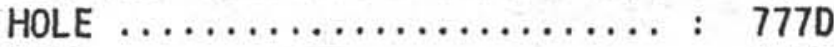

DATE ................. 2-10-89

WATER DEPTH ........... $5810.5 \mathrm{~m}$

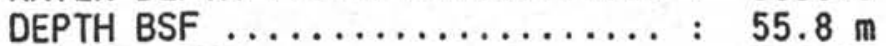

APC/XCB BIT ............ : RBI 10-1/2", 5-cone C-3, $5 \times 14$ nozzles

BHA NOTES .............. : $6 \mathrm{DC}$ w/ Non-mag Latch Sub

\section{NCB DETAILS}

MOTOR ................ Mach 1P, Drain Hole type

BIT TYPE ................ : Used, piloted impregnated

CORE CATCHER TYPE .......... Collet

THRUSTER NOZZLES $\ldots \ldots \ldots \ldots \ldots$ : $20-20$

FLOW DIVIDER NOZZLES $\ldots \ldots \ldots \ldots$ : 11-11-20

INNER TUBE / LINER .......... P : Plast ic liner

ANTI-JAM /HWD4 STD.BEARING ....: : Anti-jam

DEPLOYMENT MODE ............ F : Freefal1, 36 minutes to bottom

UNLATCH MECH.RESET WHEN RCVD? . : See notes at end

\section{OPERATING DATA}

PUMPING (CORING?) TIME ...... : 41 minutes

PUMP RATE .............. $170-180 \mathrm{gpm}$

CALCULATED WEIGHT ON NCB BIT ... :

TOP DRIVE RPM ............. None

COMPENSATED WT. ON XCB BIT ....: $10-12 \mathrm{~K}$

HOLE CONDITIONS ............ : Okay

ASSUMED FORMATION .......... : Chert porcellanite interbedded $w /$ ??

RESULTS

INDICATED PENETRATION ....... : $4.2 \mathrm{~m}$ (probable false indication)

AMOUNT OF CORE ............ $0.5 \mathrm{~m}$

CORE DESCRIPTION ........... Jammed and baked, a few well-trimmed then

fractured pieces of banded porcellanite

BIT CONDITION ............. : Face discharge jets plugged, worn on crown but good diamond exposure and excellent. O.D./I.D. gage protection.

OTHER MECHANICAL PROBLEMS ..... : HWD4 core barrel lower box belled out, torque segments worn on one side but hinged smoothly. Anti-jam bearing frozen. 
NOTES - 777D, Core $4 \mathrm{~N}$

The core barrel was found stuck at the bit because the flat spring in the thruster unit had shattered and jammed pieces throughout the BHA. The tool could not pass thru the double window latch sleeve or the Top Sub. Heavy jarring with W/L link jars destroyed the RS overshot but could not free the core barrel, forcing a round trip of the pipe. On deck, the 3-lug Q/R was found disengaged but (miraculously) the lower core barrel stayed in the BHA.

After loss of the flat spring downhole, the preload nut for the spring pack had screwed down allowing the split sleeves to fall out which also helped jam the mechanism in the BHA.

The downhole jarring caused the thruster unit to overstroke in the up direction. Later, the unit would not reset and excess play was observed in the balls and grooves. 
NAVIDRILL CORE BARREL

NCB-124E

DATA SUMMARY SHEET

GENERAL

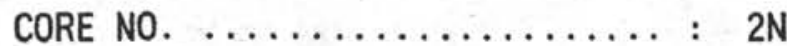

HOLE $\ldots \ldots \ldots \ldots \ldots \ldots \ldots \ldots \ldots \ldots \ldots \ldots, 777 E$

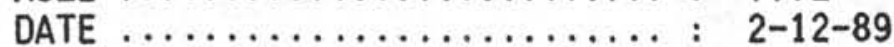

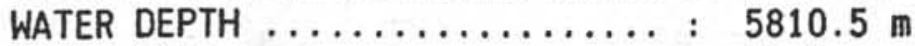

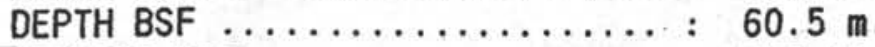

APC/XCB BIT $\ldots \ldots \ldots \ldots \ldots \ldots \ldots$ : RBI 10-1/2", 5-cone C-3, 5 × 14 nozzles

BHA NOTES $\ldots \ldots \ldots \ldots \ldots \ldots \ldots$ : $6 \mathrm{DC}$ w/ non-mag Latch Sub

NCB DETAILS

MOTOR $\ldots \ldots \ldots \ldots \ldots \ldots \ldots \ldots \ldots$

BIT TYPE $\ldots \ldots \ldots \ldots \ldots \ldots \ldots \ldots$

Mach 1C, tight rotor

Used, piloted surface set

CORE CATCHER TYPE $\ldots \ldots \ldots \ldots \ldots$ : Dog type

THRUSTER NOZZLES $\ldots \ldots \ldots \ldots \ldots$ : $20-20$

FLOW DIVIDER NOZZLES $\ldots \ldots \ldots \ldots: 11-11-18$

INNER TUBE / LINER ........... : Plastic liner

ANTI-JAM /HWD4 STD.BEARING .... : Std. bearing

DEPLOYMENT MODE ............. : Freefall, $30 \mathrm{~min}$. to bottom

UNLATCH MECH. RESET WHEN RCVD? . : Never unlatched

OPERATING DATA

PUMPING (CORING?) TIME ....... : 15 Minutes (Intentional early stop)

PUMP RATE .............. $185-190 \mathrm{gpm}$

CALCULATED WEIGHT ON NCB BIT ... :

TOP DRIVE RPM $\ldots \ldots \ldots \ldots \ldots \ldots$ :

COMPENSATED WT. ON XCB BIT ....: $10-12 \mathrm{k}$

HOLE CONDITIONS $\ldots \ldots \ldots \ldots \ldots$ : Okay

ASSUMED FORMATION ........... : Chert/porcellanite interbedded w/ ??

RESULTS

INDICATED PENETRATION ........ : None

AMOUNT OF CORE ............. Non : No

CORE DESCRIPTION ............ N : None

BIT CONDITION .............. No : Near, never contacted formation

OTHER MECHANICAL PROBLEMS ...... : Landing sleeve jammed due to incorrect assembly. Sandline broke while recovering core barrel allowing NCB to freefall 1000m back to bit. Mach 1C motor non-functional. 
NAVIDRILL CORE BARREL

NCB-124E

DATA SUMMARY SHEET

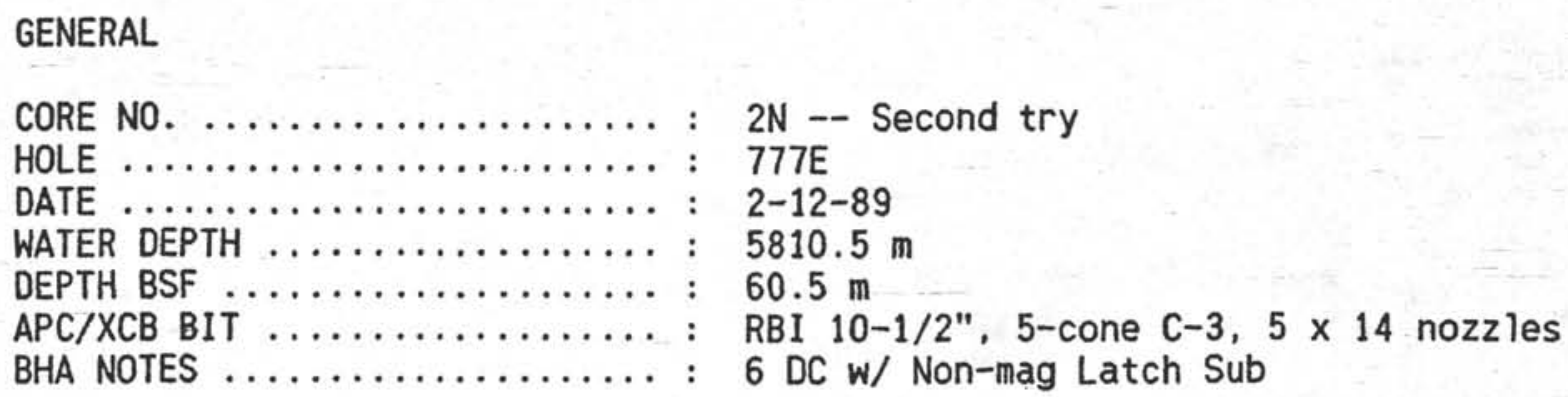

\section{OPERATING DATA}

PUMPING (CORING?) TIME ......: 60 minutes

PUMP RATE $\ldots \ldots \ldots \ldots \ldots \ldots \ldots$ : $100-160 \mathrm{gpm}$

CALCULATED WEIGHT ON NCB BIT .. :

TOP DRIVE RPM .............

COMPENSATED WT. ON XCB BIT ....: $10-12 \mathrm{~K}$

HOLE CONDITIONS ............. : Good

ASSUMED FORMATION ........... Chert/porcellanite interbedded $w /$ ??

\section{RESULTS}

INDICATED PENETRATION ........ : None

AMOUNT OF CORE ............ None

CORE DESERIPTION ........... No : None

BIT CONDITION ............. : No apparent contact with formation

OTHER MECHANICAL PROBLEMS ..... : Mach 1C motor non-functiona 1 
NAVIDRILL CORE BARREL

NCB-124E

DATA SUMMARY SHEET

\section{GENERAL}

CORE NO. $\ldots \ldots \ldots \ldots \ldots \ldots \ldots, 2 \mathrm{~N}-\mathrm{m}$, Third try

HOLE $\ldots \ldots \ldots \ldots \ldots \ldots \ldots \ldots \ldots \ldots \ldots \ldots, 777 \mathrm{E}$

DATE $\ldots \ldots \ldots \ldots \ldots \ldots \ldots \ldots \ldots \ldots \ldots \ldots \ldots \ldots \ldots \ldots$

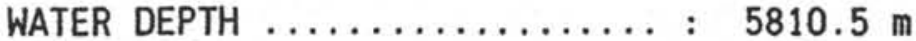

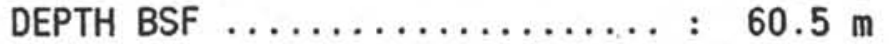

APC/XCB BIT $\ldots \ldots \ldots \ldots \ldots \ldots \ldots$ : RBI 10-1/2", 5-cone $C-3,5 \times 14$ nozzles

BHA NOTES $\ldots \ldots \ldots \ldots \ldots \ldots \ldots$ : 6 DC w/ Non-mag Latch Sub

NCB DETAILS

MOTOR ................ Mach 1P, Orain Hole type

BIT TYPE ................. U : Used, piloted surface set

CORE CATCHER TYPE .......... D : Dog type

THRUSTER NOZZLES $\ldots \ldots \ldots \ldots \ldots: 14-14$

FLOW DIVIDER NOZZLES $\ldots \ldots \ldots \ldots: 11-11-16$

INNER TUBE / LINER ........... : Plastic liner

ANTI-JAM /HWD4 STD.BEARING .... : Std. bearing

DEPLOYMENT MODE ............. : Freefall

UNLATCH MECH.RESET WHEN RCVD? . : Yes

OPERATING DATA

PUMPING (CORING?) TIME $\ldots \ldots \ldots: \quad 34.5$ minutes

PUMP RATE $\ldots \ldots \ldots \ldots \ldots \ldots \ldots \ldots \ldots \ldots \ldots \ldots$ : $80-160 \mathrm{gpm}$

CALCULATED WEIGHT ON NCB BIT .. :

TOP DRIVE RPM .............. :

COMPENSATED WT. ON XCB BIT ...: : $10-12 \mathrm{k}$

HOLE CONDITIONS .............. : Poor, $7 \mathrm{~m} \mathrm{fill}$ getting back to bottom

ASSUMED FORMATION ............ : Chert/porcellanite interbedded w/ ??

RESULTS

INDICATED PENETRATION ........ : $0.5 \mathrm{~m}$

AMOUNT OF CORE $\ldots \ldots \ldots \ldots \ldots \ldots$ : $0.21 \mathrm{~m}$

CORE DESCRIPTION ............. A few chunks and a handful of small chips

BIT CONDITION ............... : Pristine

OTHER MECHANICAL PROBLEMS .....: None 


\section{NAVIDRILL CORE BARREL \\ NCB-124E}

DATA SUMMARY SHEET

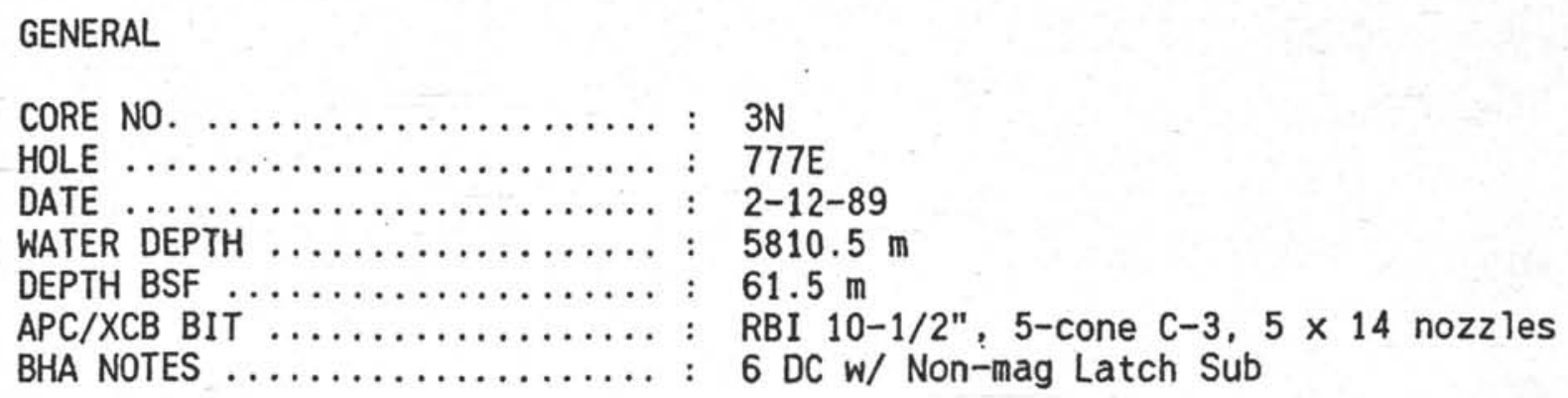

RESULTS

INDICATED PENETRATION ........ : 1m (more likely matches amount XCB bit

AMOUNT OF CORE ............. Non: None

CORE DESCRIPTION ............ None

BIT CONDITION .............. Slightly worn, 3 jets plugged with chips OTHER MECHANICAL PROBLEMS ..... : Apparent stall in rubble, paint on landing shoulder indicated proper landing. 
Appendix F

MDCB: Summary Report - September 1990 
SUMMARY REPORT

MOTOR DRIVEN CORE BARREL.

ENGINEERTNG DEVELOPNENT

PN4661

Prepared For

OCEAN DRTIIING PROGRAM

TEXAS ASM RESEARCH PARK

College Station, Texas

Prepared By

STRESS ENGINEERING SERVICES, INC.

13800 Westfair East Drive

Houston, Texas 77041

SEPTEMBER. 1990

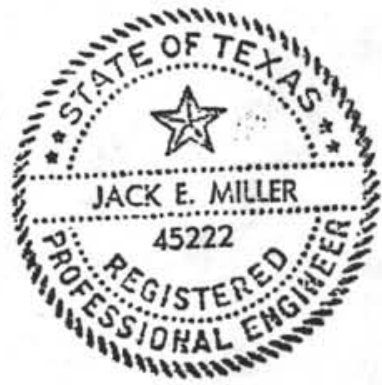


1.0 OVERVIEW . . . . . . . . . . . . . . . . . . . . . . 1

2.0 KEY FEATURES OF THE NEW MDCB . . . . . . . . . . . . . . . . 1

3.0 BASIC SETTINGS FOR THE MDCB ................. . 11

4.0 MDCB PERFORMANCE ANALYSIS . . . . . . . . . . . . . . 12

5.0 CONCLUSIONS OF THE ANALYSIS . . . . . . . . . . . . . . 22

6.0 OBSERVATIONS AND COMMENTARY ............... 23

\section{APPENDICES}

APPENDIX A - LOCKING PISTON CALCULATIONS

APPENDIX B - CALCULATIONS FOR KELLY \& BIT FLOW TUBE

APPENDIX C - LISTING OF "MDCB WOB" WITH SAMPLE OUTPUT

APPENDIX D - TIME DOMAIN FORMULATION

APPENDIX E - COMMENTS AND SOURCE CODE LISTING FOR "MDCBTIME"

APPENDIX F - SELECTED TIME DOMAIN ANALYSIS RESULTS

APPENDIX G - MOTOR PERFORMANCE ALGORITHMS AND

BIT TORQUE ALGORITHM

APPENDIX H - CONCEPT STUDIES REPORT 


\subsection{OVERVIEW}

During the period from January through July, 1990, Ocean Drilling Program and Stress Engineering Services jointly developed a new Motor Driven Core Barrel (MDCB). It is anticipated that this new tool will be deployed during ODP Leg 134 in October, 1990. The design of this tool evolved from a formal and methodical approach that spanned research into diamond coring, conceptual studies, steady state hydraulic analyses and computer simulation of operation through transient dynamic analysis. The analytical results of this work have been embodied in a detailed mechanical design which accurately reflects and executes the analytically determined parameters.

This brief report overviews the work performed and the basic operating parameters for the MDCB.

\subsection{KEY FEATURES OF THE NEW NIDCB}

The heart of the new MDCB is the drill motor. The Christensen Machl-P $7 / 8$ lobe ("Drainhole") motor has been specified due to the outstanding torque and speed capabilities as represented by Christensen. One set of specifications for this motor gives a torque of $1250 \mathrm{ft}-1 \mathrm{bs}$ at $410 \mathrm{rpm}$, yielding 96 Horsepower. This performance is specified at 1160 psi differential pressure at $170 \mathrm{gpm}$. These numbers indicate a 838 efficiency. It is envisioned that the high torque and speed capabilities of this motor will greatly enhance the coring performance of the new MDCB, resulting in high penetration rates and making motor stall very unlikely.

Figure 1 shows the layout of the new tool. The layout of the tool places the lower end of the motor connected to the fluid swivel housing which is, in turn, supported on the landing shoulder in the Bottom Hole 

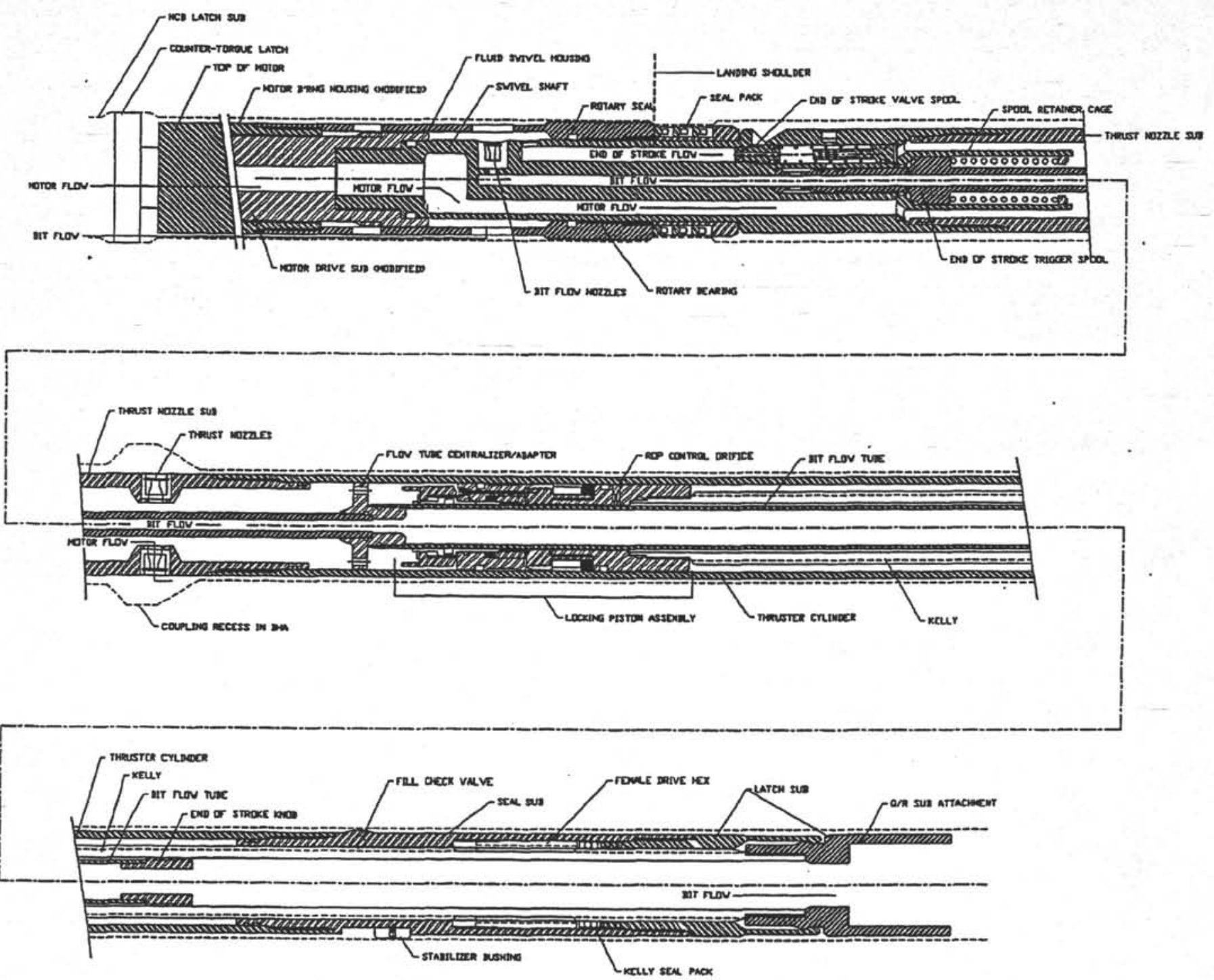

FIGURE 1

GENERAL LAYDUT DF NEW MDCB

(NDTE: PRIDR TQ FINAL MACHINE DETAIL) 
Assembly (BHA). The motor bearing housing and drive sub have been appropriately modified for this purpose. A latch mechanism is located on the top end of the motor to counteract motor torque at the the NCB latch sub in the BHA. All flow exhausting the motor passes through a fluid swivel shaft which transmits motor rotation to the thruster nozzle sub and is forced to exit the nozzle sub through restrictive orifices which produce a high pressure on the top side of a hydraulic piston. This piston is connected to the core barrel via a hex shaped shaft (kelly) which is also used to transmit torque and piston load to the core barrel. In this way, downward thrust for coring is produced. Motor torque and rotation are transmitted through the nozzle sub to the thruster cylinder. A female drive hex is located in a sub which is threaded into the lower end of the thruster cylinder to conduct torque to the kelly. The function of the fluid swivel, shown in Figure 2, is to divide bit flow from motor flow at motor entry pressure while accommodating relative rotation of the bit and the motor housing. As opposed to the earlier NCB2, bit flow is arranged in parallel with the drill motor. This is made possible by the fluid swivel section which includes flow restriction nozzles in the rotating fluid swivel shaft and a central flow tube which conducts fluid directly to the core barrel. Two totally separate flow paths for the motor and the bit are produced. Several benefits accrue from this layout:

(1) Overall system flow rate is increased

(2) Flow to the bit is regulated by highly restricted nozzles due to the higher available pressure above the motor. The restriction of these nozzles is much higher than the restriction of the bit itself. Therefore, any attempt to clog the bit is met with a rapid increase in bit face feed pressure.

(3) For the same reason as item (2), pumpoff force, resulting from high bit feed pressure, will become rapidly available to reduce Weight on Bit (WOB) during clogging conditions.

(4) During high torque demand, some motor flow (and thus thrust nozzle flow) will be diverted to the bit, which reduces WOB and increases the motor stall threshold.

Below the hydraulic piston, a cylinder area composed of a $3^{\prime \prime}$ bore sans the $4.34 \mathrm{sq}$. in. kelly area is provided. Sliding seals are arranged on the 


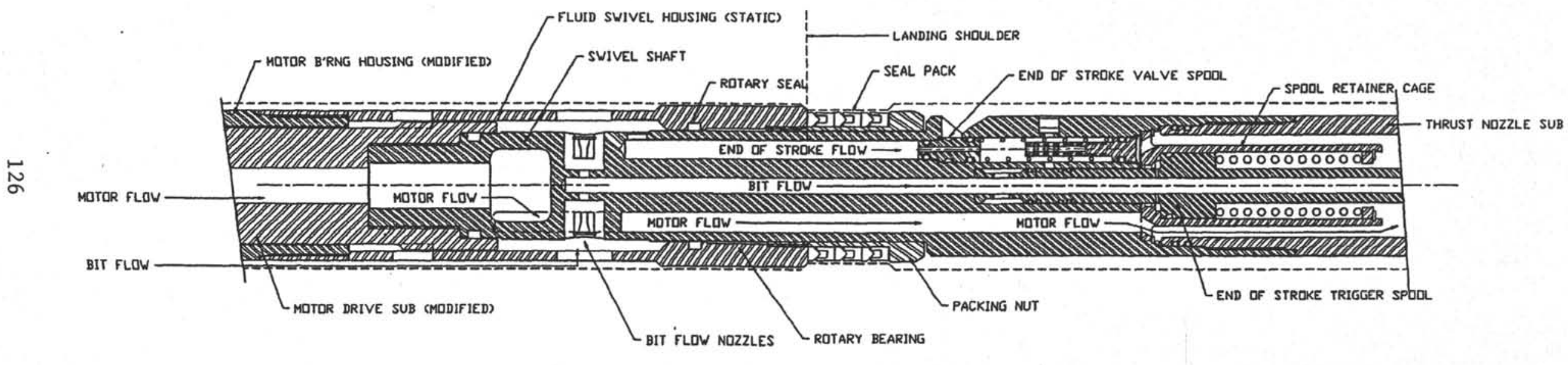

FIGURE 2

MDCB FLUID SWIVEL ASSEMBLY

(NOTE: PRIOR TO FINAL MACHINE DETAIL) 
kelly adjacent to the female kelly drive to provide a sealed volume. Forward advance of the core barrel requires that this swept volume be exhausted from below the piston. A control orifice composed of a 1/32" diameter hole drilled through a set screw is provided as the only means of exhaust for this otherwise trapped fluid. The fluid exhausted is conducted to the bit feed circuit to enhance reduction in WOB during clogging conditions as characterized by high bit feed pressure. The primary purpose of controlling exit flow, however, is to prevent forward lunge of the core barrel during initiation of coring and to generally damp the aggressiveness of bit advance in soft or non supportive soils. Rate of advance is limited to approximately 2" per second. For other control orifice sizes, rate of penetration will follow a square relationship. For example, orifice size of .015" would yield a maximum rate of advance of about .46 inches per second. To prevent clogging of the small 1/32" control orifice, it is placed in the piston where exit flow must pass through a nominal .003" annular radial clearance before passing through the orifice. In order to properly damp the initial deployment of the core barrel, trapped air must be purged from the lower portion of the cylinder. Automatic water filling and purging of trapped air is provided in the lower cylinder portion by virtue of a centrifugally loaded check valve allowing inward flow only on the bottom end and a buoyant ball check valve in the piston to allow air escape to the thruster cavity at the top end. Since the major seating load on the lower check valve is centrifugally produced, it will allow easy filling and air purge while running down hole, but close after rotation is initiated. See Figure 3.

The piston assembly is a multiple piece design that includes a spring loaded, friction coated, wedge ring that prevents downward stroke of the core barrel in the absence of thruster pressure. The coating is provided to create a large sliding friction while preventing scoring of the thruster cylinder. Figure 4 illustrates the piston assembly. The purpose of this mechanism is to indicate penetration into the formation achieved during coring by "freezing" the thruster piston (and thus the core barrel) in position once circulation is terminated. The angles are intended to cause a tighter lock to be produced by a pulling load on the kelly as might occur during the process of breaking the core. The mechanism is also designed so 


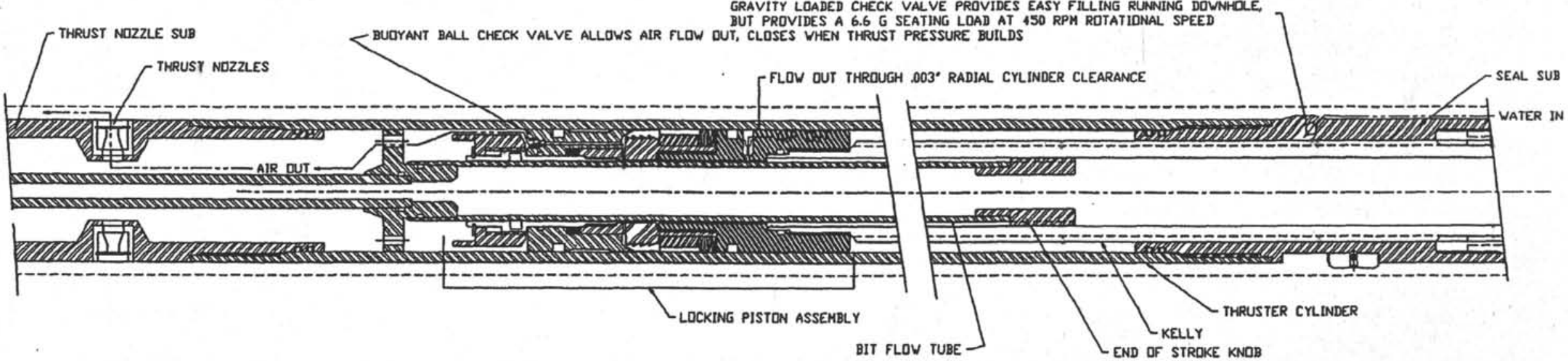

FIGURE 3

AIR PURGE VALVE FUNCTIIN

SHOWN DURING DEPLOYMENT

(NDTE: PRIOR TO FINAL MACHINE DETAIL) 

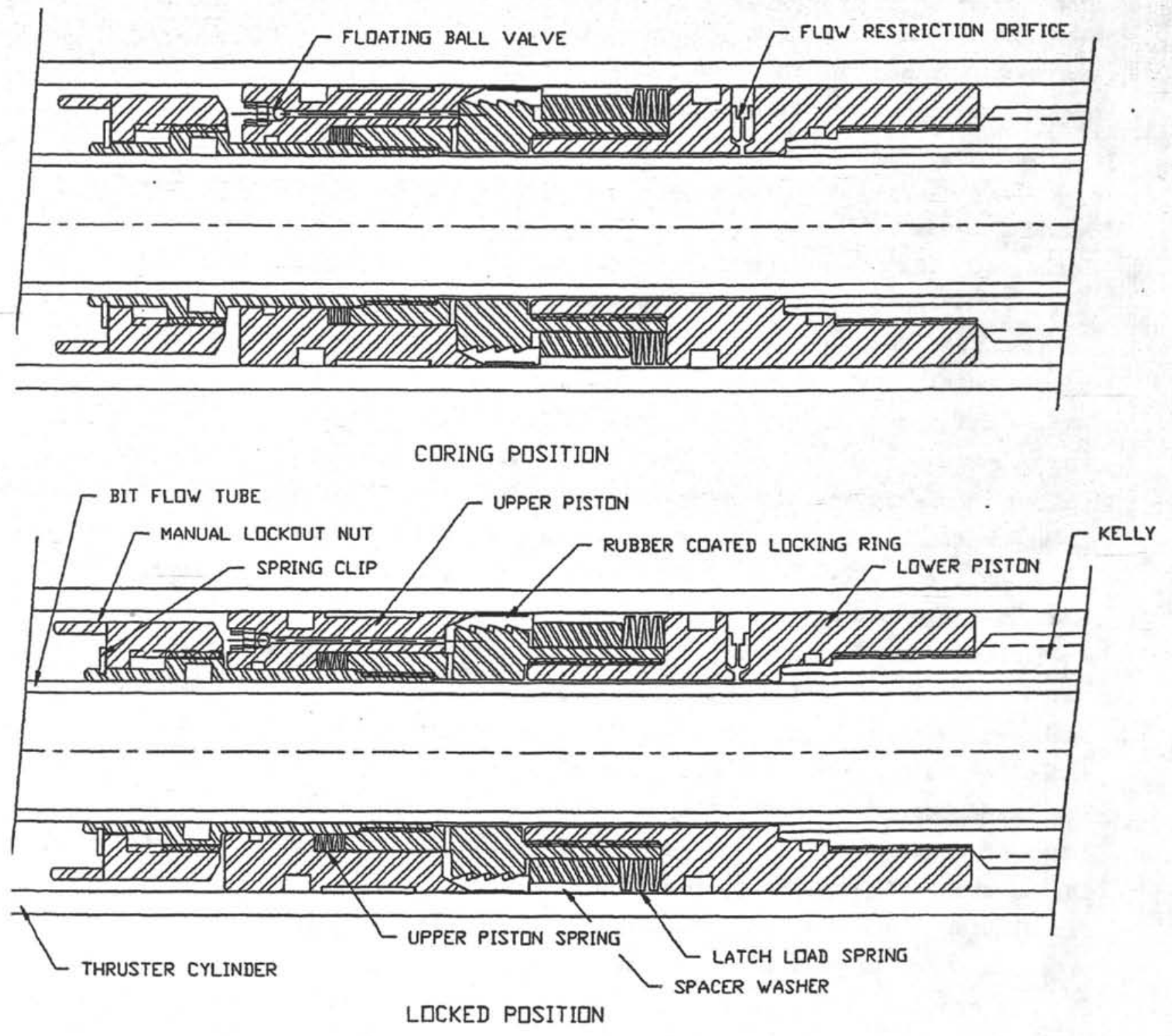

FIGURE 4

LUCKING PISTON ASSEMBLY 
that an upward load of 150 pounds or more on the core barrel will overcome the spring pre-load and allow the core barrel to retract so that the tool may be reset on the surface by simply lowering the weight of the tool while supporting the core barrel. Thruster pressure in the range of 60 to 150 psi produced by pump circulation will unlock the piston assembly to allow forward advance of the core barrel for normal coring operation. Appendix A shows the kinematic calculations for the locking piston design.

End of stroke is indicated by a rapid pressure loss created by opening an additional 1/2" diameter flow path in parallel with the motor and bit circuits. The mechanism is located in the lower end of the fluid swivel shaft. The end of stroke valve initiation is created by engagement of knob located on the lower end of the bit flow tube by the thrust piston at approximately one inch before the full 4.5 meter stroke. The mechanical engagement creates a pulling load sufficient to overcome a retainer spring and produce stroke out of the bit flow tube. Once the bit flow tube has been pulled downward approximately $3 / 8^{n}$, a leakage path from the high motor feed pressure to the low bit feed pressure is produced through a $1 / 8$ " diameter bore drilled through a $1 / 2^{\prime \prime}$ diameter valve spool. Allowing a relatively small leakage through this valve spool will cause a pressure end load sufficient to fully open the valve spool against its retainer spring. The valve spool is dimensioned so that pressure loading, in the absence of leakage, will hold the spool closed during normal coring. The end of stroke indicator is designed so that the small motion of the bit flow tube is amplified to cause a large bypass flow area to be produced. This design is intended to provide a sudden, detectable, leak event. Also, the valve spool is automatically re-set by the retainer spring with the termination of pump circulation. Note that the hydraulic areas and porting have been designed to pressure load the bit flow tube so that an upward bias of approximately 300 lbs. is created at a thruster pressure to bit feed pressure differential of $1000 \mathrm{psi}$. The upward bias load is intended to prevent seal drag or spurious mechanical drag on the bit flow tube from providing a false end of stroke indication. Surface pressure readings at end of stroke is predicted from the computer models to be no greater than 1000 psi. This should provide a clear indication of. end of stroke, since the next lowest pressure reading achievable during coring (again from computer simulations) is above 1500 
psi, which would be the kind of pressure noted during a core block incident in which no torque resistance was applied to the motor. The valve spool is provided with a groove so that indication of full valve reset is externally visible at the surface. Figure 5 illustrates the operation of the end of stroke indicator.

The bit flow tube and kelly cross sections are relatively large with relatively thin walls. These dimensions were determined to increase the fundamental critical rotational speeds to the maximum practical extent since the "Drainhole" motor speed is high enough for lateral "whirl" to be of concern. However, external pressure on the bit flow tube without the accommodating pressure end load will probably increase the stability of this component. With regard to the kelly, the cross-section provides an axial compressive buckling load of approximately 11,300 lbs., assuming the upper and the lower ends pinned. Torsional stress in the kelly is approximately $9,200 \mathrm{psi}$ at a maximum motor torque of 1,250 ft.-1bs.

Use of the high speed Christensen Mach 3 motor is not recommended with the MDCB due to its low torque and the probability of exciting mechanical vibrations in the kelly and bit flow tube. The high rotary speeds also eclipse the allowable operating range of the rotary seals. Any future proposals to increase core length (with this tool concept) should be critically examined based on stability considerations. The square law relationships describing both axial buckling and critical rotational speed do not require large length increases before becoming cause for concern. However, axial buckling and shaft whirl may be survivable based on the fact that there is not adequate radial room for either of these components to enter the plastic stress range, so the concern could be satisfied if experience shows that no other detriment exists to proper operation and coring performance. Further, only near each extreme end of stroke do the effective lengths allow these phenomena. Appendix B shows the important calculations for the kelly and bit flow tube.

In addition to the retaining mechanism of the piston assembly, a two piece mechanical latch sub composed of spring fingers and a mating groove is threaded into the lower end of the female kelly sub located at the bottom of 


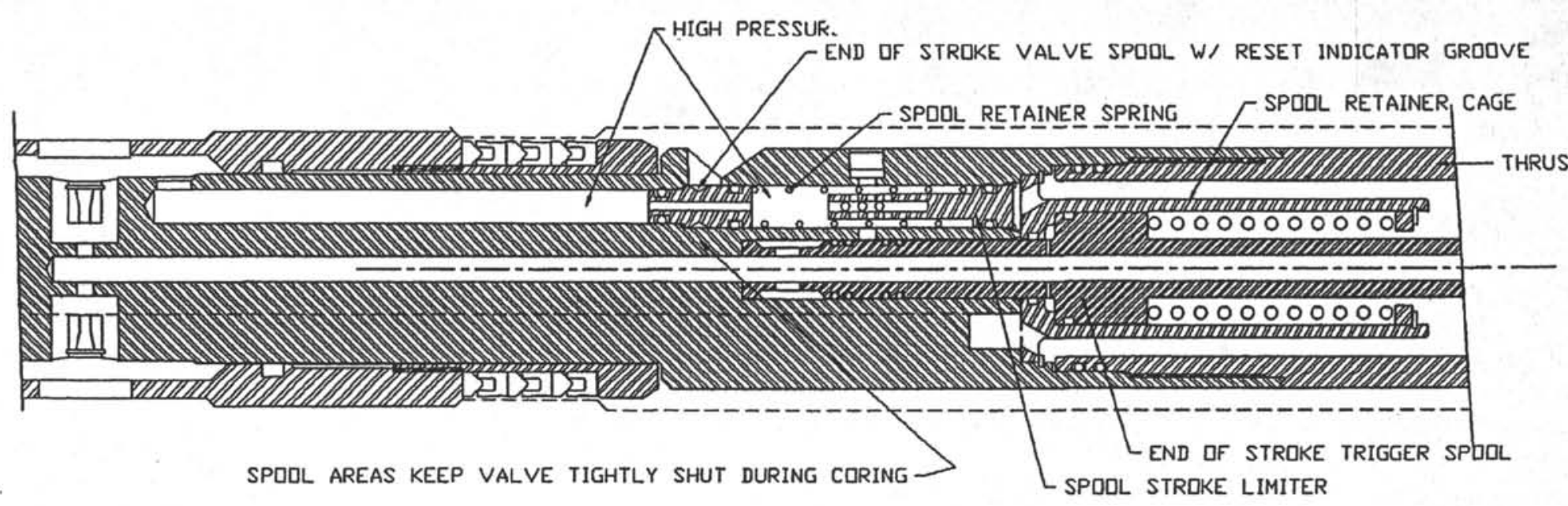

NURMAL CORING POSITION

1500 PSI MIN SURFACE PRESSURE

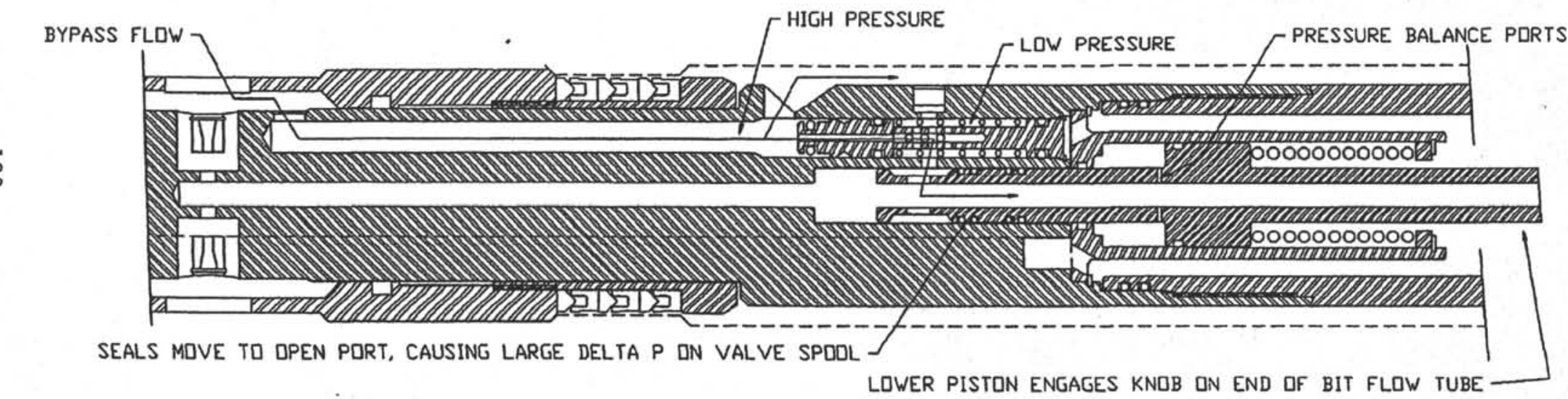

END OF STRDKE INDICATED

LESS THAN 1000 PSI SURFACE PRESSURE

\section{FIGURE 5}

END DF STROKE INDICATOR FUNCTION

(NDTE: PRIDR TO FINAL MACHINE DETAIL) 
the thruster cylinder to positively hold the core barrel in the retracted position until the downward thrust load (from pressure) exceeds $1,200 \mathrm{lb}$. after circulation for coring is initiated. A shallow angle is used to allow re-setting the latch function at approximately 300 1bs. down-load.

To ease adjustment and maintenance, both bit flow and thruster nozzles are externally accessible without disassembly of the tool. Also, a sealed quick release sub, a pre-existing ODP design, is located between the core barrel and the latch sub to allow quick change of the core barrel between coring runs.

\subsection{BASIC SETTINGS FOR THE MDGB}

A survey of diamond coring bit suppliers revealed recommended operating ranges of WOB from 4 to $8 \mathrm{kips}$ and bit flow rates of 15 to $40 \mathrm{gpm}$ for various kinds of bits. Therefore, the basic nozzle settings used for analysis and recommended for field operations are designed to produce a nominal WOB of $6300 \mathrm{lbs}$. and a bit flow rate of 28.5 gallons per minute with no motor load. These settings are within the specified operating range for all of the bits surveyed. To produce these values, a bit nozzle size combination of $3 / 32$ 's and $4 / 32$ 's is recommended in conjunction with a thrust nozzle combination of $10 / 32$ 's and $12 / 32$ 's. Recommended pump flow rate to produce the basic settings is 215 gallons per minute. These settings should produce a motor speed of approximately $460 \mathrm{rpm}$, unloaded and $420 \mathrm{rpm}$ at maximum motor load. During coring that produces torque resistance to the motor, the basic settings above will reduce WOB to below $6000 \mathrm{lbs}$. and increase bit flow to approximately $30 \mathrm{gpm}$. Due to the parallel paths of the motor and bit, a change in one nozzle combination impacts the resulting operating values in the other path. The relationship is quite complex and depends on motor load as well as overall flow rate. To aid the on-site refinement and prediction of operating parameters, a computer program has been written to provide a tool for study of the impact of changing nozzle sizes, flow rates and hole depths. This PC compatible program is called "MDCBWOB.EXE". This program solves for the flow distribution through the tool and also provides predictions of low and high load conditions as reflected in pressure readings monitored at the surface. This program was 
written and compiled using Microsoft Basic version 7.0. A source code listing of the program and a representative output of this program appears in Appendix C.

When using the computer program, it should be noted that there is more than one way to achieve a given goal. For instance, if a bit flow rate of 40 gpm is desired, the bit nozzles may be simply increased in size, with a resulting decrease in motor power and WOB. However, this goal may also be accomplished by increasing nozzle size a smaller amount, while increasing overall flow rate to keep motor power and WOB near the original values. Achievement of the desired settings will require checking several combinations of nozzle sizes and flow rates in an iterative fashion to arrive at the best configuration depending on the goals of any particular coring run and bit type.

In order to take further advantage of the high performance of the "Drainhole" motor, a higher than normal motor flow rate of $185 \mathrm{gpm}$ is specified. Providing higher flow to the motor is justified due to the fact that the motor is normally rated for continuous duty with hot, abrasive, drilling fluid for oil well drilling service. ODP coring operations are run with relatively cool, clean, sea water in intermittent service and relatively short run times.

\subsection{MDGB PERFORMANGE ANALYYSES}

At the beginning of the MDCB development project, competing concepts were assimilated as candidates for further development. Each of the new concepts articulated ideas to correct the perceived faults of the NCB2 coring tool. All of the concepts provided support of the motor on the landing shoulder of the BHA and provided separate means for providing WOB, independent of the motor. Elimination of the motor as a WOB producing element provides the most significant benefit of the new concepts when compared to the NCB2. In order to quantify the performance of each concept, theoretical flow models, embodied in computer programs, were constructed that predicted the steady flow and pressure distribution through each 
candidate concept using classical flow resistance formulations. From the pressure distributions, $W O B$, bit flow rate, and motor torque could be predicted as a function of coring conditions. This work has been previously documented; see Appendix H, "Summary Report, Motor Driven Core Barrel Concept Studies" dated March, 1990 presented to ODP by Stress Engineering Services, Inc. The methods, conclusions, and approach used to isolate the concept of choice are detailed there.

Following choice of the concept for further development, a preliminary mechanical layout was performed to ensure that the concept was reducible to practice. No required mechanical details appeared to present undue difficulties that would prevent proceeding with further work on the chosen concept. A more exhaustive analysis effort then ensued to predict the transient/dynamic performance of the tool. A computer model was constructed that used what is called a "Time Domain" approach. This approach is able to simulate transient dynamics by re-computing and updating the status of a system at small increments of time. The method requires that the entire system be separated into individual "degrees of freedom" representing masses and control volumes which must be properly inter-connected with common forces. A "forcing function" is applied to the model to excite accelerations in the mass degrees of freedom and pressure change rates in control volumes. The accelerations are then integrated to yield instantaneous velocities and resulting velocities integrated to yield instantaneous positions. The pressure change rates are integrated to yield instantaneous values of pressure. After re-computation of all positions, velocities, pressures, and flow rates, all forces and parameters dependant on the integrated values may be updated. A small time step is added to the previous instant in time and all parameters re-calculated. This process is repeated for as long as desired to yield a complete time history of events of interest. The rotational degrees of freedom are modeled in the same way to produce angular accelerations which produce instantaneous values of rotational speed. In the MDCB model, the primary forcing function was pump flow rate. The pump would be started at time $=0$ and flow rate was linearly ramped up to full flow in a brief time (usually 1 second). A user selectable number of degrees of freedom (usually five) was used to simulate the flow and pressure distribution in the drill string leading to the tool. Rotational degrees of 
freedom included the drill motor rotor and thruster assembly and the kelly and core barrel assembly. The primary axial degree of freedom was the core barrel, kelly and piston assembly. Pressure degrees of freedom in the tool included the thruster volume, the trapped volume below the thruster piston, the pressure in the BHA at the top of the core barrel, and the bit feed pressure. Tool flow degrees of freedom included the motor flow, the thrust nozzle flow, the bit nozzle flow, the bit face flow, the flow between the BHA and the core barrel, and the flow exiting the thruster cylinder below the thruster piston.

Ship heave impacts the effective pump flow rate by virtue of inefficiency in the drill string motion compensator. Losses in the motion compensator produce an alternating drill string stretch that superimposes an alternating flow rate with that provided by the surface pump. The computer model is programmed. to simulate this phenomena by computing the drill string volume change produced by a motion compensator inefficiency of $+/-3 \%$. This volume change is then multiplied by the summation of three sinusoids of periods of 7.5 seconds, 8.5 seconds and nine seconds (each making a $1 / 3$ contribution). This alternating volume may then be summed with that from the pump. Inclusion of ship heave produced flow fluctuation is a run-time selectable option.

The time domain analysis approach was chosen since frequency and phase responses and dynamic interactions are automatically manifested in the results. Transient peak events that could not be easily predicted become apparent and non-obvious phenomena are noted. More detail on the formulations used are provided in Appendix D.

One of the first tests of the time domain model was to note if, under similar steady conditions, it agreed well with the more simplistic steady flow model performed during the first analysis phase. The agreement was generally close, but the time domain model gave lower WOB values than the steady flow model (as much as 1,000 lbs. at high torque). This difference was ultimately isolated to the kelly drive friction which had been overlooked in the steady flow model. Once the steady flow model was corrected, the agreement was very close and inspired confidence in both 
approaches since the two modeling techniques were inherently different and independently formulated.

A large portion of the overall analysis effort was to develop a method to simulate cutting at the bit and soil interface. A theoretical study into rock mechanics and the underlying mechanics of how soil is actually removed was outside the envisioned scope of this work. Therefore, no attempt was made to delve into the theory of rock mechanics or to simulate specific rock or sediment types; rather a more intuitive approach was taken. The simple type of thinking that was used to develop a soils model is exemplified by the following thought. If one walks on a concrete drive, the shoes leave no perceptible, lasting impression; however, stepping off the drive into' a deep pool of quicksand will cause one to continuously sink at a controlled rate. An intuitive analysis of this simple thought would lead one to conclude that in the first instance, the concrete must respond chiefly as a spring since no perceptible permanent deformation occurred while the quicksand must be like a damper in that the required supporting load is provided only at the expense off a controlled sink rate.

In general, we cannot know a priori the exact mathematical model that will simulate each soil condition to be dealt with by the MDCB. Therefore, a general soil model was assumed that was composed of a spring and damper in parallel. By input of a high spring stiffness in combination of a low damping coefficient, we assume that a "hard rock" type of soil is being simulated, while reversing the significance of these input parameters creates a more "plastic" condition as we envision "clay" might respond to bit loading.

of course, the simple-model expands in complexity as the effects of material removal, clogging of the bit and inconsistency of the soil is accounted for.

Fundamental to the MDCB analysis is to quantify tool torque loading as a function of Weight on Bit (WOB). Some data regarding this relationship was found as referenced in Appendix $G$. The algorithm found was: 
Torque $=$ WOB $\times$ Bit Diameter $\times .216 \times \mathrm{RPM}^{-1}$ (compacted limestone)

The above relationship shows that rotational speed is also a factor in the torque loading. Intuitively, it would seem that the factor relating torque to load through radial dimension is essentially a friction coefficient. The -.1 exponent on rotational speed indicates that torque falls as speed increases. The equivalent friction coefficient along with the speed term could be viewed as a static friction coefficient and a dynamic coefficient of friction. This type of formulation was intuitively logical, and was adopted throughout the analysis effort. Each soil model could then specify a "static friction coefficient" to substitute into the above formula for torque calculation. In the case of the above formula, the equivalent static coefficient of friction for "compacted limestone" would be $2 \times .216$, or .432 since the formula uses bit diameter instead of radius.

The next issue that had to be addressed was to formulate a method to simulate material removal. Drill test performed by ODP in Germany, during the NCB development project, indicated that a penetration rate of up to 18 meters per hour was achievable with high speed motors. To form a "baseline" condition for penetration rate, the following conditions were assumed:

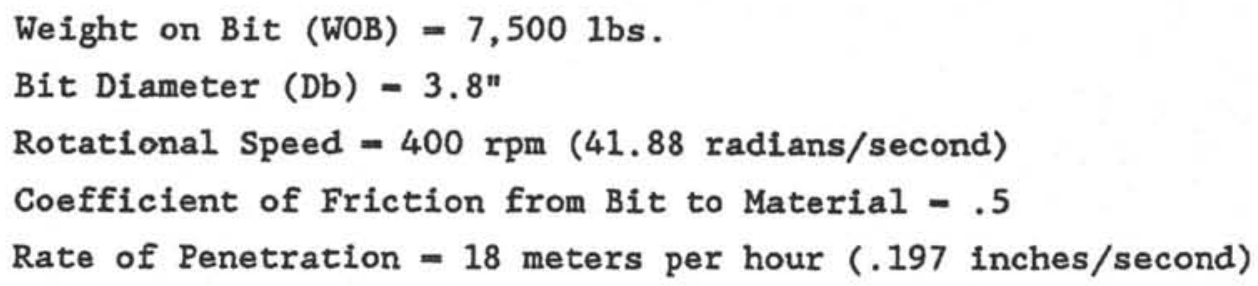

Note that the product of weight on bit, bit radius, and coefficient of friction is torque, while the product of torque and rotational speed is power. Using these numbers in the torque formulation gives $326 \mathrm{ft}-1 \mathrm{bs}$, while using them as shown below implies $593.75 \mathrm{ft}$-lbs. We now assume that there is some coefficient (which we call Cc, or cutting coefficient) that will relate power consumed at the bit with rate of penetration as shown below:

7500 lbs. $\times 3.8^{\prime \prime} / 2 \times .5 \times 41.88 \mathrm{rad} / \mathrm{sec} \times \mathrm{Cc}=.197 \mathrm{in.} / \mathrm{sec}$. or, 
$\mathrm{Cc}=.197 \mathrm{in} / \mathrm{sec} /\left(7500 \mathrm{lbs} . \times 1.9^{n} \times 41.88 \mathrm{rad} / \mathrm{sec} \times .5\right)$

$\mathrm{Cc}=6.7 \times 10^{-7}$

or, $7,125 \mathrm{in}-1 \mathrm{~b} \times 41.88 \mathrm{rad} / \mathrm{sec} \times 6.7 \times 10^{-7} / 1 \mathrm{~b}-\mathrm{rad}-.197 \mathrm{in} / \mathrm{sec}$

By recomputing the product of bit torque and speed at each time step, and multiplying further by the $\mathrm{Cc}$, an.instantaneous rate of penetration is computed. The instantaneous rate of penetration may then be multiplied by the time increment to yield a small, finite amount of penetration during the time step. The incremental penetration is summed (integrated) with the running total to update the new penetration for the following time step. The value of $\mathrm{Cc}$, as shown above, is imbedded in the computer code. To model soils with more or less cutting resistance than the baseline as implied by the imbedded value of $\mathrm{Cc}$, a soils specification includes a factor for the soil to provide a relative measure of cutting resistance of the soil. For instance, if the soils specification file specifies a cutting factor of .5, the penetration rate will be half of that for the baseline soil, given the same power at the bit. The $\mathrm{RPM}^{-} \cdot 1$ factor in the torque formulation produces an inconsistency in the fact that the baseline case reduces to a torque of $593.75 \mathrm{ft}-1 \mathrm{bs}$, while the torque formulation gives $326 \mathrm{ft}-1 \mathrm{bs}$ for the same WOB, static friction coefficient, and RPM, however, it is inconsequential since there is an arbitrary component to the formulation.

Bit loading is produced by the following formula:

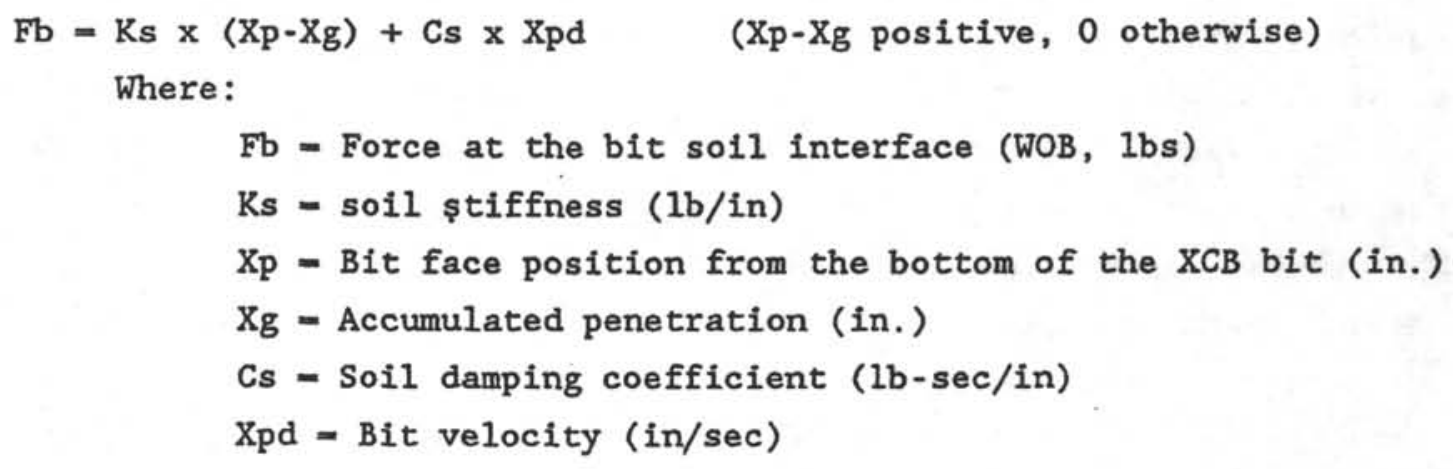

Note that $\mathrm{Xp}, \mathrm{Xg}$ and $\mathrm{Xpd}$ are positive down. 
Since $\mathrm{Xg}$ is incrementally increased every time step as explained above, coring ahead is simulated. In other words, the effective base for the soil spring moves downward at the rate of penetration.

The damping (or velocity dependent) force is produced as a result of the product of the bit velocity and the damping coefficient. To allow the soil damping coefficient to be input on a relative basis, the program uses the moving mass of the core barrel and thrust assembly in combination with the soil stiffness to compute the critical damping coefficient for the spring mass system according to the following formula:

$$
\begin{aligned}
& \mathrm{Cd}=2 \times(\mathrm{Ks} \times \mathrm{M})^{3 / 2} \\
& \text { Where: } \\
& \text { Cd - Soil critical damping coefficient (lb-sec/in) } \\
& \mathrm{Ks}=\text { Soil Stiffness (lb/in) } \\
& \text { M - Total moving axial mass of core barrel / thrust } \\
& \text { assembly ( } \left.1 b-\sec ^{2} / i n\right)
\end{aligned}
$$

The soil specification included a relative damping coefficient. An input value of 2.0 , for example, would provide twice as much velocity dependent load as given by Cd, i.e. Cs $-2 \mathrm{x}$ Cd.

The tendency of the cored material to choke off bit flow is also known to be an important factor in coring performance. As in the bit loading and cutting formulation, no attempt was made to develop a theory of how this occurs. Survey of bit manufacturers revealed that a typical flow area for the size of bits used with the MDCB would be about $.15 \mathrm{sq}$. in. and a typical total width of all flow channels could be about $.75 \mathrm{in.,}$ indicating a channel depth of . $2^{\prime \prime}$. Note that a differential position of the bit face and the soil penetration $(\mathrm{Xp}-\mathrm{Xg}$ ) is used above to compute soil spring load. The simple assumption was made that this value subtracted from the flow channel depth to choke off bit flow area. For example, if the total flow area of the bit was .15 sq. in., and the channel depth was .2", then an instantaneous value of $(\mathrm{Xp}-\mathrm{Xg})-.1 "$, would result in an instantaneous bit face flow area of half the $.15 \mathrm{sq}$. in., or $.075 \mathrm{sq}$. in. It is easy to see that stiff soil would have less clogging tendency than soft soil under this 
formulation. Therefore, a relative bit clogging coefficient is input to reduce or increase the clogging tendency of any given soil. For example, a clogging coefficient of .1 would only use $.1 \mathrm{x}$ ( $\mathrm{Xp}-\mathrm{Xg}$ ) in computing a reduced bit face flow area.

When the analysis software was constructed and run, one unanticipated result of this formulation was that, in soft soils, the flow area would choke off to the point that the internal pressure (and resulting pumpoff force) in the core barrel would increase to the level that all down thrust load was exactly equilibriated by the pumpoff force. The effective WOB would reduce to zero, and coring ahead would come to an absolute halt. The program would reach a stagnant equilibrium stage as the coring bit would become a virtual hydrodynamic bearing. What was clearly missing was a mechanism to allow high internal core barrel pressure to "wash away" material clogging the flow channels. To formulate a way to simulate washing, a baseline was arbitrarily assumed that supposed that bit flow at 500 psi differential at 30 gallons per minute would remove the clogging material at the volume rate of one cubic inch per second. As with the other variable soil factors, this baseline could be factored for any given soil by inputting a relative "washout coefficient", Cw. For example, a Cw - 10 would specify that the soil washed out at 10 times the baseline rate. The amount of material removed is an integrated value that is subtracted from the amount of soil clogging the bit until such time as the flow area is restored to the full flow area of the bit. Further, the integrated value of material washed away is reset to zero at each new soil condition, otherwise only one clogging event per run would be simulated. As each new soil is encountered, this formulation frequently leads to $a$ initial high bit feed pressure that exponentially decreases with time to some lower limit.

Implicit in the factors composing the soil modeling scheme discussed to this point is that the soil is homogeneous and "smooth". In reality we know this is not true and that frequently the soil may be inconsistently composed with hard materials interspersed with soft materials. The practical investigation necessary as related to the analysis of the MDCB is to determine if there may be any loading frequencies that amplify to produce a destructive effect on the tool or coring performance. The method chosen to 
model soil inconsistency was to input a alternating load magnitude and frequency that would sum with the WOB, as shown above. The loading was applied to the bit in the form of a sinusoidal variation peaking at the specified load. The input frequency for this loading was on a per revolution basis, as opposed to an absolute frequency. For example, an input frequency of 6.0 would provide six load cycles per revolution of the bit, while .1 would provide one load cycle every ten revolutions.

The methods used in the soils model have been explained. Since it is clear that the methods are based on an intuitive approach, and that specific values for any given type of sediment were not produced, the model was formulated so that a entire spectrum of all the factors cited could be tested by "scanning" across parameter ranges for each of the parameters without pre-judging what type of sediment was being simulated. This. was physically executed by constructing computer files that listed each coefficient value to be simulated for a given soil condition. During initialization of a simulation run, the time domain analysis software "MDCBTIME.EXE", would read in the name of the soils file, the soil numbers to use in the file, and the penetration depth to the bottom of that soil specification from the run configuration file "MDCBGFG.DAT". The program would then open the listed soils file and load all the input parameters for the soils in the specified sequence into data arrays, (25 soils maximum). During coring simulation, a strata of soils could be simulated since the program would check at the start of each time step iteration to determine if the current soil bottom had been cored through. If this check was positive, the program would change all coefficients to the next set of soil coefficients.

To reiterate, the configuration file "MDCBCFG.DAT" specifies:

1. The name of the file containing soil parameters

2. The numbers of the soils in the file to use

3. The penetration elevation to the bottom of each soil input

4. The sequence in which the soils were to be used

and,

The named soils file has one line to describe each soil condition, composed of nine fields, they are: 
1. The soil number in the file

2. The soil stiffness in $1 \mathrm{bs} /$ in

3. Soil damping as ratio of critical

4. Static friction coefficient

5. Soil washout coefficient, relative to baseline

6. Soil cutting coefficient, relative to baseline

7. Soil clogging tendency, relative to flow channel penetration

8. Impulse loading magnitude on bit

9. Impulse loading frequency, per bit revolution

The ranges of tested parameters during the entire MDCB analysis were:

1. Soil stiffness: $2,500 \mathrm{lb} /$ in to $250,000 \mathrm{lb} / \mathrm{in}$

2. Soil damping: .1 to 4

3. Static friction coefficient: .4 to 3

4. Soil washout coefficient: .2 to 2

5. Soil cutting coefficient: .01 to 1

6. Soil clogging tendency: 0 to 50

7. Impulse loading magnitude: 0 to $2000 \mathrm{Ib}$

8. Impulse frequency: .1 to 6 times per revolution

The time domain analysis software writes the key result values to a file as frequently as specified by the user. If the user has requested plotting, the time domain software "MDCBTIME.EXE" automatically passes control to another program "MDCBPLOT. EXE" upon termination. "MDCBPLOT.EXE" reads in the numerical data and displays the maximum and minimum values of each data field and prompts the user for the desired plotting range for each parameter and further produces an Autocad script file. After completion of "MDCBPLOT", the user may convert the script file into an Autocad drawing and display the graphical output to the screen (in the Autocad environment) by simply typing "PLOT". The normal Autocad commands may then be used to edit or save the plot drawing as desired.

Appendix $F$ shows more specific detail on the soils files, and the physical operation of the time domain software. Also, Appendix F provides a detailed the interpretation of the graphical output for one test case and further shows the graphical output for a variety of cases. 
Appendix E provides a listing of the source code for the time domain model.

\subsection{CONGLUSIONS OF THE ANALYSIS}

Due to a significant delay in receipt of motor performance data for the "Drainhole" motor from Christensen, most of the modeling was performed using the standard Mach-1 motor. The tool configuration at that time included a centrifugal valve to create a hydraulic lock in the lower cylinder below a rotational speed that would open the valve. The original purpose of the valve was to lock the core barrel in its final position once coring had been halted to provide an indication of total penetration achieved. However, once the valve was modeled, it became clear that the valve was a very effective anti-stall device since decreasing motor speed would shut the valve and prevent core barrel advance until enough material had been cored to allow motor speed to be restored. This also resulted in a continuous drift in motor speed and load above soil friction coefficients of about 1.5. However, once the powerful Mach-1P ("Drainhole") motor was simulated, this performance was not observed except during motor start-up prior to establishment of full flow down hole. Also, the model predicted much improved penetration rates when using the more powerful motor. Finally, the centrifugal valve idea was abandoned entirely. The reasons were that (1) the valve had to be totally packaged in a $3^{\prime \prime}$ O.D. $x 2^{\prime \prime}$ I.D. annulus, activation loads available were quite small in comparison with the sealed pressures, (3) any source of leakage in the lower cylinder section would defeat the function of the valve, (4) the valve would have to be an intricate design deemed too sensitive for the service and anticipated contamination levels, and (5) the "Drainhole" motor has sufficient power to maintain rotary speed in the most severe conditions modeled. The core barrel locking feature was ultimately provided in the locking piston, described previously.

In general, the model predicted that the tool responded to severe transients effectively and no great surprises were noted. The transient analysis also showed that at extremely high WOB related torque loads, the 
drill motors did not stall in the conventional sense of total "lock-up", rather, arresting motor rotation causes a decrease in flow to the thruster nozzles and thus loss of WOB, and an increase in motor feed pressure which results in the motor re-starting. This cycle will repeat for as long as the soil conditions and pump flow exists. Also shown clearly in the analysis is the fact that one can know very little about the transient coring conditions by monitoring surface pump pressure. Surface pressure fluctuations lag tool loading and only an indication of overall torque loading is possible. Rapid transients are completely filtered. Sine wave shaped pressure variations in the six to 12 second period range are a result of ship heave and are not indications of $\mathrm{MDCB}$ status.

The time domain analysis verified that the MDCB has all the proper feedback tendencies. WOB naturally decreases at high torque values due to diversion of flow from the thrust circuit and due to kelly friction. The analysis showed that stall of the "Drainhole" motor will require virtually inconceivable soil friction coefficients of greater than 3.0. With regard to clogging conditions, clogging will cause a rapid decrease in WOB and rapid increase in pressure inside the bit face. A bit flow reduction of approximately 25\% will result in total loss of WOB and thus it is not possible to arrest bit flow.

Further, the time domain analysis did not indicate any resonance problems associated with torsional vibrations of the kelly or resulting from bit impulse loadings.

Appendix F are some selected results of the time domain analysis that demonstrate the stated performance.

\subsection{OBSERVATIONS AND COMMIENTARY}

An extreme amount of effort has been expended in analyzing the new MDCB under $a$ wide variety of difficult coring conditions. The analysis has predicted that this tool should operate successfully. 
A perceived "weak link" in this effort remains. The analyses only treated motor torque resulting from WOB applied to the bit by the tool and internal tool friction. Other possible torque sources could exist from lateral core barrel loading as caused by hole collapse, crooked hole trajectory, motion of the BHA during coring, etc. Significant loadings caused by these potential sources cannot be compensated for in the tool design and will require study of the core barrel itself and deployment procedures. Providing that the tool mechanisms are tested to function as intended, any future motor over-load related difficulties will probably be attributable to lateral effects as mentioned above.

With regard to testing, the following tests are recommended prior to coring deployment:

A. Testing of the locking piston assembly in a test fixture that will allow top-side pressurization through a removable closure and provide for a pull down and push-up piston loading. Fully test locking function, the manual defeat function, and un-locking function. The test sub should be composed of a short cylinder section (18" or less). identically finished and coated to the thruster cylinder.

B. On deck flow testing of the tool, BHA assembly, with no torque load using the basic settings to measure pressure drop, un-latching function, stroke rate, locking piston function, motor rpm (strobe. of core barrel suggested), and end of stroke indicator function. This test should be followed by removal of the MDCB and setting down against core barrel (or $Q / R$ sub) to test retraction of the core barrel. Note that this test will require manual filling of the lower thruster cylinder prior to mounting tool in the BHA.

C. Repeat of test described in B. with BHA suspended above the sea floor. Halt circulation and retrieve tool at a time known to be prior to full stroke. Check that core barrel is locked and has stroked out at a rate approximately the same as determined in Test B. (above) Apply a tension of approximately 5,000 1bs. to the core barrel to test locking function. Re-check core barrel retraction function by supporting tool weight on core barrel. 
D. Repeat test C. allowing circulation until end of stroke is indicated and note times and pressures. Retrieve tool to inspect for proper spool valve reset.

Note that test $D$ may not be allowable due to core barrel whirl, unless a guide fixture is used to control lateral motion of the core barrel.

For future reference, Appendix $G$ documents the key motor performance algorithms and the bit friction algorithm underlying this work. 
Appendix G

MDCB: MDB-134 Final Report 


\title{
MDCB-134 Final Report
}

\section{MOTOR DRIVEN CORE BARREL}

\author{
D. HUEY, LEG 134, DECEMBER 1990
}

\section{INTRODUCTION}

The MDCB-134 is the third generation of the developmental coring system previously known as the Navidrill core barrel (NCB, NCB2). It is a freefall-deployable, self-contained, motorized coring tool capable of cutting a core using mining-type, thinkerf diamond coring action. It is designed to be compatible with the APC, XCB, and PCS coring systems and utilize the same bottomhole assembly. It will recover up to a $4.5 \mathrm{~m}$ long core.

The design of the new MDCB was achieved by way of an extensive computer model analysis. Based on empirically derived data from (and observed shortcomings of) the NCB2, a fully theoretical analysis of various candidate improved designs was performed. The best design was then hydraulically modeled for computer simulation of all possible downhole coring conditions. Special attention was paid to make the new design hydrodynamically stable in all potential environments. A superlative Summary Report on MDCB Engineering Development was produced by Stress Engineering Services detailing how this was all done. The report also has some general advice on how to best use the MDCB and some of its sub-systems. A reference copy was left aboard the ship.

The biggest change in the design, as compared to the NCB2, was the repositioning of the motor and thruster sections. The motor in the NCB2 was immediately above the core barrel section and was allowed to move down as the core barrel advanced. This system made motor pressure drop, which was variable, a part of the thrust pressure which created weight on bit. The resulting undesirable positive feedback almost always caused the motor to stall when fough coring conditions were encountered.

The MDCB-134 has the thruster section between the motor and the core barrel. The motor is on top and sits firmly on the landing shoulder in the seal bore saver sub; 
its variable pressure drop is not felt as part of the WOB thrust. The flow down the pipe is allowed to flow both through the motor (about $85 \%$ ) and around the motor (about $15 \%$ ). The portion passing through the motor creates both torque and weight on bit. The portion of the flow allowed to pass around the motor goes exclusively to the diamond bit at the end of the core barrel. This arrangement leads to negative pressure feedback which keeps the system from stalling when coring conditions get difficult.

The motor used is a 3-3/4" Eastman-Christensen Mach 1P "drainhole technology" Navidrill positive displacement mudmotor. It was bench tested by the manufacturer prior to delivery. Those data were then used to construct a reasonably accurate hydraulic computer model for addition to the overall MDCB computer simulation. The Mach IP motor produces a better combination of torque and rpm than any motor previously available in this size range. Because it has much more torque potential than the motors used with NCB2 it produces a more stable output with minimum rpm variation even when the formation changes suddenly. It is left in its normally oversize O.D. (up to about $\mathbf{3 . 8 2}$ inches) because it does not enter the restricted, 3.800 I.D. of the seal bore drill collar.

At the start of Leg 134 the motor was on rental from Eastman-Christensen. That rental agreement was extended to include MDCB work scheduled for Legs 135 and 136. Rental includes daily charges plus circulating hour charges. Total circulating time at the end of Leg 134 was 2.1 hrs.

There have been many design changes to make the MDCB easier to operate. Assembly simplification is one improvement. Ease of changing nozzles is another nice feature. There are four nozzles: two swivel nozzles to control flow to the diamond bit, and two thruster nozzles in the nozzle sub which determine WOB. All four can be changed from the outside of the tool without any disassembly. Also, there are no dynamic external seals, so seal replacement is less frequent.

The other big change in the design since NCB2 is in the torque reaction/latch/release/shock absorber systems. The shock system has been deleted. The fussy little ball release system has been replaced with an external collet latch. The spring-loaded, hinging torque segments have been replaced by the robust dogs of a conventional XCB latch and relocated to the top of the mudmotor. The old NCB latch sub (outer barrel component) is used with the XCB latch and is relocated to a position 13 feet above the standard outer core barrel, BHA components.

There are no pre-loaded springs to control the release mechanism. The tendency to lunge into the formation after latch (collet) release has been throttled with a damping chamber that is automatically filled with seawater inside the pipe when the tool is.dropped. The damping chamber is the annulus between the hex kelly and the thruster barrel, below the thruster piston assembly and above the hex seals in the 
latch sub. When the thruster piston and kelly try to move down, the fiuid in the annular damping chamber must be expelled. If the check valves (in the piston assembly and the check off sub) and hex seals don't leak the only path for the fluid to escape is through a 1/32 inch orifice in a set screw in the piston assembly. This can only happen slowly so the core barrel cannot lunge ahead rapidly - either at the moment of latch release or when the diamond bit breaks through a firm formation into a soft one. Some leakage in the seals is even tolerable. During deck tests on Leg 134 the slow motion advance of the core barrel after collet release was visually observed and verified.

There are two other sub-systems new to the MDCB design: the end-of-stroke indicator and the thruster brake for total penetration indication. Neither of these systems was successful in the limited trials during Leg 134. The end-of-stroke (EOS) system is triggered by the thruster piston when it pulls down the flow tube at the physical end of the stroke. This, in turn, changes the flow path through the internal passages in the swivel forcing the EOS shuttle to move down. At that point a large pressure drop (800-1200 psi) is expected to be seen on deck as the motor flow is allowed to bypass the motor. (The EOS system never worked during Leg 134 for unknown reasons.)

The thruster piston is a complex assembly which is designed to act as a normal piston when pressure is moving the piston and thruster down, and to act as a brake when pressure is removed and the thruster assembly is pulled down by formation drag during retrieval. The brake bands tested on Leg 134 could not develop the minimum required friction to activate the clever brake mechanism, so the brake feature did not function. The braking portion of the piston mechanism can be locked out with a special nut. This will be the normal mode of operation until the piston/brake assembly can be tested and perfected on shore.

The standard APC/XCB bottom hole assembly must be expanded by three new elements: two subs making up 13 feet of spacer to account for the motor length, and the MDCB latch sub with its internal slots for engaging the XCB latch dogs. The latch sub is non-magnetic, above it is the normal 30 -ft non-magnetic drill collar. Thus, the 43-ft non-magnetic zone for the Multishot camera is located 13-ft higher than normal. The sinker bar used for the oriented piston cores must include an extra 13-ft of steel extenders. This addition was made during Leg 134 and only caused minor rig floor handling inconveniences while doing oriented APC work. A special extender assembly was put together to make the changeover fairly easy when MDCB operations are planned. The only significant drawback is the requirement to realign the sinker bar/pressure case assembly whenever the extender bars are inserted or removed. The various pressure case arrangements are shown in a sketch in the appendix.

The MDCB was deployed for three coring runs on Leg 134. The hardware was left aboard for further testing and use on Legs 135 and 136. 


\section{SUMMARY OF LEG 134 DEPLOYMENTS}

Only three downhole deployments with the MDCB were attempted during the leg, primarily due to the fact that XCB coring was terminated long before depths were reached where lithified sediments suitable for diamond coring were encountered. At Hole 828A the MDCB experimentation was stopped after two cores when marginal recovery and slow penetration rate led to a desire to make an immediate change to the RCB coring mode.

At Hole $831 \mathrm{~A}$ a classic, coral limestone sequence offered a rare opportunity to attempt diamond coring in a formation which is generally unrecoverable by conventional coring techniques. Only one MDCB core was attempted, however, after it was discovered that the formation would not allow the placement of adequate weight on bit to produce BHA reaction weight. Two XCB cores were attempted after the single MDCB deployment but netted zero recovery. ХCB coring was terminated long before the hole was deepened to a point where MDCB coring may have been more productive.

\section{HOLE 828A}

Formation:

A foram 00ze APC sequence ended with indications of unexpected hard strata impossible to penetrate with the piston corer. Two XCB cores detected hard material but recovered only $0.36 \mathrm{~m}$ each. Core $14 \mathrm{~N}$ started at $97.4 \mathrm{~m}$ bsf.

\section{CORE 14N --}

Bit: Slightly used, piloted, surface set, face discharge

Reaming Shell: New

CC: Dog Type

Liner: Polycarbonate

Freefall deployment, no problems with MDCB. A carbide ball in the LFV assembly was later found chipped and had to be retired.

Coring Time: 14 minutes at satisfactory coring pressures before a rapid $1000 \mathrm{psi}$ pressure drop indicated core block.

Results: $0.24 \mathrm{~m}$ core was recovered with $0.8-1.0 \mathrm{~m}$ apparent core barrel penetration beyond the roller cone bit. A piece of core was moderately jammed in the core catcher and slightly in the plastic liner. The material was volcanic hard rock but very rotten, low strength and pre-fractured. 
Comments: Operating pressures were within about $250 \mathrm{psi}$ of calculated values prior to the core block. WOB would have been about $5 \mathrm{k}$ with the nozzle combination used. Flow to diamond bit at about $36 \mathrm{gpm}$. The core jam indication was probably valid. Handling and deployment of the tool was no worse than the APC with magnetic orientation.

\section{CORE 15N -}

Bit: New geoset, face discharge

Reaming Shell: Same, re-run

CC: Same, re-run

Liner: None (deleted to reduce core jam potential).

Coring Time: 65 minutes with adequate coring pressures, but little definitive pressure variation. No evidence of jam, stall or end-of-stroke.

Results: $1.85 \mathrm{~m}$ core was recovered with an apparent $3.5 \mathrm{~m}$ of penetration beyond the roller cone bit (based on wear of the core barrel O.D.) The core was handfuls of broken, rotten lava material with only very slight evidence of soft matrix. Five or six pieces were well trimmed about $8-12 \mathrm{~cm}$ long. Many of the smaller sized pieces showed surfaces that were obviously diamond trimmed. The rock was so rotten that several pieces broke up when split by hand on the saw.

Comments: The same WOB and diamond bit flow rate were used. In general $15 \mathrm{~N}$ could be considered a pretty good run in unappetizing rock. Neither the XCB nor the RCB was able to recover the equivalent section. Fifty percent recovery and tiny traces of soil/sediment suggested that a soft matrix may have been present but was not recovered (this is similar to the results in basalt/clay ITE tests with the geoset bits).

Mechanical problems, $14 \mathrm{~N}$ and $15 \mathrm{~N}$ :

End-of-stroke indication was not induced at pullout on either run as it should have been. Later disassembly revealed the EOS shuttle was jammed in the swivel due to a fabrication concentricity error. A minor fix was required. The thruster assembly lacked about $1 / 4$ inch of being able to fully scope together and relatch. An undiagnosed internal interference was occurring. Lack of proper initial latching probably allowed the barrel to advance as soon as the tool landed which may have contributed to the first core jam. The $3 \mathrm{~m} / \mathrm{hr}$ average rate of penetration on core $15 \mathrm{~N}$ was unimpressive but, in general, give the MDCB a B-plus for its first downhole trials. 
HOLE 831A

Formation:

Core $13 \mathrm{~N}$ was attempted at $87 \mathrm{~m}$ bsf in a classic coral limestone sequence after several XCB cores had garnered only minimal recovery (ave. $0.23 \mathrm{~m}$ each).

\section{CORE 13N -}

Bit: Used surface set, piloted, face discharge

Reaming Shell: Re-run

CC: Dog type

Liner: Polycarbonate

Coring Time: 40 minutes

WOB: About $6000 \mathrm{lbs}$

Results: Recovered about 5 inches of soft coral chalk slightly jammed in the core catcher. The core barrel was well polished over its lower $2 \mathrm{~m}$ indicating partial penetration beyond the roller cone bit. The diamond bit did not have clogged face discharge jets but all waterway/jets were cracked through the thickness of the crown. There was no other unusual wear on the bit.

Comments: Further MDCB deployments were canceled due to the inability to hold the BHA motionless in the vertical direction. Even with zero rpm on the drill pipe the BHA advanced downhole at 6-10 $\mathrm{m} / \mathrm{hr}$ as $10 \mathrm{k}$ WOB and the flow through the system continued to make hole. The poor MDCB core was followed with two XCB cores using extended (not fully retractable) cutting shoe assemblies (one with a finger core catcher, one with flapper core catcher). Neither core barrel had any core recovery.

Mechanical problems: The MDCB apparently functioned as designed mechanically with two exceptions:

1) locking feature of thruster piston was shop tested and does not work with available brake materials. It was disabled for this deployment.

2) The end of stroke feature did not successfully activate despite mechanical inducement at pullout. This feature is looks good on paper but remains to be proven under true field conditions. It can and should be tested at a shore-based facility separately, along with thruster piston brake and hex seals.

All other problems from previous runs were eliminated. Disassembly inspection revealed no damage to working elements. 


\section{DECK TESTS}

The MDCB had been rushed through fabrication at seven different machine shops in Texas and delivered to the vessel without the benefit of assembly checks or any form of testing. The initial assembly at the start of the leg went very well and stilled many fears. In order to test the MDCB in actual drilling a deck test was conducted during the presite survey prior to the first site. A pallet of sack concrete was mixed into one and one-half $55 \mathrm{gal}$ drums. The concrete was allowed to set for about four days. The MDCB BHA was then assembled and suspended from the top drive. The MDCB damping chamber was filled with drill water and the tool was inserted in the BHA.

With the roller cone bit firmly on the concrete in the drum at the rig floor a worn impregnated diamond bit was allowed to core for eight minutes. It penetrated only about 8 inches. A surface set diamond bit was installed and cored three times through the concrete with relative ease although penetration rates were not as high as anticipated. At one point the roller cone bit was suspended about two feet above the drum as the coring action for a new hole was initiated. The observers were able to watch the diamond bit begin rotation and then advance slowly and smoothly into the top of the concrete with no evidence of lunge.

The first clue to the internal interference problem occurred when the final $3 / 8$ inch of mechanical re-latch could not be achieved. Also, standpipe pressures were about 1800 psi higher than computer prediction (2735 psi actual vs 900 psi predicted) for the nozzles and flow rates employed. The improper pressures led to incorrect weight on bit. The Martin-Decker weight indicator did not clearly show the $2000 \mathrm{lb}$ weight on bit as expected. The main nitroxile polypak seal on the motor output shaft was later found burned up from friction, most likely as a by-product of the high back pressures.

Disassembly of the tool after the deck test revealed probable causes for all of the problems observed. Incompletely drilled holes in the swivel main fluid passages were found and probably caused excess pressures plus low weight on bit. Both hex kellys were found to be tapered (about 0.040" in the worst case). The female splines (properly made) would only fit on one end of one kelly. Luckily that was the end used in the short-stroke deck test. The inside hex of one spline was enlarged via some ingenious machining by the rig mechanics.

It is probable that the net weight on bit during the deck test was considerably less than $2000 \mathrm{lbs}$, explaining why the bits had a pretty tough time getting through the cement and loose aggregate which should have been easy drilling. 


\section{INITIAL ASSEMBLY, MAINTENANCE AND FIELD MODIFICATIONS}

\section{INITIAL ASSEMBLY}

The initial MDCB assembly and check out went more smoothly than is the norm with prototype tools. Only minor fit problems were encountered. (This is probably a testament to the benefits of Autocad design and drafting). Although the logistics of manufacturing and delivering all of the parts was quite a bit more unwieldy than usual, the only parts missing from the various shipments were: one latch X/O sub (OP8088), and two packing nuts (OP8024). It was later determined that all three of these parts had been made and delivered to ODP in time but had been mislaid during the packing process. A temporary replacement packing nut was made in the ship's machine shop complete with left hand, stub acme threads. It was used during the leg with no problems.

\section{MAINTENANCE AND FIELD MODS}

After the deck tests and each of the two deployment sites the MDCB subassemblies were taken apart and inspected for unusual wear. A few problems were discovered at assembly; a number of problems which had not been discovered during initial assembly were observed and fixed after the deck test or downhole runs. The list of mods and fixes is as follows:

\section{Control orifice set screws, OP8069}

The set screws in the thruster piston which contain the 1/32" hole for controlled damping fluid flow were found to be too long and stuck out beyond the O.D. of the piston body. They were shortened and later exchanged for a stainless steel set screw when the tiny hole began to show signs of clogging due to its own corrosion products.

\section{Thruster piston T-seals}

The I.D. T-seals delivered were an incorrect type and were immediately replaced by equivalent sized o-rings. The twin O.D. T-seals were found after the deck tests to have dislodged their hard back-up rings and suffered roll damage. Several small pieces of the broken back-up rings were found in the thruster barrel. The Tseals were ultimately replaced with equivalent sized o-rings. No problems were observed with the o-rings in later deployments. 


\section{3. "Rulon" Bearings}

The Rulon, teflon tape bearing made for the swivel assembly performed admirably in all of the deployments. The bearing made for the thruster piston was omitted, however, when it proved nearly impossible to assemble along with the piston in the thruster barrel. Special installation fixturing would have been required. It was determined that the piston's o-ring seals and Xylan coating were sufficient to centralize and reduce friction. This proved to be true, at least for the limited deployments on the leg.

\section{Swivel flow passages}

The two, gun drilled, 1/2" flow holes in both swivels were found to be pinched to less than $1 / 4^{\prime \prime}$ useful diameter at the point where they broke out of the body. This restriction was the cause of the excessively high standpipe pressures observed during the deck test. The holes on both units were enlarged at the break-thru points to eliminate the extra, unnecessary pressure drop.

\section{Brake band tests}

A special section of tubing was brought along to shop test the thruster piston braking system. The tubing was the same internal size as the thruster barrels and had an identically prepared, slightly roughened, nickel plated interior surface. Several types of high-friction, carbide chip coated, brake bands were included. None of the brake bands were able to provide the minimum coefficient of friction $(0.42)$ to activate the $20^{\circ}$ wedge-shaped locking mechanism, even with the equipment in dry air. Frictional coefficients with the equipment in water expected to be were lower. Each brake band was able to hold the piston until about $200 \mathrm{lbs}$ of pull was applied. At that point the assembly was able to move smoothly inside the tubing leaving only minor scratches. The wedging/locking action of the thruster piston assembly was never initiated. The thruster pistons were assembled in the "locked-out" condition (no braking action possible) for all three downhole deployments.

\section{Hex seals, trimming and installation}

Both nitrile and urethane, die cut, hex seals were included as options for sealing around the hex kelly but only the nitrile seals were used. They had to be hand trimmed to produce the specified cross-sectional shape after very rough die cutting. Three hex seals were installed sandwiched with four delrin hex spacers in the latch sub seal cavity. To achieve the correct amount of squeeze on the seals (at least the correct amount if original hex seal assumptions were true) required the addition of some stainless hex shims. The axial clearance inside the seal cavity with the seals relaxed (not forced over the kelly) was found to be $0.115^{n}$. It was calculated that the

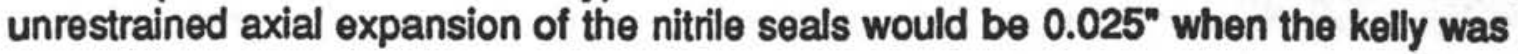


introduced. The remaining axial void space was occupied by the shims so that the seal could not relieve either the I.D. or O.D. rubber squeeze when fluid pressure occurred. The hex seals were induced to be leak free under pressure by giving them nowhere else to go. Thus, a $1 / 16^{\prime \prime}$ and $1 / 32^{\prime \prime}$ shim was added to fill the $0.090^{\prime \prime}$ axial gap. This arrangement appeared to work perfectly in the three deployments plus the deck test. No leakage at the hex seals was observed. The seal pack was inspected between runs but did not require replacement.

\section{Flow tube centralizer, OP8046}

A design misfit between the centralizer and the top of the flow tube was corrected by enlarging the inside diameter of the centralizer at the o-ring gland.

\section{Packing nut, OP8024}

Both packing nuts missed the shipment. A very adequate replacement was made by the rig mechanic.

\section{Thruster assembly: Internal length interference}

After the deck tests it was evident that the hex kelly could not be scoped back into the thruster barrel far enough to fully latch the latch sub collet. When inspected in the shop after the tests the collet was fully latchable without signs of a problem. After a repeat of the incident following the first downhole deployment a serious internal interference was discovered. The lengths of the various components allowed the top of the thruster piston assembly to contact the centralizer before the latch collet could engage completely. The root problem was that the thruster barrel was incorrectly depicted on the assembly drawing so that clearance appeared where there was none. In addition to the relatch problem, the inaccurate stack up length would not allow the end-of-stroke action to occur, either. The thruster piston would complete its stroke by contacting the pin of the check off sub before the piston reached the flow tube stop.

To alleviate these problems the centralizer was machined back in a stepped fashion so no interference could occur. A temporary, thin-walled sleeve was added between the thruster piston and the flow tube stop to activate the end-of-stroke signal (pulling down the flow tube against its support piston.)

\section{Hex kellys}

The most serious mechanical/fabrication problem was improper manufacture of both hex kellys. The distance across the flats on the kellys were carefully measured. Both were found to be tapered as much as $0.040^{\prime \prime}$ from one end to the other. The low clearance female splines, which were made correctly, would slide freely over only one end of one of the kellys. Since the kellys were over 16 feet long and teflon coated it 
was not possible to re-machine them on the ship. Instead, one female spline was laboriously enlarged until it would slide freely on both kellys.

\section{Extra spares} the leg.

The following additional spare parts for MDCB work were ordered at the end of
10 ea.
No. 2-226
O-rings, buna 70
20 ea.
No. 2-334
O-rings, buna 70
10 ea.
No. 2-325
O-rings, buna 70

2 ea. OP8024 Packing nuts

1 ea. OP8088 Latch $\times / 0$ sub

$12 \mathrm{Ea}$ OP8091 Tool steel nozzles

(4 eа. $3 / 32,4 / 32,5 / 32$ )

2 ea. OP8067 Retainer nuts

(17-4PH or 15-5PH annealed

instead of mild steel)

1 ea. OP8086 Female spline

(with hex WAF $=2.310 / 2.330$ )

another three (3) copies of assembly Dwg. R-OP 8000

\section{CONCLUSIONS AND COMMENTS}

The limited deployments of the MDCB were sufficient to "wring out" the new design and highlight areas of needed improvement. The specific improvement items can be broken down into two categories: upgrades to the MDCB-134 design, and alterations to consider if and when an MDCB redesign is undertaken.

\section{MDCB-134 DESIGN UPGRADES}

1. The end-of-stroke indication system must be tested in lab simulation to verify that it can be expected to work under actual downhole conditions. The system did not function during Leg 134 deployments despite several overhauls to correct related mechanical problems. Ultimately, a reliable EOS system is necessary.

2. A positive indication of actual penetration for any core run is necessary. The thruster piston brake function was designed to provide this feature, but was not

$$
\therefore \text { : }
$$


successful in its original form. Either the brake system must be improved or another approach incorporated to provide reliable post-run indication of core barrel penetration.

3. For better motor upkeep a flushing sub is needed which can be put at the top of the motor allowing a $500+$ psi fresh water flush after deployment. The new sub would be temporarily installed in place of the motor X/O sub (OP8020) with a crossover to a $2^{\prime \prime}, 10,000$ psi hammer union so the rig pumps can be used to do the job with drill water.

4. Until a redesign is done some temporary on-deck handling aids are needed. A thread protector is required for the bottom of the swivel threads when the motor section is handled and stored separately. A lifting clamp sub is needed for the top of the thruster section since no natural clamp location currently exists there.

\section{FUTURE MDCB REDESIGN (IF AND WHEN)}

1. A quick release-type break point located between the thruster and motor sections would be a significant improvement. It would need to be compact and simple to engage/disengage on deck while being strong enough to handle full coring torque plus random impact loads. Such a design change should also include adding the appropriate clamp point near the top of the thruster section.

2. A location to engage a C-plate for freefall drop release should be added to the top of the motor section immediately below the uppermost handling clamp location.

3. Since core blocks still may tend to dominate MDCB coring results in the future it would be a natural extension of the current MDCB design to include a suitable vibration/impact Anti-jam system in the core barrel assembly. This is recommended only after the general value of the MDCB has been adequately demonstrated in ODP operations.

\section{MDCB PROJECT ENGINEER COMMENTS}

The potential success of MDCB coring within the larger picture of ODP coring operations is directly related to the versatility, success and acceptance of the XCB coring system. There is no persuasive evidence yet that the MDCB will be a boon to coring in formations of intermediate sedimentary lithification. If the MDCB is to find a valuable nitch in the overall ODP coring plan, it will be in coring fully lithified materials in a hole where XCB coring has reached its limit in a hard formation. The present state of the XCB coring system does not allow this set of circumstances to occur very often; part of the problem is mechanical, part geological, and part psychological. 
The attempt to devise XCB hard formation cutting shoes at a reasonable cost has not been particularly successful. A large part of that shortfall is related to the inability to force adequate flow to the XCB cutting shoe for cooling and cleaning. This inadequacy of the hard formation XCB shoes leads to severe core blocks, slow penetration rates, and occasional catastrophic cutting shoe failure in many commonly encountered lithologies. Those cases where XCB-corable sediments continue uninterrupted to a hard crystalline basement contact suitable for MDCB diamond coring have become quite rare since the ship has entered the Pacific. This lack of notable XCB coring success has not done anything to banish the notion, held by some individuals, that the XCB is "unreliable, high tech" coring equipment suitable for design engineers to play with, but is not "real oilfield" and therefore not to be used when the good, old RCB will do. Whether an accurate assessment or not this mind set exists.

The visionary plan to accomplish a bulk of the common ODP coring missions with a single hole (APC-to-XCB-to-MDCB) without a pipe round trip will only come to pass if the XCB system can be upgraded to fulfill its role.

In itself, the MDCB-134 design appears to be completely viable. All lingering mechanical problems apply only to bells and whistles, not primary functions. NCB2 fundamental problems of stall, lunge, galling, nuisance assembly, etc, have all been eliminated. This tool needs only a chance to find legitimate downhole assignments and the time for people to climb the learning curve and determine what it can and cannot do. Additional MDCB operations will help to determine best diamond WOB, optimum bit types, decline in system performance as parts rust and wear, mechanical weak points, best core catchers, most reliable deployment and operating techniques, and so on.

The difficulties stabilizing the BHA at Hole 831A highlighted a separate MDCB issue which will require future analysis. The BHA continued to advance while the MDCB was coring despite attempts to limit its motion. This problem invalidates many of the assumptions about which the MDCB is designed and leads to unpredictable performance, especially regarding diamond WOB and core jamming. The problem is not related to sea state. At least $10 \mathrm{kips}$ on the roller done bit must be maintained via the heave compensator even in calm seas just to react MDCB thrust (4-8 kips) and avoid lifting the BHA off the bottom of the hole where all lateral support to the spinning HWD4 core barrel would be lost. Rougher seas would exaggerate the problem. Medium soft lithologies may continue to be a real problem for the MDCB. This applies to chert- chalk intervals unless a given chert horizon is substantial enough to allow placing the XCB bit firmly and exactly on it without any further downward movement. Chert nodules in a soft chalk matrix would be very difficult to core under these conditions. 


\section{MDCB OPERATING PARAMETERS}

The MDCB mechanism, with its self-correcting pressure feedback and uncomplicated mechanical layout, has shown all early signs of being everything that was sought in the long-standing NCB/MDCB development program. The purely mechanical problems which plagued earlier designs have been eliminated. The MDCB is quite easy to operate. In the future it should be possible to achieve quality cores from formations where previous coring technologies have not been very productive. The key to successful operation of the MDCB is proper selection of weight on bit (WOB), bit flow, and type of diamond bit. To do this the various operators will require a period of trial and error learning to take best advantage of the MDCB's unique coring characteristics. To assist in this effort several operational learning aids were produced during Leg 134.

A nozzle selection computer program, "MDCBWOB", had been written as a subset of the MDCB hydraulic analysis. It allows theoretical change of nozzles, water depth, and pumped flow rate to see the effect on WOB, rpm, standpipe pressure, and bit flow. During Leg 134 "MDCBWOB" was run with each of the normal nozzle combinations and the results were plotted on three coring parameter charts for use on the rig floor during MDCB coring operations. These charts appear in the appendix at the end of this report and are included in an "MDCB Operator's Manual" which was written for future MDCB users who have not been intimate with the MDCB development details. The Operator's Manual Table of Contents is also included here for reference.

\section{ROUTINE MDCB OPERATIONS: SELECTING NOZZLES FOR WOB \& BIT FLOW}

STANDARD SET-UP: The calculations done on the computer model used to design the MDCB were based around a "Standard Operating Condition" as follows:

Swivel nozzles (bit flow) $=$
Thruster nozzles (WOB) $=$
Pump rate =
WOB =
Bit flow $=$

Swivel nozzles (bit flow) $=$ Pump rate = Bit flow = 
This set up is adequate for the initial MDCB runs at any hole. After that, bit changes or coring results are used to determine if changes are required to WOB or Bit flow. Trial and error plus the cumulative results of previous cores determine ongoing changes in nozzles and bit types.

MDCB OPERATING PARAMETER CHARTS: There are three charts, divided for convenience so that there is one chart for each of the common swivel nozzle possibilities: $3 / 3,3 / 4$, and $4 / 4$. All of the charts assume $3000 \mathrm{~m}$ water depth. Variation in water depth has only a small effect on standpipe pressures and no effect on other coring parameters. The Example chart shows how to use them. In general, a desired WOB is selected and a nozzle combination to produce that weight is determined for one swivel nozzle set (for fixed bit flow). For more or less bit flow the operator goes to one of the other two charts (with different swivel nozzle choices) and tries again.

Ideally the operating pressure range will vary between those indicated between torque factors 0.2 and 0.9. Steady higher pressures (500-700 psi) would indicate stall, steady lower pressures (200-500 psi lower) would indicate core block, a sudden drop to pressures 800-1200 psi lower than normal indicate end of stroke. The experiences during Leg 134 showed that the standpipe pressures were actually quite a bit higher (150-800 psi) than the parameter charts predicted. Even with unexpectedly high operating pressures the general trends are still valid: a big change up means stall, a big change down means end of stroke, etc.

\title{
OPERATOR'S MANUAL TABLE OF CONTENTS
}

\author{
INTRODUCTIONS/COMMENTS \\ OPERATING PROCEDURES AND PARAMETERS \\ Normal Operating Mode \\ Core Barrels, Bits \& Core Catchers \\ Core Barrels \\ Core Catchers \\ Bits \\ Impregnated bits \\ Surface set bits \\ Geoset bits \\ Special \\ Selecting Nozzles for WOB \& Bit Flow \\ Standard Set-up \\ MDCB Operating Parameter Charts \\ BHA REQUIREMENTS \\ SINKER BAR/PRESSURE CASE REQUIREMENTS \\ ASSEMBLY \\ Assembly of the Motor Section
}


Assembly of the Thruster Section

Hex Seal Pack

Thruster Piston Assembly

Check Valves

Assembly of the Core Barrel

HANDLING ON DECK

Deployment

Recovery

DISASSEMBLY

STORAGE

INVENTORY 

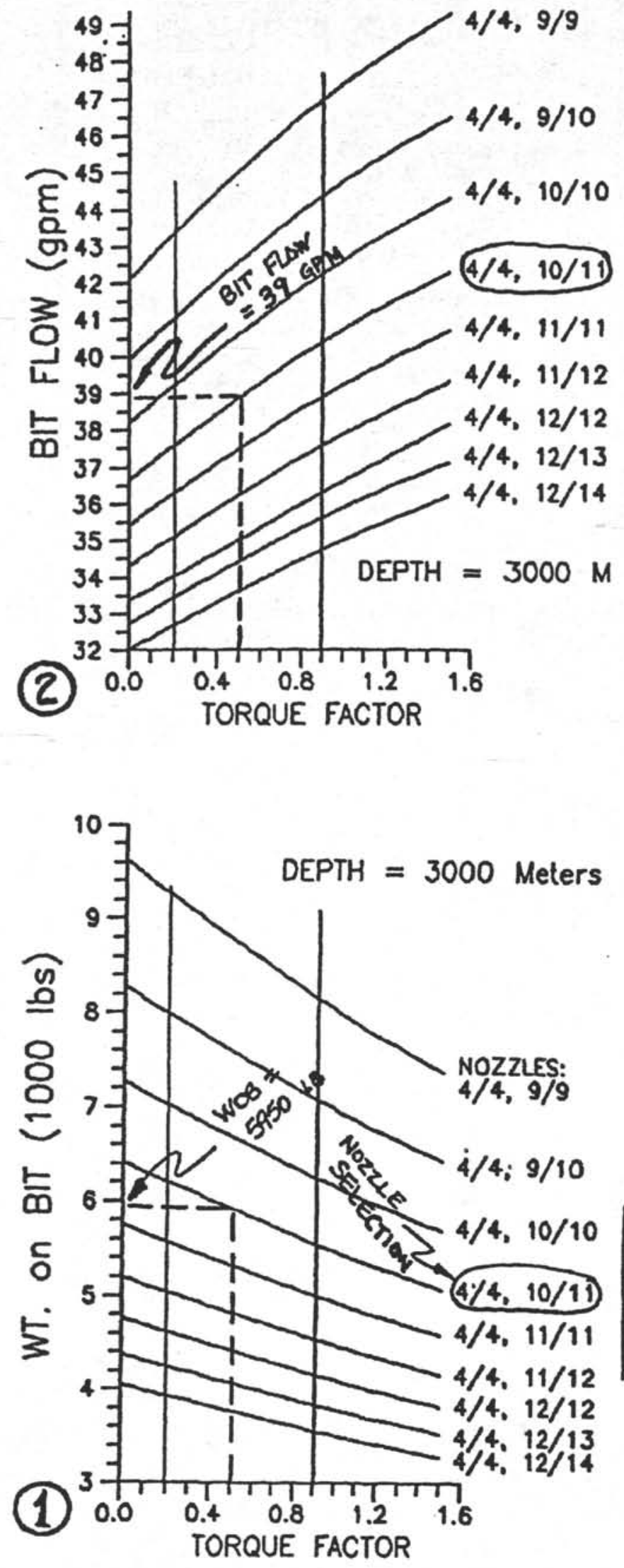

MDCB OPERATING PARAMETERS

SWIVEL NOZZLES: $4 / 4$

Depth $=3000$ m. Flow $=215 \mathrm{gpm}($ max.)

1. Se lect nozzle combination to achieve desired WOB on graph 11 . Assume torque factor $=0.5$. (Swive) nozzles determine flow to the diamond bit. thruster nozzles determine weight on diamond bit.)

2. Check graph 12 to see if the chosen nozzle combo will also produce the desired flow rate to the diamond bit. If not, go to another page with different swivel nozzle parameters.

3. If the nozzle combo is okay use graph $\$ 3$ to monitor standpipe pressures while the MDCB is running downhole.

4. Torque factors should nornally be between 0.2 and 0.9 when cor ing. Steady lower pressures indicate core block. Steady higher pressures indicate motor stall. End of stroke pressure $=800-900$ psi.

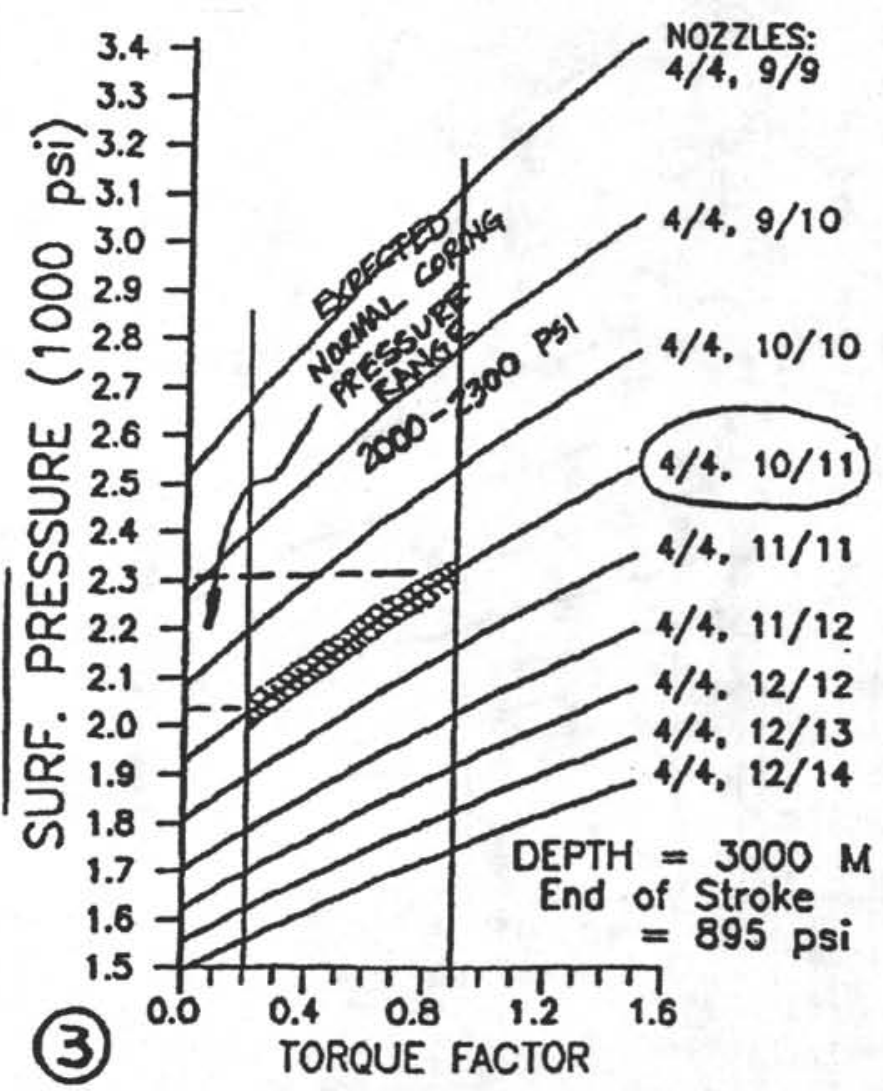



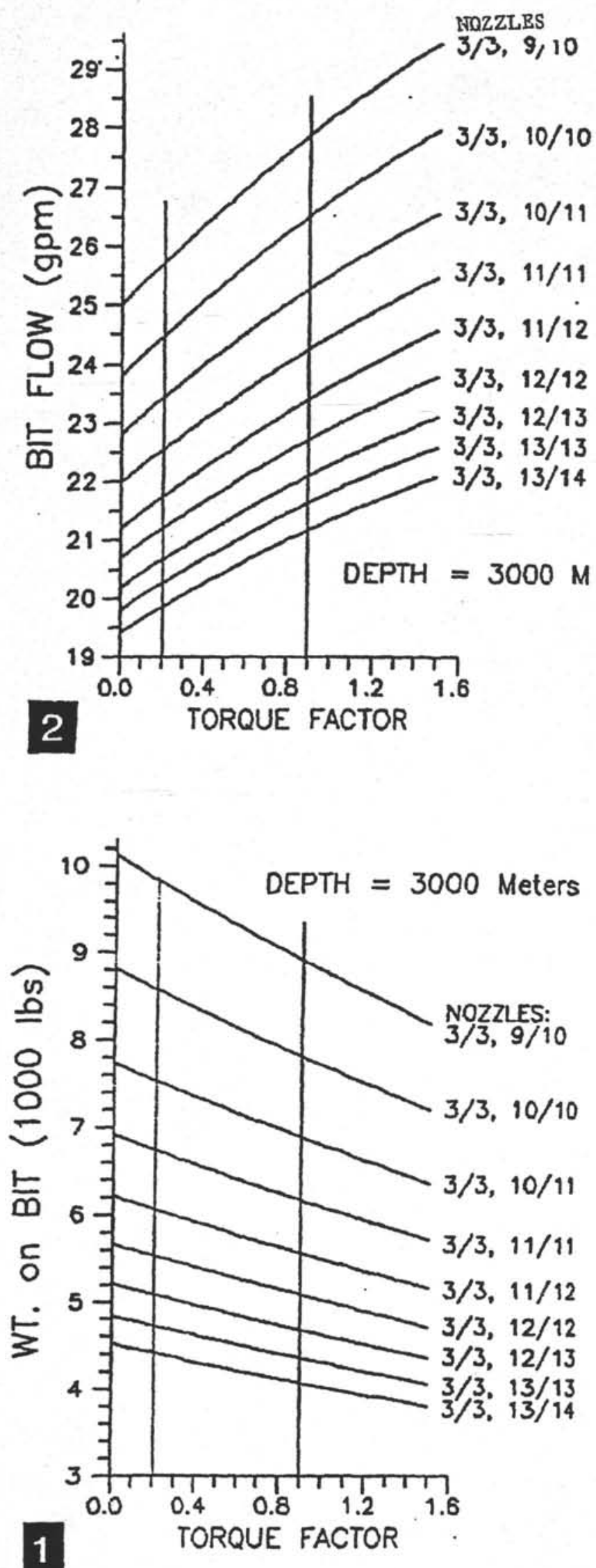

MDCB OPERATING PARAMETERS

SWIVEL NOZZLES: $3 / 3$

Depth $=3000 \mathrm{~m}$, F low $=215 \mathrm{gpm}(\max$.

1. Select nozzle combination to achieve desired WOB on graph 11 . Assume torque factor $=0.5$. (Swive) nozz ies determine flow to the diamond bit. thruster nozzles determine weight on diamond bit.l

2. Check graph $\$ 2$ to see if the chosen nozzle combo will also produce the desired flow rate to the diamond bit. If not. go to another page with different swivel nozzle parameters.

3. If the nozzle combo is okay use graph \$3 to monitor standpipe pressures while the MDCB is running downhole.

4. Torque factors should normally be between 0.2 and 0.9 when coring. Steady lower pressures indicate coré block. Steady higher pressures indicate motor stall. End of stroke pressure $=800-900$ psi.

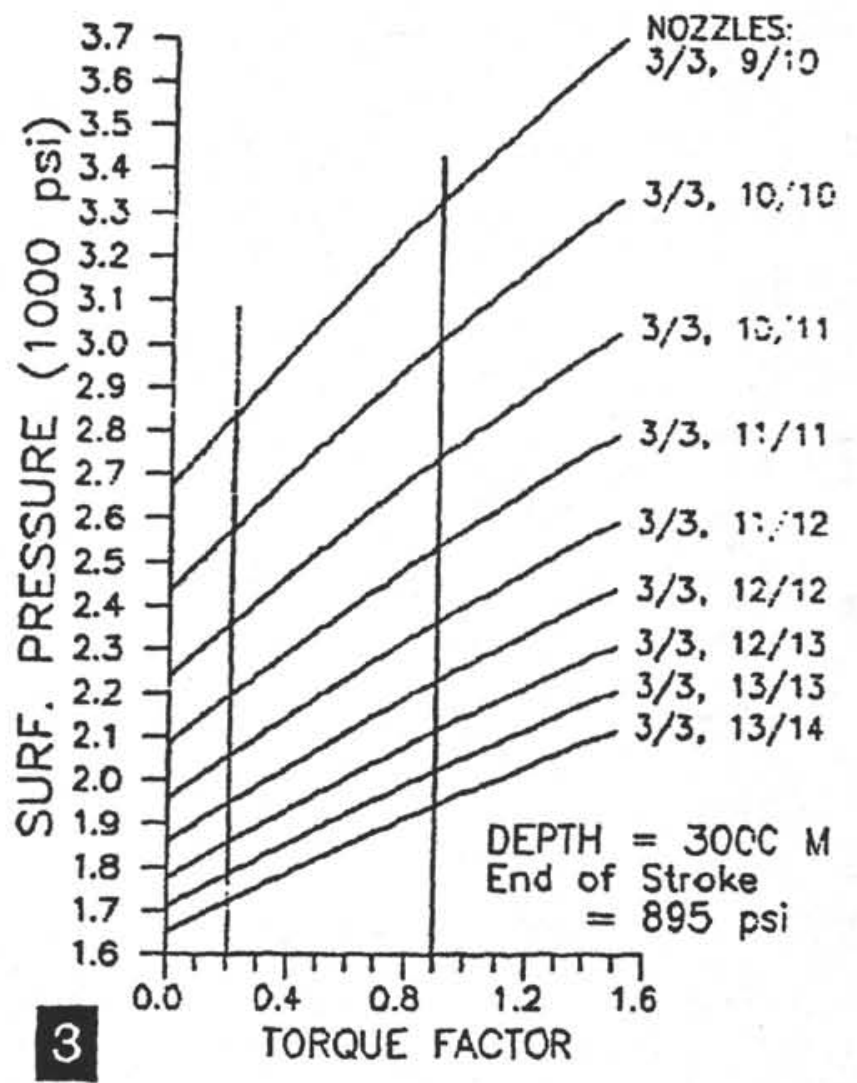



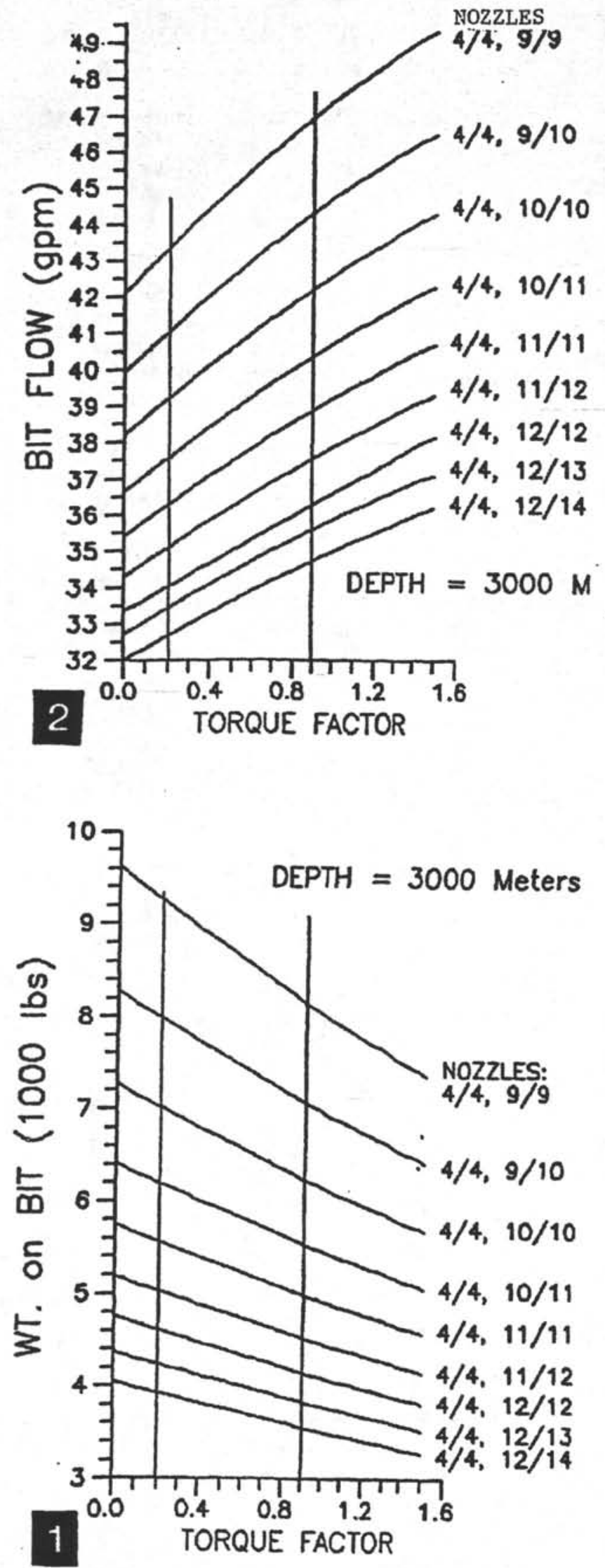

\section{MDCB OPERATING PARANETERS}

SWIVEL NOZZLES: $4 / 4$

Depth $=3000 \mathrm{~m}$, flow $=215 \mathrm{gpm}(\max$.

1. Se lect nozzle combination to achieve desired WOB on graph 1 . Assume torque factor $=0.5$. (Swivel nozzles determine flow to the diamond bit. thruster nozzles determine weight on dianond bit.)

2. Check graph $\$ 2$ to see if the chosen nozzle conbo will also produce the desired flow rate to the diamond bit. If not, go to another page with different swivel nozzle parameters.

3. If the nozzle combo is okay use graph \#3 to monitor standpipe pressures while the MDCB is running downhole.

4. Torque factors should normally be between 0.2 and 0.9 when coring. Steady lower pressures indicate core block. Steady higher pressures indicate motor stall. End of stroke pressure $=800-900$ psi.

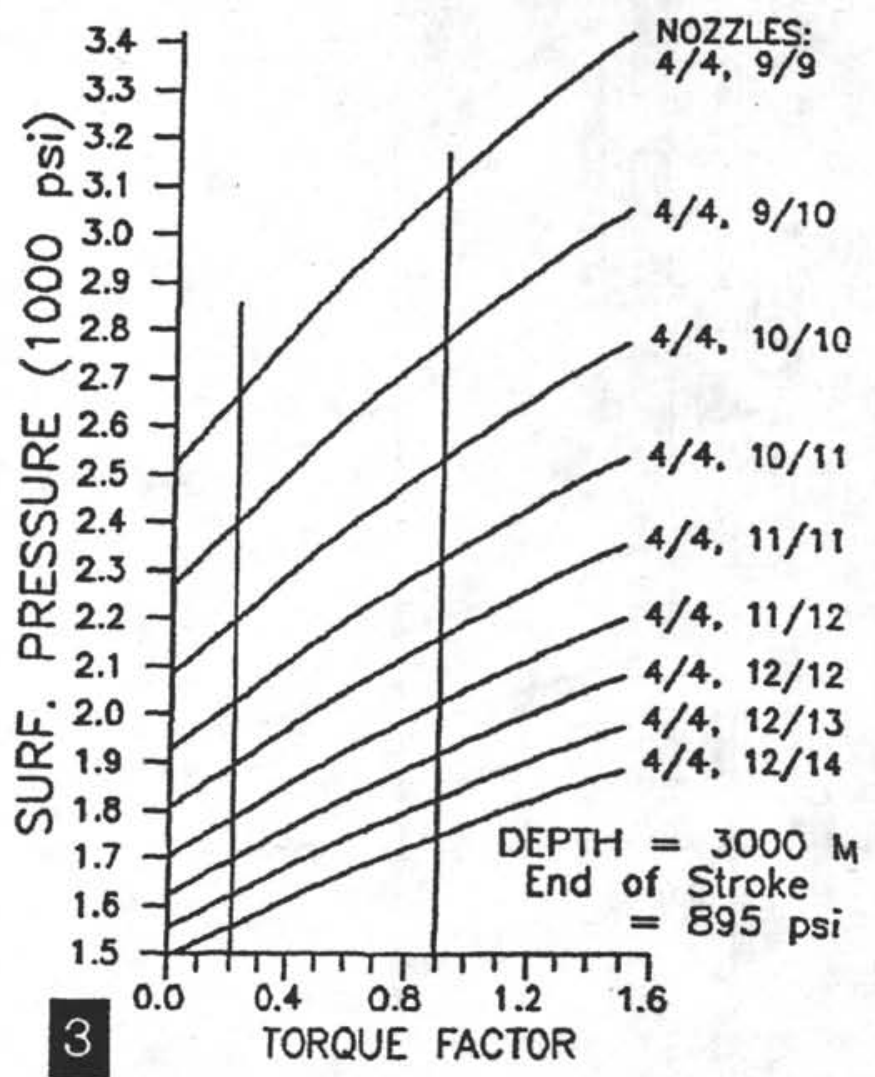



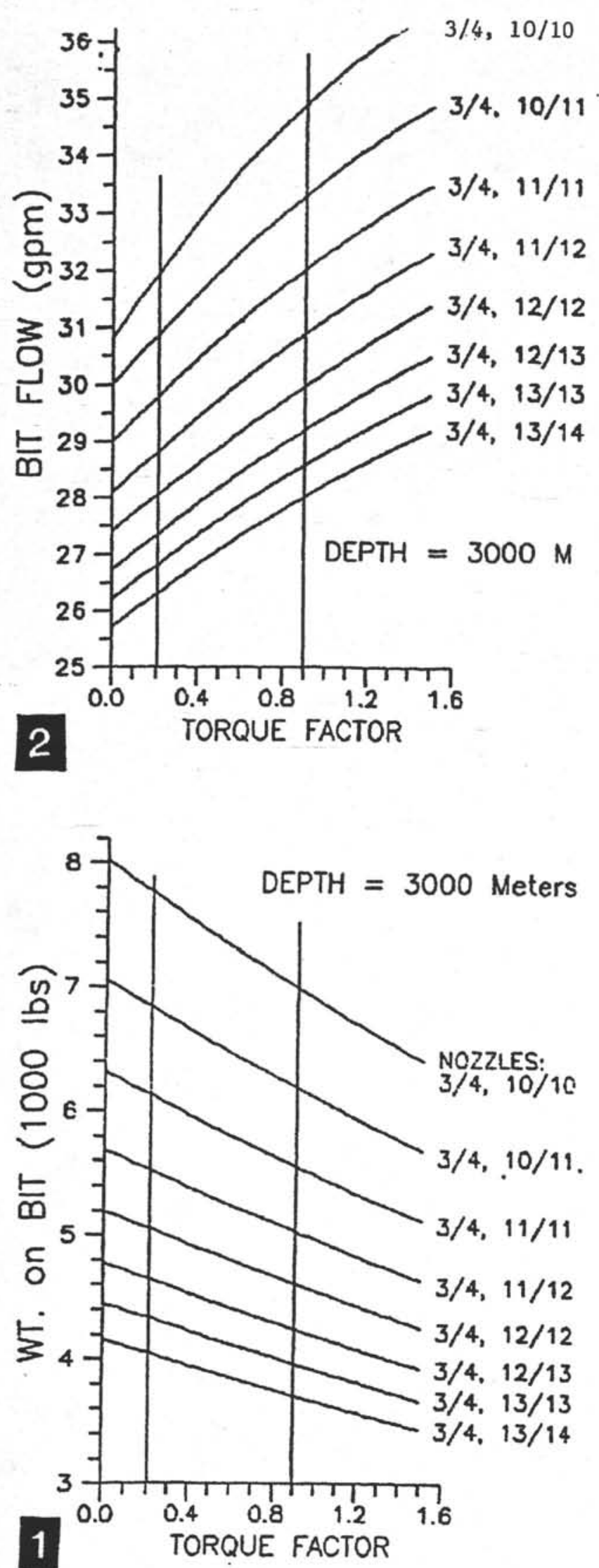

MDCB OPERATING PARAMETERS

SWIVEL NOZZLES: $3 / 4$

Depth $=3000$ m. Flow $=215$ gpm $(\max$.

1. Select nozzle combination to achieve desired WOB on graph $\$ 1$. Assume torque factor $=0.5$. (Swive) nozzles determine flow to the diamond bit. thruster nozzles determine weight on diamond bit.)

2. Check graph $\$ 2$ to see if the chosen nozzle combo will also produce the desired flow rate to the diamond bit. If not, go to another page with different swivel nozzle parameters.

3. If the nozzle combo is okay use graph 13 to monitor standpipe pressures while the MDCB is running downhole.

4. Torque factors should normally be between 0.2 and 0.9 when coring. Steady lower pressures indicate core block. Steady higher pressures indicate motor stall. End of stroke pressure $=800-900$ psi .

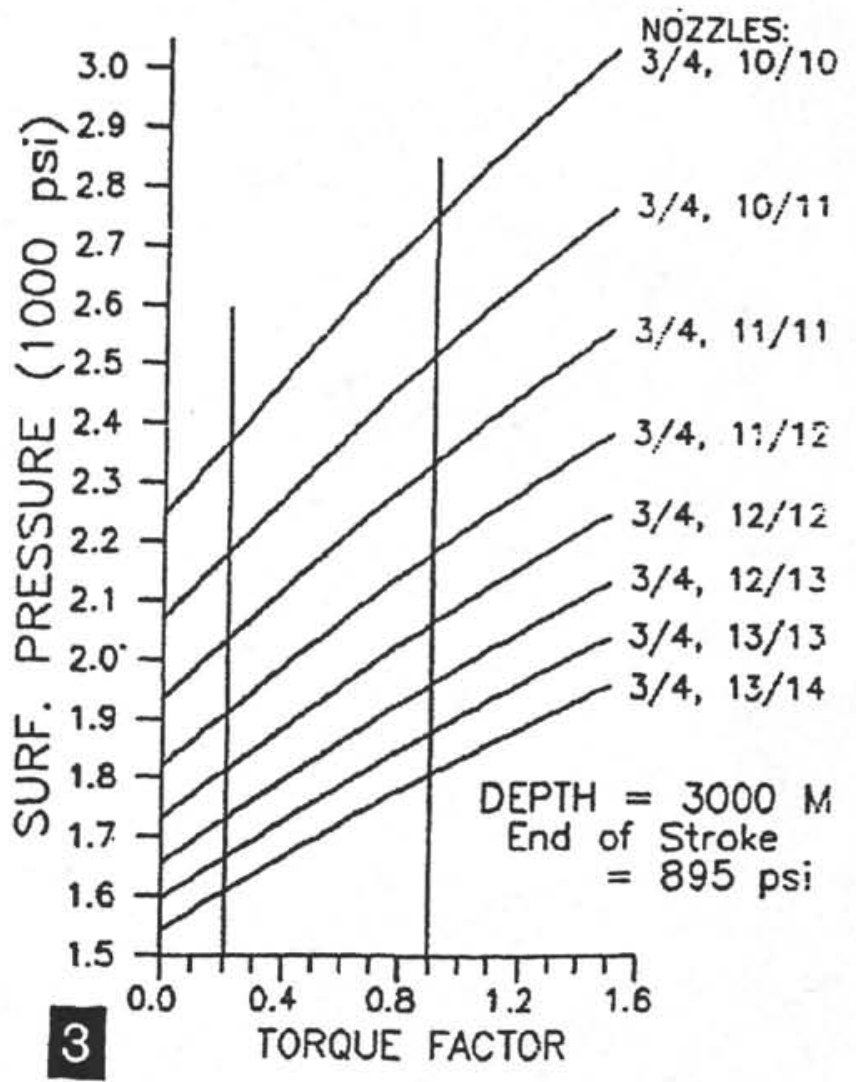


Appendix H

MDCB: Summary Report - February 1992 


\title{
SUMMARY REPORT \\ MOTOR DRIVEN CORE BARREL \\ ENGINEERING UPDATE \\ THROUGH LEG 141
}

PN5068

\author{
Prepared For \\ OCEAN DRILLING PROGRAM \\ TEXAS A\&M RESEARCH PARK \\ College Station, Texas
}

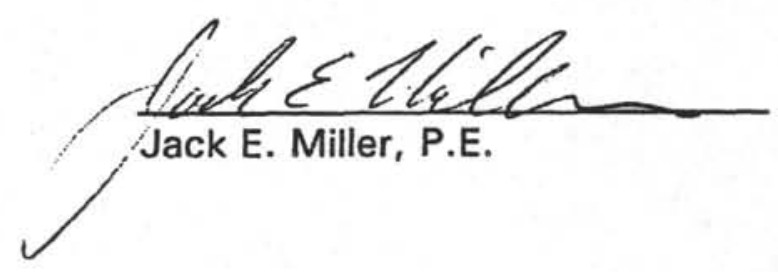

STRESS ENGINEERING SERVICES, INC.

13800 Westfair East Drive

Houston, Texas 77041

FEBRUARY, 1992 
1.0 OVERVIEW $\ldots \ldots \ldots \ldots \ldots \ldots \ldots \ldots \ldots \ldots \ldots \ldots \ldots$

2.0 TOOL STATUS AT THE END OF LEG $135 \ldots \ldots \ldots \ldots \ldots \ldots$

3.0 FURTHER ANALYTICAL STUDIES and RESULTING TOOL

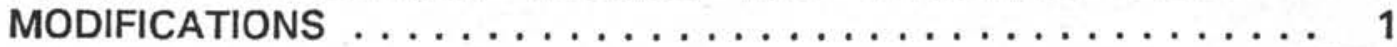

4.0 MDCB FLOW TESTING $\ldots \ldots \ldots \ldots \ldots \ldots \ldots \ldots \ldots \ldots$

5.0 INTERPRETATION OF LEG 141 CORING RUNS $\ldots \ldots \ldots \ldots \ldots$

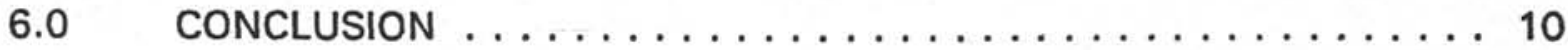

\section{LIST OF ATTACHMENTS}

ATTACHMENT A -

ATTACHMENT B -

ATTACHMENT C -

ATTACHMENT D ATTACHMENT E -

ATTACHMENT F -

ATTACHMENT G -

"MDCB-134 FINAL REPORT": INTERNAL ODP MEMORANDUM BY D. HUEY, DECEMBER 1990 "MDCB CORE BARREL RUN AT SITE 135-835B-25N \& 839A-25N": INTERNAL ODP MEMORANDUM, DECEMBER, 1990

ENGINEERING REPORT FOR LEG 141, SECTION ON MDCB: INTERNAL ODP REPORT BY D. HUEY, JANUARY, 1991 MEMO OF MARCH 18, 1991 FROM J. MILLER TO D. HUEY TEST RESULTS FROM MDCB FLOW TESTING TEST DATE SEPTEMBER 12, 1991: MEMO

"DESCRIPTION OF LEG 141 MDCB STATUS INTERIM REPORT": REPORT BY J. MILLER, SES TO ODP, NOVEMBER, 1991

MEMO OF JULY 18, 1991 FROM J. MILLER TO W. RHINEHART

\section{REFERENCE}

"Summary Report - Motor Driven Core Barrel Engineering Development": Report by Stress Engineering Services, Inc. to ODP, September 1990 


\section{SUMMARY REPORT \\ MOTOR DRIVEN CORE BARREL \\ ENGINEERING UPDATE through LEG 141}

\subsection{OVERVIEW}

During the period from January through July, 1990, Ocean Drilling Program and Stress Engineering Services jointly developed a new Motor Driven Core Barrel (MDCB). This tool was deployed during ODP Leg 134 in October, 1990 and was also used during Leg 135. The design and the engineering of this tool prior to Leg 134 is described in Reference (1), "Summary Report: Motor Driven Core Barrel Engineering Development". The results of deployment for the tool during Leg 134 is summarized in "MDCB-134 Final Report", Attachment A. Deployment results from Leg 135 are described in "MDCB Core Barrel Run - Site..... ", included as Attachment B.

Problems with the tool prompted its return to College Station for modification and testing after Leg 135. Certain details of the tool were modified and the tool was flow tested during September, 1991 at the Stress Engineering Services Lab in Houston, Texas. The tool was once again deployed during LEG 141 and met with some success as described in the Leg 141 engineering report excerpt, Attachment $C$.

This report describes the engineering work and modifications to the MDCB performed between Legs 135 and 141 . Since most of this work has been previously described in various reports and memoranda, this document only attempts to pull together these sources into a coherent package.

\subsection{TOOL STATUS AT THE END OF LEG 135}

The most troublesome aspect of the tool performance during Legs 134 and 135 was the fact that the basic operating pressures were significantly higher (usually 500 to $600 \mathrm{psi}$ more) than predicted. The hydraulics of this tool had been extensively analyzed as shown in (1), so this caused some concern. Second, deck testing and downhole deployment proved the rate of penetration to be quite low and the coring performance to be lackluster. Third, each of the major ancillary features (the locking piston, the core barrel latch, the end of stroke indicator) showed some malfunction.

\subsection{FURTHER ANALYTICAL STUDIES and RESULTING TOOL MODIFICATIONS}

The first and foremost problem to be addressed was to discover why the overall operating pressures had been higher than predicted. There was some feeling that the analytical models were too simplistic and had not truly addressed the complex fluid 
path through the tool. Therefore, the formulations of steady state computer model "MDCBWOB", described in Reference (1), were checked thoroughly in search of additional sources of pressure loss and each of the physical dimensions input were checked for accuracy. As a result of these checks, it was discovered that implementation of the existing XCB core barrel quick release (" $Q / R^{\prime \prime}$ ) sub into the MDCB overlooked the fact that its outside diameter was excessive for use with the MDCB. Although some small loss sources were found in the model, the greatest contributor was the $\mathrm{Q} / \mathrm{R}$ sub.

In the XCB, flow predominantly travels down the center of the $Q / R$ sub. In the MDCB, the major portion of the flow travels outside the $Q / R$ sub between the 3.8" I.D. of the seal bore drill collar and the outside of the $Q / R$ sub. The size of this thin annulus is such that very small dimensional changes have significant impact on pressure losses. Therefore, the maximum diameter of MDCB parts below the landing shoulder is 3.5" and all computer modeling had used this value. The XCB Q/R sub is 3.75 " O.D. with three longitudinal slots which when located in the seal bore drill collar theoretically gives a annular flow area equivalent to a $3.726^{n}$ O.D.. The Q/R sub was responsible for adding about $300 \mathrm{psi}$ to the pressure overage and also caused excessive weights on bit (WOB) during Legs 134 and 135. The remaining pressure drop overage was largely unaccounted for.

The design of the existing Q/R sub did not allow it to be modified to 3.5" O.D. by simply shaving the outside diameter, so ODP designed and procured a new one for the MDCB prior to Leg 141.

With regard to the other tool features, problems with the locking piston, the core barrel latch and the end of stroke indicator and actions taken to correct their operation are summarized in "Description of Leg 141 MDCB Status: Interim Report" included as Attachment F. Briefly summarizing, the locking piston feature to provide core marking is still not operational and further engineering work on this device has not been performed.

Results of further study of the end of stroke indicator are summarized in a March 18, 1991 memo included as Attachment D. Resulting refinements to the design have been successful as demonstrated during Leg 141 and described in Attachment C.

The core barrel latch system was significantly revised to include a positive lock of the latch fingers prior to motor rotation in accordance with the theory outlined in a July 18, 1991 memo included as Attachment G. The core barrel latch system functioned as planned during on-deck drill testing in transit to Leg 141, but apparently allowed the core barrel to scope out prematurely during both downhole deployments during Leg 141. The malfunction of the core barrel latch system has not been resolved and future study is planned to provide a solution to this question. 


\subsection{MDCB FLOW TESTING}

Due to the tight development and procurement schedule of the MDCB prior to Leg 134, time was not available to perform controlled environment testing. The problems discovered during Leg 134 and 135 pointed up the need to test the MDCB prior to re-deployment. The testing was necessary to verify the performance of the tool and to "calibrate" the computer models of the tool. Stress Engineering Services designed a test setup as shown in Figure 1. This layout was designed around a spare ODP bottom hole assembly (BHA) in stock at the ODP testing facility ("TFAC") in Bryan. The flow tests were all configured for a horizontal orientation of the BHA to facilitate handling and eliminate the need for high clearance lifting equipment. The key test device, shown in Figure 2, was a special design "test head" assembly built around an existing ODP roller cone bit which included the following:

1. A "floating" spool restrained by load cells to allow independent measurement of weight on bit (WOB) and torque at the core bit.

2. A disc brake assembly for application of torque resistance to the core barrel.

3. A bearing mounted sub to take the place of the core bit which allowed independent measurement of bit flow, motor flow, and motor rotational speed.

4. A valve on the output of the bit flow path to allow simulation of clogging of the core bit.

The projected hydraulic power requirements of up to 350 horsepower exceeded the capabilities of in-house equipment, so the Western Company was retained to provide pumping services. Western also supplied Haliburton turbine type flow meters (2 per test). Stress Engineering Services supplied the load cells, pressure transducers, tachometer, data acquisition system and 1600 gallon capacity water tank. The turbine flow meters were recorded on the SES 7000 data acquisition system via hookup to the Western "Model C" pen recorder connected to the flowmeters.

A brief overview of the testing appears in the summary report included as Attachment $F$. As explained in Attachment $F$, elimination of the drive bushing friction term from the weight on bit calculation and revising the motor performance downward gave very good agreement between the test data and the computer simulation. Attachment $\mathrm{E}$ shows the data vs. the computer output for each of the four major test runs.

The motor performance result is important and justifies more discussion. The Eastman Christensen Mach 1P "drainhole" mud motor gives significantly higher power than the Mach 1 unit used with the previous NCB2. It provides increased power by virtue of both higher torque and speed. During the initial analysis work in 1990, the performance map of the Mach 1 motor was used to develop a set 


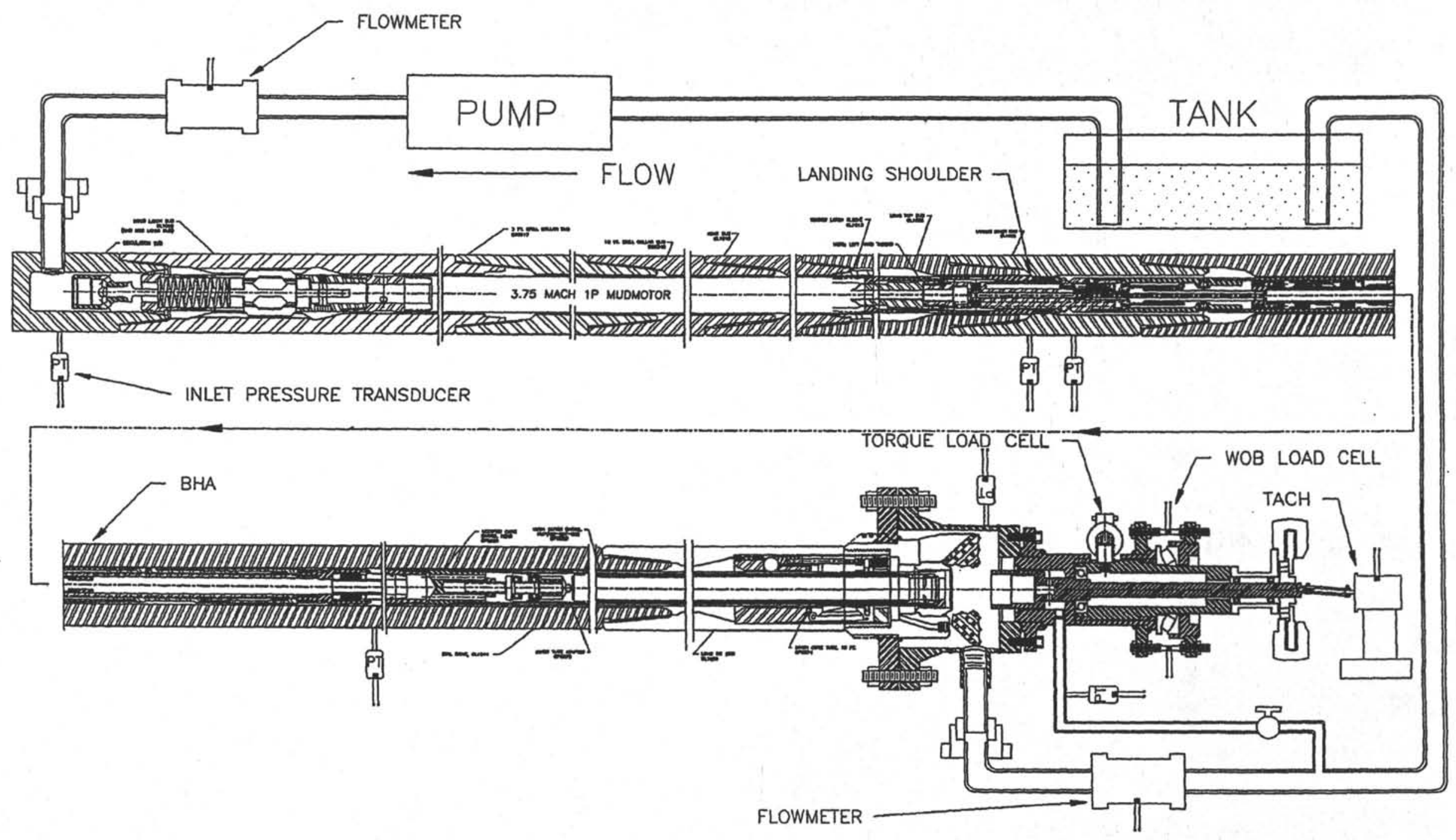

FIGURE 1

MDCB FLOW TEST SETUP 


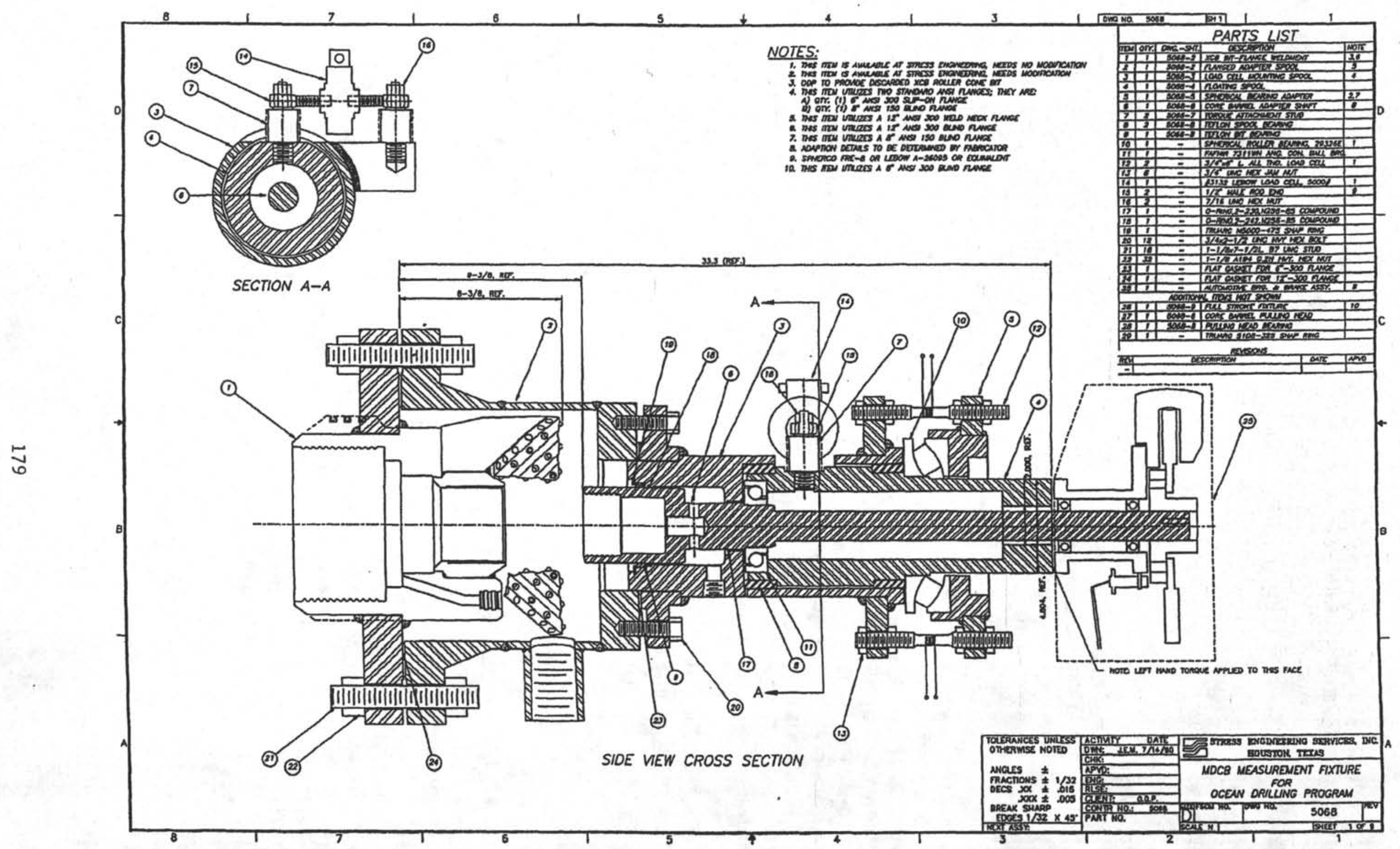

FIGURE 2

TEST HEAD ASSEMBLY 
of algorithms relating flow, pressure drop, torque, and speed. In the computer programs, the Mach 1 motor is described by two equations as follows:

$$
T=11.26 \cdot P-550-.4502 \cdot\langle W-10.47\rangle^{2.8} \ldots \ldots
$$

and,

$$
Q=23.5 \cdot W^{.85}+.2635 \cdot P \quad \ldots \ldots \ldots \ldots \ldots \ldots
$$

Where:

$$
\begin{aligned}
& T=\text { Torque (inch-pounds) } \\
& P=\text { Pressure Drop (psi) } \\
& W=\text { Rotary speed (radians per second) } \\
& Q=\text { Flow rate (in. }{ }^{3} \text { per second) } \\
& <>\text { indicates zero if negative }
\end{aligned}
$$

These equations were developed by trial and error and closely follow the Mach 1 motor performance map throughout the entire range of motor data supplied by Christensen. A physical interpretation of equation (1) is that torque is proportional to pressure drop with 550 inch pounds ( 46 ft.-lbs.) of fixed drag torque up to 10.47 radians per second $(100 \mathrm{rpm})$. At speeds higher than this amount, a non-linear speed related loss occurs. The total torque loss (drag) is about $340 \mathrm{ft}-\mathrm{lbs}$. at $400 \mathrm{rpm}$. The second equation is simpler and relates flow rate through the motor to rotary speed and pressure drop. The speed term tells us that the motor has a slight non-linearity in volumetric efficiency while the pressure term could be considered leakage.

For the Mach 1P "drainhole" motor, Christensen verbally supplied six data points. Using the same trial and error procedure as for the Mach 1 analysis gave the following:

$$
T=10.245 \cdot P-2500-.48 \cdot\langle W-17\rangle^{2.625} \ldots \ldots \ldots(3)
$$

and,

$$
Q=16.91 \cdot W^{.941}+.0634 \cdot P \ldots \ldots \ldots \ldots \ldots(4)
$$

The physical interpretation is that the motor has higher fixed drag losses than the Mach 1, but that it has less displacement per revolution and much lower leakage. The total drag losses are actually higher than the Mach 1 and are about $390 \mathrm{ft}-\mathrm{lbs}$ at $400 \mathrm{rpm}$. The lab testing showed that (1) the motor speed was lower than predicted, (2) pressure response to torque was higher than predicted, and (3) the motor lost speed faster than anticipated in response to torque. It was suspected that the rotary seals were leaking in the swivel sub, allowing some flow to bypass the motor. A leakage term was put in the model and this possibility was simulated. This work 
showed that the observed performance could not be simulated by adding any amount of swivel leakage. Leakage in the swivel seal would correctly simulate decreased motor performance, but the "character" of response was not correct and it could not follow the observations over a broad range. When leakage was modeled, almost every other pressure comparison would suffer. Changing the motor performance algorithm to reflect less efficiency gave very good agreement with the tests as shown in Attachment E. The final form of the motor algorithms used are:

$$
T=7.703 \cdot P-1880-.6 \cdot\langle W-17\rangle^{2.625} \ldots \ldots \ldots
$$

and,

$$
\mathrm{Q}=16.91 \cdot \mathrm{W}^{.941}+.185 \cdot \mathrm{P} \ldots \ldots \ldots \ldots \ldots \ldots
$$

The equations imply lower overall performance than previously modeled, giving less torque in response to pressure and greater leakage in response to pressure. The overall efficiency is significantly down-graded. For example, one data point given by Christensen for the Mach 1P was:

$$
\begin{aligned}
& \text { Speed - } 250 \mathrm{rpm} \\
& \text { Torque - } 959 \mathrm{ft}-\mathrm{lbs} \\
& \text { Pressure - } 1407 \mathrm{psi} \\
& \text { Flow - } 119 \mathrm{gpm}
\end{aligned}
$$

These numbers indicate 97.6 horsepower hydraulic input and 45.6 horsepower mechanical output for a total efficiency of about $47 \%$. The algorithms shown in Equations (3) and (4) closely simulates this data. Input of $250 \mathrm{rpm}$ and 1407 psi into (3) and (4) gives $979 \mathrm{ft}-\mathrm{lbs}$ and $118 \mathrm{gpm}$ respectively. By comparison, input of these same values into Equations (5) and (6) gives $734 \mathrm{ft}-\mathrm{lbs}$ and $162 \mathrm{gpm}$ for a $26 \%$ overall efficiency.

The additional pressure drop of the motor seemed to provide the final accounting for the increased operating pressures observed during Legs 134 and 135 . A copy of the steady flow computer program was modified to include the reformulated motor, the oversize Q/R sub, and the lack of friction in the kelly drive bushing in order to provide a retrospective analysis of tool during Legs 134 \& 135. The results of those runs are summarized below:

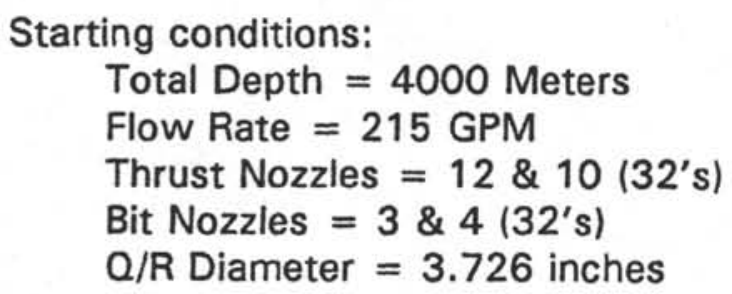




\begin{tabular}{rrrrrr}
$\begin{array}{l}\text { Results: } \\
\text { Torque }\end{array}$ & WOB & Pump Pressure & RPM's & Bit Flow & Friction \\
\hline & & & & & \\
0 & 7990 & 2325 & 426 & 27.9 & 0 \\
250 & 7819 & 2544 & 389 & 29.2 & .37 \\
500 & 7644 & 2805 & 345 & 30.8 & .75 \\
700 & 7489 & 3034 & 307 & 32.1 & 1.05
\end{tabular}

Note: $\quad$ Torque in ft-lbs, Pressure in PSI, Bit flow in GPM and friction is bit friction coefficient as explained in Reference 1.

The important points to make about the above data is that only $700 \mathrm{ft}$-lbs is available for coring prior to exceeding the 3000 psi pump popoff pressure and that the starting Weight on Bit is almost $3000 \mathrm{lbs}$. higher than previously predicted. For the $700 \mathrm{ft}-\mathrm{lb}$ torque point, a 3.5" O.D. Q/R sub would have given $5100 \mathrm{lbs}$ of WOB while the surface pressure would have been 2790 psi.

Another important finding related to the higher motor pressures is that, even with a correct $\mathrm{Q} / \mathrm{R}$ sub, at $215 \mathrm{gpm}$ the maximum achievable cutting friction coefficient is 1.97 before exceeding the 3000 psi upper bound. During the design phase, a cutting friction coefficient of 3.0 was a goal since it seemed to make the full motor torque available for coring and far exceeded the known stall point of the NCB2. For this reason, the 215 GPM flow recommendation for Leg 134 was replaced with a recommended flow rate of 190 GPM for Leg 141. The operating pressure of the tool is quite sensitive to flow rate. In the current range of operation, the basic no load pressure changes by approximately 17 psi per gpm, while motor speed changes by about $2 \mathrm{rpm}$ per gpm. Flow in the range of 180 to $190 \mathrm{gpm}$ seems to provide the best compromise of speed, pressure, and motor torque levels in view of the 3000 psi pump operating limit. At $190 \mathrm{gpm}$, over $1000 \mathrm{ft}$-lbs is usually available before the 3000 psi limit is exceeded (depending on nozzle selection).

Another test performed prior to flow testing was a "self filling" test to see if the thrust cylinder section below the piston would automatically vent air and fill with seawater while running down hole. The damping function of the thrust cylinder is only available if the volume is completely filled with water. The tool was placed in the BHA and hung in a vertical orientation. The BHA was capped and filled with water. The BHA was then pressurized to 3,000 psi and the pressure was maintained for approximately 30 minutes. The tool was then removed from the BHA and the lower cylinder section was drained. This test was repeated twice. The first test measured the net weight of water drained from the cylinder at $17 \mathrm{lbs} .1 \mathrm{oz}$. indicating a volume of $472.5 \mathrm{cu}$.in.. The second measured $17 \mathrm{lbs}, 15 \mathrm{oz}$., indicating a volume of 496.7 cu.in.. The theoretical volume is $483.5 \mathrm{cu}$.in.. The differences are within the range of dimensional tolerance of the thrust cylinder and kelly. It was concluded that the cylinder does automatically fill while running downhole. 
A tubular guide fixture was procured to allow full core barrel extension during flow testing for checking the end of stroke feature, but the modified fluid swivel was not available for testing, so this function was not checked.

\subsection{INTERPRETATION OF LEG 141 CORING RUNS}

The data taken during deck testing and deployment in Attachment $\mathbf{C}$ was simulated with the latest version of the MDCB steady flow model to see if the cutting resistance of the formation could be determined. Since the flow rate was not held exactly at one value for all runs, a different run was required at each flow rate as indicated by pump stroke count. The first drill test in the concrete went through the barrel in 2 minutes and 30 seconds. This run indicated a torque level of less than 200 $\mathrm{ft}$.-Ibs. and translates into a bit friction coefficient of .4 or less. The second run core blocked after 18 inches of penetration and the data never indicates significant torque load. The third and fourth tests core blocked due to an oversize bit throat and the pressure data indicated no torque for both runs. The fifth test was successful by again coring through drum in 2 minutes and 30 seconds. The pressure readings were indicative of up to $350 \mathrm{ft}$.lbs. of torque and bit friction coefficient ranging from . 3 to .6. Test run six was terminated due to a very slow penetration rate that only achieved 18 inches of penetration in 2-1/2 minutes. The bit matrix was apparently too hard and the diamonds were not exposed. The pressures reflect almost constant torque of $300 \mathrm{ft}$.lbs. for a cutting friction coefficient of .5 to .6. It is curious that so much work was expended without significant material removal and somewhat defies our assumption linking bit work to penetration rate. The last test run cored through the drum in 4 minutes and 40 seconds and indicated torque values of 250 to $350 \mathrm{ft}$.lbs., or a .5 to .6 cutting friction coefficient.

The data from the first downhole run indicates little or no torque until the last three minutes of the run. At about three minutes before the run ended, the pressure increased by 500 to 1000 psi indicating 400 to $800 \mathrm{ft}-\mathrm{lbs}$. of torque loading, or an equivalent cutting friction range of .9 to 1.9. Coring was stopped when pressure climbed to $3000 \mathrm{psi}$, indicating a 2.4 cutting friction coefficient. It is probably not likely that all the $\mathbf{2 . 5 1}$ meters of core recovery occurred in the last three minutes.

The second trip downhole indicates moderate torque loads in the range of 100 $\mathrm{ft}$-lbs with a sudden jump of up to $600 \mathrm{ft}$-lbs at about 20 minutes into the run. After that point, the pressures indicate no torque loading and imply that core block may have occurred. The run was terminated at 51 minutes due to the long run time. No signs of core block were noted in the recovered core barrel. If core block did occur in this run, then all real coring would have occurred in a 15 minute span. The noted penetration was 4 meters, so the core block scenario would indicate a penetration rate of $16 \mathrm{~m} / \mathrm{hr}$. Recovery was 1.37 meters. 
The BHA was picked up off bottom to allow full stroke of the core barrel. The standpipe pressure suddenly dropped to about $850 \mathrm{psi}$. The end-of-stroke analysis software was updated to the "post testing" configuration and correctly simulated this pressure, so the end of stroke indicator functioned as designed.

The steady flow analysis software, previously called "MDCBWOB" has been modified to include the latest test results and tool configuration. This version of the software is named "MDCB141". A copy of this software has been enclosed with this Report.

\subsection{CONCLUSION}

The core marking function and the positive latch assembly remain items for further study. The sources of excessive pressures noted in Legs 134 and 135 have been identified and the tool is performing as planned. The end of stroke indicator has been corrected and testing has validated the theoretical models and provided valuable data regarding the motor and lack of drive friction influence on WOB.

Looking at the deck tests and discounting the runs with the defective diamond bit, we find two runs giving penetration rates $15 \mathrm{~m} / \mathrm{hr}$, one at $8 \mathrm{~m} / \mathrm{hr}$, one core block, and one with a over-hard bit matrix. This shows that the results gained in the field will be heavily dependant on proper bit choice and nozzle configuration. Additional operating experience is critical to determination of the best tool configurations. 


\section{Appendix I}

MDCB: Source Code for "MDCBTIME" 


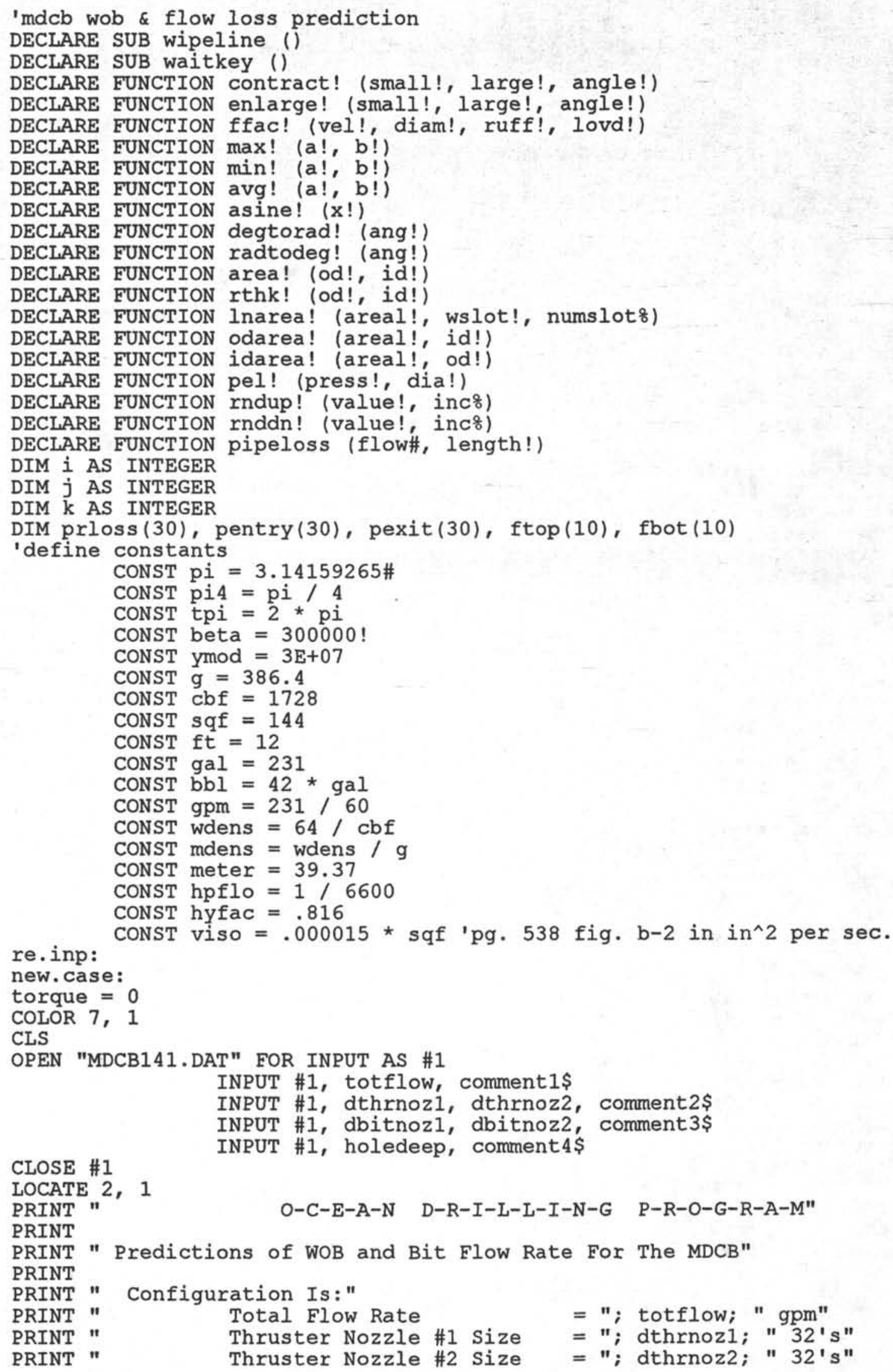




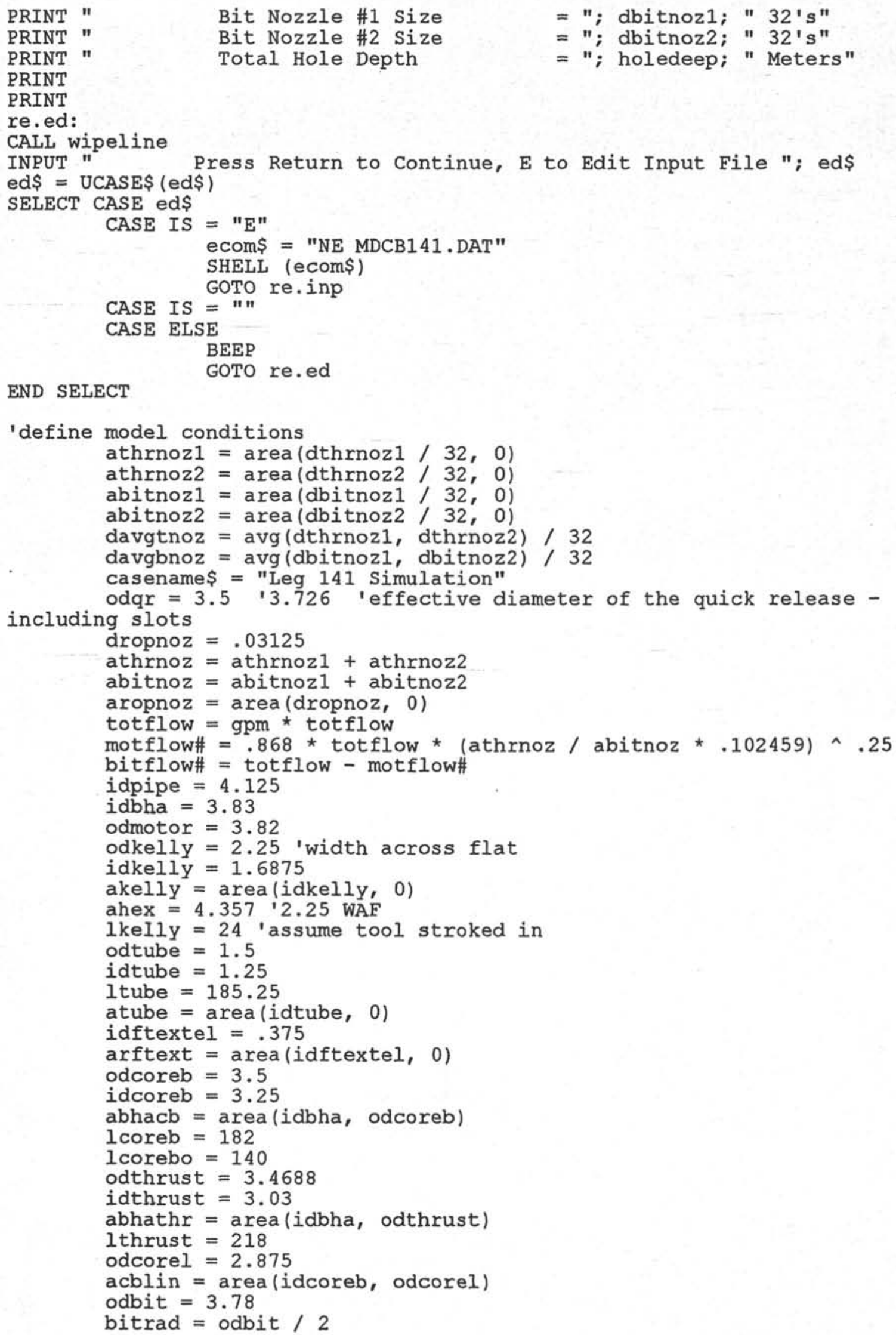




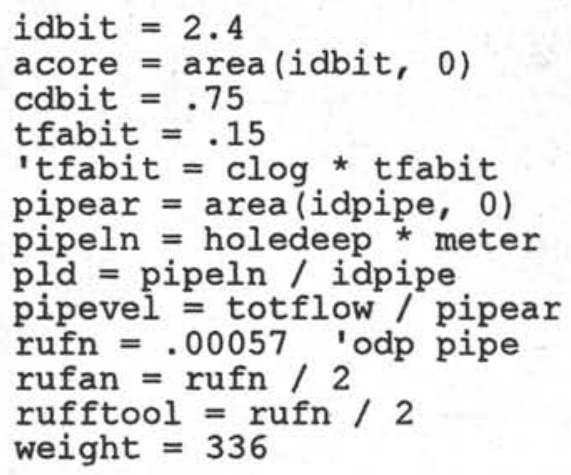

'note for pipes: "ohmxx" = mdens $/\left(2 * a r e a x x^{\wedge} 2\right)$ which multiplies times ffac and qxx^2 to give pdrop

'note for nozzles:"ohmxx" = csubd * mdens / $\left(22^{\star}\right.$ areaxx^2) to multiply $q x x^{\wedge} 2$

'++++++++++++++++++++++++++++++++++++++++++++++++++++++++++++++++++++++t

' first, compute losses involving total flow - prior to split

1++++++++++++++++++++++++++++++++++++++++++++++++++++++++++++++++++++t

- compute pressure drop prior to split for drill pipe

ohmpipe $=$ mdens $/(2 \star$ pipear $\wedge 2)$

pdrpipe $=$ totflow $\wedge 2 *$ ohmpipe $*$ ffac (pipevel, idpipe, rufn, pld)

prloss $(1)=$ pdrpipe

arfneck = area (idpipe, 3.75)

ohmfneck $=$ mdens $/(2 *$ arfneck $\wedge 2)$

lfneck $=5$

hydfneck $=($ idpipe -3.75$) *$ hyfac

ldfneck $=1$ fneck $/$ hydfneck

pdrfneck $=$ totflow $\wedge 2$ * ohmfneck * ffac ( totflow / arfneck),

hydfneck, rufn, ldfneck)

prloss $(2)=$ pdrfneck pdrtot $=$ pdrpipe + pdrfneck

i++++++++++++++++++++++++++++++++++++++++++++++++++++++++++++++++++++++++++++

'compute parameters for bit flow path

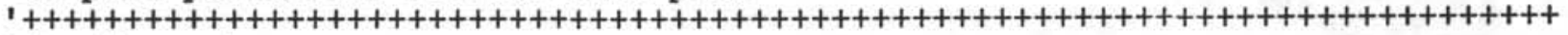

' for bha-motor

abhamtr $=$ area (idpipe, odmotor)

dhybhamt $r=$ hyfac $*$ (idpipe - odmotor)

lovdbhamtr $=200 /$ dhybhamtr

ohmbhamtr $=$ mdens $/(2$ * abhamtr $\wedge 2)$

' for bit nozzle kbnoz $=$ enlarge $($ davgbnoz, .625, 180) + contract (davgbnoz, .5, 90) ohmbnoz $=$ kbnoz * mdens $/(2$ * abitnoz $\wedge 2)$

'for first swivel passage

idbswiv $=.5$

abswiv = area (idbswiv, 0)

lbswiv $=9.625$

lovdbswiv = lbswiv / idbswiv

ohmbswiv $=$ mdens $/(2 *$ abswiv $\wedge 2)$

' for bit feed thru flow tube extension

lovdftext $=19.5 /$ idftextel

ohmftext $=$ mdens $/(2 *$ arftext $\wedge 2)$

ktext $=$ enlarge (idftextel, idtube, 180)

' for tube to kelly

lovdtube = ltube / idtube

ohmtube $=$ mdens $/(2 \star$ atube $\wedge 2)$

'for transition from tube to kelly

dtrans $=.875$

atrans $=$ area (dtrans, 0$)$

1 trans $=2.375$

lovdtrans = ltrans / dtrans

ohmtrans $=$ mdens $/(2 *$ atrans $\wedge 2)$

ktrans $=$ contract $(d t r a n s$, idtube, 180) + enlarge (dtrans, idkelly, 180) 
'for hole in kelley to gr

lovdkelly $=1 \mathrm{kelly} /$ idkelly

ohmkelly $=$ mdens $/(2 \star$ akelly $\wedge 2)$

'for hole thru gr

diqr $=1.5$

aidqr $=$ area $($ diqr, 0$)$

lqr $=23$

lovdidgr $=$ lqr $/$ digr

ohmidqr $=$ mdens $/(2 *$ aidqr $\wedge 2)$

'for core barrel / core barrel liner

dhycblin $=$ hyfac $*$ (idcoreb - odcorel $)$

lovdclin = lcoreb $/$ dhycblin

ohmcblin $=$ mdens $/(2 \star$ acblin $\wedge 2)$

' for bit face

ohmbface $=$ mdens $/(2 *($ cdbit * tfabit $) \wedge 2)$

ohmbstart $=$ ohmbface

$1++++++++++++++++++++++++++++++++++++++++++++++++++++++++++++++++++++++++++$

'compute parameters for motor flow path

' +++++++++++++++++++++++++++++++++++++++++++++++++++++++++++++++++++

'for holes thru $x$-over to motor

$\mathrm{dxov}=.75$

axov $=6 \star$ area $(\mathrm{dxov}, 0)$

lovdxov $=1$

ohmxov $=$ mdens $/(2 *$ axov $\wedge 2)$

'assume 2 to 1 contraction \& enlargement in xover

$\mathrm{kxov}=$ contract $(.75,1.5,45)+\operatorname{enlarge}(.75,1.5,180)$

' for holes thru swivel to thruster

lovdtswiv $=16 / .5$

atswiv $=2 \star \operatorname{area}(.5,0)$ 'was 2

ohmtswiv $=$ mdens $/(2 *$ atswiv $\wedge 2)$

'assume 1.75 to . $5^{\prime \prime}$ contraction in swivel and .5 to 1.72 enlargement ktswiv $=$ contract $(.5,1.75,180)+\operatorname{enlarge}(.5,1.72,180)$

' for holes thru spring housing

dsholes $=3 / 8$

asholes $=8$ * area (dsholes, 0 )

lsholes $=.5$

lovdholes $=1$ sholes $/$ dsholes

ohmsholes $=$ mdens $/(2 *$ asholes $\wedge 2)$

chamfers

ksholes $=$ contract $(.375, .875,180)+$ enlarge $(.375, .57,180)$ 'no

'for $0 . d$. of spring housing

asphous $=\operatorname{area}(2.75,2) \quad$ 'was 2.565

dsphous $=$ hyfac $*(2.75-2)$

lsphous $=5.25$

lovdshous $=1$ sphous $/$ dsphous

ohmsphous $=$ mdens $/(2 \star$ asphous $\wedge 2)$

'for lower end of spring housing

alsphous $=\operatorname{area}(2.565,2.276)$

dlsphous $=$ hyfac $*(2.565-2.276)$

1 sphous $=.5$

lovdlshous $=$ lsphous $/$ dsphous

ohmlsphous $=$ mdens $/(2 *$ asphous $\wedge 2)$

kbshous = enlarge (dlsphous, $1.15,180$ )

' for entry into nozzle area

aentry $=\operatorname{area}(1.5,1)$

dentry $=$ hyfac * $(1.5-1)$

lovdentry $=1$

ohmentry $=$ mdens $/(2 *$ aentry $\wedge 2)$

kcnozsub $=$ contract $((1.5-1),(2.56-1), 30)$

'for thruster nozzle

ktnoz = enlarge (davgtnoz, 1.15, 180) + contract (davgtnoz, .625, 43)'

was 80

ohmtnoz $=$ ktnoz * mdens $/(2 *$ athrnoz $\wedge 2)$

'for annulus of bha/thruster 


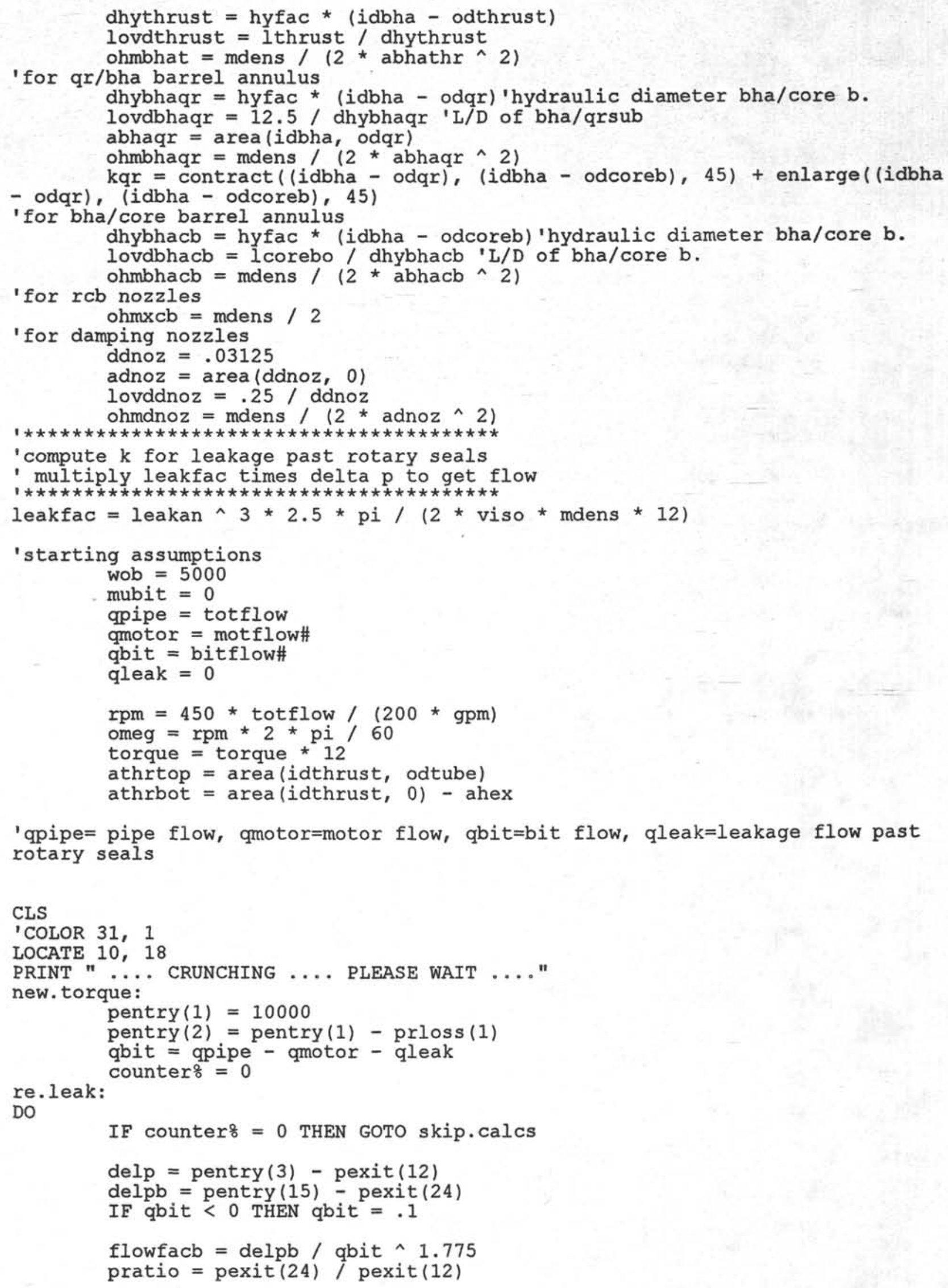




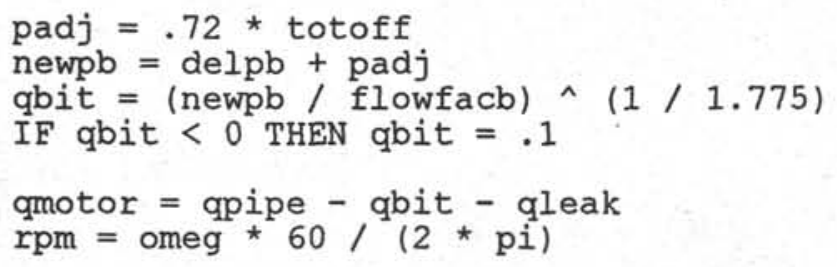

skip.calcs :

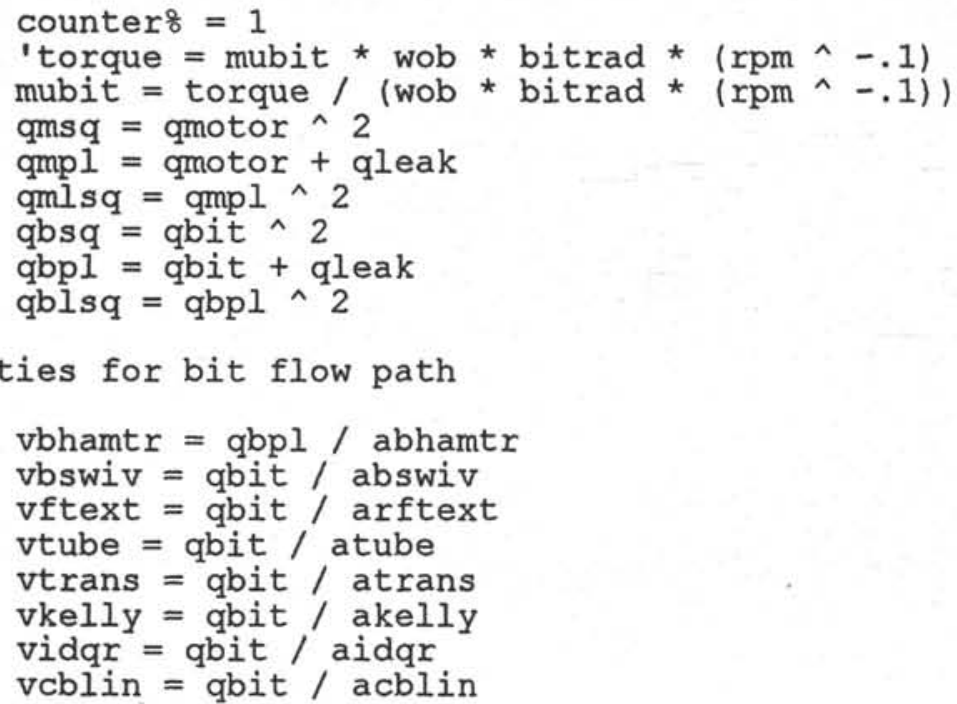

vbhamtr $=$ qbpl $/$ abhamtr

vbswiv = qbit / abswiv

vftext = qbit / arftext

vtube = qbit / atube

vtrans = qbit / atrans

vkelly = qbit / akelly

vidqr = qbit / aidqr

vcblin = gbit / acblin

'velocities for bit flow path

'velocities for motor flow path

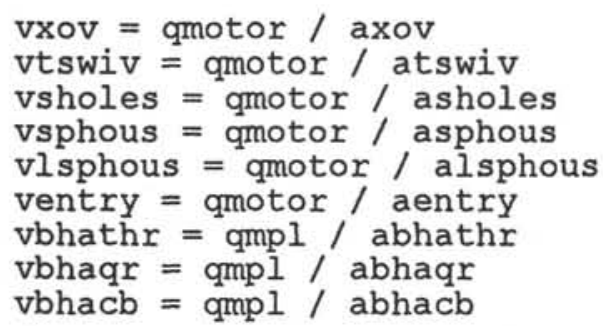




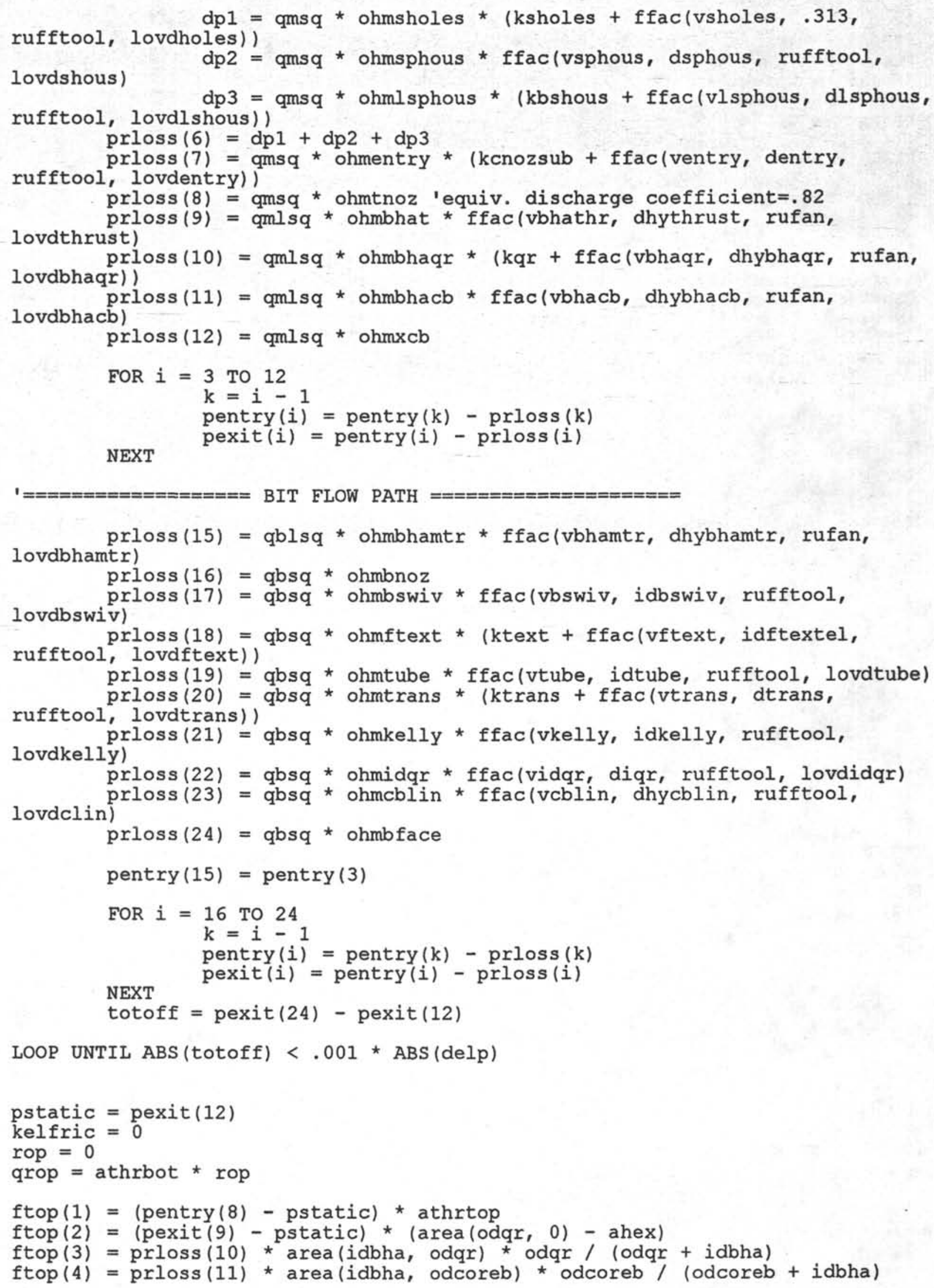




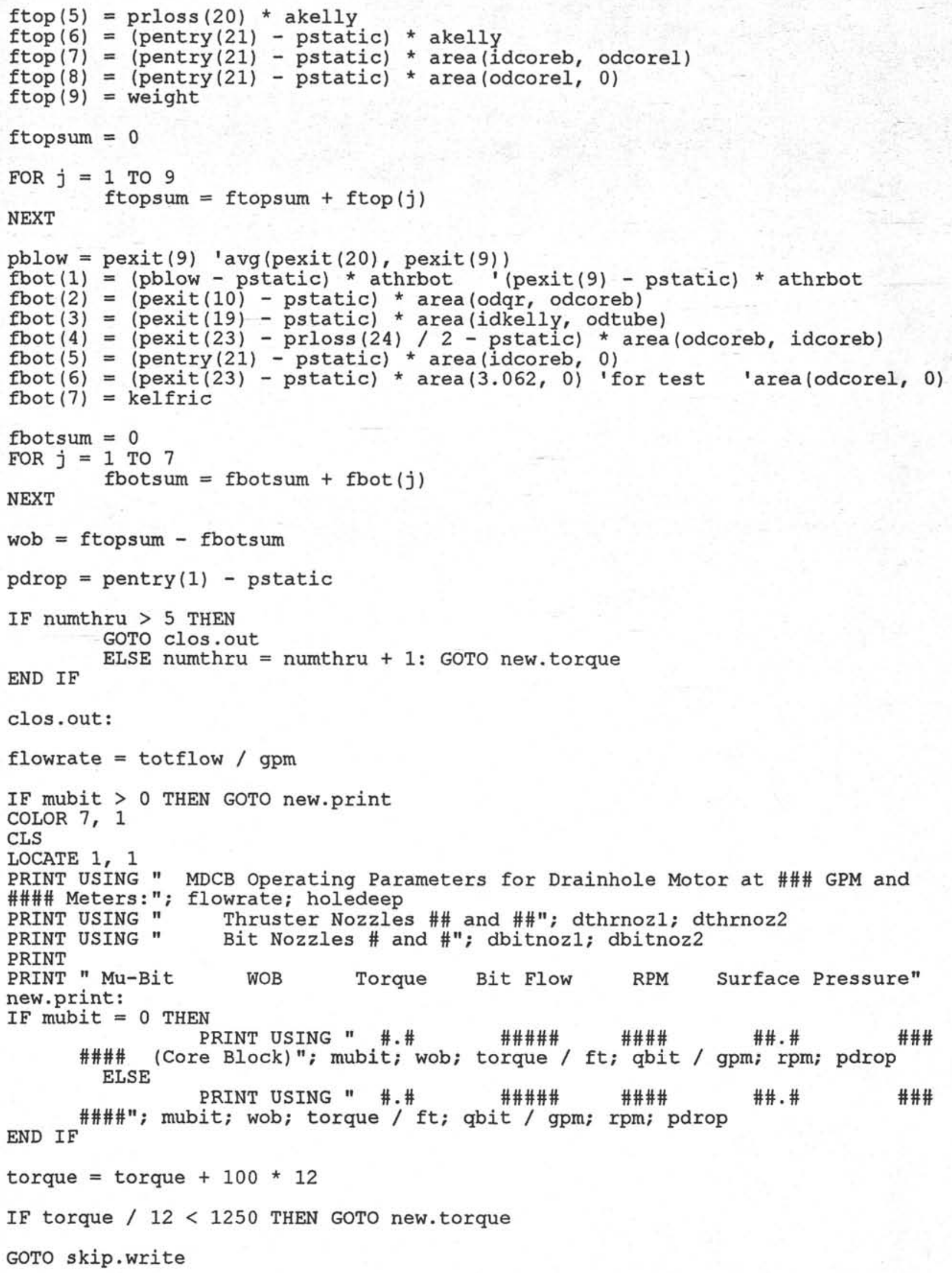




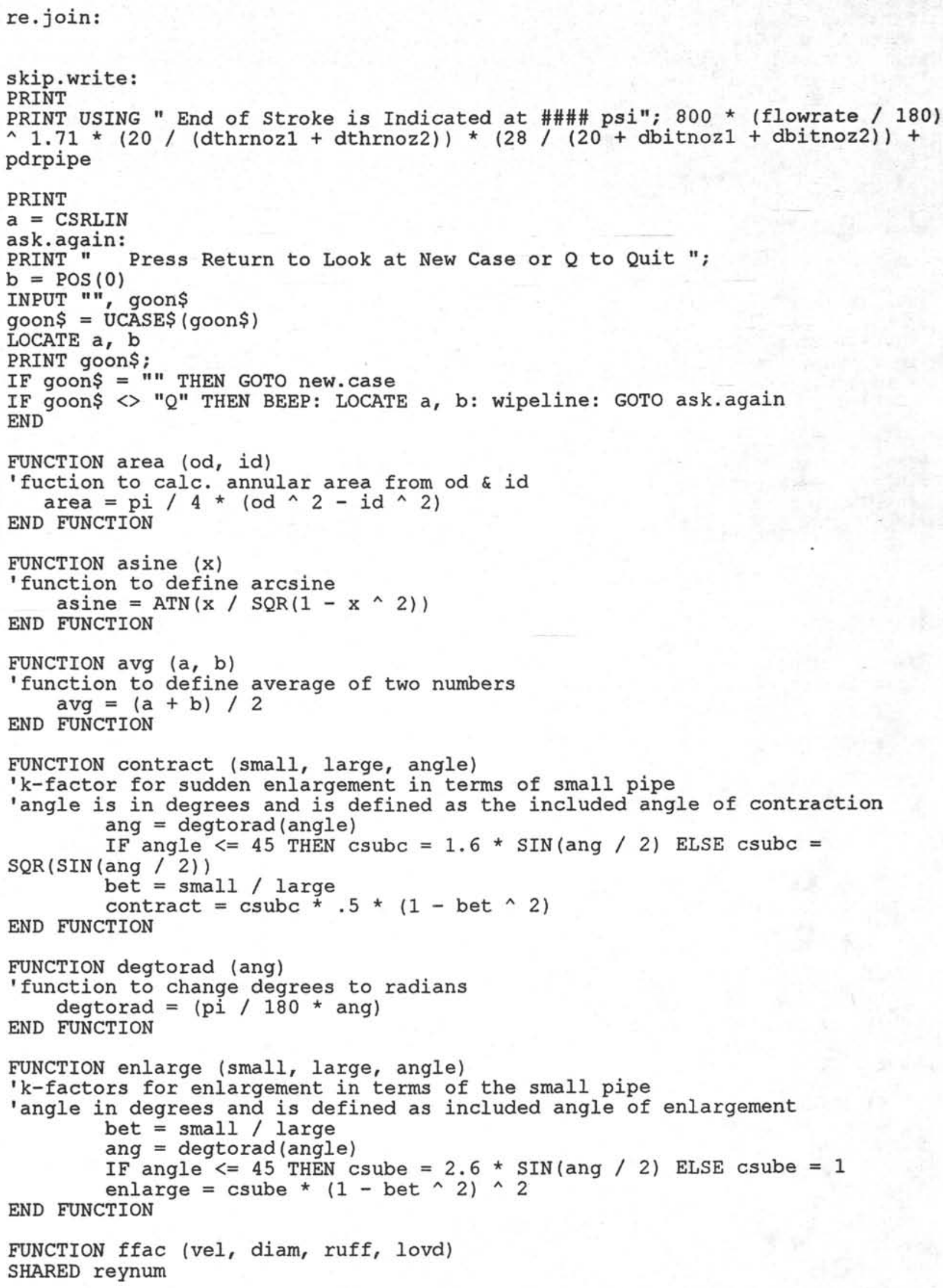


' formulation of friction factor shown on pg. $81 \& 82$ of Hein

' formulation by Churchill

' where lovd = length to diameter ratio

'ruff $=$ pipe roughness or $e / D$, reynum $=$ Reynolds' Number

'viso is kinematic viscosity, vel = velocity, diam = diameter IF vel $=0$ THEN

ffac $=1$

END IF

EXIT FUNCTION

vel $=A B S($ vel)

reynum $=$ vel $*$ diam / viso

$\mathrm{a \#}=(-2.457$ * $\operatorname{LOG}((7 /$ reynum $) \wedge .9+.27 *($ ruff $)))) \wedge 16$

$\mathrm{b \#}=(37530 /$ reynum $) \wedge 16$

$\mathrm{c \#}=(8 /$ reynum $) \wedge 12$

END FUNCTION

ffac $=$ lovd $\star 8 *(c \#+(1 /(a \#+b \#) \wedge 1.5)) \wedge(1 / 12)$

FUNCTION idarea (areal, od)

' function to return i.d. given area and o.d.

idarea $=\operatorname{SQR}($ od $\wedge 2-(4 / \mathrm{pi}$ * areal $))$

END FUNCTION

FUNCTION Inarea (areal, wslot, numslot?)

'function to define length of periferal slot given width, number, area lnarea $=$ areal $/($ wslot $*$ numslot: $)$

END FUNCTION

FUNCTION $\max (\mathrm{a}, \mathrm{b})$

'function to find largest of two numbers

IF $\mathrm{b}>\mathrm{a}$ THEN $\mathrm{c}=\mathrm{b}$ ELSE $\mathrm{c}=\mathrm{a}$

END FUNCTION $\max =c$

FUNCTION $\min (a, b)$

'function to find smallest of two numbers

END FUNCTION

IF $\mathrm{b}<\mathrm{a}$ THEN $\mathrm{c}=\mathrm{b}$ ELSE $\mathrm{c}=\mathrm{a}$ $\min =\mathrm{c}$

FUNCTION odarea (areal, id)

' function to calculate o.d. of annulus given i.d. and annular area odarea $=\operatorname{SQR}(4 / \mathrm{pi}$ * areal $+\mathrm{id} \wedge 2)$

END FUNCTION

FUNCTION peI (press, dia)

' function to pressure end load given pressure and enclosed diam. pel $=$ press $* \mathrm{pi} / 4 *$ dia $\wedge 2$

END FUNCTION

FUNCTION pipeloss (flow\#, length)

- function to give pipe losses of ODP pipe nflow\# = ABS (flow\#)

END FUNCTION pipeloss $=3.84634 \mathrm{E}-09$ * length * nflow\#. .84 * flow\#

FUNCTION radtodeg (ang)

'function to convert radians to degrees radtodeg $=(180 / \mathrm{pi}$ * ang $)$

END FUNCTION

FUNCTION rnddn (value, inco)

'function to round down to next specified fraction rnddn $=$ INT (inc: * value $) /$ inc $\%$

END FUNCTION 


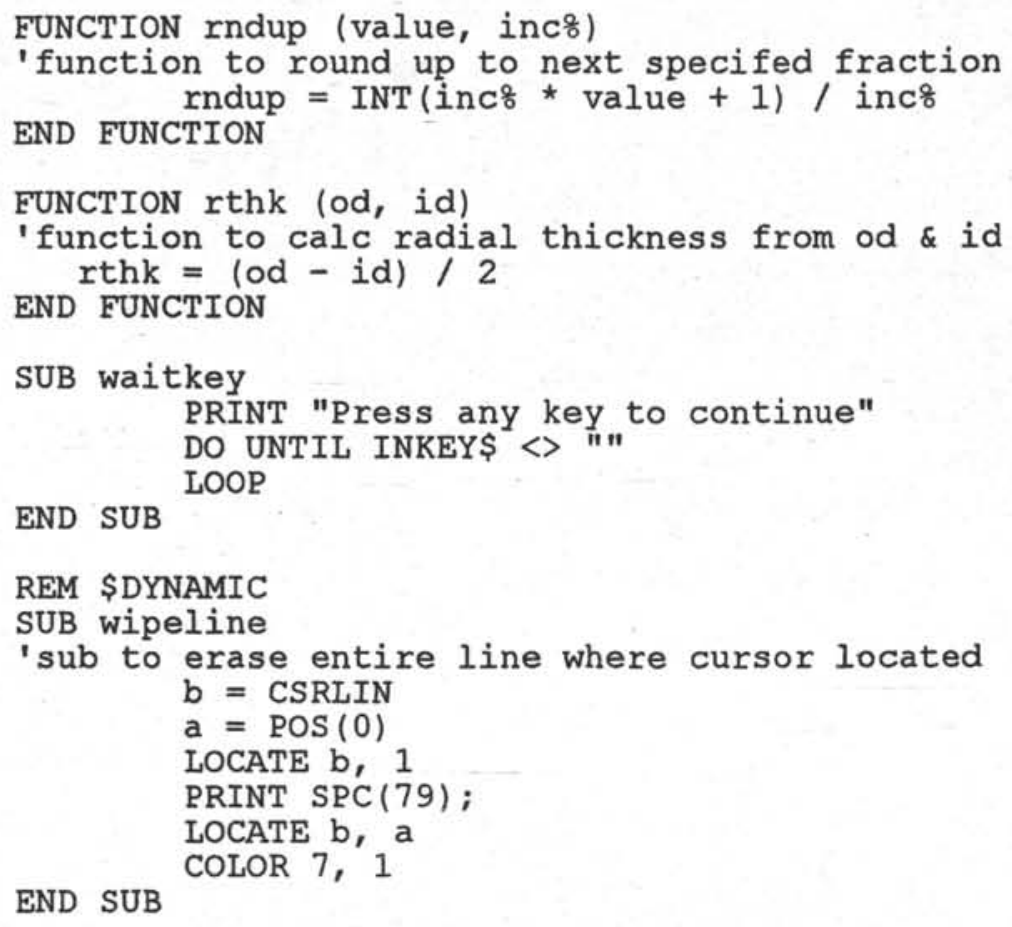


Appendix $\mathbf{J}$

MDCB: Leg 141 Report 


\section{Excerpt from Leg 141 Engineering Report..}

\section{MOTOR DRIVEN CORE BARREL (MDCB)}

\section{Motor Driven Core Barrel Deck Test \\ Leg 141 Transit}

\section{Summary}

The Motor Driven Core Barrel (MDCB) was deck tested successfully on November 21, 1991 during the Leg 141 transit from Panama to Valparaiso. Two fifty-five gallon drums filled with cement, unconsolidated sand, gravel, and rocks were used as the formation. The BHA with the MDCB inside was set down on the drum with the main bit holding the drum in place for each test. Nozzle combinations of $4 / 4$ bit nozzles and $10 / 11$ and $10 / 10$ thruster nozzles were used for the testing. At the specified flow rate of $190 \mathrm{gpm}$ (38 strokes per minute) this provided an estimated WOB of 4500-5000 lbs and 5000-5600 lbs, respectively.

Seven "coring runs" were done with results as follows;

A) Three successful runs cored completely through the drum. Two were done with a new, piloted surface set mining bit in $2 \mathrm{~min} .30 \mathrm{sec}$. each(about $15 \mathrm{~m} / \mathrm{hr}$ ROP), and a third with a new impregnated bit in $4 \mathrm{mins} 40 \mathrm{sec}$.(about $8 \mathrm{~m} / \mathrm{hr}$ ROP)

B) One run experienced a core jam.

C) One run suffered extremely slow ROP due to improper bit selection. The new impregnated bit had a matrix too hard for our formation; no diamonds were exposed after coring 12 in.

D) Two unsuccessful runs were due to improper throat I.D. on impregnated bit; the throat was too large. Incoming core was insufficiently trimmed to pass through the smaller I.D. core catcher resulting in immediate core blockage.

Standpipe pressures were usually within 10-15 percent of those predicted from testing done at Stress Engineering Services in Houston during September 1991.

The new positive latch system was mostly successful. The latch released the hex kelly at between $350-400$ psi consistently through all the runs. However, there was a problem with relatching the kelly twice during the testing. After supposedly relatching the system, it scoped out again unexpectedly. We suspect that friction from the new latch mechanism requires more energy to relatch the system. This problem will be looked at in depth in the coming months.

The new 3-1/2 in. quick release system was also used with success. Breaking the core barrel and thruster barrel apart was done in a few seconds. The unit was slightly more difficult to put back together, but with practice it should be comparable to the old quick release. 


\section{Description of Testing}

Two fifty-five gallon drums had been filled with 25 in. of cement, unconsolidated sand, gravel, and rocks at ODP prior to the Leg 141 Transit for the MDCB deck testing. The MDCB was assembled with the new positive latch system and the new 3-1/2 in. quick release. The BHA was configured for MDCB work with a $10 \mathrm{ft}$. drill collar, a $3 \mathrm{ft}$. drill collar, and the "Monel" latch above our standard APC/XCB BHA. The MDCB was placed inside the BHA, and the entire BHA was lifted and set down on the first drum, with the main bit holding the drum in place.

The first two coring runs were done with a $4 / 4$ bit nozzle and $10 / 11$ thruster nozzle configuration and a new, piloted, surface set mining bit. We estimated that for a pump rate of $190 \mathrm{gpm}$ (38 strokes per min.) this would give us a weight on bit of 4500 to $5000 \mathrm{lbs}$. with a standpipe pressure between 1750 and 2050 psi. These figures were arrived at from test data taken at Stress Engineering Services in Houston during September 1991 and an estimated required torque for coring the cement/rock formation. During the first run the actual standpipe pressure was $1550-1750$ psi. The MDCB cored through the drum in 2 min $30 \mathrm{sec}$., which corresponds to a rate of penetration (ROP) of approximately $15 \mathrm{~m} / \mathrm{hr}$. The pressure during the second core run dropped from 1875 psi initially to about $1400 \mathrm{psi}$. We stopped coring after 5 minutes on the second run and raised the barrel. The bit had cored approximately $18 \mathrm{in}$. and had been blocked off.

The remaining five tests were performed with a $4 / 4$ bit nozzle and a $10 / 10$ thruster nozzle configuration, increasing WOB to 5000-5500 lbs. Two unsuccessful runs were done with an impregnated mining bit only to discover that the bits throat I.D. was considerably larger than specified. This caused immediate core blockage at the smaller I.D. core catcher. We switched back to the piloted, surface set bit for the fourth run. Breakthrough was again achieved in 2 mins. $30 \mathrm{sec}$. as on the first run. The two final tests were run with new, impregnated coring bits. The matrix on the first of these bits was too hard for our formation; after coring 12 in. no new diamonds were exposed and coring was effectively stopped. The final test achieved breakthrough in $4 \mathrm{mins} 40 \mathrm{sec}$.(about $8 \mathrm{~m} / \mathrm{hr}$ ROP). We flushed the unit with drill water prior to breaking it down and storing it in the scabbards.

The positive latch system released at between $350-400$ psi consistently through the test. On two occasions the hex kelly came unlatched unexpectedly. The reason for this was unexplained. Our initial thoughts were that the new latch mechanism required more energy to overcome its friction and relatch. Both times the kelly was relatched by the weight of the motor and thruster assembly without further incident.

The new 3-1/2 quick release assembly was also tried during the test. Releasing the core barrel was extremely fast. Slightly more effort was needed to makeup the connection; however, the second time went easier and with more practice should be adequate. 


\section{Test Data}

\section{Run\#1}

Bit Nozzles $\quad: 4 / 4$

Thruster Nozzles : $10 / 11$

Coring Bit $\quad$ : New, Piloted Surface Set

$\begin{array}{lll}\underline{\text { Time }} & \underline{\text { Strokes }} & \underline{\text { Pressure }} \\ 0: 30 & 37 & 1550 \\ 1: 00 & 38 & 1650 \\ \text { 1:30 } & 38 & 1700 \\ \text { 2:30 Through bottom of drum } & \end{array}$

\section{Run \#2}

$\begin{array}{cll}\begin{array}{ll}\text { Bit Nozzles } \\ \text { Thruster Nozzles }\end{array} & \begin{array}{l}: 4 / 4 \\ : 10 / 11\end{array} \\ \text { Coring Bit } & : \text { New, Piloted Surface Set } \\ & \text { Strokes } & \underline{\text { Pressure }} \\ \underline{\text { Time }} & 44 & 1875 \\ 0: 30 & 38 & 1500 \\ 0: 45 & 36 & 1400 \\ 1: 00 & 36 & 1400 \\ 1: 30 & 36 & 1400 \\ 2: 00 & 37 & 1400 \\ 2: 30 & 36 & 1400 \\ 3: 00 & 36 & 1450 \\ 3: 30 & 36 & 1450 \\ 4: 00 & \end{array}$




\section{Run \#3}

Bit Nozzles : $4 / 4$

Thruster Nozzles $\quad: 10 / 10$

Coring Bit : Old, Impregnated

$\begin{array}{cll}\underline{\text { Time }} & \underline{\text { Strokes }} & \text { Pressure } \\ 0: 30 & 38 & 1650 \\ 1: 00 & 38 & 1650 \\ 1: 30 & 38 & 1700 \\ 2: 00 & 38 & 1650 \\ 2: 30 & 38 & 1675 \\ 3: 00 & 38 & 1650 \\ \text { I } & \mid & \mid\end{array}$

8:00 Stopped, (Bit throat too large, core jammed ; discovered after Run \#4)

\section{Run \#4}

$\begin{array}{clc}\begin{array}{ll}\text { Bit Nozzles } \\ \text { Thruster Nozzles }\end{array} & \begin{array}{l}: 4 / 4 \\ : 10 / 10\end{array} \\ \text { Coring Bit } & : \text { Old, Impregnated } & \\ & \underline{\text { Strokes }} & \frac{\text { Pressure }}{2100} \\ \frac{\text { Time }}{0: 30} & 45 & 1600 \\ 1: 00 & 38 & 1600 \\ 1: 30 & 38 & 1600 \\ 2: 00 & 38 & 1600 \\ 2: 30 & 38 & \\ 3: 00 & \text { Stopped, Bit throat too large, core jammed }\end{array}$




\section{$\underline{\text { Run \#5 }}$}

Bit Nozzles $\quad: 4 / 4$

Thruster Nozzles $\quad: 10 / 10$

Coring Bit $\quad$ : New, Piloted Surface Set from Runs \#1 \& \#2

$\begin{array}{lll}\underline{\text { Time }} & \underline{\text { Strokes }} & \text { Pressure } \\ 0: 30 & 38 & 1750 \\ 0: 45 & 38 & 1800 \\ 1: 00 & 39 & 1850 \\ 1: 15 & 39 & 2000 \\ 1: 30 & 39 & 2000 \\ 1: 45 & 39 & 2000 \\ 2: 00 & 39 & 2150 \\ 2: 15 & 39 & 2050 \\ 2: 30 & \text { Through drum } & \end{array}$

\section{$\underline{\text { Run \#6 }}$}

\begin{tabular}{|c|c|c|}
\hline Bit Nozzles & $: 4 / 4$ & \\
\hline Thruster Nozzles & $: 10 / 10$ & \\
\hline Coring Bit & : New, I & "Green" \\
\hline$\underline{\text { Time }}$ & Strokes & Pressure \\
\hline $0: 30$ & 40 & 2100 \\
\hline $0: 45$ & 40 & 2100 \\
\hline $1: 00$ & 40 & 2100 \\
\hline $1: 30$ & na & na \\
\hline $2: 00$ & 40 & 2150 \\
\hline $2: 30$ & 39 & 2150 \\
\hline
\end{tabular}

2:52 Stopped, 18 in. penetration, bit not worn, matrix too hard 
Run \#7

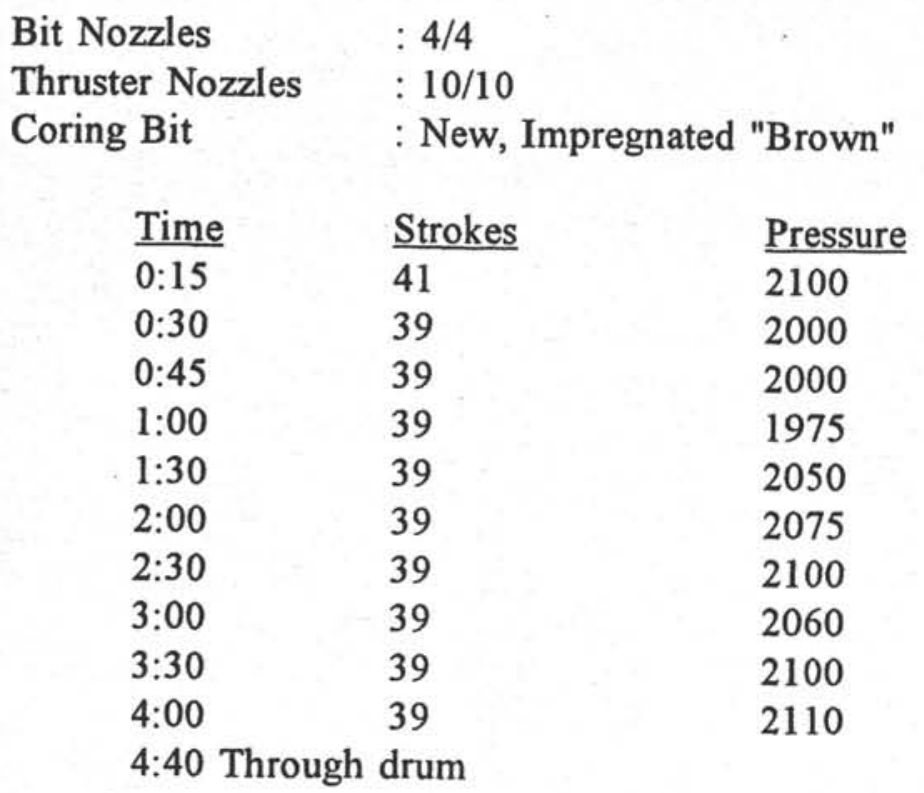


At Hole 863B the MDCB was deployed for Cores $7 \mathrm{~N}$ and $8 \mathrm{~N}$ shortly before the XCB/MDCB BHA was to be pulled to change to the RCB drilling mode in the same hole. The formation was very firm siltstone with some cemented sandstones. Non-cemented, loose constituents may have been present. The formation was either quite fractured or very fracturable. It had already proved to be too tough for several TC-insert, hard formation XCB cutting shoes.

Core 7N: Recovered $2.51 \mathrm{M}$, about half highly fractured and half well preserved and trimmed. Recovery percentage appeared to be 100 (although lack of penetration indicator makes this only an estimate at best. The estimate was made based on the amount of paint worn off of the outer core barrel.) A surface set piloted diamond bit was used with about $5000 \mathrm{lbs}$ wob. Coring time was 32.5 Mins and ended when pressure suddenly climbed 1400 psi and held there (to $3000 \mathrm{psi}$ ). The bit was undamaged and unclogged. No core was blocked in the bit or core catchers.

Core 8N: Recovered $1.37 \mathrm{M}$ very similar to core $8 \mathrm{~N}$. On this run penetration was clearly about $4 \mathrm{~m}$ so some core had to have been washed away. An ODP-designed sawtooth impregnated bit was used with about $5000 \mathrm{lb}$ WOB. The bit had only about 10 percent wear. Coring time was 51 mins and the run was terminated arbitrarily due to length of time downhole. End-of-stroke indication was induced during pullout while the motor was still running (minus $700 \mathrm{psi}$ ).

Both runs: Pressures (at a constant flow rate) were about $350 \mathrm{psi}$ lower than the cement barrel deck tests when using the same bit and also lower than predicted ranges. Rpm was $360-400$ (according to charts). In both runs the tool apparently stroked out during pump down and seemed to stroke back together at bottom for 3-4 minutes before actually beginning to core. This was indicated by a low starting pressure that gradually built up to operational pressure as the seals engaged the seal bore drill collar. There were no apparent adverse affects from this, however.

$\mathrm{XCB}$ Cores $5 \mathrm{X}$ and $6 \mathrm{X}$, just before the MDCB run recovered only jammed cutting shoe samples, $0.27 \mathrm{M}$ and $0.46 \mathrm{M}$. Core $9 \mathrm{X}$, after MDCB runs, recovered a similar small amount $0.52 \mathrm{M}$. Recovery rate and quality of preservation in the MDCB cores were greatly superior to the XCB cores immediately before and after.

Conclusions: Except for the premature scope-out, and low pump pressures the tool performed exactly as expected. ROP could have been better but perhaps it will improve with experience. No doubt that a pilot hole for GEOPROPS could have been made under these conditions. (Whether such a hole would remain open long enough to insert GEOPROPS is still the big question.) Minor design improvements to the MDCB can upgrade speed of deployment, reduce on-deck handling and turnaround time, and fix improper scope-out tendencies.

The MDCB components and small mudmotor will stay aboard for possible use on legs 143, 144, 145 and for GEOPROPS support on Leg 146. 


\section{DATA FROM CORES 7N AND 8N}

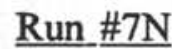

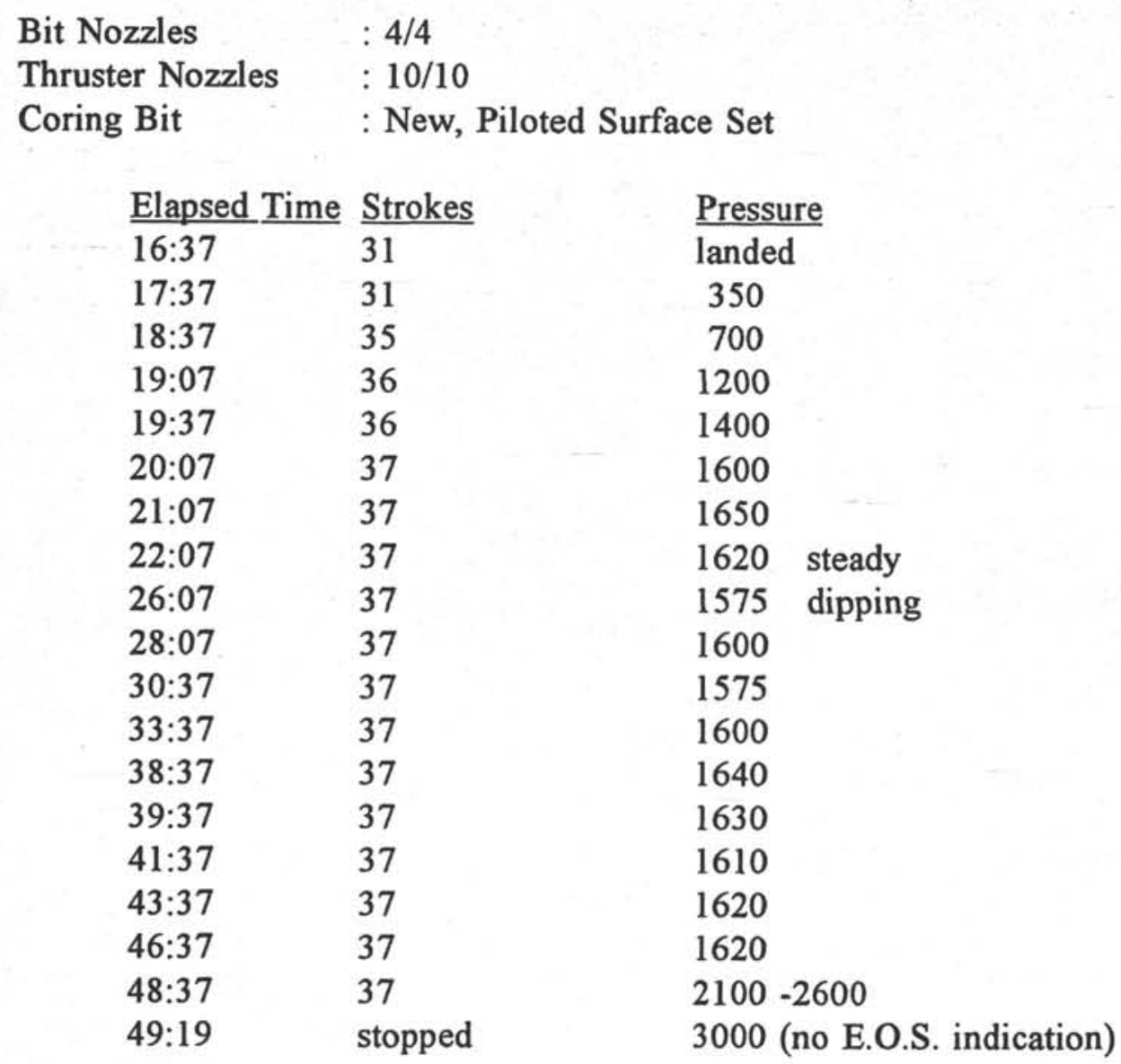




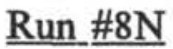

\begin{tabular}{|c|c|c|}
\hline $\begin{array}{l}\text { Bit Nozzles } \\
\text { Thruster Nozzles } \\
\text { Coring Bit }\end{array}$ & $\begin{array}{l}: 4 / 4 \\
: 10 / 10 \\
: \text { New, }\end{array}$ & ce Set \\
\hline Elapsed Time & Strokes & Pressure \\
\hline 00:00 & 36 & landed \\
\hline 01:00 & 36 & 350 \\
\hline 02:00 & 36 & 350 \\
\hline $02: 15$ & 33 & 700 \\
\hline 03:00 & 38 & $\mathrm{p} / \mathrm{u}$ pipe and \\
\hline 05:00 & 34 & relower. \\
\hline $05: 30$ & 34 & 1750 \\
\hline $06: 30$ & 36 & 1650 \\
\hline 09:00 & 36 & 1575 \\
\hline $12: 00$ & 37 & 1700 \\
\hline $15: 00$ & 37 & 1700 \\
\hline $18: 00$ & 36 & 1590 \\
\hline $19: 45$ & 37 & $1750-2300$ \\
\hline $24: 00$ & 37 & 1585 \\
\hline $27: 00$ & 37 & 1625 \\
\hline $30: 00$ & 36 & 1520 \\
\hline $33: 00$ & 37 & 1550 \\
\hline $36: 00$ & 37 & 1590 \\
\hline $40: 00$ & 37 & 1590 \\
\hline $43: 00$ & 36 & 1550 \\
\hline $48: 00$ & 36 & 1540 \\
\hline $51: 00$ & $\mathrm{POOH}$ & \\
\hline
\end{tabular}

Core $8 \mathrm{~N}$ was pulled out of the hole with the pumps still on at 36 strokes and the pressure dropped off to 850 indicating End Of Stroke!! 


\section{Appendix K}

\section{MDCB: Leg 144 Report}




\section{Excerpt from Leg 144 Engineering Report..}

\subsection{Motor Driven Core Barrel (MDCB) 873B}

\subsection{Background}

The motor driven core barrel (MDCB) was deployed at Hole 873B in an attempt to capture the interface material between the pelagic cap and manganese crusted-limestone which had not been recoverable with either the XCB or RCB on previous holes. The MDCB was run three times beginning at 1403 meters and ending at 1414 meters. Cores were consecutively numbered $8 \mathrm{~N}, 9 \mathrm{~N}$, and $10 \mathrm{~N}$. All the core runs were performed with the same geoset diamond bit and with the same flow settings. The motor was set with one 12/32 nozzle and one 14/32 nozzle. The bit nozzles were set with two $3 / 32$ jets. Recovery rates with the RCB through the same interval on Hole $873 \mathrm{~A}$ was less than 2 percent as compared to the 39 percent for the MDCB in Hole 873B. The two holes were approximately 100 meters apart. Individual pressure recordings of the tests are summarized on Figures 1 through 3 with a plot of the pressure versus time illustrated on Figure 4.

\subsection{Performance}

\section{$\underline{5.2 .1}$ Core $\underline{8 \mathrm{~N}}$}

The MDCB was deployed after the APC had violently impacted the interface boundary resulting in the liner being splintered and the brass bushing in the GS overshot being flattened. It was doubtful for a while if the APC was going to be able to be retrieved by the wireline or if the string was going to have to be pulled to recover the APC. Finally after 30 minutes and several attempts with refitted overshots, the APC was retrieved. With the interface boundary found, the MDCB was tried with a geoset diamond bit. The formation was expected to be limestone coated with a thin layer of manganese.

The MDCB took approximately 11 minutes to free fall to the bottom of the hole with the DES depth recorded as 1403 meters. The mud pump was running at 20 SPM during the descent. The outer bit was compensated with $10,000 \mathrm{lbs}$ WOB but was not rotated during the test. Once landed, 475 - 500 psi registered on the mud pump gauge. The strokes were brought up to 39 SPM without any further pressure increase being seen. The flow rate was held constant for over 20 minutes without any EOS signal. It was hypothesized that the previous APC might have left something in the hole which was obstructing the MDCB from landing out or that the bit/space out was slightly longer than the outer barrel assembly. The pipe was raised off bottom of the hole slightly to see if either of the above problems might be occurring. As soon as the bit was raised, pressure begin building in the string. The string was immediately set back down on the bottom of the hole as the core barrel being rotating into the formation. Pressures consistently dropped until the end of stroke indication was observed approximately 5 minutes later. The pressure stabilized at $850 \mathrm{psi}$. The barrel was retrieved with 2.17 meters of core recovered, even 
though the barrel had plugged off. Paint markings on the barrel indicated that a full stroke was obtained thus verifying the EOS signal was valid. Core jam appeared to have occurred in the liner. The recovered sample using the hard formation core catcher showed gouges around the diameter.

\subsubsection{Core $9 \mathrm{~N}$}

The second core cut with the MDCB was attempted after the previous core was reamed out without an XCB inner barrel installed. Free fall time of the barrel was recorded as 8 minutes. The pressure was again observed to hover around 475 to 500 psi until the pipe was again picked up to initiate rotation. The test data for the second test appears very similar to the first test performed. A high initial pressure was recorded with constant pressure thereafter. However, just before the EOS was observed, the pressure increased momentary to nearly as high as the initial starting pressure.

A core jam was obvious from the effort it took to remove the sample from the core catcher. The amount of recovery was recorded as 1.05 meters. The worn paint marks on the barrel again verified the EOS signal observed on the pressure gauge. Gouging was again noted on the sample.

\subsubsection{Core $10 \mathrm{~N}$}

The third test appeared to resemble the second test in many ways however the EOS signal was never observed after 28 minutes of rotation. The pipe also had to be picked up off bottom for core initiation to begin. The flow rate or 42 SPM was slightly higher than the optimum recommended which might partly explain the evaluated pressures that were observed. There was a pressure spike near the end of the run but not followed with a decrease in pressure as observed in either of the previous tests. Once the pipe was lifted off the bottom of the hole it was several minutes later and 13 meters off the bottom before the pressure dropped to 850 PSI while the pump was still running. Recovery for the third test was recorded as 1.08 meters. Jamming was again noted in the liner. The barrel apparently never reached full penetration since the EOS signal was observed late in the test sequence. Paint marking on the barrel were of little value in determining the amount of penetration.

\subsection{Conclusions/Recommendations}

The tool appeared to perform as designed except for having to lift the bit off the bottom of the hole to initiate the test. The rate of penetration (ROP) appeared to be adequate and occur within the suggested time limits of testing. Core quality was excellent especially in the brittlebone-marrow like structure of the soft limestone recovered. Core jamming may continue to be a problem in soft granular formations where the skin friction and gouging developed against the wall of the liner is more than what can be developed to overcome it at the tip. Additional operating hours in different material types will be needed to better understand the flow characteristics (nozzle influences on recovery rate) of the MDCB in order to optimize the core recovery. 
The turn-around time of the tool was less than 20 minutes. The new quick connect latch seems to work well. However it is recommended that a positive means of engagement be devised on the back of the dogs (threaded hole) in place of prying them out which possibly might result in loss down the hole of one of the dogs. An alternative location to restroke the tool, besides inside the pipe might be devised to enhance turn-around time if a large number of MDCB tests are to be performed. This might also reduce the potential for dropping items down the hole by not having to work over it. A second core barrel would also greatly reduce the time on deck and provide a clearer picture as to the depth of penetration by the paint having time to dry before being redeployed. A second barrel might also provide a better opportunity for comparison to run different nozzle combinations while alternating the two barrels. A small strip chart recorder to monitor mud pressure during the test would be beneficial to aid in better correlation between core recovery and jet size. While not always a positive indicator, feeling the pipe during operation can provide tell tale signs if the motor is working or stalled. This indicator may be limited to shallower water depths though. 


\section{Appendix L}

\section{MDCB: Operator's Manual}




\title{
Motor Driven Core Barrel MDCB-141
}

\author{
Operator's Manual
}

Original Updated Updated
D. Huey

D. Huey

B. Rhinehart
Leg 134

Leg 141

Leg 152
December 1990

January 1992

November 1993 


\section{Table of Contents}

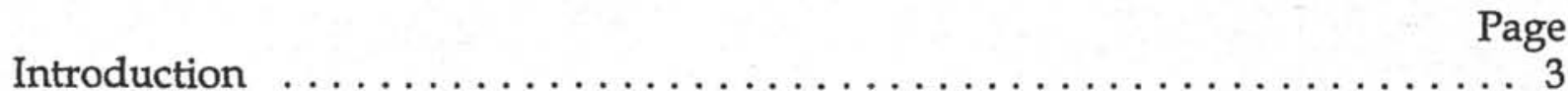

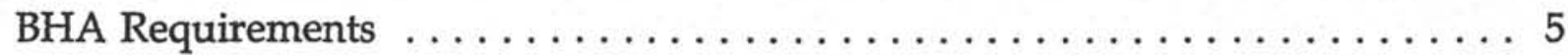

Sinker Bar/Pressure Case Requirements $\ldots \ldots \ldots \ldots \ldots \ldots \ldots \ldots$

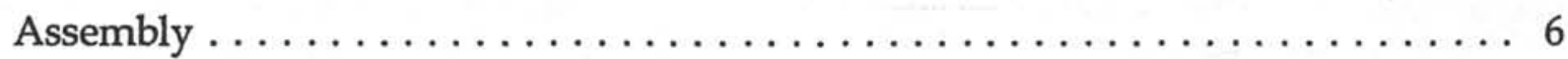

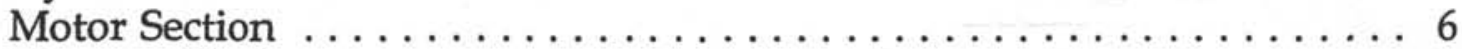

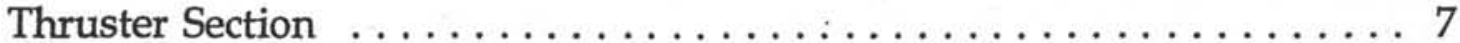

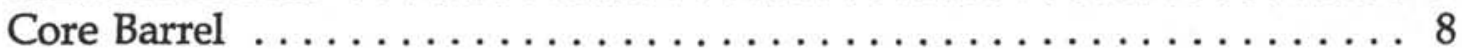

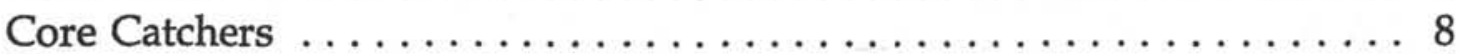

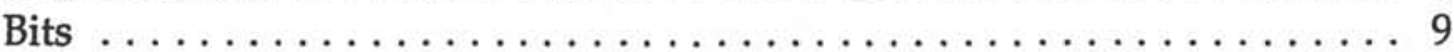

Operating Parameters and Procedures $\ldots \ldots \ldots \ldots \ldots \ldots \ldots \ldots \ldots \ldots \ldots$

Selecting the Bit Flow and Thruster (WOB) Nozzle Size $\ldots \ldots \ldots \ldots 11$

Normal Operating Mode $\ldots \ldots \ldots \ldots \ldots \ldots \ldots \ldots \ldots \ldots \ldots \ldots \ldots \ldots \ldots$

Handling on Deck ........................ 13

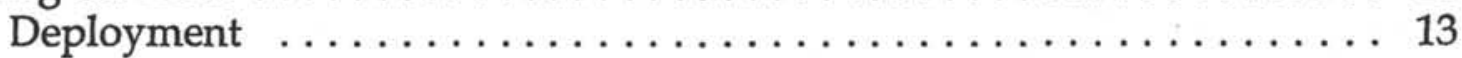

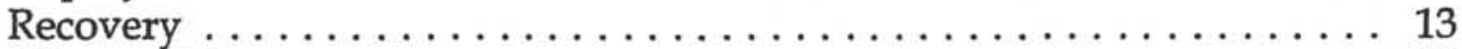

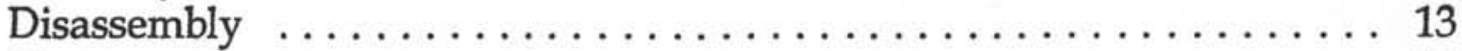

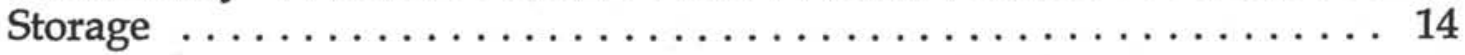

Appendix A: Operating Parameter Charts for the MDCB

Appendix B: Parts List for MDCB 


\section{INTRODUCTION}

The MDCB-141 is an improvement to a third generation of the coring tool formerly known as the Navidrill Core Barrel (NCB2). It is designed to take a $4.5 \mathrm{~m}$ long core. The biggest change in the MDCB design was the repositioning of the motor and thruster sections. The motor in the NCB2 was immediately above the core barrel section and was allowed to move down as the core barrel advanced. This system made motor pressure drop, which was variable, a part of the thrust pressure which created weight on bit (WOB). The resulting positive feedback almost always caused the motor to stall when tough coring conditions were encountered.

The MDCB-141 has the thruster section between the motor and the core barrel. The motor is on top of the overall assembly and sits firmly on the landing shoulder in the seal bore saver sub; its variable pressure drop is not felt as part of the WOB thrust. The seawater pumped down the pipe is allowed to flow both through the motor (about $85 \%$ ) and around the motor (about 15\%). The portion passing through the motor creates both torque and weight on bit. The portion of the flow allowed to pass around the motor goes exclusively to the diamond bit at the end of the core barrel. This arrangement leads to negative pressure feedback which keeps the system from stalling when coring conditions get difficult.

The design of the new MDCB-141 was based on an extensive computer model analysis. The Summary Report on MDCB Engineering Development by Stress Engineering Services (in the Ops office) explains how this testing was done. The report also has general advice on how to best use the MDCB and some of its subsystems.

The motor used is a 3-3/4" Eastman-Christensen Mach 1P "drainhole technology" positive displacement mudmotor. It produces a higher combination of torque and rpm than any motor previously available in this size range. Because it has much more torque than the motors used with NCB2 it produces very stable output with minimum rpm variation even when the formation changes suddenly. It is left in its normally oversized O.D. (about 3.82 inches as received from the factory) because it does not enter the restricted I.D. of the seal bore drill collar

There have been many design changes to make the MDCB easier to operate. Assembly simplification is one improvement. Ease in changing nozzles is another added feature. There are four nozzles: two swivel nozzles to control flow to the diamond bit, and two thruster nozzles in the nozzle sub which determine WOB. All four can be changed from the outside of the tool without disassembly. Also, there are no dynamic external seals, so seal replacement is less frequent.

The other big change in the design since NCB2 is in the latch/release/shock absorber systems. The shock system has been deleted. The fussy little ball release 
system has been replaced with an external collet latch. There are no pre-loaded springs to control the release mechanism. The tendency to lunge into the formation after latch release has been throttled with a damping chamber that is automatically filled with seawater inside the pipe when the tool is dropped.

The damping chamber is the annulus between the hex kelly and the thruster barrel, below the thruster piston assembly and above the hex seals in the latch sub. When the thruster piston and kelly try to move down, the fluid in the damping chamber must be expelled. If the check valves (in the piston assembly and the check off sub) and hex seals do not leak the only path for the fluid to escape is through a $1 / 32$ inch orifice in a set screw in the piston assembly. Fluid can only escape slowly so the core barrel can not lunge ahead rapidly -- either at latch release or when the core barrel breaks through a firm formation into a soft one. Some leakage in the seals and check valves is tolerable. During deck tests on Leg 134 the slow motion advance of the core barrel after collet release was visually observed and verified.

A locking piston has also been added just below the thruster section. This locks the thruster in place until a pressure differential from the mud pump flow forces it to release the collet fingers. This is intended to prevent the premature release of the thruster hex kelly while deploying the barrel.

There is one other sub-system new to the MDCB design: the end-of-stroke indicator. The end-of-stroke (EOS) system is triggered by the thruster piston when it pulls down the flow tube at the physical end of the stroke. This, in turn, changes the flow path through the internal passages in the swivel forcing the EOS shuttle to move down. At that point a large pressure drop (800-1200 psi) is seen on deck as the motor flow is allowed to bypass the motor. 


\section{BHA REQUIREMENTS}

Refer to assembly drawing R-OP8000 for BHA and coring assembly details.

The BHA required for MDCB work is a slight modification of the normal $\mathrm{APC} / \mathrm{XCB}$ bottom hole assembly. It consists of:

Bit

Long Bit Sub w/LFV

Seal Bore Drill Collar

Landing/Saver Sub

Long Top Sub

Head Sub w/Double window latch sleeve

10-ft Drill Collar Sub, OGO340

MDCB Latch Sub, OL1050

Regular 8-1/4 DC -or- 30-ft Non-Mag DC

No latch sleeve is required in the MDCB Latch Sub.

\section{SINKER BAR/PRESSURE CASE REQUIREMENTS}

The BHA must allow APC, XCB and MDCB coring interchangeably. Since the MDCB BHA has more elements below the non-magnetic $D C$ than the regular $\mathrm{APC} / \mathrm{XCB}$ version, the start of the non-mag $\mathrm{DC}$ zone is almost 18 feet higher than normal. This requires an extension to the sinker bar assembly so that magnetic orientation tool is centered in the non-mag DC. Two 10 feet sinker bars (OT3200) are used below the two 78 inch non-magnetic sinker bars (OT4755) to provide this extension. See OP6602 for a schematic of the core barrel and sinker bar options between $\mathrm{APC}, \mathrm{XCB}$, and $\mathrm{MDCB}$.

NOTE: The pressure case assembly MUST be realigned whenever the extender assembly is added to, or removed from, the standard non-magnetic pressure case assembly used for routine oriented APC coring. 


\section{ASSEMBLY}

The MDCB (OP8000) can be thought of as three separate sub-sections:

* Motor section,

* Thruster section,

* Core barrel section.

The motor section consists of, top to bottom, a regular XCB latch, a crossover sub with inlet holes, the Mach $1 \mathrm{P}$ motor, and the motor swivel and swivel housing parts. The break point is the connection between the swivel (OP8010) and the nozzle sub (OP8014).

The thruster section (top to bottom) consists of the nozzle sub, thruster barrel, check off sub, latch sub, latch $x / o$ sub, and sealed male quick release. Inside the thruster barrel is the thruster piston and kelly; inside the kelly is the flow tube.

The core barrel section (top to bottom) consists of the sealed female quick release, the modified core barrel head, HWD4 core barrel, reaming shell, and diamond core bit. Inside the core barrel is the bearing assembly, inner tube adapter, inner core tube, long inner tube breakoff sub, and core catcher.

Assemble all three sections separately. Both the core barrel and thruster sections need more space for assembly than is convenient in the CT shop. The roof of the CT shop has been used in the past. When running the MDCB it is handy to leave the motor section and thruster section assembled and hanging in the working stands between runs.

\section{MOTOR SECTION}

Assembly of the motor section is straight forward. The only items deserving particular attention are: Be aware of the left hand threads on the packing nut (OP8024) and at the top of the swivel housing (OP8018) where the housing attaches to the motor. With the swivel housing made up to the motor, the swivel can be made up to the motor drive shaft (RH thread). To stop the motor drive shaft from turning insert stop pieces through the holes in the swivel housing until they engage the recesses on the drive shaft. Kinley crimper knives work perfectly as stop pieces. Hold them in with a C-clamp.

The XCB latch at the top of the assembly is standard, no modifications are required. The dogs on the latch seek the vertical slots in the MDCB Latch Sub in the $\mathrm{BHA}$ to react to the drilling torque produced by the mudmotor.

The polypak in the swivel should be installed without its o-ring energizer. 
There is a "Rulon bearing" next to the polypak which is made from a roll of $1 / 16$ " thick Rulon, teflon impregnated tape. Cut it off with scissors at an angle and trim to fit so it covers the circumference of the swivel. No glue or anything required. The set screw in the side of the swivel is there to close off a hole that was required during fabrication. It is staked in place and should not need to come out.

\section{THRUSTER SECTION}

Assembly of the thruster section is more difficult. The kelly, piston and flow tubes all slide relative to one another but require a dinky tugger line to overcome friction and seal drag. The collet latch sub can be both latched and unlatched with the pull of a dinky tugger to aid in assembly and disassembly. The kelly slides much more easily through the hex seal in the latch sub if the seal compression is relaxed by backing off the connection between the latch sub and the check off sub. The last two steps in assembling the thruster section are to make up the latch sub to the checkoff sub, and to snap the collet together. The latch sub must rotate around the hex seal pack as the connection is made up so some stiffness is expected.

The hex seal pack in the latch sub is made up of one urethane and two buna-n die-cut hex seals, separated by four brass/delrin spacers. Below the spacers and seals is a selection of stainless steel hex shims. See Figure 1 below. The required thickness of the shim stack is determined thus:

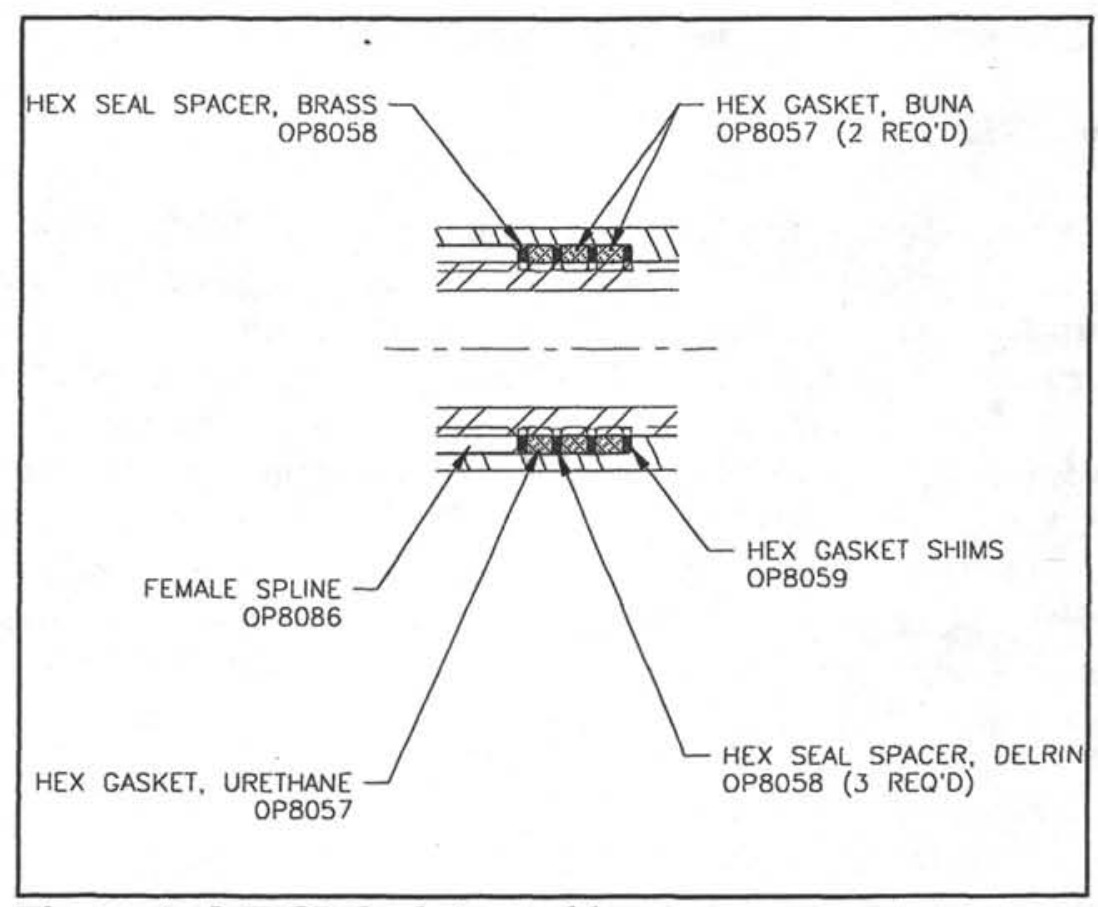

Figure 1: MDCB Seal Assembly 
1. Trim the I.D. and O.D. edges of the hex seals to remove the sloppy finish. The O.D. edges just need to have the excess removed. The I.D. edges can get up to $1 / 16 \times 45$ bevel to help keep the seals from rolling. Scissors work fine for this job.

2. Install (tightly) the four spacers and two buna and one urethane hex seals in the cavity in the latch sub. Again see Figure 1.

3. Measure how much clearance will exist between the seal pack and the female spline when the checkoff sub is fully assembled to the latch sub. (e.g. $0.115^{\prime \prime}$ clearance)

4. Subtract 0.025" (which is the amount the seals will expand lengthwise when the seal pack is jammed over the hex kelly.) e.g. $0.115-.025=$ $0.090^{\prime \prime}$

5. Select the stainless shims to get as close as possible to the remaining gap. (e.g. $1 @ 0.062$, and $\left.1 @ 0.031=0.093^{\prime \prime}\right)$. Place the shim pack below the bottom spacer.

The $1 / 4^{\prime \prime}$ polypropylene ball in the piston check valve is the white plastic ball that floats, white plastic delrin balls (used in the checkoff sub check valve), will sink in water. In the check off sub check valve, be sure the $3 / 16^{\prime \prime}$ delrin ball is free to move after installing the fill valve set screw (OP8083). Flush water through it each time it is used. Make sure water will flow in but not out. A third of the way around the check off sub from the angled check valve is a $1 / 4$ NPT pipe plug which is used as a port for pumping the damping chamber full of water for deck tests.

\section{CORE BARREL}

The core barrel assembly is a mining-type HWD4, double tube barrel. The outer barrel is yellow (when new) and is usually chrome plated at the double box ends. Although it looks symmetrical there are actually different threads on each end. The inner tube hangs from a swivel/bearing on top and is adjusted so about $1 / 10$ $1 / 8$ inch of gap is left at the bottom where the core catcher sub almost meets the inner profile of the bit. The gap is vital for proper flow to, and around, the diamond bit. The inner tube has a breakoff sub and a core catcher sub at the bottom. Polycarbonate liners (slightly smaller than ODP butyrate liners) are available for use when desired but are not mandatory. Be sure there is a clean, steel check ball in the inner tube adapter on the bottom of the bearing assembly. The anti-jam assembly at the top of the inner tube is not yet used with the MDCB.

\section{CORE CATCHERS}

There are two choices for core catchers - dog type and full-closure type. They are physically interchangeable. The default is the dog type (OP5963) since it 
is a general purpose catcher. The full-closure type (OP9833) is an experimental catcher from Longyear with three series of fingers for medium to soft formations, such as clay or sand. There are also standard Christensen soft-formation catchers on board, but they are recommended as a last resort.

\section{BITS}

There are five types of diamond bits available - geoset, tungsten carbide, impregnated, surface set, and "special". Please see Table 1 below for MDCB bit suggested operating parameters.

Table 1: Suggested Bit Operating Parameters

\begin{tabular}{|r|c|c|c||}
\hline \hline Bit Type & RPM & WOB & GPM \\
\hline Geoset & $250 / 400$ & $4,000 / 10,000$ & $15 / 25$ \\
\hline Tungsten Carbide & $250 / 400$ & $2,000 / 4,000$ & $15 / 25$ \\
\hline Impregnated & $500 / 650$ & $4,000 / 8,500$ & $12 / 16$ \\
\hline Surface Set & $250 / 400$ & $6,000 / 10,000$ & $14 / 18$ \\
\hline
\end{tabular}

Geoset bits (OC0912) - So far these have proven to be the most universal bits in the MDCB arsenal. The WOB range for these is $4-10 \mathrm{k} \mathrm{lbs}$ but is tough to call because the diamond contact area keeps enlarging as the diamonds wear, thus greater WOB is required as they drill. The diamonds are TSD (thermally stable diamond compacts) and look like little triangular pyramids set in the crown. This is a very aggressive bit which is useful for hard rock, soft rock, broken rock or conglomerate. Since the TSD's stand so far off the bottom of the hole there is room for a lot more flow. This results in serious core washing if soft materials are interbedded with hard rock. The bits are vulnerable to shock, overheat and general wear. When most of the TSD's are broken or gone the bit is dead.

Tungsten Carbide (OC0919) - These are soft-formation coring bits from Christensen. As of this writing they had not been used.

Impregnated bits - - The WOB range for 3-3/4 inch impregnated bits is given as $4-8 \mathrm{k}$ lbs. These are general purpose bits that the mining industry uses for every formation from very hard rock, to shale, to loose rubble. They may be subject to. balling up in sticky formations. These bits work by wearing away the soft matrix material and continuously exposing new diamonds to the rock. A good, well broken- 
in, impregnated bit feels like rough sand paper on the face. The matrix hardness is indicated by the color of the bit. The medium, or normal, hardness bits (OC0908) are green. A harder matrix bit (OC0906, silver) is used for harder rock so that the matrix wears away at the correct rate, exposing new diamonds. The piloted, face discharge impregnated bits (OC0917) are best for hard/soft interbeds since they will not break through into the soft material all at once.

Surface set bits - - The WOB range for these is $6-10 \mathrm{~K}$ lbs. These are the bits with small, rounded diamonds set exposed from the crown material. The mining industry tends to use these for softer, unbroken rock (e.g. limestone), especially nonabrasive material that would have trouble wearing away the matrix on an impregnated bit. Surface set bits are more vulnerable to shock, overheating, and so on than impregs, but stand a better chance of resisting balling if a sticky formation is encountered. It is also a little easier to accidentally wash away core with these bits. When the bit begins to lose or burn its set diamonds it is finished. Watch for ringing out of all the diamonds at one radius. Surface set bits have salvage value so return the used ones to ODP.

Special -- There are several special bit types. The plug bit (OC0916) is a fullface diamond bit specifically for making MDCB pilot holes for tools such as the Geoprops. There are sawtooth impregnated variety that look like one of the old versions of the $\mathrm{XCB}$ cutting shoes. They are also for making $\mathrm{MDCB}$ pilot holes in semi-solid sediment for the Geoprops probe. There is also one "Bulldog" bit with Klusterite instead of diamonds for general purpose use as needed (e.g., run it if there might be a little junk or rubble in the hole). 


\section{OPERATING PARAMETERS AND PROCEDURES}

\section{SELECTING THE BIT FLOW AND THRUSTER (WOB) NOZZLE SIZE}

The operation of the MDCB is very similar to the NCB2, only simpler. It is set up on deck by selecting diamond bit and core catchers, then inserting two pairs of nozzles to achieve the flow to the diamond bit (Bit flow) and the chosen weight on bit (WOB). A suggested starting configuration for the MDCB is as follows:

Bit Geoset (OC0912)

Bit Flow Nozzles . . . . . . . . . . . . . . . . . . . . 3/32" \& 3/32"

Thruster nozzles (WOB) $\ldots \ldots \ldots \ldots \ldots \ldots \ldots \ldots . . \ldots 11 / 32^{\prime \prime} \& 12 / 32^{\prime \prime}(11 / 12)$

Pump rate $\ldots \ldots \ldots \ldots \ldots \ldots \ldots \ldots \ldots \ldots \ldots \ldots \ldots \ldots \ldots \ldots \ldots$ gpm (yields $350 \mathrm{rpm}$ )

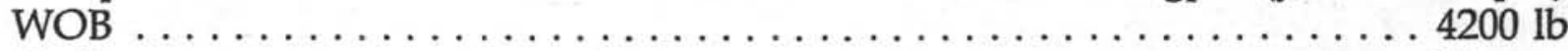

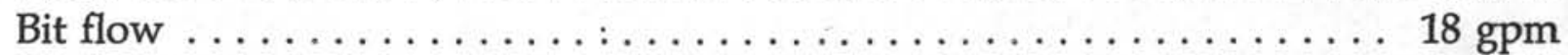
Surface Pressure ......................... 1830 psi

This configuration with the Geoset bit is an overall good starting place for the first MDCB run when little is known about the formation. After that, RAP, bit wear, formation changes, and coring results are used to determine if bit, WOB, and/or bit flow changes are needed.

One can see how the above parameters were arrived at by reviewing the MDCB Operating Parameter Charts in Appendix 1. These charts are the qualitative results from MDCB testing done at Stress Engineering Services in Houston, Texas. Chart 1 shows the motor speed versus the torque required to core the formation at a pump flow rate of $190 \mathrm{gpm}$. The three curves represent the range of nozzle configurations, from the smallest to the largest. Note that there is not a lot of variation in motor speed between the different nozzle configurations. A torque of $240 \mathrm{ft}-\mathrm{lbs}$ is chosen as the starting torque. This number is somewhat arbitrary until more experience with the MDCB is obtained. By following the $240 \mathrm{ft}-\mathrm{lbs}$ line up to just under the $3 / 3-9 / 9$ nozzle combination, a motor speed of approximately 350 rpm is obtained.

The next three charts represent MDCB bit flow nozzle options. Basically there are three options: $3 / 3$ (low flow), 3/4 (medium flow), and 4/4 (high flow), with a set of graphs for each On the second chart, for the $3 / 3$ bit flow nozzle combination, on graph \#1 follow the $240 \mathrm{ft}-1 \mathrm{bs}$ torque line up to the 11/12 line. Move to the left to read the WOB. For this nozzle combination the WOB is approximately $4200 \mathrm{lbs}$. Next, on graph \#2, again following the $240 \mathrm{ft}-\mathrm{lbs}$ torque line up to the 11/12 line gives a bit flow of about $18 \mathrm{gpm}$. Graph \#3 indicates a surface pressure of $1830 \mathrm{psi}$ for this combination.. All of the charts assume $3000 \mathrm{~m}$ water depth. Variation in water depth has little effect on coring parameters. 
To change the operating parameters simply change either the bit flow nozzle and/or the thruster nozzle combinations. Then read the predicted values off the charts. In general, increasing the bit nozzle size increases the bit flow. Decreasing the thruster nozzle size increases the WOB and the standpipe pressure.

Steady higher pressures (500-700 psi greater than predicted by graph \#3) would indicate stall, steady lower pressures (200-500 psi lower) would indicate core block. A sudden drop to pressures $800-1200$ psi lower than normal indicate end of stroke. Experience has shown that standpipe pressures are 10-15\% lower than that predicted by the charts. Even with unexpectedly high or low operating pressures the general trends are still valid: a big change up means stall, a big change down means end of stroke.

\section{NORMAL OPERATING MODE}

The three separate sub-sections of the tool are assembled in the working stands before sticking the whole tool in the pipe and freefalling it to the BHA. It should be pumped down at about 40-50 strokes/min and will take about the same time to reach bottom as an $\mathrm{XCB}$ barrel. Iust before landing the pumps should be cut back to $20 \mathrm{spm}$ (max.) to protect the balls and flapper in the LFV. Three carbide LFV balls were chipped during three MDCB deployments on Leg 134. The MDCB creates a high pressure drop in the BHA -- even at $20 \mathrm{spm}$ there will be no doubt when it lands.

Before the MDCB reaches the BHA the pipe should be on the bottom, heave compensated, and with a minimum of $10-15 \mathrm{~K}$ WOB. It is important to keep at least $10 \mathrm{~K}$ WOB on the Martin-Decker at all times to counter the push-off force produced by the MDCB and its diamond bit. It is recommended that the top drive be allowed to turn the pipe slowly during the whole $\mathrm{MDCB}$ drilling phase to give the driller some early warning if the pipe is about to get stuck.

When the MDCB lands the mud pumps should be turned up until the desired flow rate is achieved. Normal flow for the MDCB is held at $190 \mathrm{gpm}$ so that the motor is allowed to develop optimum rpm. WOB on the core barrel and diamond bit is normally varied by changing the nozzle selection the next core, not by varying mud pump flow rates. With the flow up to $190 \mathrm{gpm}$ all you have to do is wait -either for end-of-stroke indication or for enough time to elapse that the core barrel should have drilled off its full $4.5 \mathrm{~m}$ penetration.

Recovery is done by pulling the pipe up five meters or more with the pumps still on at $190 \mathrm{gpm}$ so that the diamond bit can back-ream its way out of the pilot hole. Then the pumps are shut down and the MDCB is retrieved with the GS overshot. The pump pressure may drop on retrieval as the EOS indicator actuates. 


\section{HANDLING ON DECK}

\section{DEPLOYMENT}

After assembling the three MDCB sections, the deployment procedure is very simple. Hang off all three sections in the working stands. There is no proper upset for the handling clamp on the thruster section so it is best to use TWO handling clamps side-by-side for safety. This is only a temporary step since the motor section and thruster section stay together for the rest of the coring exercise. The motor section must be mated carefully to the thruster section to avoid damaging the uplooking few inches of the flow tube extension.

Make up the quick release between the core barrel section and the thruster section. Please note that you can slightly rotate the thruster section relative to the core barrel section to make it easier for the retaining ring to slide down over the dogs. Move the whole tool to the drill pipe and hang off on a clamp located at the crossover sub on top of the motor. Lift off the pipe with the special, short GS pulling tool attached to a tugger line. Insert a small c-plate over the thin part of the XCB latch bar under the "GS" cup to allow release for freefall. Unfortunately that is the best place for a c-plate. The MDCB is heavy enough to require tugger assistance to pull the c-plate.

\section{RECOVERY}

When the tool comes back on deck it will be scoped out like an APC. It is easiest to scope it back together while still in the drill pipe. Simply lower the upper part of the tool against a handling clamp set immediately below the female quick release. (As the thruster is scoped back together a lot of water will come out of the nozzle sub.) The collet and locking piston will snap back together and lock. Break out the quick release to lay down the core barrel. Again note that you can rotate the two sections relative to each other to "pop" out the quick-release dogs. Be sure to check that the check valve in the check off sub is clear. If it is contaminated it will be obviously leaking as the tool is pulled from the pipe. Also check that the EOS shuttle has returned to its deployment position. The necked portion of the shuttle should be aligned with the small bleed port in the swivel

\section{DISASSEMBLY}

When the MDCB coring operations are finished disassemble the critical parts of the tool and inspect or service the following:

Motor section: Inspect the V-packing on the outside and the polypak, wiper, and Rulon bearing on the inside. Disassemble the EOS shuttle and see that is in good operating condition. 
Flush the motor with fresh water while turning the motor drive shaft so that all salt water is expelled for the rotor/stator. Use the OP8138 Flushing Sub on the top of the motor for proper flushing.

Thruster section: Check the I.D. and O.D. seals on the thruster piston. Confirm that the 1/32" hole in the control orifice set screw is not clogged. Also check for contamination in the thruster piston check valve. Check the hex seal pack.

Core Barrel: Inspect the bit and reamer shell for wear. Clean up the core catcher. Grease the bearing assembly.

\section{STORAGE}

After servicing each of the sections of the MDCB, the three sections can be stored separately in three storage scabbards. Any two sections assembled together are too long for a single scabbard. 


\section{Appendix A: Operating Parameter Charts for the MDCB}

Due to the high running pressures, the flow rate for the MDCB has been downrated from 215 GPM to 190 GPM. Chart 1 attached shows motor speed as a function of torque at $190 \mathrm{GPM}$. Since the tool configuration impacts flow split to the motor, the nozzle combinations will slightly impact the speed vs. torque curves. The three curves represent the smallest, median, and largest nozzle combinations.

Charts 2, 3 \& 4 are the $\mathrm{MDCB}$ operating parameter charts for the three different bit flow nozzle configurations. Note that a new graph has been included called "Cutting Friction". The idea is to observe standpipe pressures, determine the torque range from the pressure and then to convert that to an equivalent "Cutting Friction". If we track this parameter, we may learn something about formation vs. expected torque, or how to adjust WOB. At this time, we have no idea as to what "normal" coring pressures really are. 


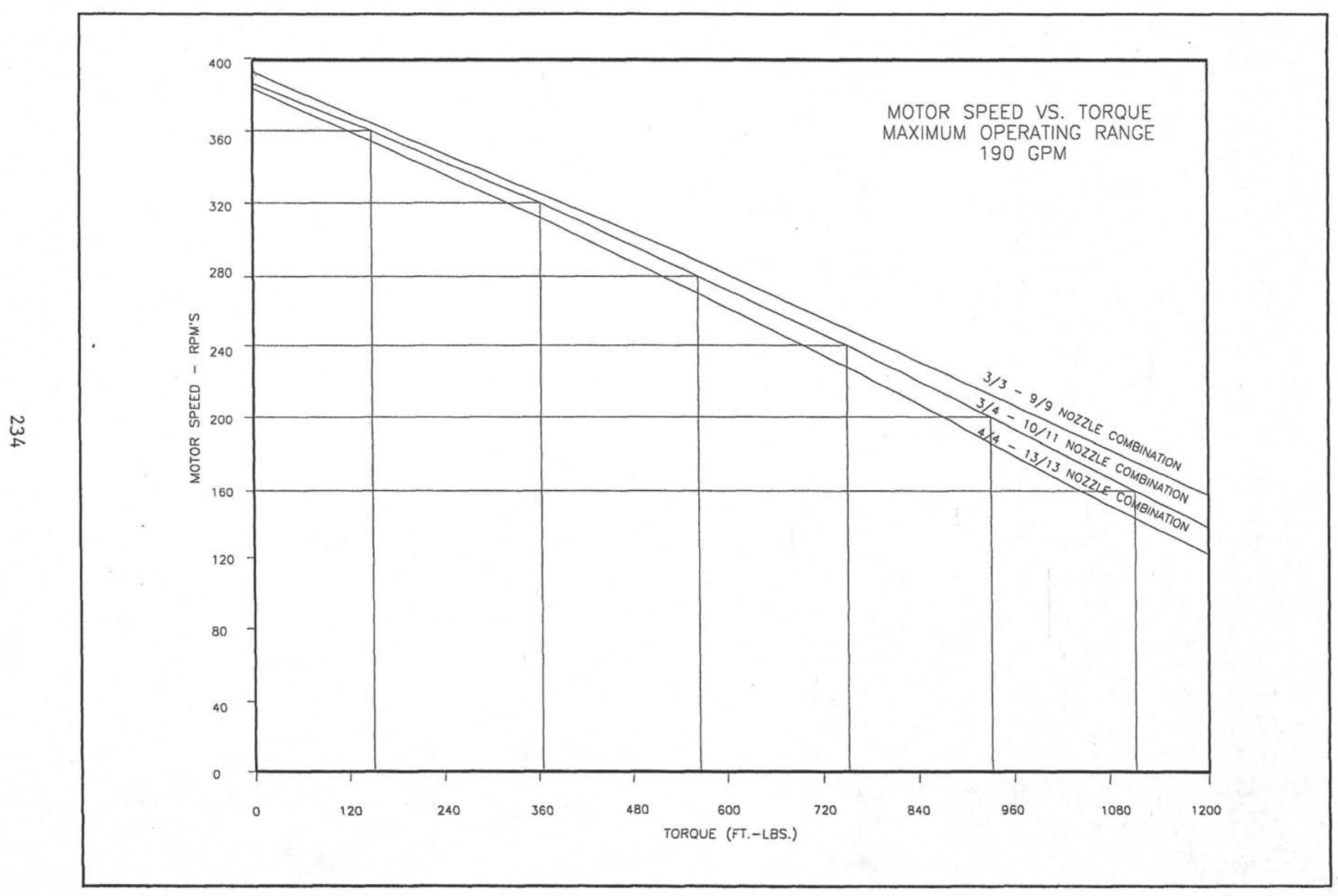




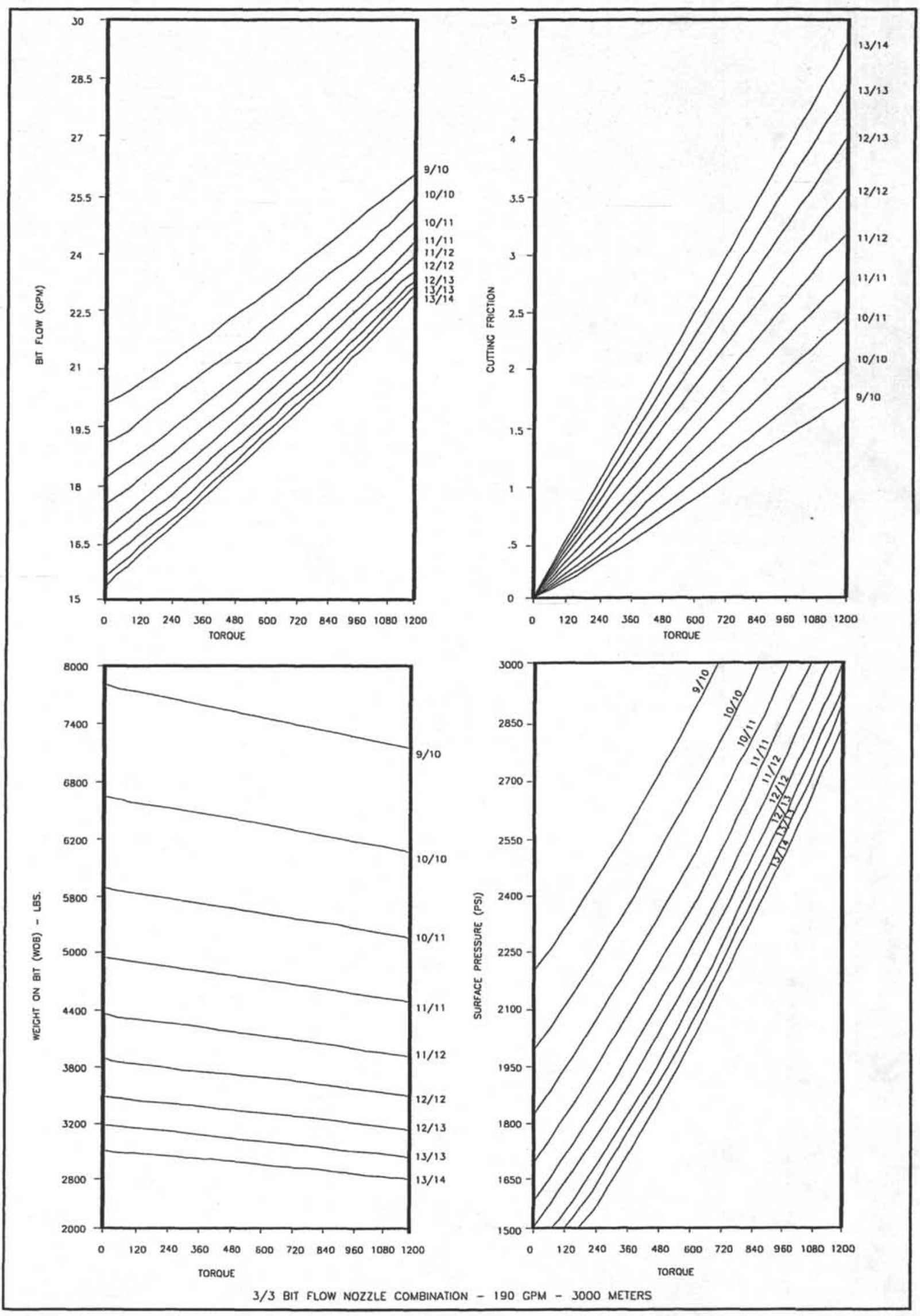




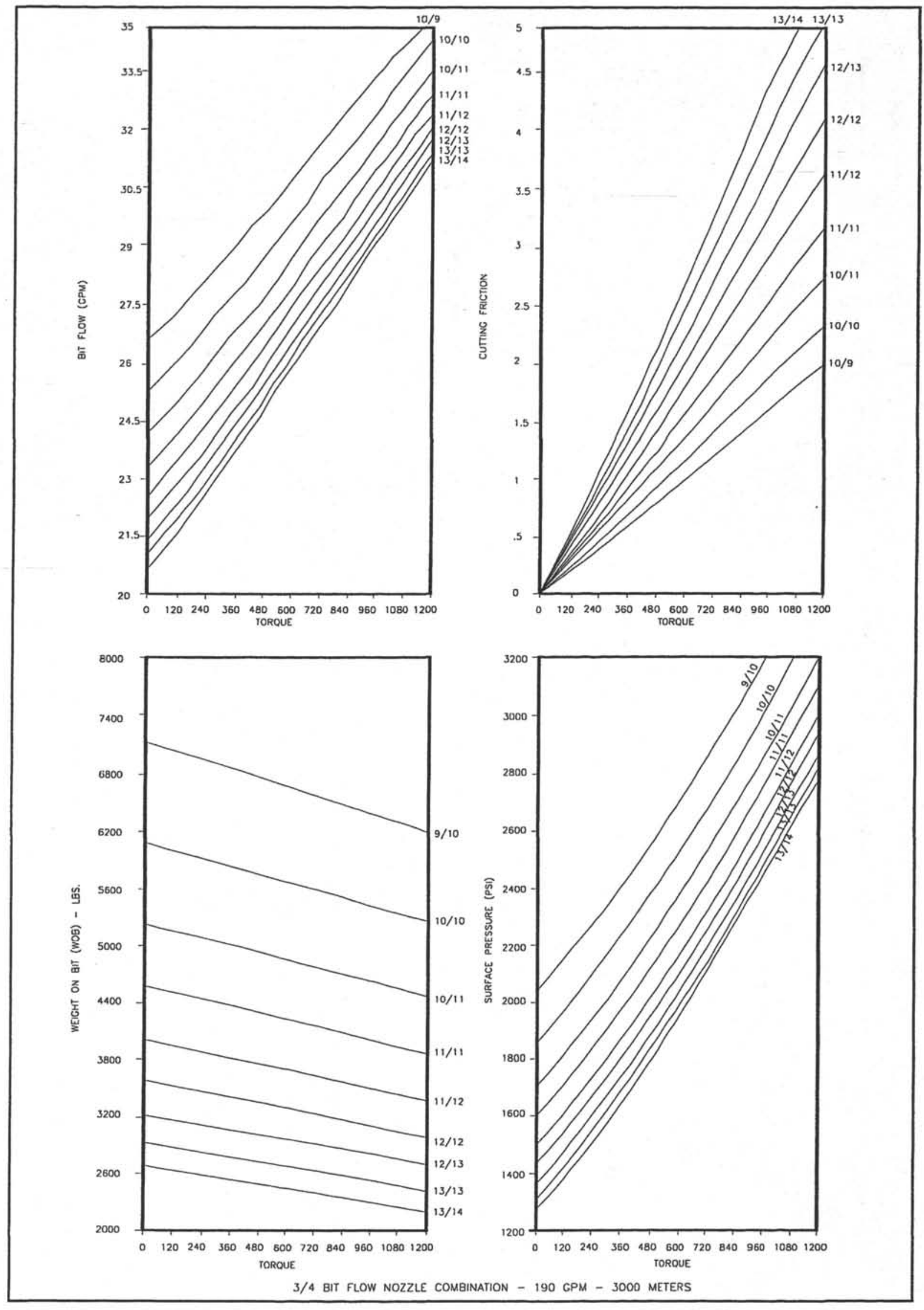




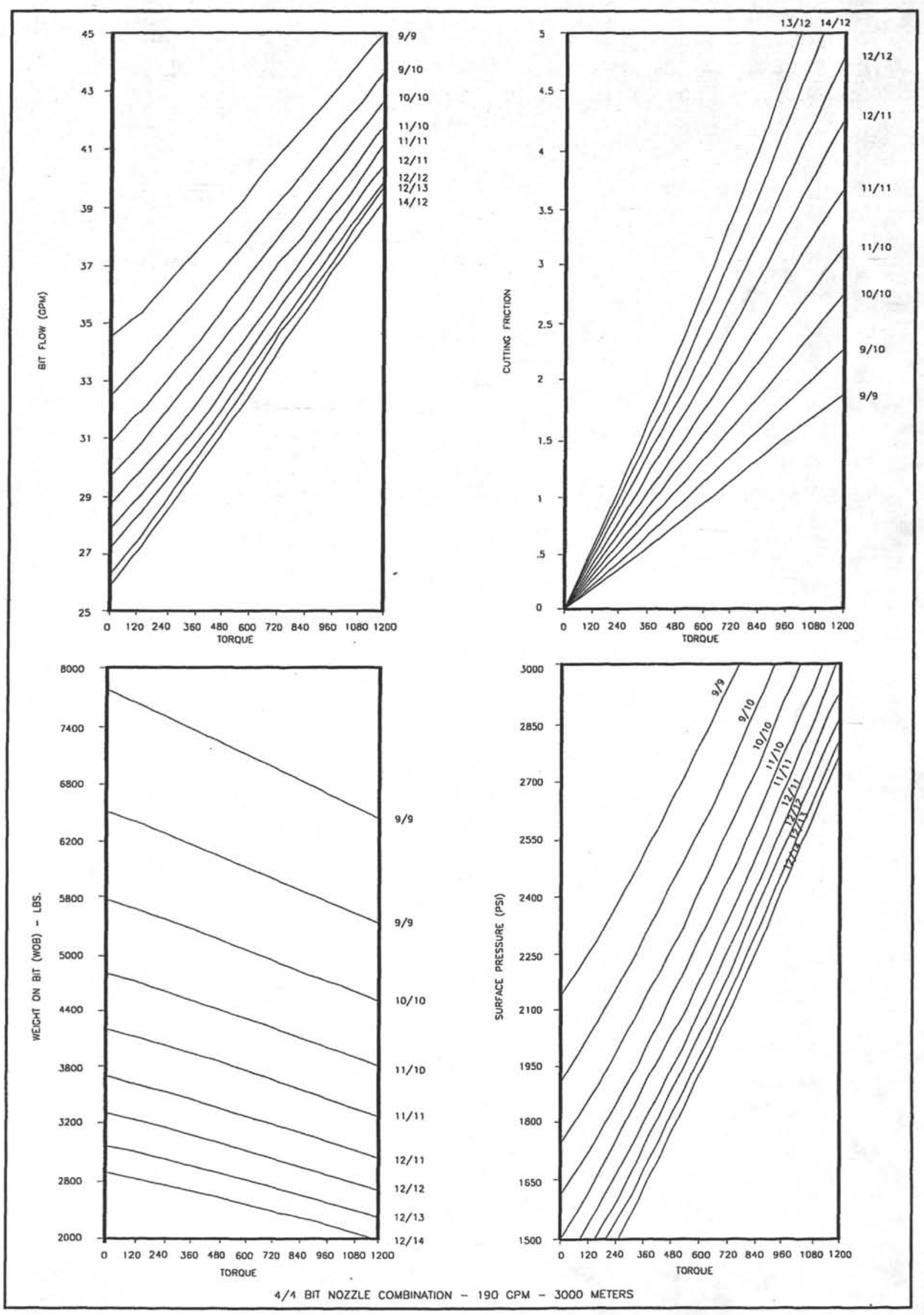




\section{Appendix B: Parts List for MDCB}

A parts list for the MDCB is attached. A schematic of the 3-3/4 in. Mach 1P/ODP mudmotor and a motor parts list is also attached. A maintenance manual for the mudmotor is also available in the Operations Office. 


\begin{tabular}{|c|c|c|c|}
\hline System. & PN. & Description & Reqd \\
\hline MDCB & OC0906 & Core Bit, Dia. Impreg, 3-3/4 × 2-1/4, Hard & na \\
\hline MDCB & OC0907 & 3.75 HWD4 Reaming Shell, 3-3/4 O.D. & 1 \\
\hline MDCB & OC0908 & Core Bit, Dia Impreg, 3-3/4 × 2-1/4, Med. & na \\
\hline MDCB & OC0909 & Core Bit, Dia SS, 3-3/4 x 2-1/4, 40/ct & na \\
\hline MDCB & OC0910 & Core Bit, Dia. SS, 3-3/4 × 2-1/4, 8-12/ct & na \\
\hline MDCB & OC0911 & Core Bit, Dia. Impreg, 3-3/4 × 2-1/4 & na \\
\hline MDCB & OC0912 & Core Bit, Geoset, 3-3/4 x 2-1/4 & 1 \\
\hline MDCB & OC0914 & Core Bit, Sawtooth, Geoset, 3-3/4 x 2-1/4 & na \\
\hline MDCB & OC0916 & Plug Bit, Dia. Full Face 3-3/4 × 2-1/4 & na \\
\hline MDCB & OC0917 & Core Bit, Dia. Piloted Impreg, 3-3/4 × 2-1/4 & na \\
\hline MDCB & OC0918 & Core Bit, Dia. Piloted SS, 3-3/4 × 2-1/4 & na \\
\hline MDCB & OC0919 & Core Bit, TC, Soft-formation, 3-3/4 x 2-1/4 & na \\
\hline MDCB & OD2204 & O-ring, 2-204 & 3 \\
\hline MDCB & OD2208 & O-ring, 2-208 & 2 \\
\hline MDCB & OD2210 & O-ring, 2-210 & 1 \\
\hline MDCB & OD2212 & O-ring, 2-212 & 1 \\
\hline MDCB & OD2220 & O-ring, 2-220 & 2 \\
\hline MDCB & OD2224 & O-ring, 2-224 & 1 \\
\hline MDCB & OD2225 & O-ring, 2-225 & 1 \\
\hline MDCB & OD2227 & O-ring, 2-227 & 1 \\
\hline MDCB & OD2231 & O-ring, 2-231 & 1 \\
\hline MDCB & OD2233 & O-ring, 2-233 & 8 \\
\hline MDCB & OD2325 & O-ring, 2-325 & 1 \\
\hline MDCB & OD2328 & O-ring, 2-328 & 1 \\
\hline MDCB & OD2331 & O-ring, 2-331 & 1 \\
\hline MDCB & OD2334 & O-ring, 2-334 & 2 \\
\hline MDCB & OD3160 & Parker Polypak \#25002750 Nitroxile & 1 \\
\hline MDCB & OD4300 & V-Packing , 3-3/4 & 3 \\
\hline MDCB & OD5020 & Parker Wiper Ring \#02750 Nitroxile & 1 \\
\hline MDCB & OD6550 & 1/2-13 UNC x 3/8 LG Set Screws & 2 \\
\hline MDCB & OD6795 & 3/8-16 UNC x 1/4 LG Set Screws & 3 \\
\hline MDCB & OD7177 & Snap Ring, Truarc N5000-68 & 1 \\
\hline MDCB & OD7194 & Snap Ring, Truarc N5000-165 & 1 \\
\hline MDCB & OD7213 & Air Relief Ball 1/4" dia Polyprop & 1 \\
\hline MDCB & OD7214 & 3/16 dia. Delrin Ball & 1 \\
\hline MDCB & OD7240 & Hex Hd. Bolt & 1 \\
\hline MDCB & OD7252 & 1/4 NPT Hex Soc Pipe Plug & 1 \\
\hline MDCB & OL1050 & MDCB Latch Sub & 1 \\
\hline MDCB & OL1050 & MDCB Latch Sub & 1 \\
\hline MDCB & OP4473 & Latch Dogs & 2 \\
\hline MDCB & OP4474 & Washers & 2 \\
\hline MDCB & OP4475 & Latch Body & 1 \\
\hline MDCB & OP4477 & Modified Pulling Neck & 1 \\
\hline MDCB & OP4478 & Spring & 1 \\
\hline MDCB & OP4479 & Landing Shoulder Cap & 1 \\
\hline MDCB & OP4728 & V-Pack Male Adapter & 1 \\
\hline MDCB & OP4729 & V-Spacers, 3-3/4 & 2 \\
\hline
\end{tabular}




\begin{tabular}{|c|c|c|c|}
\hline System & P.N. & Description & Reqd \\
\hline MDCB & OP4730 & V-Pack Female Adapter & 1 \\
\hline MDCB & OP5865 & HWD4 Bearing Assembly & 1 \\
\hline MDCB & OP5874 & Inner Core Tube $15 \mathrm{ft}$ & 1 \\
\hline MDCB & OP5875 & Inner Tube Adapter & 1 \\
\hline MDCB & OP5926 & Modified Core Barrel Head & 1 \\
\hline MDCB & OP5928 & HWD4 Outer Bbl CMP \#25-287-038 & 1 \\
\hline MDCB & OP5963 & Core Catcher, Dog-type & 1 \\
\hline MDCB & OP5967 & Inner Tube Sub, Long & 1 \\
\hline MDCB & OP5972 & Polycarbonate Liner & 1 \\
\hline MDCB & OP8004 & Titanium Flex Shaft (included in Motor) & 1 \\
\hline MDCB & OP8005 & 3-3/4 Mach 1P Mudmotor Assy & 1 \\
\hline MDCB & OP8006 & Modified Drive Sub & 1 \\
\hline MDCB & OP8008 & Modified Lower Bearing Housing & 1 \\
\hline MDCB & OP8009 & Thrust Bearing, 3-3/4 Mach 1P Mudmotor & na \\
\hline MDCB & OP8010 & Swivel & 1 \\
\hline MDCB & OP8014 & Nozzle Sub & 1 \\
\hline MDCB & OP8018 & Swivel Housing & 1 \\
\hline MDCB & OP8020 & Crossover Sub & 1 \\
\hline MDCB & OP8024 & Packing Nut & 1 \\
\hline MDCB & OP8036 & Spring Housing & 1 \\
\hline MDCB & OP8038 & Spring Stop & 1 \\
\hline MDCB & OP8040 & Thruster Barrel & 1 \\
\hline MDCB & OP8041 & Flow Tube Support Spring & 1 \\
\hline MDCB & OP8044 & Swivel Brg, 1/16" Rulon LR Tape & 1 \\
\hline MDCB & OP8046 & Flow Tube Centralizer & 1 \\
\hline MDCB & OP8048 & Flow Tube Extension & 1 \\
\hline MDCB & OP8050 & Flow Tube & 1 \\
\hline MDCB & OP8052 & Flow Tube Stop & 1 \\
\hline MDCB & OP8055 & Hex Kelly & 1 \\
\hline MDCB & OP8057 & Hex Gasket & 3 \\
\hline MDCB & OP8058 & Hex Seal Spacer, Delrin/Brass & 4 \\
\hline MDCB & OP8059 & Hex Gasket Shims & 5 \\
\hline MDCB & OP8061 & Thruster Piston & 1 \\
\hline MDCB & OP8063 & Locking Wedge & 1 \\
\hline MDCB & OP8065 & Unlocking Piston & 1 \\
\hline MDCB & OP8067 & Piston Retainer Sleeve & 1 \\
\hline MDCB & OP8069 & Control Orifice Set Screw & 1 \\
\hline MDCB & OP8074 & Ball Cage Set Screw & 1 \\
\hline MDCB & OP8080 & Check-off Sub & 1 \\
\hline MDCB & OP8082 & Centralizer Pads & 3 \\
\hline MDCB & OP8083 & Fill Valve Set Screw & 1 \\
\hline MDCB & OP8084 & Latch Sub & 1 \\
\hline MDCB & OP8086 & Female Spline & 3 \\
\hline MDCB & OP8090 & Carbide Nozzle & 2 \\
\hline MDCB & OP8091 & Tool Steel Nozzle & 2 \\
\hline MDCB & OP8092 & Nozzle Retainer & 4 \\
\hline MDCB & OP8118 & Positive Latch Spring & 1 \\
\hline
\end{tabular}




\section{MDCB Parts List}

\begin{tabular}{|c|c|c|c|}
\hline System & P.N. & Description & Reqd: \\
\hline$\overline{M D C B}$ & OP8120 & Female Q-Release & 1 \\
\hline MDCB & OP8122 & Q-Release Retaining Ring & 1 \\
\hline MDCB & OP8124 & Positive Latch XJO Sub & 1 \\
\hline MDCB & OP8126 & Positive Latch Piston & 1 \\
\hline MDCB & OP8128 & Male Q-Release & 1 \\
\hline MDCB & OP8130 & Q-Release Dogs & 2 \\
\hline MDCB & OP8132 & Shuttle Stop & 1 \\
\hline MDCB & OP8134 & Shuttle Spring & 1 \\
\hline MDCB & OP8136 & E.O.S. Shuttle & 1 \\
\hline MDCB & OP8138 & Flushing Sub & 1 \\
\hline MDCB & OP9833 & Core Catcher, Triple Closure & na \\
\hline MDCB & OT2574 & GS Inside Fishing Neck & 1 \\
\hline MDCB & SK8010 & Spool & 1 \\
\hline MDCB & & Core Bit, Dia. Impreg, Sawth, 3-3/4 × 2-1/4 & na \\
\hline MDCB & & Core Bit, Klusterite, 3-3/4 × 2-1/4 & na \\
\hline MDCB & & Nozzle Blanks & 1 \\
\hline MDCB & & Nozzle Retainer Blanks & 1 \\
\hline MDCB & & Nozzle Tool & 1 \\
\hline
\end{tabular}




\section{ODP WIRE LINE / CORING MOTOR}

\begin{tabular}{|c|c|c|c|c|c|}
\hline \multicolumn{4}{|c|}{ ND MACH 1} & \multirow{3}{*}{$\begin{array}{l}\text { SIZE } \\
\text { DESCRIPTION } \\
\text { MOTOR SECTION }\end{array}$} & \multirow{3}{*}{ PART NUMBER } \\
\hline \multicolumn{2}{|c|}{ ITEM NO. } & \multicolumn{2}{|l|}{ QTY } & & \\
\hline 1 & & & & & \\
\hline & 1.1.1 & 1 & & STATOR MACH 1C/standard short & 913-004-781 \\
\hline & 1.1.2 & 1 & & ROTOR COMPLETE 1C & 913-004-785 \\
\hline & 1.1.2.1 & & 1 & ROTOR TS coated & $913-004-782$ \\
\hline & 1.1.2.2 & & & NOZZLE HOLDER COMPLETE & \\
\hline & & & 1 & NOZZLE HOLDER & $913-000-746$ \\
\hline & & & 1 & BLIND PLUG & $913-000-631$ \\
\hline & & & 1 & SNAP RING & $900-000-722$ \\
\hline & & & 1 & O-RING & $900-000-176$ \\
\hline & & & 1 & O-RING & $900-000-219$ \\
\hline & 1.2.1 & 1 & & STATOR MACH IP/ODP & 913-004-783 \\
\hline & 1.2 .2 & 1 & & ROTOR COMPLETE IP / ODP & 913-004-786 \\
\hline & 1.2.2.1 & & 1 & ROTOR TS coated & 913-004-784 \\
\hline & 1.2.2.2 & & 1 & NOZZLE HOLDER COMPLETE & \\
\hline & & & 1 & NOZZLE HOLDER & $913-000-746$ \\
\hline & & & 1 & BLIND PLUG & $913-000-631$ \\
\hline & & & 1 & SNAP RING & $900-000-722$ \\
\hline & & & 1 & O-RING & $900-000-176$ \\
\hline & & & 1 & O-RING & $900-000-219$ \\
\hline 2 & & 2 & & U-JOINT HOUSING & $913-004-778$ \\
\hline 3 & & & & FLEX SHAFT ASSY. & 913-004-779 \\
\hline & 3.1 & & 1 & FLEX SHAFT (made of TITAN) & 913-004-780 \\
\hline & 3.1 & & 1 & BONNET / ODP & $913-004-586$ \\
\hline 4 & & 1 & & BEARING ASSEMBLY & $913-004-777$ \\
\hline & & & & WITH MODIFIED DRIVE SUB & \\
\hline & 4.1 & & & THRUST BEARING & $913-000-348$ \\
\hline & & & & & \\
\hline & & & & & \\
\hline
\end{tabular}




\section{3/4" ODP Coring Motor}

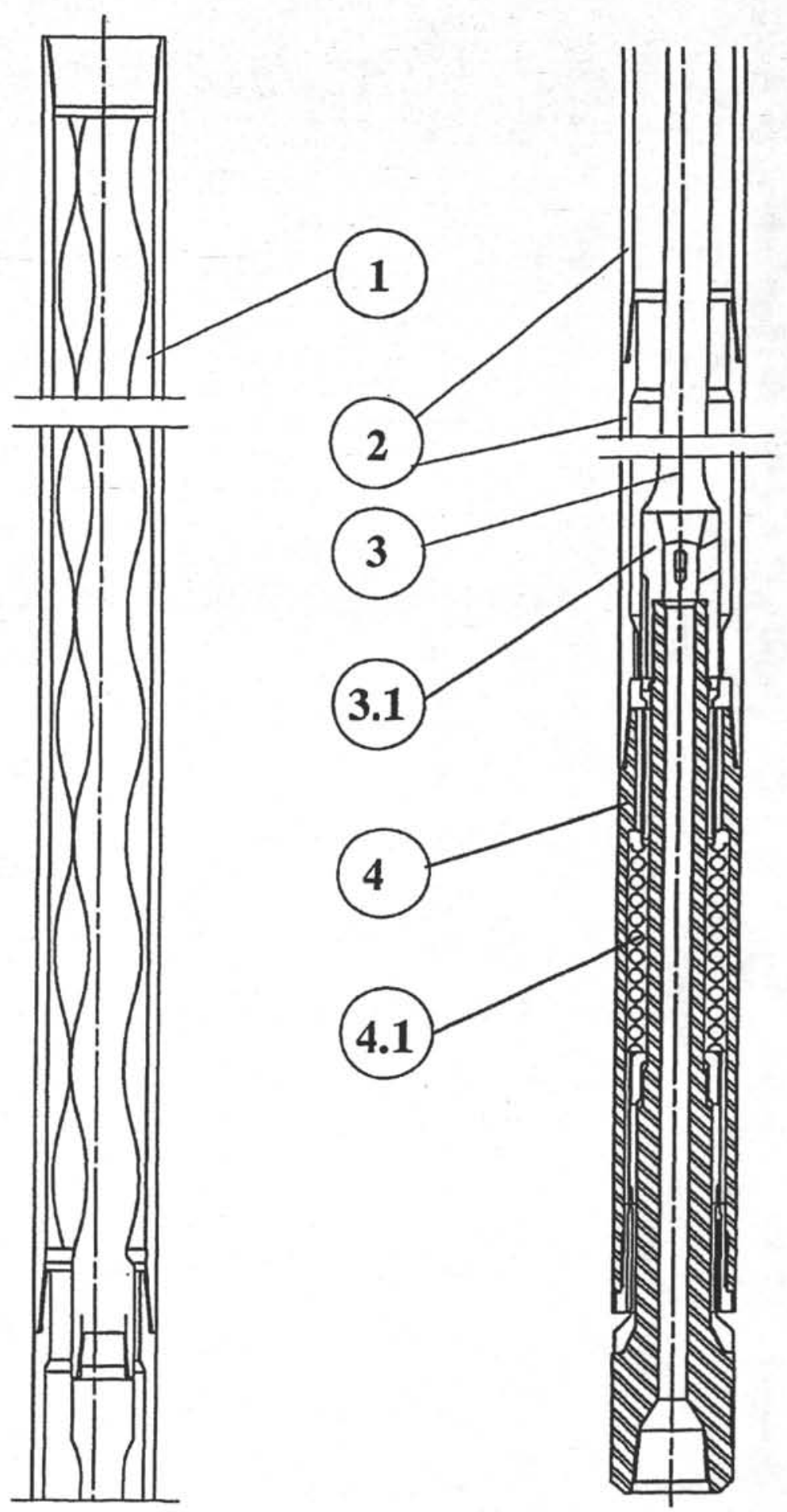

